INSTITUTO DE PESQUISAS ENERGÉTICAS E NUCLEARES

Autarquia associada à Universidade de São Paulo

\title{
ESTUDO DOS EFEITOS DO FÁRMACO PROPRANOLOL PARA CERIODAPHNIA SILVESTRII (CLADOCERA, CRUSTACEA) COM ÊNFASE EM EFEITOS NAS POPULAÇÕES.
}

Gustavo Almeida Borges Rosa

Dissertação apresentada como parte dos requisitos para obtenção do Grau de Mestre em Ciências na Área de Tecnologia Nuclear Materiais.

Orientadora:

Dra. Maria Beatriz Bohrer-Morel 
Agradecimentos

À minha orientadora por toda paciência e apoio.

À CAPES (Coordenação de Aperfeiçoamento de Pessoal de Nível Superior) pela bolsa concedida.

À Vanessa, Fábio e Angélica pelas sugestões com minha pesquisa e pelo excelente convívio.

Ao Marcão e Daniel pela paciência e ajuda com as análises estatísticas.

Aos meus pais pelo apoio incondicional.

A todas as pessoas e amigos que estiveram presentes na minha vida nestes últimos anos e que me ajudaram em todos os momentos, bons ou ruins. 
"A alegria está na luta, na tentativa, no sofrimento envolvido. Não na vitória propriamente dita." Mahatma Gandhi 


\title{
ESTUDO DOS EFEITOS DO FÁRMACO PROPRANOLOL PARA CERIODAPHNIA SILVESTRII (CLADOCERA, CRUSTACEA) COM ÊNFASE EM EFEITOS NAS POPULAÇÕES.
}

\begin{abstract}
RESUMO
A ocorrência de produtos farmacêuticos no ambiente aquático pode causar efeitos adversos à saúde humana e às comunidades aquáticas. Propranolol, $\beta$-bloqueador não seletivo, é largamente prescrito no tratamento de doenças ligadas ao coração como angina e hipertensão. Simples medidas de efeito, como a CL50, não fornece informações sobre o impacto de contaminantes em populações. A taxa de crescimento populacional ( $r$ ) é uma ferramenta importante para estudos que objetiva determinar os efeitos em nível populacional. Este trabalho foi desenvolvido com o objetivo de estabelecer a toxicidade aguda e crônica de Propranolol para a espécie autóctone Ceriodaphnia silvestrii (CLADOCERA, CRUSTACEA) com ênfase em efeitos nas populações. Os valores determinados para $\mathrm{CE}(\mathrm{I}) 50 ; 48 \mathrm{H}$ foram de 2,87 e 2,63 mg. $\mathrm{L}^{-1}$ para água destilada e natural reconstituídas, respectivamente. Para a toxicidade crônica, os valores obtidos para CENO e CEO encontraram-se na faixa de 0,62-1,25 e 1,25-2,50 mg.L $\mathrm{L}^{-1}$ para água natural reconstituída. Como critérios de aceitabilidade para os ensaios crônicos populacionais foram estabelecidos para o controle 73 neonatas $( \pm 10 \mathrm{DP})$ e taxa intrínseca de aumento natural de 0,596 ( $\pm 0,13$ DP) em sete dias de experimento com água natural reconstituída. No teste de sensibilidade, os valores obtidos para CENO e CEO populacional foram 0,275 e 0,723 g.L. $\mathrm{L}^{-1}$ de $\mathrm{NaCl}$, respectivamente, semelhante aos valores nos ensaios crônicos individuais. Para Propranolol, as análises indicaram que os ensaios populacionais foram iguais ou mais sensíveis que a exposição individual. Os resultados nos ensaios crônicos populacionais e com indivíduos encontraram-se entre 1,25 (CENO) e 2,50 mg.L ${ }^{-1}$ (CEO), respectivamente. Os endpoints populacionais parecem ser medidas mais sensíveis. Comparando-se os valores de ICP para populações e indivíduos, observa-se que as populações foram mais sensíveis na ordem de $70 \%$.
\end{abstract}




\title{
STUDY OF THE EFFECTS OF THE PHARMACEUTICAL COMPOUND PROPRANOLOL TO CERIODAPHNIA SILVESTRII (CLADOCERA, CRUSTACEA) WITH EMPHASIS ON THE EFFECTS ON POPULATIONS.
}

\begin{abstract}
The pharmaceutical products occurrence in the aquatic environment could cause adverse effects on the human health and aquatic communities. Propranolol, non selective $\beta$-blocker, is widely prescribed for the treatment of heart related diseases as angina and hypertension. Simple effect measures, like LC50, don't provide information about contaminant impacts in populations. The intrinsic population growth rate $(r)$ is an important tool for doing research on determining the effects in population level. This work has been developed with the goal to establish the Propranolol acute and chronic toxicity to the autochthon specie Ceriodaphnia silvestrii (CLADOCERA, CRUSTACEA) with emphasis on the effects on the populations. The determined values to $\mathrm{EC}(\mathrm{I}) 50 ; 48 \mathrm{H}$ were 2.87 and $2.63 \mathrm{mg} . \mathrm{L}^{-1}$ to distillated and natural reconstituted waters, respectively. To the chronic toxicity, the obtained values to NOEC and OEC ranged from 0.62 to 1.25 and 1.25 to $2.50 \mathrm{mg} . \mathrm{L}^{-1}$. As acceptance criteria to the chronic populational assays 73 neonates $( \pm 10$ SD) and an intrinsic rate of natural increase of $0.596( \pm 0,13 \mathrm{SD})$ were established to its control for seven days of experiment with reconstituted natural water. In the sensitivity test, the obtained values to populations NOEC and OEC were 0.275 and 0.723 g.L $\mathrm{L}^{-1}$ of $\mathrm{NaCl}$, respectively, similar to the values in the individual chronic assays. To propranolol, the analyses indicated that the populational assays were similar or more sensitive than the individual exposition. The results in the chronic populational assays and with individuals were between 1.25 (NOEC) and $2.50 \mathrm{mg} . \mathrm{L}^{-1}$ (LOEC), respectively. The populational endpoints seem to be more sensitive measure. Comparing the ICP values to both populations and individuals, it is observed that the populations were more sensitive of the order of $70 \%$.
\end{abstract}


1. Introdução 1

2. Objetivos 5

3. Revisão Bibliográfica 6

3.1 Monitoramento ambiental e ensaios ecotoxicológicos 6

3.2 Efeitos e ensaios de ecotoxicidade aguda 12

3.3 Efeitos e ensaios de ecotoxicidade crônicos 13

3.4 Ensaios ecotoxicológicos populacionais 13

3.5 Taxa de crescimento populacional 16

3.6 Fármacos no ambiente $\quad 17$

3.6.1 Fontes dos fármacos para o ambiente 20

3.6.2 Efeitos ecotoxicológicos 22

3.6.3 Monitoramento de fármacos residuais no Brasil 23

3.6.4 Beta-Bloqueadores e Propranolol 24

4. Materiais e métodos 28

$\begin{array}{ll}4.1 \text { Cultivo } & 28\end{array}$

4.1.1 Água natural $\quad 28$

4.1.2 Água reconstituída $\quad 30$

4.1.3 Teste de Viabilidade $\quad 30$

4.1.4 Manutenção de C. silvestrii 30

4.1.5 Teste de sensibilidade 31

4.1.5.1 Coeficiente de variação 31

4.2 Avaliação da toxicidade do propranolol para Ceriodaphnia silvestrii 32

4.2.1 Substância-teste 32

4.2.2 Toxicidade Aguda

4.2.2.1 Preparo das Soluções-teste 33

4.2.3 Toxicidade Crônica 33

4.2.3.1 Para indivíduos de Ceriodaphnia silvestrii 33

4.2.3.2 Para populações de Ceriodaphnia silvestrii 34

4.2.3.2.1 Otimização das condições do ensaio 34

4.2.3.2.2 Critérios de aceitabilidade dos ensaios populacionais e Teste de 35 \begin{tabular}{ll} 
4.2.3.2.3 Avaliação da Toxicidade do Propanolol & 35 \\
\hline
\end{tabular}

4.3 Análise Estatística 36

4.3.1 Teste de sensibilidade e Ensaio de Toxicidade aguda 36

4.3.2 Toxicidade Crônica 36

4.3.2.1 Individual 36

$\begin{array}{ll}\text { 4.3.2.2 Populacional } & 37\end{array}$

4.3.2.2.1. Condição do teste 37

4.3.2.2.2. CEO (p), CENO(p), Ir\%, IC25 e IC50 37

5. Resultados 38

5.1 Avaliação da toxicidade de propanolol para Ceriodaphnia silvestrii 38

5.1.2 Toxicidade Aguda 38 
5.1.3 Toxicidade Crônica 39

5.1.3.1 Individual 39

5.1.3.2 Populacional 42

5.1.3.2.1 Otimização das condições do ensaio - Número de indivíduos de 42

Ceriodaphnia silvestrii e volume da câmara-teste

5.1.3.2.2 Validação dos critérios de aceitabilidade do controle a partir de ensaios de sensibilidade com Cloreto de Sódio.

5.1.3.2.3 Sensibilidade de C. silvestrii para o Cloreto de Sódio 46

5.1.3.2.4 Toxicidade $\quad 52$

$\begin{array}{ll}5.2 \text { Sensibilidade } & 60\end{array}$

6. Discussão 61

$\begin{array}{ll}6.1 \text { Avaliação da toxicidade } & 61\end{array}$

$\begin{array}{ll}\text { 6.1.2 Toxicidade Aguda } & 61\end{array}$

6.1.3 Toxicidade Crônica 65

6.1.3.1 Para populações de Ceriodaphnia silvestrii 69

6.1.3.1.1 Condição do ensaio e Critérios de aceitabilidade 69

6.1.3.1.2 Taxa intrínseca de aumento natural (r) 71

7. Conclusões 78

Apêndices $\quad 80$

$\begin{array}{lr}\text { Referências bibliográficas } & 154\end{array}$ 


\section{Introdução}

Durante séculos, a humanidade considerou a água como um recurso inesgotável e a utilizou de forma predatória e insustentável. No século XX, o uso inadequado foi acirrado com a aceleração do crescimento populacional, o intenso uso pelos diversos ramos de atividades, dentre eles, doméstica, agrícola e industrial. Estes fatores levaram a constatação de que a água se torna cada vez um bem escasso, necessitando de um uso racional e equilibrado, de modo a garantir a sua conservação e sustentabilidade.

O padrão de qualidade de vida de uma população está diretamente relacionado à disponibilidade e à qualidade de sua água, sendo esta, o recurso natural mais crítico e mais susceptível a impor limites ao desenvolvimento, em muitas partes o mundo.

Uma das causas fundamentais do aumento no consumo de água é provocado pelo acréscimo da população, estimada para o ano de 2030 em 8 bilhões de habitantes, com uma taxa de incremento anual de 1,33\%. Isto significa um crescimento de 2 bilhões de pessoas nos próximos 30 anos (FORNO, 1999). Os números apontam um crescimento significativo da população, todavia, os recursos hídricos naturais não acompanham este crescimento, e, à medida que aumenta a demanda, os ecossistemas se deterioram.

Segundo ODUM (1988) as maiores cidades do mundo se localizam próximos à grandes rios e lagos, que passam a servir como corpos receptores de esgotos. A água doce do planeta corresponde a apenas 3\% do total disponível. Desse total, $75 \%$ encontram-se nas calotas polares e $10 \%$ em aqüíferos, restando apenas $15 \%$ disponíveis. Percentagem que diminui intensamente com o crescimento da população e poluição dos corpos d' águas existentes (TUNDISI, 2003).

A demanda e a oferta dos recursos hídricos estão cada vez mais comprometidas na medida em que, em muitos lugares do mundo, as águas superficiais e as subterrâneas estão contaminadas com esgotos industriais, agrícolas e municipais (CORSON, 2002). O crescente número de poluentes que podem causar efeitos preocupantes cresce anualmente, conforme novos compostos vão sendo sintetizados. O acelerado crescimento urbano e industrial, verificado nos últimos anos na maioria dos países, tem aumentado a quantidade e complexidade dos resíduos tóxicos lançados nos recursos de água doce, provocando 
sérios problemas ecológicos, e episódios de graves conseqüências para a saúde do homem (BITTON \& DUTKA, 1986; WHO, 1992).

Segundo USEPA (1985), tanto as águas superficiais quanto as subterrâneas têm sido amplamente deterioradas, quer seja pela adição de novos produtos químicos ou por contaminação biológica. A contaminação química merece grande atenção na sociedade, uma vez que o uso de substâncias sintéticas tem aumentado de maneira quase exponencial. Atualmente, cerca de seis milhões de substâncias químicas são conhecidas, das quais 63 mil são de uso cotidiano e, por conseqüência, freqüentemente encontradas no ambiente (ZAGATTO, 1999), porém menos de 500 têm sido avaliadas quanto a toxicidade nos organismos aquáticos (LINDEGAARD, 1995).

Esses produtos são colocados no mercado sem avaliação prévia de seu impacto ambiental, resultando, muitas vezes, na poluição dos recursos hídricos por poluentes genotóxicos e teratogênicos, colocando em risco a saúde humana, biota aquática e a integridade dos ecossistemas (SAXENA, 1984; HOUK, 1992). Tomando como base 118 agentes químicos, 103 orgânicos e 15 inorgânicos, considerados mundialmente como prioritários para efeito de controle, verifica-se que a maioria deles é persistente e acumulativa no meio aquático, sendo assim, pode-se constatar que a biota aquática pode estar sujeita aos efeitos dessas substâncias por prolongados períodos de tempo em diferentes locais (ZAGATTO, 2000).

HOLT (2000) aponta que se por um lado a industrialização e a urbanização, juntamente com a intensificação das atividades agrícolas, têm resultado no aumento da demanda da água, por outro lado aumentam a contribuição de contaminantes nos corpos d'água. As maiores e mais significativas rotas de contaminação são ocasionadas por emissões diretas e indiretas dos esgotos tratados e não-tratados, escoamento e deposição atmosférica e pelo processo de lixiviação do solo.

Apenas uma pequena porcentagem destes contaminantes tem seus efeitos conhecidos, acentuando assim, a fragilidade destes ecossistemas, pois a complexidade e a variabilidade dos compostos que alcançam um corpo hídrico e sua distribuição e interação ocorre em função das suas características e das condições do meio receptor, estando sujeitos a transformações químicas (hidrólises), físicas (fotólises) e biológicas (decomposição). Portanto, podem causar efeitos deletérios agudos e crônicos na biota, chegando a afetar até o nível mais alto da cadeia trófica através de bioacumulação, gerando desequilíbrio no sistema (BERGAM \& PUGH, 1994). 
Em decorrência da conscientização da sociedade e das autoridades governamentais sobre os riscos da presença de compostos químicos tóxicos em águas e devido às alterações profundas que provocam nesses ambientes, inúmeros ensaios biológicos foram desenvolvidos para avaliação da toxicidade de efluentes líquidos, corpos d'água receptores e sedimentos (USEPA, 1985; KWAN e DUTKA, 1992).

A utilização de testes de caráter ecotoxicológico, que venham a dar informações quanto ao efeito tóxico causado em ecossistemas por substâncias químicas nele presentes, torna-se cada dia mais importante nas avaliações de impacto ambiental. Deste modo, a realização de testes de toxicidade tem sido incluída em programas de monitoramento, constituindo uma das análises indispensáveis no controle de fontes de poluição (CETESB, 1990).

A adoção de estudos ecotoxicológicos permite fazer predições sobre riscos de extinção, constituindo-se em ferramenta para compreensão da extensão dos impactos pois os organismos vivos utilizados nos testes de toxicidade funcionam como verdadeiros "biosensores" que respondem à presença de contaminantes.

Neste sentido, este trabalho visa aplicar estudos ecotoxicológicos, que vem sendo realizados em regiões temperadas em organismos-teste autóctenes, para populações, avaliando e prevendo as consequiências ecológicas de contaminantes emergentes em ecossistemas tropicais, complementando as avaliações de rotina dos efeitos fisiológicos em indivíduos.

Na seleção do agente tóxico optou-se por testar um fármaco devido à ênfase atual em estudos com poluentes emergentes. No Brasil são raros os estudos que avaliam este impacto. Para isto, selecionou-se o propranolol, amplamente utilizado no tratamento de hipertensão, angina pectoris, arritmias cardíacas, infarto do miocárdio e enxaquecas, com o intuito de se otimizar o ensaio com a espécie autóctone Ceriodaphnia silvestrii para avaliar se os efeitos das populações são ecologicamente mais sensíveis que em indivíduos da espécie.

O organismo-teste selecionado neste estudo, C. silvestrii, pertence à Ordem Cladocera que, segundo MALTBY e CALOW (1989), são os mais comumente utilizados em programas de avaliação da qualidade de ecossistemas aquáticos. Apresenta características importantes que possibilitam a sua utilização em bioensaios: facilidade de obtenção, simplicidade de cultivo, pequeno tamanho, ciclo de vida relativamente curto e o fato de representarem um grupo extremante importante responsável pela conversão de 
fitoplâncton e bactérias em proteína animal que é disponibilizada para animais superiores (MOUNT e NORBERG, 1984).

Ceriodaphnia silvestrii tem sido utilizada em avaliações ecotoxicológicas por diversos autores brasileiros (OLIVEIRA-NETO et al., 2000; FONSECA, 1991; 1997; CASTILHO, 2005), pois apresenta alta relevância ecológica e representatividade na cadeia alimentar de ecossistemas aquáticos tropicais brasileiros, que, segundo CHAPMAN (1995), são requisitos de suma importância para a avaliação da qualidade de um ambiente visando a proteção da biota. 


\section{Objetivos}

\section{Geral}

- Avaliar a toxicidade do fármaco propranolol sobre indivíduos e populações da espécie nativa Ceriodaphnia silvestrii.

\section{Específicos}

- Estabelecer as condições do ensaio ecotoxicológico com populações de Ceriodaphnia silvestrii como duração, número inicial de organismos, número de réplicas e volume por réplica.

- Conhecer a toxicidade aguda e crônica de propranolol para indivíduos de Ceriodaphnia silvestrii;

- $\quad$ Estabelecer os critérios de aceitabilidade do ensaio com Ceriodaphnia silvestrii a partir de parâmetros populacionais;

- Conhecer a toxicidade crônica de propranolol para populações de Ceriodaphnia silvestrii comparando com valores de toxicidade aguda e crônica obtidos a partir de ensaios com indivíduos de Ceriodaphnia silvestrii; 


\section{Revisão bibliográfica}

\subsection{Monitoramento ambiental e ensaios ecotoxicológicos}

Monitoramento é, segundo a Resolução CONAMA n ${ }^{\circ} 357$, artigo $2^{\circ}$, inciso XXV, a medição ou verificação de parâmetros de qualidade e quantidade de água, que pode ser contínua ou periódica, utilizada para acompanhamento da condição e controle da qualidade de água (BRASIL, 2005). Observa-se que o monitoramento do estado dos corpos hídricos vem crescendo rapidamente, particularmente sob pressão de organizações nacionais e internacionais, entre elas a Organização Mundial da Saúde (OMS), que dita uma série de padrões para a água potável. Como resultado, o número de descritores da qualidade da água excede normalmente mais de 100 (MEYBECK, 1996).

CULLEN (1990) entende que monitoramento é o processo pelo qual se realiza observações repetitivas, com objetivos bem definidos em um ou mais elementos do ambiente utilizando métodos comparáveis para a coleta de dados e avaliação ambiental. Para ABEL (1989), o monitoramento é feito para detectar e descrever as alterações que possam ocorrer e para procurar entender as relações qualitativas e quantitativas entre a poluição e suas conseqüências biológicas.

Segundo CHAPMAN (1989) o monitoramento ambiental aquático auxilia o gerenciamento dos recursos hídricos fornecendo informações a respeito da extensão e dos impactos causados pela poluição e avalia a eficiência das medidas mitigadoras adotadas com o propósito de eliminar ou reduzir sua origem.

O enfoque no monitoramento de ambientes aquáticos por muito tempo foi dado pela presença ou ausência de substâncias químicas potencialmente tóxicas na água superficial. Atualmente ele é dividido em dois tipos: os que se baseiam em parâmetros físicos e químicos, que podem detectar a presença de certas substâncias, bem como alterações de $\mathrm{pH}$, oxigênio dissolvido, condutividade, entre outros e, aqueles que detectam respostas dos organismos frente à alterações ambientais, denominados de biomonitoramento (BOHRER, 1995).

O termo geral "monitoramento da qualidade da água" inclui, portanto, tanto o monitoramento físico e químico quanto o monitoramento biológico. Para LOBO e CALLEGARO (2000), desses dois enfoques, o monitoramento biológico destaca-se basicamente em função de dois importantes argumentos. Primeiro, os organismos apresentam uma resposta integrada ao seu ambiente, e, segundo, se o que interessa é 
manter comunidades biológicas em seu estado natural é muito mais apropriado monitorar as comunidades aquáticas que somente as variáveis físicas e químicas.

O conceito de biomonitoramento pode ser definido como o uso sistemático das respostas biológicas para avaliar as mudanças ambientais de origem antropogênicas, com a intenção de usar estas informações em programas de controle de qualidade (MATTHEUS et al., 1982).

Dentro do paradigma da Toxicologia Ambiental encontra-se a Ecotoxicologia, que, segundo NEWMAN \& UNGER (2003), pode ser definida como a ciência dos contaminantes na Biosfera. Esta ciência tem como objetivo estudar o efeito dos contaminantes nos diversos constituintes da biosfera, incluindo o Homem. $\mathrm{O}$ termo Ecotoxicologia foi cunhado pelo professor e pesquisador francês René Truhaut, em 1969, reunindo a designação eco (do grego oikos, elemento de composição com o significado de casa, domicílio, habitat: ecologia) e a palavra toxicologia (ciência dos agentes tóxicos, dos venenos e da intoxicação) (AZEVEDO E CHASIN, 2003). ZAGATTO et al. (1988) e GOLDSTEIN (1988), definem a Ecotoxicologia como uma moderna ciência que estuda o impacto potencialmente deletério de substâncias ou compostos químicos que constituem poluentes ambientais sobre os organismos vivos.

O monitoramento usual, realizado através de parâmetros físicos e químicos, ao ser complementado pelo monitoramento de caráter ecotoxicológico, permite avaliar amplamente corpos d'água complexos, uma vez que o resultado do teste ecotoxicológico baseia-se na resposta da biota ao conjunto de substâncias que compõe o meio aquático (BRENTANO \& LOBO, 2003).

Os testes de toxicidade se constituem em um valioso instrumento para diagnóstico da qualidade ambiental, revelando, com freqüência, uma qualidade inadequada não detectável por outros métodos analíticos (NAVAS-PEREIRA et al, 1994). Para GOLDSTEIN et al. (1988), através destes testes é possível avaliar efeitos aditivos, sinérgicos e antagônicos dos agentes químicos não detectados por qualquer outro tipo de análise.

Aqueles autores ainda citam exemplos de produtos que antes de serem lançados no mercado, devem passar por testes para se conhecer seus efeitos sobre o ambiente e consideram que na avaliação de risco ecológico os testes de toxicidade são componentes fundamentais do estágio analítico. Nesse estágio os efeitos ecológicos em vários níveis de exposição são determinados. 
A utilização de bioindicadores em programas de monitoramento ambiental leva a dois tipos de informação adquirida: a qualitativa e a quantitativa, surgindo, então, dois tipos de monitoramento. O biomonitoramento passivo prevê a utilização de organismosindicadores naturalmente presentes no ambiente em estudo, mais caracterizado como bioindicação. No biomonitoramento ativo ocorre a utilização de organismos-teste introduzidos e expostos ao impacto ambiental a ser avaliado (PRINTES, 1996).

Segundo SOARES (1990), monitoramento e o estabelecimento de critérios de qualidade das águas não podem se basear exclusivamente em métodos químicos, visto que: - $\quad$ Alguns agentes químicos produzem efeitos biológicos adversos em concentrações bastante inferiores às detectadas pelos atuais métodos analíticos;

- $\quad$ As análises químicas apenas revelam a presença das substâncias para as quais estão especificamente destinadas. Sendo impraticável analisar todas as substâncias químicas, a presença insuspeita de possíveis poluentes pode passar despercebida;

- Nos sistemas aquáticos as substâncias químicas não ocorrem, normalmente, em concentrações constantes. Logo, um monitoramento químico regular pode não detectar picos ocasionais de concentrações elevadas, que terão obviamente um significado biológico muito maior do que os níveis normais;

- As águas residuárias contem misturas complexas de substâncias químicas cuja toxicidade não pode ser atribuída a um ou vários componentes isolados, Assim, devido a possíveis efeitos antagonísticos e sinergísticos, a toxicidade pode ser maior, menos, ou igualar a soma da toxicidade dos seus componentes;

- $\quad$ Os efeitos biológicos de um agente químico são função de sua concentração e das características do sistema em que atua;

- As análises físicas e químicas são pontuais no tempo, enquanto que os testes de toxicidade indicam, além do estado no momento da amostragem, as condições previamente existentes.

BASSOI et al. (1990) apontam que o monitoramento biológico complementa os procedimentos já adotados através do monitoramento químico. Outros autores também ressaltam a importância da realização de ambos os tipos de monitoramento para uma completa avaliação dos efeitos resultantes das atividades humanas sobre o meio ambiente (ELDER, 1990; FOWLER \& AGUIAR, 1991; RAVERA, 1998; VAN DER VELDE \& LEUVEN, 1999). 
Os ensaios de toxicidade constituem uma forma de biomonitoramento ativo, pois neles são utilizados organismos-teste como indivíduos padronizados e cultivados em laboratório, que podem fornecer indicações sobre as condições de um ecossistema frente à presença de impacto ambiental. Sua utilização fundamenta-se na exposição dos organismos-teste, representativos do ambiente aquático, a várias concentrações de uma ou mais substâncias ou matrizes ambientais durante um determinado período de tempo (GOLDSTEIN et al., 1990).

Por meio destes se determinam o tempo e a concentração em que o agente é potencialmente prejudicial. Para qualquer produto, o contato com a membrana celular ou sistema biológico pode não produzir um efeito adverso se a concentração do produto for baixa, ou o tempo de contato for insuficiente. Concentração e tempo de exposição estão diretamente relacionados e, portanto altas concentrações poderão ter efeitos prejudiciais em tempos de exposição extremante curtos (RAND, 1995).

Os ensaios de toxicidade podem ser utilizados no auxílio do controle da qualidade da água dos corpos receptores quanto à presença de tóxicos. O que interessa neste tipo de experimento, não é a identificação individual dos agentes tóxicos na água, mas sim verificar se a água é tóxica, através de ensaios de toxicidade e não somente pela determinação da composição química e física, comprometendo a qualidade da vida aquática. Os ensaios são aplicados também para avaliar a sensibilidade relativa de organismos aquáticos para um determinado agente tóxico, para determinar a qualidade de água e as concentrações seguras de agentes químicos para preservação da vida aquática, além de avaliar a fertilidade potencial das águas e a eficiência de diferentes métodos de tratamento para efluentes industriais em termos ecotoxicológicos (METCALF \& EDDY, 1991).

A toxicidade é definida como sendo os resultados nocivos à saúde proveniente do sistema composto por substâncias químicas e substâncias próprias do organismo. Desta maneira, a toxicidade tem como objetivo a análise do efeito causado por uma substância química ou uma mistura, levando em consideração o tempo de exposição e a concentração, sobre um determinado organismo, (ZAGATTO et al., 1988).

Nas últimas décadas, testes de toxicidade com organismos de águas continentais, estuarinas e marinhas, em condições laboratoriais e/ou campo vem sendo cada vez mais utilizados. Portanto, verifica-se a importância desta metodologia quando utilizada como ferramenta para o estabelecimento de critérios de qualidade de águas e sedimentos de modo a proteger a biota aquática, no monitoramento de efluentes industrias e áreas de 
influencia, como também na avaliação da eficiência de sistemas de tratamento (EPA, 1994).

Os estudos ecotoxicológicos representam, portanto, um instrumento para obtenção de dados quali e quantitativos sobre os efeitos adversos de químicos e outros tóxicos aos organismos, permitindo avaliar o potencial ou o nível de impacto a que um dado ambiente está submetido. Para BOHRER (1995) os testes ecotoxicológicos apontam informações como os efeitos resultantes das interações de compostos químicos e, ainda, permitem estabelecer diluições necessárias para reduzir ou prevenir efeitos tóxicos em águas receptoras, bem como avaliar o impacto dos corpos receptores e determinar a persistência da toxicidade.

Em geral, os testes de toxicidade são utilizados para se detectar e controlar poluentes tóxicos que estejam presentes nos efluentes industriais (CETESB, 1990a). Os testes adotados devem ser bem definidos e padronizados, para que se possa realizar o mesmo nível de controle de toxicidade, em diferentes corpos receptores e em efluentes com os mais diversos poluentes (BERTOLETTI, 1989). Fundamentando-se na toxicidade foram desenvolvidos ensaios que constituem um dos principais instrumentos utilizados nos estudos de Ecotoxicologia Aquática. Os dados gerados são utilizados na avaliação de risco ambiental e regulamentação de novas substâncias químicas, assim como no estabelecimento de critérios de qualidade da água para a preservação das comunidades aquáticas e no controle da toxicidade de efluentes líquidos industriais e municipais (GOLDSTEIN et al., 1990).

Os ensaios ecotoxicológicos podem ser realizados tanto em laboratório, como "in situ", e seguem diversas metodologias, que apresentam como objetivo a avaliação dos efeitos de contaminantes potencialmente danosos para a vida aquática, tais como: alterações na qualidade da água, morte do organismo ou ainda efeitos sub-letais em seu ciclo de vida, como a diminuição da fecundidade e alterações na taxa de crescimento individual ou populacional. Os testes realizados em laboratórios incluem diversas modalidades tais como, os testes de toxicidade agudo, crônica, de bioacumulação e biodegradação além dos testes sub-letais que podem ser reunidos em outros grupos básicos: bioquímicos, fisiológicos, moleculares, comportamentais e histológicos (RAND, 1995).

Recomenda-se realizar ensaios com três organismos, sendo estes os produtores primários, os consumidores primários e os consumidores secundários, pois, dependendo da concentração e da composição do poluente químico, pode ocorrer que estes, além de serem 
tóxicos para todos os organismos, apresentem toxicidade para apenas uma ou outra espécie (BEHRENS, 1995).

Os atributos dos ecossistemas que podem ser medidos como respostas a um estresse são ilimitados e não podem ser todos monitorados. "Endpoints" são as poucas respostas selecionadas para serem monitoradas pelos testes de toxicidade. De acordo com ADAMS (1995), "end points" toxicológicos são valores resultantes de medidas específicas feitas durante ou após a conclusão do teste de toxicidade, sendo comuns as descrições dos efeitos do agente tóxico sobre sobrevivência, crescimento e reprodução.

Atualmente, esforços têm sido realizados no país com o objetivo de desenvolver metodologias de ensaios de toxicidade utilizando espécies nativas, tanto em ambientes de água doce, como no marinho. Neste sentido, FONSECA (1991) e CASTILHO (2005), utilizaram a espécie nativa Ceriodaphnia silvestrii, de ampla distribuição na região tropical no Brasil, na avaliação da toxicidade de efluentes de indústrias têxteis e na validação de ensaios ecotoxicológicos com organismos autóctones, respectivamente.

Apenas no final da década de 70, com a implantação do Laboratório de Bioensaios da CETESB, São Paulo, é que os testes de toxicidade com organismos aquáticos foram mais difundidos no Brasil. No final desta década houve a implantação de normas tendo por base os trabalhos desenvolvidos em instituições internacionais de controle ambiental como, Enviroment Canadá, United States Envorimental Protection Agency, Association Française de la Qualité d'eau, e American Public Health Organization (DAMATO, 1997).

Internacionalmente, normas para realização de testes de toxicidade têm sido desenvolvidas e implementadas para organismos de água doce (EPA 2002; OECD, 2006). No Brasil, a referência legal para o controle de toxicidade consta na Resolução do Conselho Nacional do Meio Ambiente - CONAMA 357/2005, que dispõe sobre a classificação de corpos d'água preconiza a utilização de testes de toxicidade para classificação, avaliação e monitoramento dos corpos d'água e efluentes (BRASIL, 2005). Para o Estado de São Paulo, a Resolução da Secretaria do Meio Ambiente - SMA-3, publicada no Diário Oficial do Estado de São Paulo em 25/02/2000 estabelece no Art. 1ª; “Além de atenderem ao disposto na Lei 997/76, que institui o Sistema de Prevenção e Controle de Poluição do Meio Ambiente, com regulamentação aprovada pelo Decreto 8468/76 (Art. 18) e, considerando eventuais interações entre as substâncias no efluente este não deverá causar ou possuir potencial para causar efeitos tóxicos aos organismos aquáticos no corpo receptor". 


\subsection{Efeitos e ensaios de ecotoxicidade aguda}

O efeito agudo é definido como sendo uma resposta severa e com rapidez dos organismos aquáticos a um estímulo que pode se manifestar num período de até 96 horas, causando quase sempre a letalidade, sendo que pode ocorrer à alguns microcrustáceos a imobilidade .

Normalmente o efeito é a letalidade, ou imobilidade onde são determinadas a CL50 e a CE50:

- CL50: concentração letal média, ou a concentração do agente tóxico que causa mortalidade a 50\% dos organismos expostos num intervalo de 24 a 96 horas;

- $\quad$ CE50: concentração efetiva média, ou a concentração do agente tóxico que causa imobilidade a $50 \%$ dos organismos expostos num intervalo de 24 a 96 horas (ABNT, 2005).

De acordo com RAND \& PETROCELLI (1985), os testes de toxicidade aquática aguda têm por objetivo determinar, sob condições controladas, a concentração de substância químicas ou efluentes, ou o nível de um agente, como a temperatura ou pH, que causa efeitos deletérios a um grupo de organismos-teste durante um curto período de tempo.

De acordo com a EPA (2002), os testes agudos podem ser estáticos (renováveis ou não renováveis) ou de fluxo contínuo:

- Testes estáticos não renováveis: os organismos teste são expostos à mesma soluçãoteste durante toda realização do teste;

- Testes estáticos renováveis: os organismos testes são expostos a uma nova solução da mesma concentração da amostra a cada $24 \mathrm{~h}$ ou outro intervalo prescrito, com a transferência dos organismos-teste de um recipiente-teste a outro, ou por transferência total ou parcial da solução nos recipiente-teste;

- Testes de fluxo contínuo: neste caso a solução-teste e bombeada (continuamente ou intermitentemente) para o recipiente-teste.

Testes estáticos não renováveis e estáticos renováveis (semi-estáticos) não são apropriados quando a substância teste é instável, volátil, apresenta alta demanda de oxigênio ou ainda quando é sorvida pelo recipiente-teste. Quando isso ocorre é preferível utilizar o sistema de fluxo contínuo (RAND \& PETROCELLI 1985; ADAMS, 1995). 
Sistemas estáticos são normalmente limitados a $1,0 \mathrm{~g}$ de biomassa por litro de soluçãoteste, de maneira a não causar desoxigenação na solução-teste.

\subsection{Efeitos e ensaios de ecotoxicidade crônicos}

Efeito crônico é uma resposta a um estímulo que continua por longo tempo, parte ou todo o ciclo de vida, que normalmente é subletal e afeta funções biológicas como a reprodução, desenvolvimento dos ovos, crescimento e maturação, entre outras (CETESB, 1990a).

A toxicidade crônica se traduz pela resposta a um estímulo contínuo, podendo abranger parte ou todo o ciclo de vida dos organismos, como no caso da emissão de efluentes (RAND \& PETROCELLI, 1985).

A expressão de muitos agressores ambientais somente se torna visível quando estão presentes em altas doses. Entretanto, quando eles existem em porções menores seus efeitos na bagagem genética dos indivíduos, interferem nas suas funções fisiológicas, altera a freqüência reprodutiva e/ou a qualidade e quantidade de organismos gerados (TERRA \& FEIDEN, 2003). Os efeitos crônicos são subletais e são observados no ambiente quando as concentrações do agente tóxico permitem a sobrevida dos organismos, causando distúrbios em suas funções biológicas, tais como na reprodução, desenvolvimento de ovos, crescimento e maturação.

Os ensaios de toxicidade crônica variam de acordo com o ciclo de vida do organismo-teste, e podem também ser realizados expondo ovos, embriões, larvas, etc. $\mathrm{O}$ "endpoint" avaliado é a concentração máxima do agente tóxico que não causa o efeito observado no teste (CENO), isto é, a maior concentração do poluente tóxico que não cause efeito deletério estatisticamente significativo, na sobrevivência e reprodução dos organismos-teste (CETESB, 1990b). Os ensaios crônicos são importantes e complementam os ensaios agudos, pois a ausência de efeito agudo não caracteriza ausência de efeito sobre a biota.

\subsection{Ensaios ecotoxicológicos populacionais}

Recentes desenvolvimentos nas análises populacionais têm refinado o entendimento nos determinantes das taxas de crescimento populacionais estabelecendo uma conexão entre a teoria e os resultados obtidos em campo. Com conseqüência, tem 
havido um interesse crescente em aplicar estes métodos em Ecologia, como conservação e manejo da vida selvagem, e em Ecotoxicologia, na realização de ensaios ecotoxicológicos (SIBLY \& HONE, 2002).

Pelo fato da Ecotoxicologia ter evoluído da Toxicologia e não da Ecologia, as variáveis medidas geralmente são focadas nos indivíduos. No entanto, de uma perspectiva ecológica, os sistemas de maior preocupação são os grupos coletivos de organismos, e não existem necessariamente simples relações diretas entre respostas dos indivíduos e respostas com níveis hierárquicos mais elevados. Crescentemente, ecotoxicologistas estão voltando suas atenções para estas relações e, para populações, tem sido focada a relação entre a taxa de crescimento populacional e os elementos da história de vida individual que contribui para isto (FORBES \& CALOW, 1999).

A CL50 é o "endpoint" laboratorial predominante para estimar a toxicidade dos contaminantes. O CENO e o CEO são outros "endpoints" determinados a partir de dados sobre a reprodução. No entanto estes dois "endpoints" são medidos baseados na observação de indivíduos e são supostamente estimados para uma população de organismos.

O Conselho de Pesquisas Nacionais dos USA, em relatório elaborado pelo Comitê de Revisão de Métodos em Ecotoxicologia (NRA, 1981), de muito tempo, recomenda que os contaminantes já deveriam ser estudados nos níveis de população, comunidades e ecossistemas, ainda que poucos pesquisadores adotem procedimentos para avaliar os efeitos dos contaminantes em níveis de organização maiores que indivíduos (MARSHALL, 1978; KAREIVA et al.,1996).

Embora os efeitos sub-letais dos contaminantes sejam geralmente reconhecidos como sendo importantes, pouco é conhecido como se manifestam no nível da população (HALLAM et al., 1993). O nível da organização biológica ou da escala em que as medidas são feitas pode ter um efeito profundo na interpretação dos dados. Sem verificação experimental, pode não haver garantia que as respostas medidas em um nível organizacional serão refletidas em mudanças em um nível mais elevado.

Apesar desta sustentação, a avaliação pelos parâmetros individuais ainda domina a literatura ecotoxicológica, primeiramente com medidas de mortalidade aguda e fecundidade individual em curto prazo (BECHMANN, 1994). A hipótese de que os parâmetros individuais podem extrapolados aos sistemas de organização maiores tais como populações, comunidades e ecossistemas. Entretanto, a avaliação do risco ecológico 
baseada unicamente em parâmetros individuais pode mascarar determinados efeitos subletais críticos em uma população.

Simulações de computador revelaram que a concentração dos tóxicos, que são sub-letais em nível do indivíduo, pode facilmente conduzir à extinção da população (HALLAM et al., 1993). Estes autores concluíram que parâmetros isolados de bioensaios podem não fornecer informação suficiente para predizer exatamente efeitos populacionais. Experimentalmente, LAMPERT et al. (1989) encontrou efeitos significativos de atrazina em populações do dafinídeos do valor de duas ordens de magnitude menores do que o CL50 agudo. Definir as ligações de efeitos de bioensaios entre um único organismo e efeitos em suas populações, poderá ser a próxima etapa para se compreender os modos de ação da toxicidade dos xenobióticos nas comunidades naturais.

BECHMANN (1994) sugeriu que determinados produtos químicos podem afetar parâmetros demográficos abaixo da curva tradicional de concentração-resposta, tendo por resultado o declínio da população e a extinção nos níveis mais complexos, fato não observado em parâmetros individuais. Esta hipótese foi suportada por WALTON et al. (1981), que encontrou que testes agudos de toxicidade de 96 horas não foram sensíveis para determinar o efeito da água acidificada em populações do Daphnia pulex. Assim, uma ênfase maior deve ser colocada no efeito de contaminantes em nível populacional.

O crescimento populacional, em particular a taxa intrínseca de aumento natural (r), tem sido recomendado como um "endpoint" de maior relevância que o CL50 porque combina os efeitos letais e subletais dentro de uma medida significativa (DANIELS e ALLAN, 1981; GENTILE et al., 1982; DAY e KAUSHIK, 1987; BECHMANN, 1994). A taxa mede a habilidade de uma população em aumentar exponencialmente em um ambiente ilimitado. Sua aplicação na avaliação da toxicidade de contaminantes é ecologicamente mais relevante do que as medidas de CL50 e CE50 tradicionais, pois integra a idade especifica de sobrevivência e fecundidade num único parâmetro, o que torna a resposta populacional mais relevante e factível de ser integrada a modelos matemáticos (VAN LEEUWEN et al., 1985),

A demografia tem sido sugerida como um modo de se avaliar o efeito dos contaminantes simplesmente porque contempla todos os efeitos que sofrem as populações (KAMMENGA et al., 1996; KAREIVA et al., 1996). Estudos toxicológicos demográficos ou tabelas de vidas fornecem uma medida do efeito sobre a taxa de crescimento populacional. As tabelas da vida são usadas como metodologia para se obter os parâmetros populacionais, como a taxa intrínseca de aumento natural $(r)$, usados como medidas do 
stress toxicológico (GENTILE et al., 1982; VAN LEEUWEN et al., 1985, 1987; BECHMANN, 1994; STARK e WENNERGREN, 1995; WALTON et al., 1981). Ecólogos utilizaram-nas inicialmente desde sua modificação por BIRCH (1948) para avaliar sobrevivência, fecundidade e taxa de crescimento sob diferentes condições ambientais. As tabelas agregam medidas isoladas de idade especifica de sobrevivência e fecundidade através do tempo para estimar a taxa intrínseca de aumento natural, rm, tempo de geração, T, e a taxa reprodutiva por geração, Ro, para um grupo de animais crescendo sob determinadas condições ambientais. Estas estatísticas, bem como outros parâmetros demográficos derivados de tabelas de vidas completas, aparecem para fornecer um método realista para medir os efeitos crônicos de populações expostas aos contaminantes (DANIELS \& ALLAN, 1981; GENTILE et al., 1982; VAN LEEUWEN et al., 1985).

Esta abordagem tem sido muito desenvolvida pela elaboração de modelos de matrizes populacionais (CASWELL, 1989), e nos últimos anos, o aumento da preocupação sobre o meio ambiente tem levado a inúmeros estudos do efeito dos contaminantes sobre a taxa de crescimento populacionais (FORBES \& CALOW 1999). O parâmetro populacional tem sido utilizado com sucesso para se determinar o efeito em invertebrados aquáticos de diferentes compostos xenobióticos como pesticidas (DANIELS e ALLAN, 1981; DAY e KAUSSHIK, 1987) e metais ( BECHMANN, 1994).

\subsection{Taxa de crescimento populacional}

A taxa de crescimento populacional é um parâmetro sumário de tendências dentro de densidades populacionais ou abundância que informa se estão estáveis, crescendo ou decrescendo, e o quão rápido elas estão mudando (SIBLY \& HONE, 2002). É uma medida da habilidade de uma população crescer logaritimicamente em um ambiente ilimitado. Existem duas maneiras de expressar a taxa de crescimento populacional: a taxa intrínseca de aumento $(r)$ e lambda $(\lambda)$ (fator de multiplicação populacional), o qual é o antilog de rm. $R m$ é o expoente na equação diferencial para o crescimento da população num ambiente ilimitado sob condições específicas, de acordo com a equação:

$$
\begin{aligned}
& \mathrm{Nt}=\mathrm{N}_{0} \mathrm{e}^{\mathrm{rt}}, \text { onde: } \\
& \mathrm{Nt}=\text { número de indivíduos no tempo } \mathrm{t} ; \\
& \mathrm{N}_{0}=\text { número de indivíduos no tempo } 0 ;
\end{aligned}
$$


$\mathrm{e}=$ base do logaritmo neperiano;

$\mathrm{r}=$ taxa intrínseca de aumento natural;

$\mathrm{t}=$ tempo.

Quando o ambiente não está limitado, a taxa ou índice específico de crescimento se torna constante e máximo para as condições microclimáticas existentes. $\mathrm{O}$ valor da taxa de crescimento sob estas condições favoráveis para a população é máximo, característico para uma dada estrutura de idades da população, e constitui um índice único da capacidade que uma população tem para crescer. Esta taxa, designada normalmente por $r$, é um coeficiente instantâneo do crescimento da população, que quando se encontra com uma distribuição de idades estável e estacionária se designa por taxa intrínseca de aumento natural ou $r_{m}\left(r_{\max }\right)$ (ODUM, 2001).

Outra abordagem para o cálculo $\mathrm{r}$ é através do uso de matrizes de projeção populacionais (CASWELL, 1989). O número de organismos sobreviventes e o número de descendentes produzidos em intervalos regulares de tempo são tabulados em uma matriz e a taxa de multiplicação da população, $\lambda\left(=\mathrm{e}^{\mathrm{r}}\right)$, calculada usando métodos de álgebra matricial. A mesma taxa intrínseca de aumento, $r$, pode ser estimada por amostragens do tamanho da população em diferentes pontos de tempo (WALTHALL e STARK, 1996; SIBLY, 1999). Diferentemente dos dois primeiros procedimentos, este método não requer informações detalhadas sobre características em nível individual e por isso oferece algumas vantagens em termos de economia de tempo e de esforço.

\subsection{Fármacos no ambiente}

Os fármacos são uma classe dos contaminantes ambientais emergentes e sua ocorrência no ambiente é de interesse crescente (RICHARDSON \& BOWRON, 1985; HALLING-SØRENSEN et al., 1998; TERNES, 1998; DAUGHTON \& TERNES, 1999; KUMMERER et al, 2000; HEBERER, 2002). Somente nos últimos anos a introdução dos fármacos no ambiente emergiu como um tópico importante da pesquisa (HALLINGSØRENSEN et al., 1998; DAUGHTON \& TERNES, 1999; HIRSCH et al., 2003). Vários estudos, do meio da década de 1990 até hoje, têm concentrado na ocorrência e na distribuição dos fármacos humanos e veterinários no ambiente.

Hoje são registradas 100.000 substâncias químicas diferentes na União Européia, dos quais 30.000 destes produtos são comercializados em quantidades maiores que uma 
tonelada (GIGER, 2002). Entre eles, estão os compostos farmacêuticos, que nos últimos anos foram classificados como contaminantes ambientais emergentes. $O$ constante progresso da medicina faz com que novas drogas com novas substâncias ativas sejam disponibilizadas no mercado para o tratamento de animais e humanos. Os produtos farmacêuticos representam mais de 4.000 moléculas em 10.000 especialidades diferentes (BEAUSSE, 2004)

Uma das razões da falta de dados ecotoxicológicos de fármacos é que a regulação de drogas é feita por agências de saúde, as quais não consideram as questões ambientais, pois até recentemente os fármacos não eram vistos como substancias potencialmente tóxicas ao meio ambiente. Porém as drogas são desenvolvidas com a intenção de que apresentem efeitos biológicos. Muitas delas são lipofílicas a fim de que possam atravessar membranas; são resistentes para evitar que se tornem inativas antes do efeito da cura. Sendo assim, as substâncias medicinais apresentam propriedades semelhantes a outros xenobióticos, e podem ser bioacumulados e provocar efeitos nos ecossistemas aquáticos (HALLING-SORENSEN et al., 1998). A Tabela 1 apresenta algumas substâncias encontradas nos rios.

Tabela 1 - Principais grupos de fármacos, substâncias e respectivas concentrações encontrados nos rios.

\begin{tabular}{|c|c|c|c|}
\hline Grupo & Substância & Concentração & Referência \\
\hline Betas Bloqueadores & Metoprolol & até $1,5 \mathrm{mg} . \mathrm{L}^{-1}$ & $\begin{array}{l}\text { HIRSCH et al., 1998; SEDLAK e } \\
\text { PINKSTON, } 2001\end{array}$ \\
\hline \multirow[t]{2}{*}{ Antiinflamatório } & Diclofenaco & até $1,2 \mathrm{mg} . \mathrm{L}^{-1}$ & TERNES et al, 1998 \\
\hline & & & BUSER et al., 1998a, 1999 \\
\hline \multirow[t]{2}{*}{ Estrógenos } & 17b-estradiol & até 0,013 mg.L $\mathrm{L}^{-}$ & KUCH e BALLSCHMITTER, 2000; \\
\hline & & & $\begin{array}{l}\text { ADLER et al., 2001; HUANG e } \\
\text { SEDLAK, } 2001\end{array}$ \\
\hline \multirow[t]{2}{*}{ Antibióticos } & Eritromicina & até $1,7 \mathrm{mg} \cdot \mathrm{L}^{-1}$ & LINDSEY et al,. 2001; \\
\hline & & & ADLER et al,. 2001 \\
\hline $\begin{array}{l}\text { Agentes redutores de } \\
\text { gordura }\end{array}$ & $\begin{array}{c}\text { Ácido } \\
\text { Clofibrinico }\end{array}$ & até $0,2 \mathrm{mg} \cdot \mathrm{L}^{-1}$ & STAN et al,. 1994 \\
\hline Drogas anti-epiléticas & $\begin{array}{l}\text { Carbamazepi } \\
\text { ne }\end{array}$ & até $2,1 \mathrm{mg} . \mathrm{L}^{-1}$ & TERNES, 1998; SEILER et al,. 1999 \\
\hline
\end{tabular}


Os ingredientes farmacêuticos incluem seus metabólitos e conjugados, excretados principalmente na urina ou fezes. Entram nos sistemas de tratamentos municipais de esgoto onde podem ser degradados, adsorvidos ao lodo do esgoto, ou diluídos eventualmente na água de superfície (CARLSSON, et al., 2005). Particularmente, alguns córregos pequenos que recebem uma quantidade relativamente grande de água proveniente das estações de tratamento de esgoto são consideravelmente poluídos, com picos de concentrações de diversos fármacos de mais de $1 \mathrm{mg} \cdot \mathrm{L}^{-1}$.

Devido a seu modo da ação específica e o fato de como estes compostos são intencionalmente projetados a exercer um efeito nos seres humanos, nos mamíferos ou em outros vertebrados, os resíduos dos fármacos podem ser considerados ainda mais nocivos para a saúde humana do que aqueles de pesticidas, que são formulados tendo como organismo-alvo ervas daninhas, fungos e vermes invertebrados. Entretanto, até agora o modo de ação dos fármacos não são bem compreendidos para que se possam inferir os efeitos ambientais potenciais causados por estas substâncias. Apresentam um modo específico de ação, e muitos deles possuem alguma persistência no corpo. Estas características, entre outras, fazem com que os fármacos sejam considerados como de potencial efeito na flora e fauna aquática (FENT et al, 2003). Como uma exceção, o estrógeno sintético etiniloestradiol é bem conhecido pelo seu potencial como disrruptor endócrino e de efeito sobre a reprodução.

O tratamento para água potável diminui resíduos, porém não pode remover completamente estas substâncias. Assim, até na água da torneira alguns fármacos como o ácido Clofibrinico podem ser detectados nas concentrações de até 270 ng.L $\mathrm{L}^{-1}$ (HEBERER et al., 1997; TERNES et al., 2001). Em contrapartida, pouco é conhecido sobre efeitos ecotoxicológicos dos fármacos em organismos aquáticos e terrestres e uma revisão abrangente destes efeitos está faltando (WEBB, 2001; CLEUVERS, 2002). Os organismos aquáticos são particularmente alvos importantes, porque são expostos, muitas vezes, durante todo seu ciclo de vida. Efeitos de toxicidade aguda têm sido relatados para um número considerável de fármacos, entretanto, tais dados isolados podem não ser apropriados para responder a pergunta sobre efeitos ambientais, e, subseqüentemente, ser utilizados em avaliações de risco e periculosidade (FENT et al, 2003).

A falta atual do conhecimento se prende, em particular, para os efeitos crônicos que são investigados muito raramente. Apesar das grandes quantidades de drogas humanas liberadas no ambiente, regulamentos concisos para a avaliação do risco ecológico estão faltando. Somente nos últimos anos, agências regulatórias têm emitido normas de 
procedimentos detalhadas sobre como os fármacos devem ser avaliados para possíveis efeitos não desejados no ambiente.

\subsubsection{Fontes dos fármacos para o ambiente}

Os fármacos são excretados após sua aplicação em sua conformação inicial ou como metabólicos e ingressam no ambiente aquático por diferentes vias: descartes intencionais ou acidentais de indústrias farmacêuticas, descargas de fármacos veterinários e agrícolas após o uso terapêutico e/ou comercial e descargas de fármacos de uso humano por efluentes de estações de tratamento de esgoto, ou fontes difusas em regiões em que não há tratamento de esgotos. As possíveis rotas nos compartimentos do ambiente aquático são apresentadas na Figura 1. 


\section{EXPOSIÇÃO}

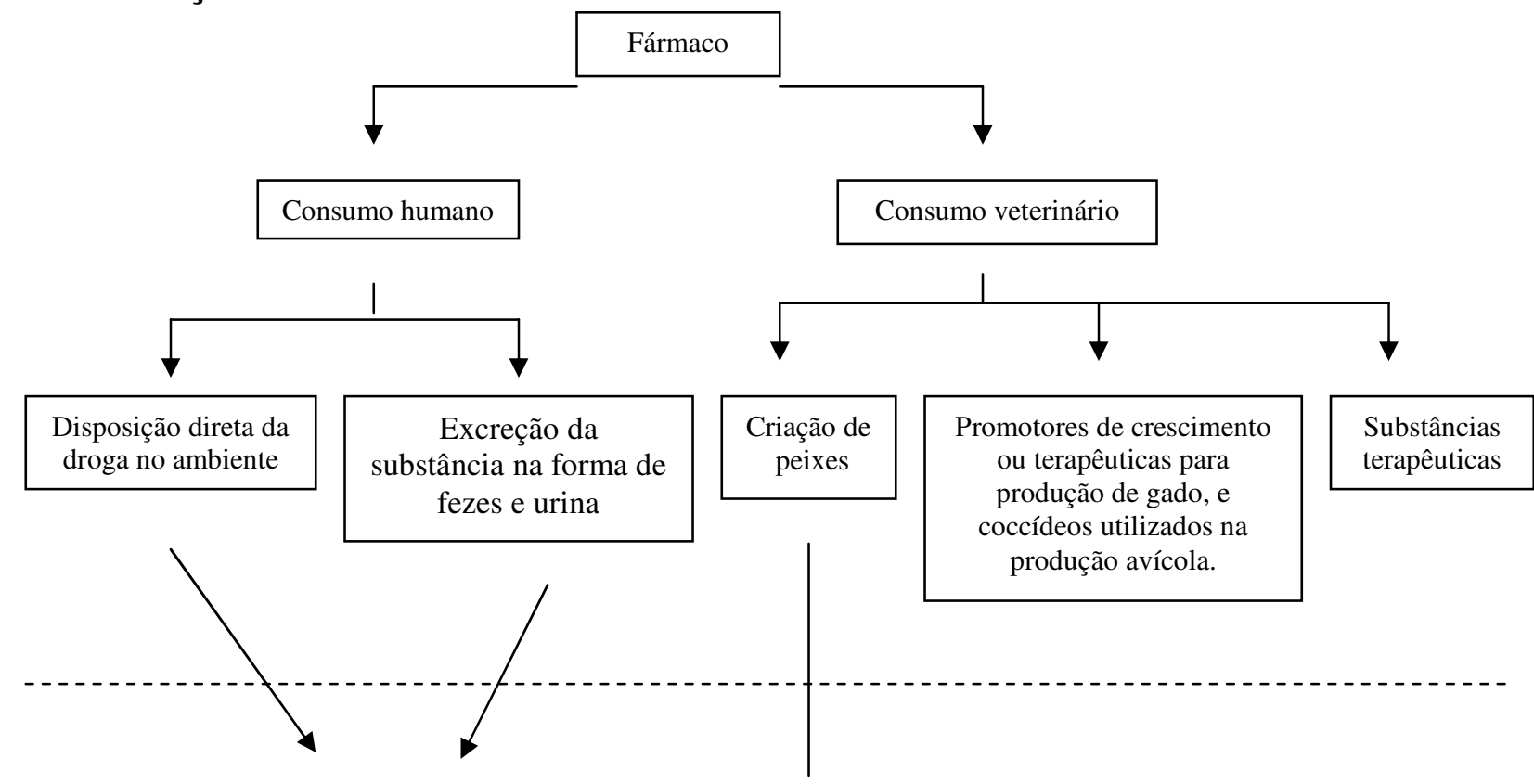

\section{DISPOSIÇÃO}

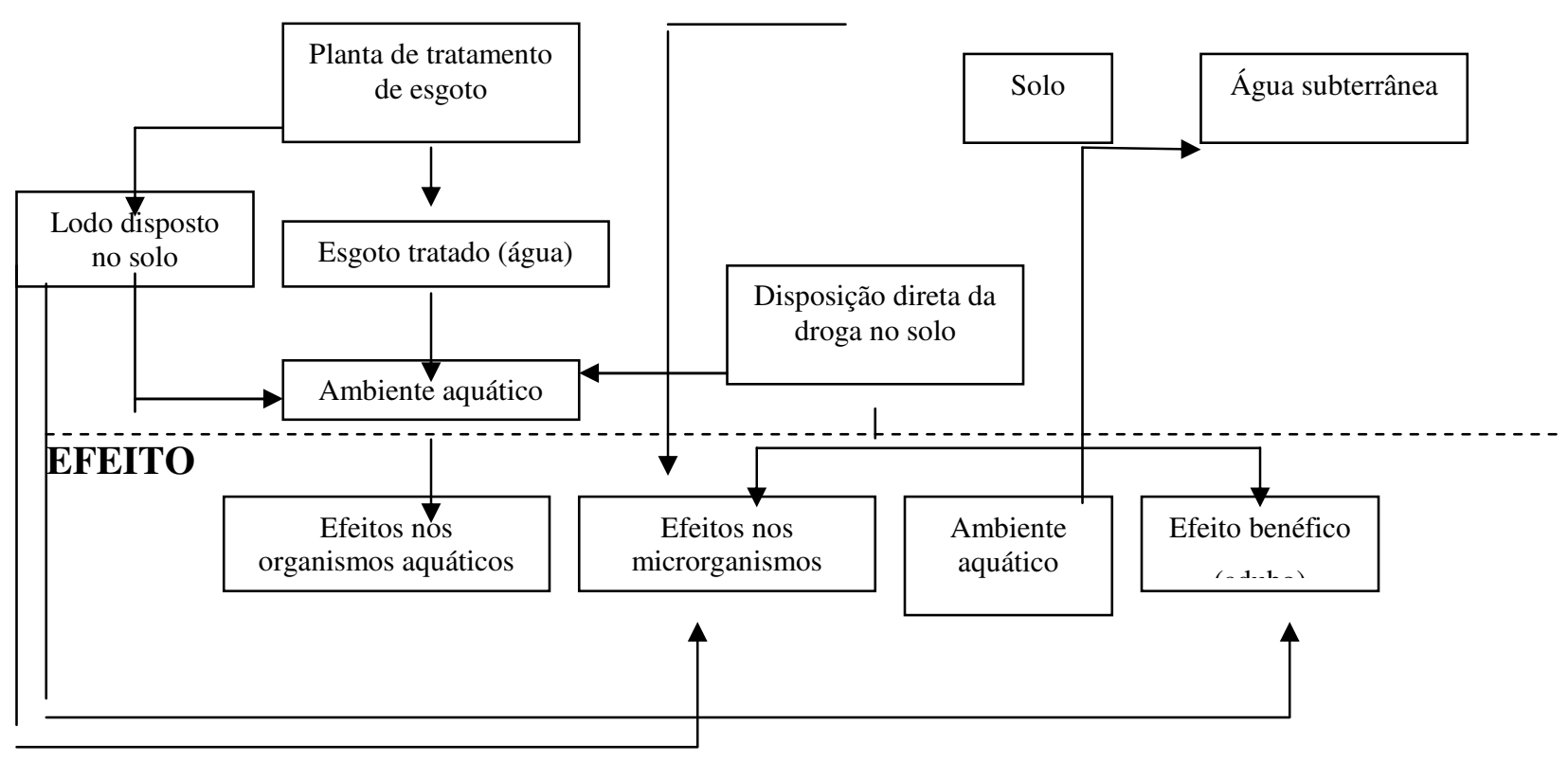

Figura 1 - Possíveis rotas de resíduos farmacológicos no ambiente aquático

(HALLING-SORENSEN, 1998).

Os fármacos não prontamente degradados em estações de tratamento de esgoto (ETE) são lançados nos corpos d'água resultando na contaminação de rios, lagos, estuários e raramente em águas subterrâneas. O lodo gerado no processo é lançado em campos agrícolas e podem causar contaminação do solo, águas superficiais e percolação para águas subterrâneas. O mesmo pode ocorrer com substâncias utilizadas no uso veterinário 
(DAUGHTON e TERNES, 1999). Além disto, os fármacos veterinários podem entrar nos sistemas aquáticos através da aplicação de adubo em campos e, subseqüente, lixiviamento, e também por aplicação direta na aqüicultura.

A grande preocupação ambiental não é necessariamente o volume de produção de um fármaco, mas sua persistência no ambiente e atividade biológica como, por exemplo, alta toxicidade e alto potencial para efeitos em funções biológicas como a reprodução. A Tabela 2 apresenta o consumo de fármacos em vários países.

Tabela 2 - Consumo anual de diferentes classes de fármacos prescritos para diferentes países (toneladas/ano).

\begin{tabular}{|c|c|c|c|c|c|c|c|}
\hline Composto & $\begin{array}{c}\text { Áustria } \\
\text { (1997) }\end{array}$ & $\begin{array}{c}\text { Dinamarca } \\
(1997)\end{array}$ & $\begin{array}{c}\text { Austrália } \\
\text { (1998) }\end{array}$ & $\begin{array}{c}\text { Inglaterra } \\
(2000)\end{array}$ & $\begin{array}{c}\text { Alemanha } \\
\text { (2001) }\end{array}$ & $\begin{array}{l}\text { Itália } \\
(2001)\end{array}$ & $\begin{array}{l}\text { Suíça } \\
(2004)\end{array}$ \\
\hline \multicolumn{8}{|c|}{ Analgésicos, antipiréticos e antiinflamatórios } \\
\hline AAS & 78.45 & 0.21 & 20.4 & - & 836.26 & - & 43.80 \\
\hline As & 9.57 & - & - & - & 71.67 & - & 5.30 \\
\hline Paracetamol & 35.08 & 0.24 & 295.9 & 390.9 & 621.65 & & 95.20 \\
\hline Naproxen & 4.63 & - & 22.8 & 35.07 & - & - & 1.70 \\
\hline Ibuprofen & 6.7 & 0.03 & 14.2 & 162.2 & 344.89 & 1.9 & 25.00 \\
\hline Diclofenaco & 6.14 & - & - & 26.12 & 85.80 & - & 4.50 \\
\hline \multicolumn{8}{|l|}{$\beta$-Bloqueadores } \\
\hline Atenolol & - & - & - & 28.98 & - & 22.07 & 3.20 \\
\hline Metroprolol & 2.44 & - & - & - & 92.97 & - & 3.20 \\
\hline \multicolumn{8}{|l|}{ Antilipêmicos } \\
\hline Genfibrazol & - & - & 20 & - & - & - & 0.399 \\
\hline Benzafibrato & 4.47 & - & - & - & - & 7.60 & 0.757 \\
\hline \multicolumn{8}{|l|}{ Neuroativos } \\
\hline Carbamazepam & 6.33 & - & 9.97 & 40.35 & 87.60 & - & 4.40 \\
\hline Diazepam & - & - & 0.21 & - & - & - & 0.051 \\
\hline
\end{tabular}

Fonte: FENT et al. (2003)

\subsubsection{Efeitos ecotoxicológicos}

Os fármacos são projetados para atingir órgãos ou rotas metabólicas e moleculares específicas tanto nos humanos como em animais, mas também possuem freqüentemente efeitos colaterais importantes. Quando introduzidos no ambiente eles podem afetar os animais pelas mesmas rotas e atingir órgãos, tecidos, células ou biomoléculas com funções semelhantes a dos humanos. 
É importante reconhecer que para muitas drogas, o efeito específico ou o modo de ação não é muito bem conhecido e muitos diferentes modos de ação podem ocorrer. Apesar disto, experimentos de toxicidade devem ser delineados para alvos específicos objetivando o efeito do fármaco em organismos vertebrados e invertebrados baseados na hipótese de semelhança no modo de ação. No entanto, ensaios ecotoxicológicos realizados hoje são desenvolvidos de acordo com procedimentos tradicionais e "endpoints" tradicionais como a avaliação da mortalidade.

A literatura atual dos efeitos ecotoxicológicos dos fármacos humanos trata principalmente da toxicidade aguda e é geralmente centrada em organismos aquáticos. No entanto, os efeitos de metabólitos dos fármacos são raramente investigados. Produtos obtidos da foto-transformação do Naproxeno, por exemplo, possuem uma maior toxicidade do que o composto original (ISIDORI et al., 2005).

Ensaios realizados em Ecotoxicologia testam somente o efeito agudo (exposição em curto prazo), destes compostos em organismos vivos de diferentes níveis tróficos e, só raramente os ensaios são conduzidos a exposições crônicas (longo prazo). Os dados obtidos são utilizados para se avaliar a taxa de risco ecológico. Devido à atual legislação em relação ao bem-estar animal, várias destas análises têm sido realizadas em in vitro, mas não são suficientes para avaliar os perfis toxicológicos de uma combinação de compostos, e pouco confiantes para gerar uma base para análise de risco (FENT, 2001).

\subsubsection{Monitoramento de fármacos residuais no Brasil}

Somente no final da última década iniciaram-se estudos com o objetivo de quantificar fármacos em água. Em 1997, antilipêmicos, antiinflamatórios e alguns metabólitos foram detectados em esgoto, em efluente de ETE e em águas de rios no estado do Rio de Janeiro por STUMPF et al., (1999). A concentração média, nos efluentes da ETE, da maioria dos fármacos investigados esteve na faixa de 0,1 a $1,0 \mu \mathrm{g} . \mathrm{L}^{-1}$. Nos rios, as concentrações médias situaram-se entre 0,02 e $0,04 \mu \mathrm{g} . \mathrm{L}^{-1}$, como consequiência da remoção incompleta dos fármacos durante sua passagem pela ETE e pelo descarte de esgoto in natura.

Em outro estudo, TERNES et al. (1999) encontrou estrogênios naturais e contraceptivos sintéticos na ETE da Penha/RJ. Os estrogênios $17 \beta$-estradiol e estrona foram detectados nas concentrações de $0,021 \mu \mathrm{g} \cdot \mathrm{L}^{-1} \mathrm{e} 0,04 \mu \mathrm{g} \cdot \mathrm{L}^{-1}$, respectivamente, em esgoto bruto. As taxas de remoção de estrona observadas foram de $67 \%$ e $83 \%$ para o 
efluente tratado em filtro biológico e tratado pelo processo de lodos ativados, respectivamente. Para o $17 \beta$-estradiol, estas taxas foram de 92 e 99,9\% para o efluente tratado em filtro biológico e para o efluente tratado pelo processo de lodos ativados, respectivamente. Para o estrogênio contraceptivo $17 \alpha$-etinilestradiol, as taxas de remoção na ETE foram de 64 e $78 \%$ para o efluente do filtro biológico e para o efluente do tanque de lodo ativado.

Em um trabalho recente, SODRÉ et al. (2007) mostrou a ocorrência de alguns compostos orgânicos emergentes em águas superficiais da Região Metropolitana de Campinas. Foram encontrados paracetamol e AAS, nas concentrações de 0,84 e 4,15 $\mu \mathrm{g} . \mathrm{L}^{-}$ ${ }^{1}$, respectivamente, nos meses de menor pluviosidade.

\subsubsection{Beta-Bloqueadores e Propranolol}

Muitas classes de drogas têm sido observadas na águas européias (TERNES et al, 1998). Umas destas classes de fármacos encontrados são os bloqueadores de receptores badrenérgicos (b-bloqueadores) que são usados extensivamente no tratamento de angina e hipertensão (TERNES, 1998; DAUGHTON e TERNES, 1999). Muitos destes compostos têm formulações nos quais estão no topo dos 200 medicamentos mais prescritos no EUA (RXLIST MONOGRAPHS, 2000). Estes compostos (atenolol, metoprolol, nadolol, and propranolol) têm um mecanismo no qual se ligam ao b-receptor, mas não causam ativação ou estimulação.

Atualmente, na prática clínica, o uso de antagonistas $\beta$-bloqueadores constitui-se em um dos principais tratamentos da síndrome da insuficiência cardíaca. Entretanto, o mercado tem oferecido uma variedade de antagonistas $\beta$-bloqueadores com diferentes propriedades farmacodinâmicas e farmacocinéticas, classificados em três diferentes gerações (Tabela 3).

Dentre os antagonistas $\beta$-bloqueadores de primeira geração, o propranolol foi o mais utilizado para o tratamento pós-infarto e o tratamento da insuficiência cardíaca (ARONOW, 1997; GOTTLIEB \& MCCARTER, 2001). Os antagonistas $\beta$-bloqueadores de primeira geração apresentam a característica de serem antagonistas não-seletivos para os $\beta$-receptores, ou seja, exercendo sua ação sobre $\beta$-receptores $\beta_{1}$ e $\beta_{2}$. 
Tabela 3 - Geração e ação dos diferentes tipos de antagonistas 3-adrenérgicos (BARTHOLOMEU, 2006)

\begin{tabular}{|c|c|c|}
\hline Geração & antagonistas $\beta$-adrenérgicos & Ação \\
\hline $1^{a}$ geração & Propanolol & $\begin{array}{l}\text { antagonistas } \beta \text {-adrenérgicos } \\
\text { não-seletivos }\end{array}$ \\
\hline $2^{a}$ geração & $\begin{array}{l}\text { Bisoprolol } \\
\text { Metoprolol }\end{array}$ & $\begin{array}{l}\text { antagonistas } \beta \text {-adrenérgicos } \\
\text { seletivos para receptores } \\
\text { adrenérgicos do subtipo } \beta_{1}\end{array}$ \\
\hline $3^{a}$ geração & $\begin{array}{l}\text { Carvedilol } \\
\text { Bucindolol }\end{array}$ & $\begin{array}{l}\text { antagonistas } \beta \text {-adrenérgicos } \\
\text { não seletivos e com ação } \\
\text { vasodilatadora e antioxidante }\end{array}$ \\
\hline
\end{tabular}

O propranolol inibe a ação de agentes adrenérgicos e reduz a taxa de batimento e a força de contração muscular do coração, na redução da permeabilidade da membrana para os íons sódio, potássio e cálcio e possue uma ação anestésica local (SWEETMAN, 2002). Suas características são apresentadas na Tabela 4. 
Tabela 4 - Características físico-químicas e estrutural do propranolol (FERRARI et al., 2003)

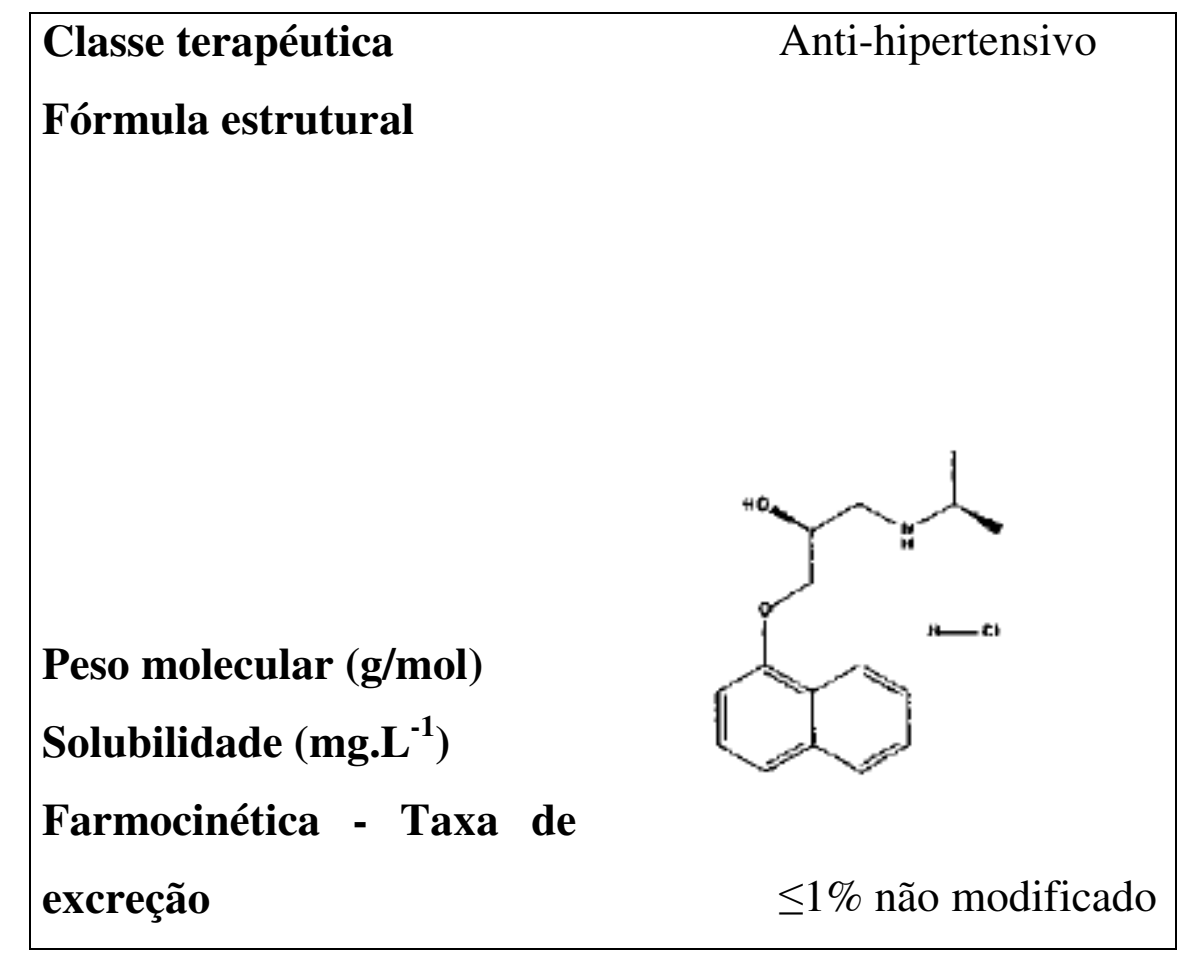

A ocorrência do propranolol em água de superfície foi relatada por (SACHER et al., 2001). Em outro estudo, TERNES (1998), também menciona a ocorrência de propranolol, bisoprolol e metoprolol nas concentrações de 0,59, 2,9 e 2,2 $\mu$ g. $\mathrm{L}^{-1}$, respectivamente.

Estudos de taxas de eliminação em processos de estações de tratamento de esgoto são realizados basicamente para avaliar a eficiência na remoção do fármaco no efluente pré e pós-tratado. A eficiência varia de acordo com a construção, tecnologia aplicada ao tratamento e retenção hidráulica (TERNES, 1998; STUMPF et al., 1999; CARBALLA et al., 2004). Alguns estudos indicam a eficiência de eliminação dos fármacos numa variação de 0 a 99\%, porém a eliminação média de alguns fármacos, como para o propranolol, é de 96\% (TERNES, 1998; TERNES et al., 1999; HEBERER, 2002). Em estudos de monitoramento de efluentes de estações de tratamento de esgoto no Reino Unido, Propranolol sempre foi encontrado na concentração média de $76 \mu \mathrm{g} . \mathrm{L}^{-1}$, (THOMAS e HILTON, 2004; WEIGEL et al., 2004). 
Evidências sugerem que peixes contenham receptores $\beta$-adrenérgicos (LAURENT et al., 1983). GAMPREL et al. (1994) indicou que o coração da truta arco-íris (Oncorhynchus mykiss) era dominado pelo receptor $\beta 2$. Além disto, foi encontrado que hepatócitos da truta continham este mesmo receptor (REID et al. 1992), onde os eritrócitos eram dominados pelo subtipo $\beta 1$ (TETANS et al. 1988). Evidências também apontam para a presença de receptores em tecidos reprodutivos de peixes (HAIDER e BAQRI 2000). Proteínas $\mathrm{G}$, as quais são componentes criticas na tradução de receptores adrenérgicos, têm sido isoladas de leveduras, fungos, equinodermos, rãs, moscas de frutas (SPIEGEL et al. 1994). NEW e WONG (1998) reportaram que protozoários eram estimulados pelo isoproterenol, sugerindo a presença de $\beta$-receptores. No entanto, WILKENS (1999) não fez menção de receptores adrenérgicos ou hormônios adrenérgicos em sua revisão sobre a ritmicidade cardíaca e do fluxo sanguíneo em crustáceos. Consequentemente, peixes e invertebrados podem ser negativamente afetados (sobrevivência, crescimento, reprodução) pela exposição a $\beta$-bloqueadores em efluentes de estações de tratamento de esgoto. 


\section{Materiais e Métodos}

\subsection{Cultivo}

\subsection{1 Água natural}

Foi utilizada água de superfície proveniente do Reservatório de Ribeirão do Piraí, coletada na barragem da captação dos municípios de Salto e Indaiatuba - local correspondente ao ponto de amostragem IRIS 02900 da Rede de Monitoramento de Qualidade das Águas Interiores do Estado de São Paulo, operada pela CETESB (Figura 2). O manancial foi selecionado pela ausência de efeito tóxico a Ceriodaphnia dubia em seis amostras analisadas durante o ano de 1999, nas quais se determinou uma média de 23,4 ( \pm 6,4) neonatas/fêmea (dados internos da CETESB não publicados; BURATINE, 2002). Além disso, este reservatório, integrante da Bacia do Rio Jundiaí (UGRHI 05), constitui alvo de ações de proteção pelo fato de se destinar ao abastecimento público (CETESB, 2000a). 

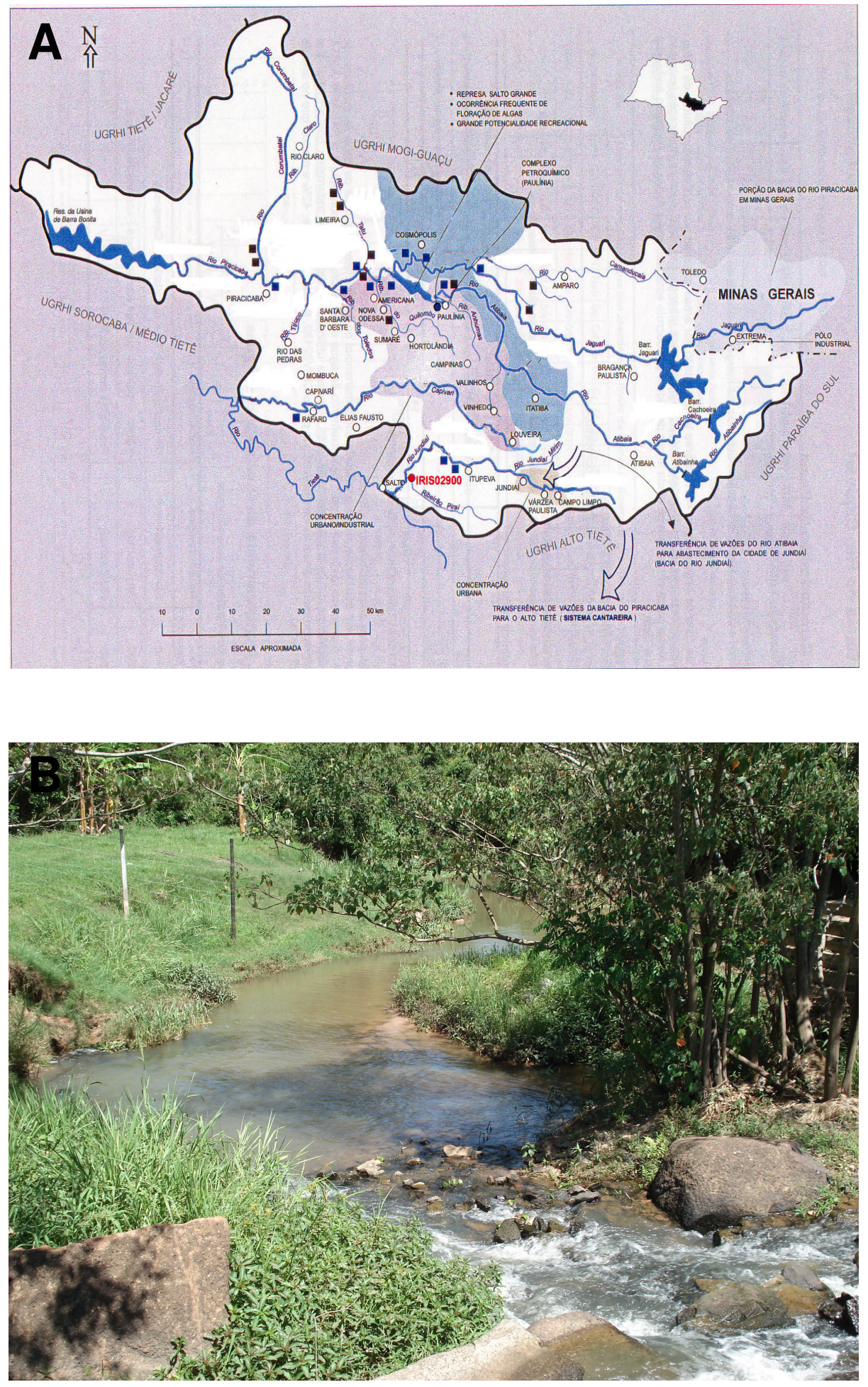

Figura 2 - A - Rios Piracicaba/Capivari/Jundiaí, com destaque para o ponto de coleta de água no Reservatório de Ribeirão do Piraí (em vermelho) (CETESB, 2000a); B - foto do ponto de coleta. 
A água foi coletada mensalmente e mantida em galões de 25 litros. Para a sua utilização foi filtrada em rede de nylon com malha de $45 \mu \mathrm{m}$, para retenção de possíveis zooplânctons oriundos do local da coleta. Em seguida, foram efetuadas as leituras de pH, condutividade e dureza, ajustando-se esta última segundo norma ABNT (2005). Após 24 horas de aeração, tais variáveis foram avaliadas novamente, permanecendo dentro dos limites definidos: $\mathrm{pH}$, entre 7,2 e 7,6; condutividade, entre 172 e $212 \mu \mathrm{S} / \mathrm{cm}$ e dureza entre 40 e $48 \mathrm{mg}$ de $\mathrm{CaCO} 3 / \mathrm{L}$ (ABNT, 2005). No momento de expor os organismos, o pH da água foi ajustado para aproximadamente $7,0( \pm 0,2)$ e monitorados os parâmetros de condutividade, oxigênio dissolvido e temperatura tanto dos cultivos iniciais quanto dos finais.

\subsection{2 Água reconstituída}

O meio sintético foi preparado mediante a adição das respectivas soluçõesestoque à água deionizada obtida pelo Sistema MILLI-Q®, o qual já havia recebido água filtrada por osmose reversa, seguindo-se assim a recomendação sugerida pela EPA (2002).

\subsubsection{Teste de Viabilidade}

Para monitorar a qualidade da água utilizada nos cultivos de C.silvestrii, foram realizados paralelamente testes de viabilidade a cada novos lote de água de cultivo e manutenção. Estes testes consistiram na exposição de cinco organismos a $100 \mathrm{~mL}$ desta água coletada, sem alimentação por 48 horas, com cinco réplicas. Foram considerados viáveis os lotes no qual o teste demonstrou imobilidade inferior a $10 \%$ dos organismos expostos (CETESB, 1991a). Com este teste se verifica a ausência de interferentes, isto é, de algum efeito prejudicial decorrente da água de cultivo que possa interferir no resultado dos testes de toxicidade.

\subsubsection{Manutenção de $C$. silvestrii}

Os cultivos de Ceriodaphnia silvestrii foram realizados de acordo com normas padronizadas (CETESB, 1992; EPA, 2002; ABNT, 2005). Os espécimes foram mantidos em culturas individuais, onde cada organismo foi colocado em um béquer de $30 \mathrm{~mL}$, 
contendo $15 \mathrm{~mL}$ de meio, com troca total de água e alimentação três vezes por semana, às segundas, quartas e sextas-feiras. Tomou-se o cuidado de não expor os organismos à mudanças de temperatura de mais de $2^{\circ} \mathrm{C}$ na água em um período de 12 horas ou 2 unidades de $\mathrm{pH}$ em um período de 24 horas (ABNT, 2005). A cada 15 dias o cultivo mais velho era eliminado e se abria um cultivo novo. Foram mantidos 20 béqueres de cultivos novos e 20 béqueres de cultivos velhos, cobertos com filme plástico de PVC, permaneceram em câmara incubadora FANEN com temperatura controlada de $25( \pm 1)^{\circ} \mathrm{C}$, fotoperíodo de $16 \mathrm{~h}$ de luz e intensidade luminosa entre 500 e 1000 lux.

A alga utilizada como alimento foi a clorofícea Pseudokirchneriella subcapitata, cultivada em meio OLIGO a $25^{\circ} \mathrm{C}$, de acordo com ABNT (2005) na concentração de $1 \mathrm{x}$ $10^{5}$ células. $\mathrm{mL}^{-1}$. Além da alga, o cultivo foi alimentado com ração de peixe.

\subsubsection{Teste de sensibilidade}

Para que os organismos possam ser utilizados em testes de toxicidade, a sensibilidade deve estar dentro de uma faixa definida de concentração da substância de referência, sendo esta a forma de se controlar a qualidade dos cultivos (BOHRER, 1995). Os testes de toxicidade são efetuados rotineiramente em laboratório não só para avaliar a sensibilidade relativa dos organismos, mas também para permitir comparações intra e interlaboratoriais, com o objetivo de verificar a precisão e confiabilidade dos resultados (LEE, 1980; ENVIRONMENT CANADA, 1990).

Os testes de sensibilidade foram realizados conforme ABNT (2005). As soluções eram preparadas no momento da realização dos testes. Uma solução mãe de cloreto de sódio de concentração de $10 \mathrm{~g} \cdot \mathrm{L}^{-1}$. A partir desta solução mãe de $10 \mathrm{~g}$. $\mathrm{L}^{-1}$ cloreto de sódio eram preparadas às concentrações a serem testadas. Uma carta-controle foi feita de modo a verificar se os resultados estão dentro dos limites prescritos $( \pm 2$ desvios padrões) (EPA, 2002).

\subsubsection{Coeficiente de variação}

A precisão analítica dos ensaios de toxicidade, dentre os quais estão os testes de sensibilidade, é avaliada através da variação entre os resultados, medida através do coeficiente de variação. É importante que se conheça a precisão analítica destes testes, de 
modo a avaliar a variabilidade dos resultados obtidos, evidenciando desta forma a confiabilidade dos métodos utilizados (BERTOLETTI et al., 1989).

A avaliação da precisão entre os testes realizados, bem como entre as réplicas foi feita de acordo com a EPA (1991), que adota que coeficiente de variação entre os resultados deve estar compreendido na faixa de 8 a 41\%, para serem considerados ótimos.

\subsection{Avaliação da toxicidade do propranolol para Ceriodaphnia silvestrii}

\subsubsection{Substância-teste}

O propranolol utilizado nos testes foi adquirido pela Merck® sob a forma de hidroclorido de propranolol com uma pureza maior de 98\%, com número de identificação CAS 3506-09-0 e de catálogo 537075. O produto foi armazenado em temperaturas não acima de $-20^{\circ} \mathrm{C}\left(-4^{\circ} \mathrm{F}\right)$ conforme recomendado pelo fabricante. A ficha de segurança se encontra no apêndice 5 .

\subsubsection{Toxicidade Aguda}

Os organismos utilizados nos ensaios foram retirados do cultivo individual a partir da terceira postura de mães oriundas do mesmo lote de cultivo e tinham um mínimo de 6 e um máximo de 24 horas (EPA, 2002)

Para determinar a toxicidade aguda foram realizados três ensaios com água destilada reconstituída e natural reconstituída. Os experimentos foram realizados de acordo com ABNT (2005) e EPA (2002). A escolha das concentrações para os testes preliminares foi baseada em resultados encontrados por HUGGETT et al. (2002), FERRARI et al. (2003) e FRAYSSE e GARRIC (2005). A avaliação nestas duas condições foi realizada com o objetivo de se verificar a existência ou não de diferença significativa dos valores encontrados para $\mathrm{CE}_{50}$ nos dois tratamentos.

Os testes agudos definitivos foram realizados em tubos de ensaios com $10 \mathrm{~mL}$ da solução-teste. Foram utilizadas 5 concentrações selecionadas a partir de resultados obtidos em testes preliminares em séries logarítmicas, com 4 réplicas cada segundo calculo:

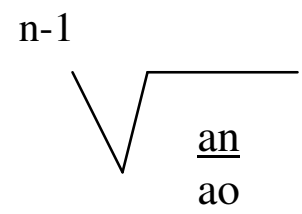

onde:

$\mathrm{n}$ = número de concentrações;

an = concentração final;

ao $=$ concentração inicial . 
As concentrações utilizadas nestes testes foram de 0,$62 ; 1,25 ; 2,5 ; 5$ e 10 mg.L. $\mathrm{L}^{-1}$ de propranolol. Os parâmetros físicos e químicos da água (condutividade, oxigênio dissolvido e $\mathrm{pH}$ ) foram determinados no início e final dos ensaios.

\subsubsection{Preparo das Soluções-teste}

Duas soluções-estoque na concentração de $1 \mathrm{~g} \cdot \mathrm{L}^{-1}$ foram utilizadas no preparo das soluções-testes, uma com água natural reconstituída e outra com água destilada reconstituída.

As soluções eram preparadas no momento da realização dos testes e as diferentes águas reconstituída, natural e destilada, eram utilizadas com suas respectivas soluçõesestoque, tendo sua dureza e $\mathrm{pH}$ ajustados para 7,00 $( \pm 2)$. Foram mantidas em temperaturas abaixo de $-20^{\circ} \mathrm{C}$ como aconselhado pela ficha informativa relativa à segurança do produto.

\subsubsection{Toxicidade Crônica}

\subsubsection{Para indivíduos de Ceriodaphnia silvestrii}

A partir dos resultados de testes preliminares, foram abertas cinco concentrações em série geométricas entre a menor concentração que causou imobilidade em todos organismos e a maior concentração que não se observou a letalidade, de acordo com ABNT (2005) e EPA (2002). As concentrações utilizadas foram 0,16;0,31;0,62; 1,25 e

2,5 mg. $\mathrm{L}^{-1}$ de propranolol. As soluções com diferentes concentrações foram preparadas através de uma solução estoque de concentração de 1 g. $\mathrm{L}^{-1}$ utilizando-se água natural reconstituída.

\subsubsection{Para populações de Ceriodaphnia silvestrii}

\subsection{Taxa Intrínseca de Aumento Natural}

A taxa intrínseca de crescimento populacional foi estimada por meio de uma equação de crescimento populacional para meio ilimitado, uma vez que as condições estipuladas para os ensaios permitiram sua utilização. A equação é expressa a seguir: 
$\mathrm{Nt}=\mathrm{N}_{0} \mathrm{e}^{\mathrm{rt}}$, onde:

$\mathrm{Nt}$ = número de indivíduos no tempo t;

$\mathrm{N}_{0}=$ número de indivíduos no tempo 0;

$\mathrm{e}=$ base do logaritmo neperiano;

$\mathrm{r}=$ taxa intrínseca de aumento natural;

$\mathrm{t}=$ tempo.

Como "endpoint" crônico escolhido para testar as diferenças entre as taxas intrínsecas de aumento natural foi escolhido o CEO (p), ou seja, a concentração de efeito observado populacional. Este parâmetro é definido como o menor efeito observado no qual a taxa intrínseca de aumento natural ( $r$ ) é afetada.

\subsection{Otimização das condições do ensaio}

Com o objetivo de estabelecer parâmetros do controle a serem utilizados nos testes populacionais com $C$. silvestrii, ou seja, determinar o número inicial de indivíduos (n) e a duração dos experimentos, realizou-se experimentos a partir de critério estabelecido pela EPA (2002) de um organismo para cada $15 \mathrm{~mL}$ de meio.

Dois experimentos foram realizados, sendo cada um com 75 e $150 \mathrm{~mL}$ e três réplicas cada. A troca de água de cultivo e a alimentação foram efetuadas de modo semelhante ao modo descrito para os cultivos laboratoriais descritos no item 4.1.4. De modo a não incluir erros que alíquotas poderiam conter, os organismos foram todos contados. Os experimentos foram realizados em câmara incubadora FANEN modelo 347 $\mathrm{CDG}$ à $25^{\circ} \mathrm{C}( \pm 2)$, fotoperíodo de 16 horas-luz e intensidade luminosa entre 500 e $1000 \mathrm{lux}$.

No que se refere ao tempo do ensaio, adotou-se o tempo de sete dias, de modo a utilizar o mesmo tempo dos testes crônicos com indivíduos de C. silvestrii. 


\subsection{Critérios de aceitabilidade dos ensaios populacionais e Teste de sensibilidade}

O teste de sensibilidade populacional foi desenvolvido a partir dos critérios estabelecidos para a condição dos testes, descrito no item anterior. Foi avaliado o total de indivíduos na população no final de cada ensaio de toxicidade crônico em três testes com cloreto de sódio, substância de referência, a fim de estabelecer um critério de aceitabilidade do controle dos testes populacionais com $C$. silvestrii. Como segundo critério, utilizou-se a taxa de intrínseca de aumento natural $r$.

A faixa de sensibilidade foi escolhida a partir dos dados obtidos por CASTILHO (2005), que determinou a faixa de sensibilidade de Ceriodaphnia silvestrii ao $\mathrm{NaCl}$ no intervalo das concentrações 1,0 e 2,2 g. $\mathrm{L}^{-1}$. Foram selecionadas cinco concentrações, com 4 réplicas cada, para realização dos testes populacionais: 0,$04 ; 0,105 ; 0,275 ; 0,723$ e 1,9 g. $\mathrm{L}^{-1}$ de $\mathrm{NaCl}$.

\subsection{Avaliação da Toxicidade do Propranolol}

A partir dos resultados dos ensaios agudos, foram estabelecidas 5 concentrações em série geométricas entre a menor concentração que causou imobilidade em todos organismos e a maior concentração que não se observou a letalidade, de acordo com ABNT (2005) e EPA (2002).

As concentrações utilizadas foram 0,$16 ; 0,31 ; 0,62 ; 1,25$ e $2,5 \mathrm{mg} . \mathrm{L}^{-1}$ de propranolol. As soluções com diferentes concentrações foram preparadas através de uma solução-estoque de concentração de $1 \mathrm{~g} . \mathrm{L}^{-1}$, utilizando-se água natural reconstituída. Realizaram-se experimentos a partir dos critérios estabelecidos para a condição do teste, descritos no item 4 2.3.2.2 . Para cada concentração foram utilizadas três réplicas com cinco organismos cada. De modo a não incluir erro que uma amostragem poderia conter, todos os organismos foram contados. As condições laboratoriais do teste, como temperatura, luminosidade e alimentação dos organismos, foram realizadas segundo as normas ABNT (2005) e EPA (2002), com modificações para avaliações populacionais. 


\subsection{Análises estatísticas}

\subsubsection{Teste de sensibilidade e Ensaio de Toxicidade aguda}

A sensibilidade de $C$. silvestrii e a toxicidade aguda para Propranolol foram avaliadas pelo programa computacional Spearman-Karber (HAMILTON et al., 1977), e expressos em $\mathrm{CE}(\mathrm{I}) 50 ; 48 \mathrm{H}$.

\subsubsection{Toxicidade Crônica}

\subsubsection{Individual}

A IC25 e a IC50 foram calculados através do método de interpolação linear, enquanto o CENO (concentração de efeito não observado) e CEO (concentração de efeito observado), para a reprodução, foram obtidos através de teste de hipóteses.

O IC25 e o IC50, isto é, a concentração do tóxico que causou a inibição de $25 \%$ e $50 \%$ na média de jovens produzidos por fêmea em relação ao controle, respectivamente, foi calculado pelo programa estatístico "A Linear Interpolation Method for Subletal Toxicity: The Inhibition Concentration (ICp) Approach" (NORBERG-KING, 1993).

Para o cálculo do CENO e CEO, os dados foram submetidos ao teste de

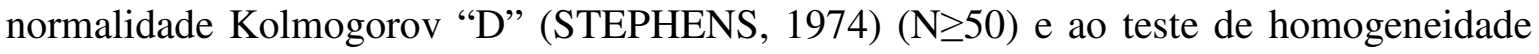
Bartlett's (SNEDECOR \& COCHRAN, 1980). Quando constatados que os dados eram normais e homogêneos, o teste paramétrico de Dunnett's (DUNNETT, 1964) foi utilizado, quando os dados não foram paramétricos, o teste Steel's Many-one Rank (STEEL, 1959; MILLER, 1981) foi utilizado (EPA, 2002).

\subsubsection{Populacional}

\subsection{Condição do teste}

A comparação das curvas de crescimento populacional para os diferentes tratamentos foi feita através do teste $\mathrm{F}$, considerando como hipótese nula que os valores encontrados não diferiam estatisticamente ao nível de significância de 5\%. 


\subsection{CEO (p), CENO(p), Ir\%, IC25 e IC50}

O IC25 e o IC50 está descrito no item anterior. O procedimento escolhido para determinar o CEO (p), CENO (p) e o Ir\%, isto é, a concentração de efeito observado na população, a concentração de efeito não observado na população e a porcentagem da inibição da taxa de crescimento, respectivamente, foi através da utilização de testes estatísticos baseado no "guideline" 201 (OECD, 2006) para crescimento populacional algal. Este procedimento é baseado na taxa média do crescimento específico, sendo esta variável calculada com base no aumento logarítmico do número de organismos durante o período de ensaio, expressa por dia.

Os dados foram submetidos ao teste de normalidade Shapiro-Wilk's (CONOVER, 1980) $(\mathrm{N} \leq 50)$ e ao teste de homogeneidade Bartlett's (SNEDECOR and COCHRAN, 1980), e quando constatados que os dados eram normais e homogêneos, o teste paramétrico de Dunnett's (DUNNETT, 1964) foi utilizado (OECD, 2006). Quando os dados não foram paramétricos, o teste Steel's Many-one Rank (STEEL, 1959; MILLER, 1981) foi usado para se determinar o CEO e CENO populacionais (EPA, 2002). 


\section{Resultados}

\subsection{Avaliação da toxicidade de Propanolol para Ceriodaphnia silvestrii}

\subsubsection{Toxicidade Aguda}

Com o objetivo de avaliar a toxicidade aguda do propranolol foram realizados 3 ensaios. Os valores médios encontrados de CE(I)50;48H foram de 2,87 e 2,63 mg. $\mathrm{L}^{-1}$ de propranolol para água destilada reconstituída e natural reconstituída, respectivamente (Tabela 5). A Tabela 6 apresenta o resultado para o teste t-Student, o qual nos indica que não há diferença significativa entre os tratamentos $(\alpha=0,01)$ e nos permite a utilização da água natural reconstituída para a realização do teste crônico populacional como sugerido pelo protocolo EPA (1996).

Tabela 5 - Toxicidade aguda de propranolol $\left(\mathrm{mg} . \mathrm{L}^{-1}\right)$ para $C$. silvestrii em água destilada reconstituída e natural reconstituída.

\section{Água Destilada Reconstituída}

\begin{tabular}{ccc}
\hline Teste $\mathbf{N}^{\mathbf{0}}$. & $\mathbf{C E}(\mathbf{I}) \mathbf{5 0} \mathbf{4 8 H}\left(\mathbf{m g . \mathbf { L } ^ { - 1 } )}\right.$ & $\mathbf{I C}$ \\
$\mathbf{1}$ & 2,87 & $2,18-3,77$ \\
$\mathbf{2}$ & 2,98 & $2,23-3,97$ \\
$\mathbf{3}$ & 2,77 & $2,21-3,47$ \\
\hline CE Médio & 2,87 & \\
$\boldsymbol{\sigma}$ & 0,105 & \\
$\mathbf{C V}$ & $4 \%$ & \\
\hline
\end{tabular}

Água Destilada Natural Reconstituída

\begin{tabular}{ccc}
\hline $\mathbf{1}$ & 2,99 & $2,39-3,75$ \\
$\mathbf{2}$ & 2,57 & $1,98-3,32$ \\
$\mathbf{3}$ & 2,33 & $1,84-2,95$ \\
\hline $\mathbf{C E}$ Médio & 2,63 & \\
$\mathbf{\sigma}$ & 0,334 & \\
$\mathbf{C V}$ & $13 \%$ & \\
IC $=$ Intervalo de Confiança; & $\mathrm{CV}=$ Coeficiente de Variação.
\end{tabular}


Tabela 6 - Teste t-Student $(\alpha=0,01)$ dos valores de CE(I)50;48H de propanolol $\left(\mathrm{mg} \mathrm{L}^{-1}\right)$ com $C$. silvestrii em água destilada reconstituída (1) e natural reconstituída (2).

\begin{tabular}{ccccc}
\hline Tratamento & $\mathbf{N}^{\mathbf{0}}$. de Réplicas & $\begin{array}{c}\text { CE(I)50;48H } \\
\left(\mathbf{m g . \mathbf { L } ^ { - 1 }}\right)\end{array}$ & $\boldsymbol{\sigma}$ & $\mathbf{C V}$ \\
$\mathbf{1}$ & 3 & 2,87 & 0,10504 & 4 \\
$\mathbf{2}$ & 3 & 2,63 & 0,33407 & 13 \\
\hline Diferença entre as médias & & $\mathbf{0 , 2 4}$ & & \\
\hline $\mathbf{t}$ & DoF & $\mathbf{P}$ & \\
1,20 & 4 & 0,30 &
\end{tabular}

\subsubsection{Toxicidade Crônica}

\subsubsection{Individual}

A reprodução (número médio de neonatas) e os valores de CENO (Concentração de Efeito Não Observado) e CEO (Concentração de Efeito Observado) para os diferentes ensaios estão apresentados na Tabela 7 e 8 e na Figura 3.

Tabela 7 - Toxicidade crônica de propranolol $\left(\mathrm{mg} . \mathrm{L}^{-1}\right)$ para $C$. silvestrii.

\begin{tabular}{ccc}
\hline \multirow{2}{*}{ TESTE } & $\begin{array}{c}\text { CENO } \\
\left(\mathbf{m g . L}^{-\mathbf{1}}\right)\end{array}$ & $\begin{array}{c}\text { CEO } \\
\left(\mathbf{m g . L}^{\mathbf{1}}\right)\end{array}$ \\
\cline { 2 - 3 } $\mathbf{1}$ & 1,25 & 2,50 \\
$\mathbf{2}$ & 1,25 & 2,50 \\
$\mathbf{3}$ & 0,62 & 1,25 \\
\hline
\end{tabular}

Tabela 8 - Reprodução (número médio de neonatas por concentração) de $C$. silvestrii nos testes de toxicidade crônica de propranolol.

\begin{tabular}{ccccccc}
\hline $\begin{array}{c}\text { Concentração } \\
\left(\mathbf{m g . ~ L} \mathbf{~}^{-1}\right.\end{array}$ & Teste $\mathbf{1}$ & Teste 2 & Teste 3 & Média & $\boldsymbol{\sigma}$ & CV \\
\hline Controle & 15,3 & 15,5 & 16 & 15,60 & 0,36 & $2 \%$ \\
$\mathbf{0 , 1 6}$ & 15,9 & 16,2 & 16,3 & 16,13 & 0,21 & $1 \%$ \\
$\mathbf{0 , 3 1}$ & 19 & 16,3 & 16,6 & 17,30 & 1,48 & $9 \%$ \\
$\mathbf{0 , 6 2}$ & 18,7 & 14,2 & 16,2 & 16,37 & 2,25 & $14 \%$ \\
$\mathbf{1 , 2 5}$ & 18,7 & 13,1 & $12,3^{*}$ & 14,70 & 3,49 & $24 \%$ \\
$\mathbf{2 , 5}$ & $7,4^{*}$ & $7,3^{*}$ & 7,9 & 7,53 & 0,32 & $4 \%$ \\
\hline
\end{tabular}

* = Concentração de efeito observado (CEO); CV= Coeficiente de Variação. 

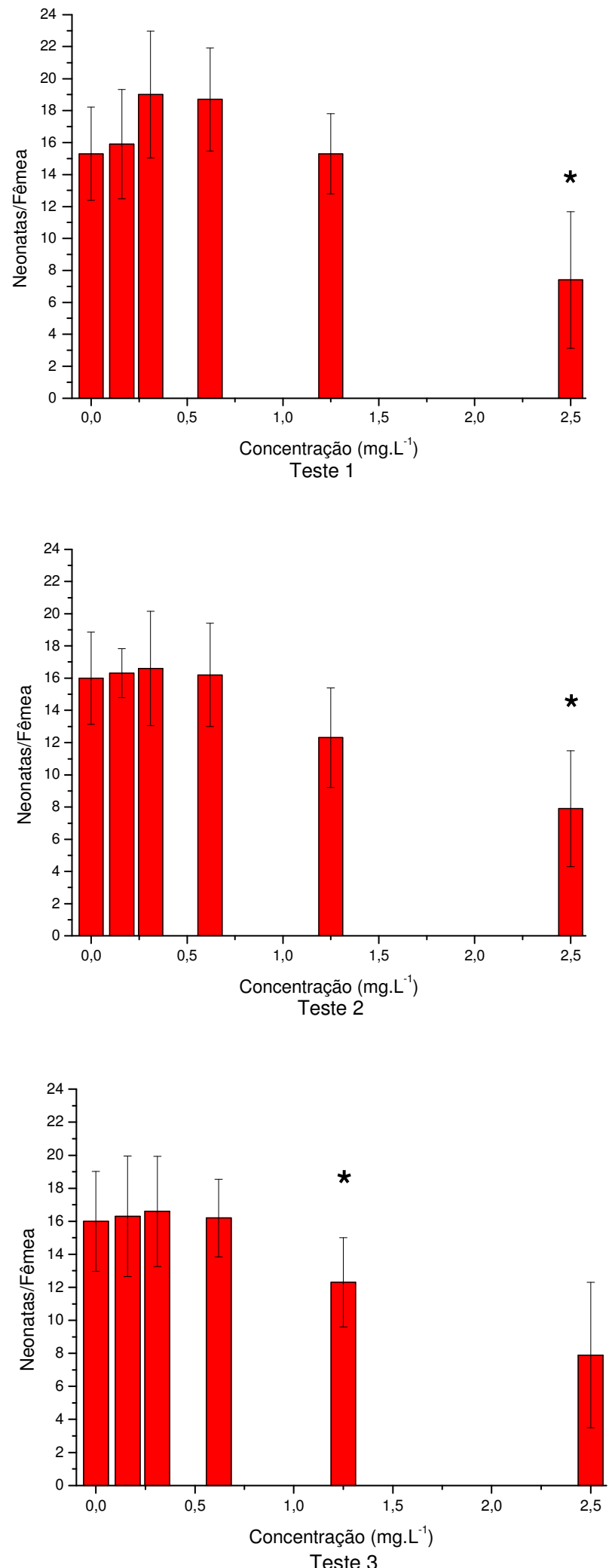

Figura 3 - Reprodução dos ensaios individuais (número médio de neonatas/fêmea) em diferentes concentrações de propranolol $\left(\mathrm{mg} . \mathrm{L}^{-1}\right)$ para ensaios individuais. As barras indicam o desvio-padrão entre as réplicas de cada concentração e o asterisco o valor de CEO. 
O IC25 e o IC50, isto é, a concentração do tóxico que causou a inibição de $25 \%$ e $50 \%$ na reprodução (número médio de neonatas fêmea) se apresenta na Tabela 9.

Tabela 9 - IC25 e IC50 de propranolol (mg. $\left.\mathrm{L}^{-1}\right)$ com $C$. silvestrii.

\begin{tabular}{ccc}
\hline Teste & IC25 & IC50 \\
\hline $\mathbf{1}$ & 1,62 & 2,3 \\
$\mathbf{2}$ & 1,48 & 2,34 \\
$\mathbf{3}$ & 1,27 & 2,42 \\
\hline Média & 1,46 & 2,35 \\
$\boldsymbol{\sigma}$ & 0,18 & 0,06 \\
$\mathbf{C V}$ & $12 \%$ & $3 \%$ \\
\hline
\end{tabular}

CV - Coeficiente de Variação.

\subsubsection{Populacional}

5.1.3.2.1 Otimização das condições do ensaio - Número de indivíduos de Ceriodaphnia silvestrii e volume da câmara-teste

A Tabela 10 e a Figura 4 apresentam o crescimento populacional de Ceriodaphnia silvestrii para diferentes volumes e número de organismos cultivados a $25^{\circ} \mathrm{C}( \pm 2)$ em 11 dias. 
Tabela 10 - Crescimento populacional de C. silvestrii em diferentes volumes de meio de cultivo $(75$ e $150 \mathrm{~mL})$ à $25^{\circ} \mathrm{C}( \pm 2)$.

\begin{tabular}{|c|c|c|c|c|c|c|}
\hline & $\mathbf{7 5} \mathbf{~ m L}$ & & & $\mathbf{1 5 0} \mathbf{~} \mathbf{L}$ & & \\
$\mathbf{D i a}$ & $\mathbf{N}$ & $\boldsymbol{\sigma}$ & $\mathbf{C V}$ & $\mathbf{N}$ & $\boldsymbol{\sigma}$ & $\mathbf{C V}$ \\
\hline $\mathbf{1}$ & 5 & & & 10 & & \\
$\mathbf{2}$ & 5 & & & 10 & & \\
$\mathbf{3}$ & 5 & & & 10 & & \\
$\mathbf{4}$ & 5 & 2,3 & & 16 & 1,2 & \\
$\mathbf{5}$ & 15 & 4,9 & & 52 & 7,0 & \\
$\mathbf{6}$ & 36 & 1,5 & & 95 & 2,0 & $2 \%$ \\
$\mathbf{7}$ & 53 & 3,2 & $6 \%$ & 149 & 20,3 & $14 \%$ \\
$\mathbf{8}$ & 72 & 6,4 & $9 \%$ & 202 & 38,2 & $19 \%$ \\
$\mathbf{9}$ & 97 & 9,5 & $10 \%$ & 271 & 53,1 & $20 \%$ \\
$\mathbf{1 0}$ & 120 & 3,6 & $3 \%$ & 292 & 70,9 & $24 \%$ \\
$\mathbf{1 1}$ & 136 & 10,6 & $8 \%$ & 296 & 22,6 & $8 \%$ \\
\hline
\end{tabular}

CV - Coeficiente de Variação.

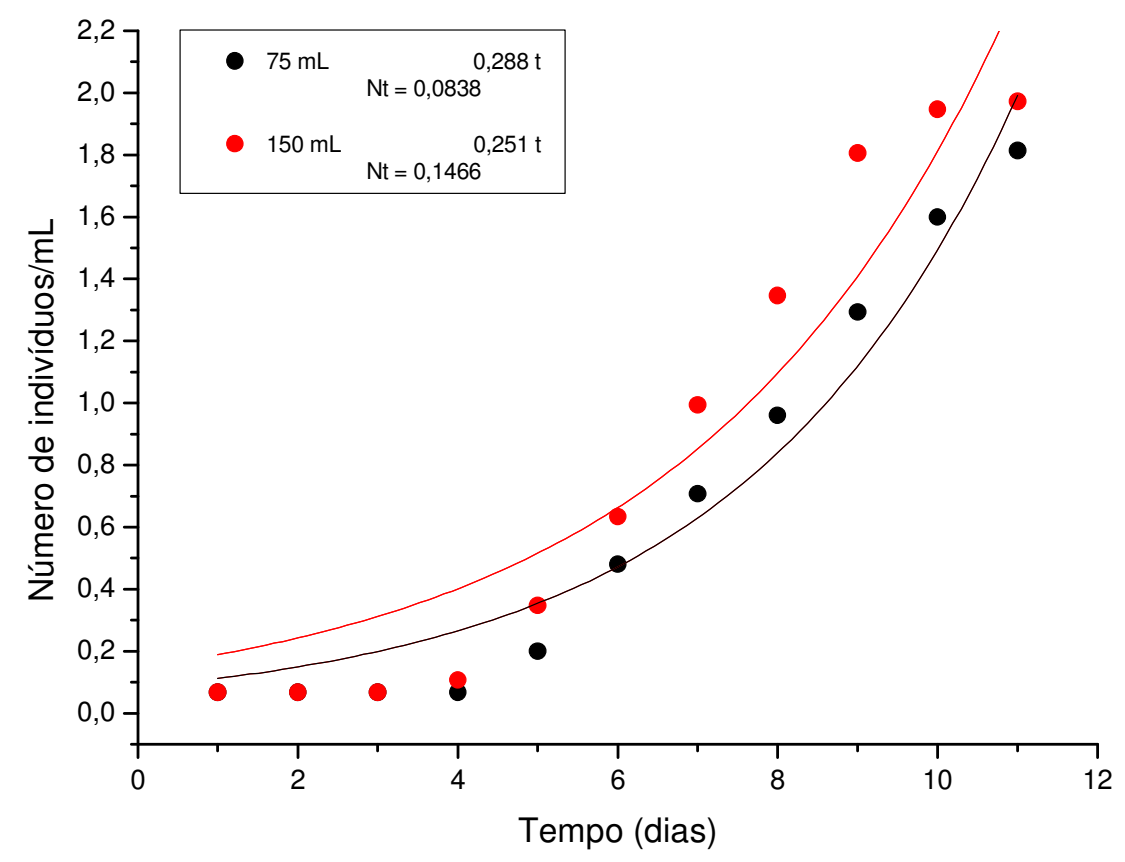

Figura 4 - Crescimento populacional de $C$. silvestrii em diferentes volumes de meio de cultivo $(75$ e $150 \mathrm{~mL})$ à $25^{\circ} \mathrm{C}( \pm 2)$.

Os valores obtidos no crescimento populacional são mostrados na Tabela 11. O valor estimado para a taxa intrínseca de aumento natural $(r)$ foi de 0,288 e 0,251 para 75 $\mathrm{mL}$ e $150 \mathrm{~mL}$, respectivamente. 
Tabela 11 - Valores logarítimos de Nt (número total), $\mathrm{N}_{0}$ (número inicial) e a taxa intrínseca de aumento natural $(r)$ de $C$. silvestrii para diferentes volumes de meio de cultivo a $25^{\circ} \mathrm{C}( \pm 2)$.

\begin{tabular}{ccccc}
\hline Volume & $\mathbf{N t}$ & No & $\mathbf{t}(\operatorname{dias})$ & $\mathbf{r}\left(\operatorname{dias}^{-\mathbf{1}}\right)$ \\
\hline $\mathbf{7 5} \mathbf{~} \mathbf{L}$ & 1,9901 & 0,0838 & 11 & 0,288 \\
$\mathbf{1 5 0} \mathbf{~ m L}$ & 2,3183 & 0,1466 & 11 & 0,251 \\
\hline
\end{tabular}

A Tabela 12 apresenta o sumário estatístico para a comparação dos resultados (indivíduos $/ \mathrm{mL}$ ) entre os diferentes volumes testados no crescimento populacional de Ceriodaphnia silvestrii para diferentes volumes cultivados a $25^{\circ} \mathrm{C}( \pm 2)$ em 11 dias. Ao nível de significância de 0,05 , os diferentes tratamentos não são estatisticamente diferentes.

Tabela 12 - Sumário estatístico para o teste F para o cultivo de C. silvestrii para diferentes volumes de meio de cultivo à $25^{\circ} \mathrm{C}( \pm 2)$.

\begin{tabular}{cccc}
\hline F & DoF & Denom.DoF & Prob $>$ F \\
3,03982 & 2 & 18 & 0,07288 \\
\hline
\end{tabular}

F - Valor de F; DoF - Graus de liberdade.

Analisando os resultados encontrados na determinação da condição do teste, ficou estabelecido como critério a utilização do volume de $75 \mathrm{~mL}$ para a realização dos testes populacionais.

\subsection{Validação dos critérios de aceitabilidade do controle a partir de ensaios de sensibilidade com Cloreto de Sódio.}

Foram realizados 3 ensaios com a substância de referência cloreto de sódio $(\mathrm{NaCl})$ de modo a validar as condições do ensaio (número inicial de organismos e volume da câmara-teste), determinar os critérios de aceitabilidade no controle em sete dias de 
experimento (número de neonatas e taxa intrínseca de aumento natural) e, ao mesmo tempo, conhecer a sensibilidade dos cultivos de populações de $C$. silvestrii .

O critério estabelecido foi de produção de $73( \pm 10)$ neonatas em sete dias de experimento, considerando-se mais ou menos dois desvios-padrão, ou seja, deve estar compreendido entre 63 e 83 (Tabela 13). Como taxa intrínseca de aumento natural aceitável para o controle dos ensaios populacionais o valor foi de 0,596 $( \pm 0,13)$ (Tabela 16 , Figura 5).

As tabela 14 apresenta as taxas de crescimento populacional intra-réplicas de cada ensaio para o controle.

Tabela 13 - Número médio de neonatas no controle dos ensaios populacionais $(n=3)$ com $\mathrm{NaCl}$ de C. silvestrii a $25^{\circ} \mathrm{C}( \pm 2)$.

\begin{tabular}{cccccccc}
\hline Teste & & Réplicas & & & Média & $\boldsymbol{\sigma}$ & $\mathbf{C V}$ \\
\hline & $\mathbf{1}$ & $\mathbf{2}$ & $\mathbf{3}$ & $\mathbf{4}$ & & & \\
\cline { 2 - 8 } $\mathbf{1}$ & 64 & 89 & 79 & 76 & 77 & 10,30 & $13 \%$ \\
$\mathbf{2}$ & 59 & 77 & 79 & 53 & 67 & 12,96 & $19 \%$ \\
$\mathbf{3}$ & 87 & 82 & 62 & 64 & 74 & 12,61 & $17 \%$ \\
\hline Total & & & & & $\mathbf{7 3}$ & $\mathbf{5}$ & $\mathbf{7 \%}$ \\
\hline
\end{tabular}

Tabela 14 - Taxas intrínsecas de aumento natural média $(r)$ no controle dos ensaios populacionais $(\mathrm{n}=3)$ com $\mathrm{NaCl}$ de $C$. silvestrii a $25^{\circ} \mathrm{C}( \pm 2)$.

\begin{tabular}{|c|c|c|c|c|c|c|c|}
\hline Teste & & Réplicas & & & Média & $\boldsymbol{\sigma}$ & $\mathrm{CV}$ \\
\hline & 1 & 2 & 3 & 4 & & & \\
\hline 1 & 0,807 & 0,635 & 0,620 & 0,675 & 0,684 & 0,085 & $12 \%$ \\
\hline 2 & 0,541 & 0,567 & 0,552 & 0,502 & 0,541 & 0,028 & $5 \%$ \\
\hline 3 & 0,617 & 0,579 & 0,508 & 0,591 & 0,574 & 0,047 & $8 \%$ \\
\hline Total & & & & & 1,799 & 0,075 & $4 \%$ \\
\hline
\end{tabular}


Tabela 15 - Taxa intrínseca de aumento natural média $(r)$ de C.silvestrii no controle dos ensaios populacionais $(\mathrm{n}=3) \operatorname{com~} \mathrm{NaCl}$ a $25^{\circ} \mathrm{C}( \pm 2)$.

\begin{tabular}{ccccccc}
\hline $\begin{array}{c}\text { Concentração } \\
\left(\text { g.L }^{-1}\right)\end{array}$ & Teste 1 & Teste 2 & Teste 3 & Média & o & CV \\
\hline Controle & 0,669 & 0,544 & 0,575 & 0,596 & 0,065 & $11 \%$ \\
\hline
\end{tabular}

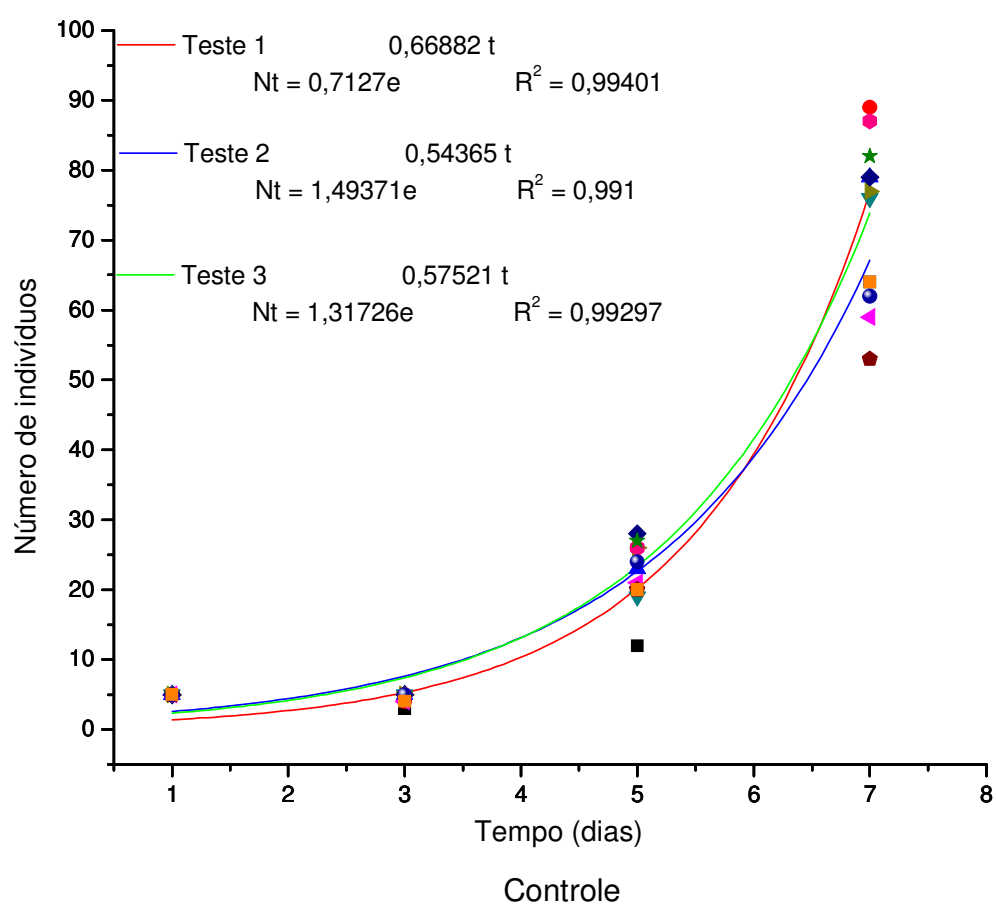

Figura 5 - Crescimento populacional de $C$. silvestrii no controle dos ensaios $(\mathrm{n}=3)$ a $25^{\circ} \mathrm{C}( \pm 2)$. Os diferentes pontos correspondem às réplicas de cada teste.

\subsection{Sensibilidade de $C$. silvestrii para o Cloreto de Sódio}

Os valores obtidos para CENO (p), CEO (p) e Ir\% para os diferentes testes de sensibilidade são apresentados na Tabela 17. 
Tabela 16 - Sensibilidade ao $\mathrm{NaCl}\left(\mathrm{g} . \mathrm{L}^{-1}\right)$ para populações de $C$. silvestrii .

\begin{tabular}{cccc}
\hline TESTE & CENO $(\mathbf{p})$ & CEO $(\mathbf{p})$ & \% Ir \\
\hline $\mathbf{1}$ & 0,275 & 0,723 & $49 \%$ \\
$\mathbf{2}$ & 0,275 & 0,723 & $51 \%$ \\
$\mathbf{3}$ & 0,275 & 0,723 & $55 \%$ \\
\hline
\end{tabular}

A taxa intrínseca de aumento natural média $(r)$ de $C$. silvestrii para o $\mathrm{NaCl}$ está representada na Tabela 18 e na Figura 6. O gráfico para concentração 1,9 g.L $\mathrm{L}^{-1}$ de cloreto de sódio não pode ser plotado devido ao efeito agudo observado, ou seja, mortalidade de todos os organismos. $\mathrm{O}$ valor de $\mathrm{CEO}$ foi de $0,723 \mathrm{~g} \cdot \mathrm{L}^{-1}$ de $\mathrm{NaCl}$.

Tabela 17 - Taxa intrínseca de aumento natural média $(r)$ de C.silvestrii para $\mathrm{NaCl}$ (g. $\left.\mathrm{L}^{-1}\right)$ a $25^{\circ} \mathrm{C}( \pm 2)$.

\begin{tabular}{ccccccc}
\hline $\begin{array}{c}\text { Concentração } \\
\text { (g.L-1) }\end{array}$ & Teste 1 & Teste 2 & Teste 3 & Média & $\boldsymbol{\sigma}$ & CV \\
\hline Controle & 0,669 & 0,544 & 0,575 & 0,596 & 0,065 & $11 \%$ \\
$\mathbf{0 , 0 4}$ & 0,657 & 0,667 & 0,606 & 0,643 & 0,033 & $5 \%$ \\
$\mathbf{0 , 1 0 5}$ & 0,532 & 0,531 & 0,552 & 0,538 & 0,012 & $2 \%$ \\
$\mathbf{0 , 2 7 5}$ & 0,718 & 0,664 & 0,643 & 0,675 & 0,039 & $6 \%$ \\
$\mathbf{0 , 7 2 3}$ & $0,545^{*}$ & $0,359 *$ & $0,600 *$ & 0,502 & 0,126 & $25 \%$ \\
\hline
\end{tabular}

* Concentração de efeito observado (CEO) 


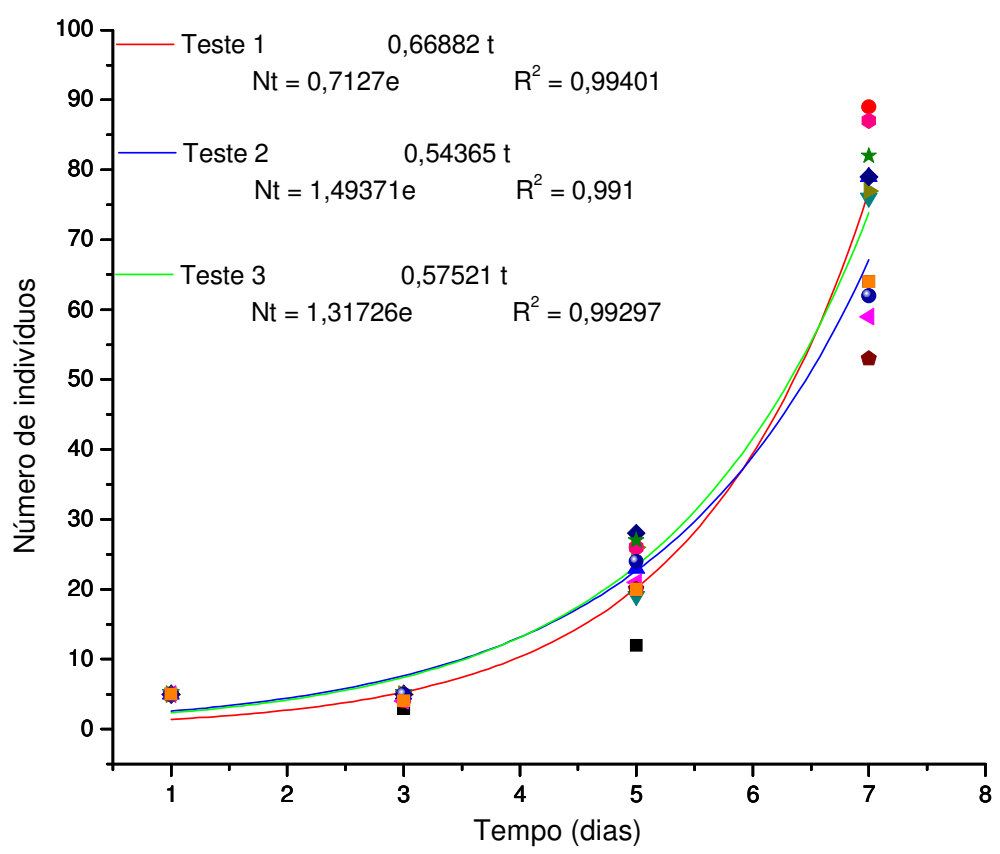

Controle

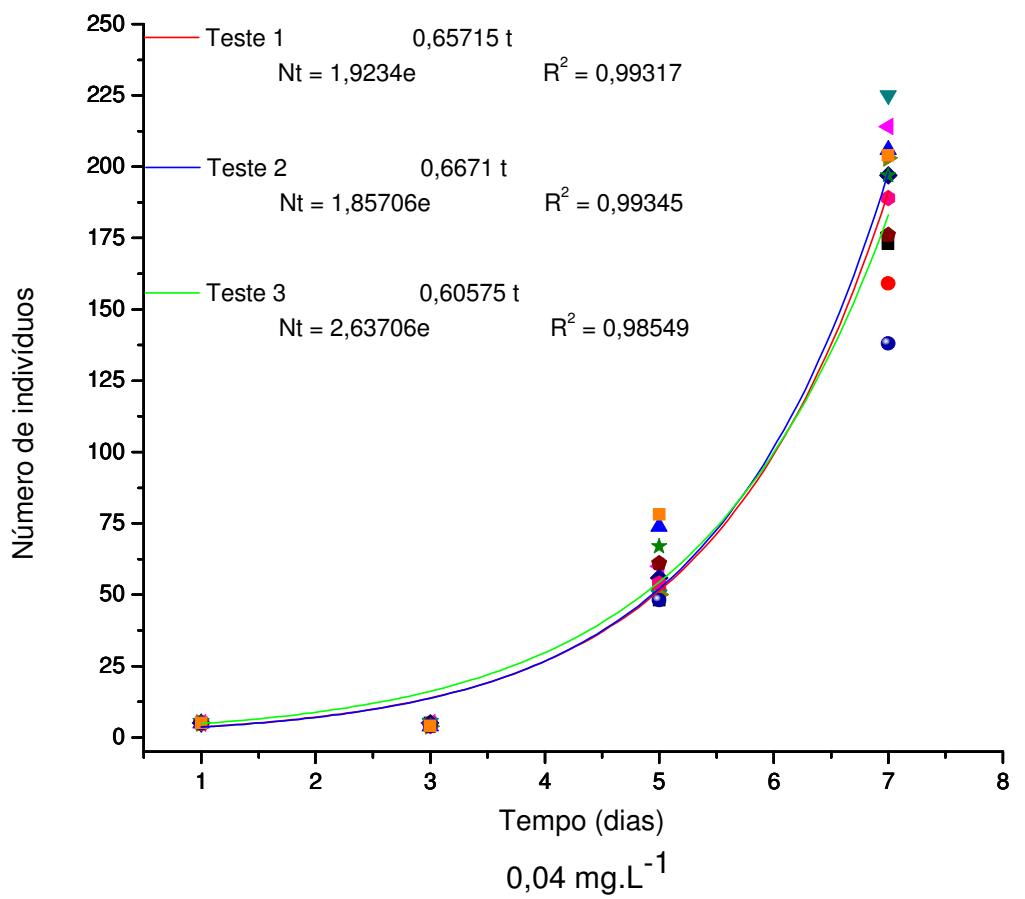

Figura 6 - Crescimento populacional $(\mathrm{n}=3)$ de $C$. silvestrii para o controle e a concentração 0,04 g. $\mathrm{L}^{-1}$ de $\mathrm{NaCl}$ a $25^{\circ} \mathrm{C}( \pm 2)$. Os diferentes pontos correspondem às réplicas de cada teste. (cont.) 

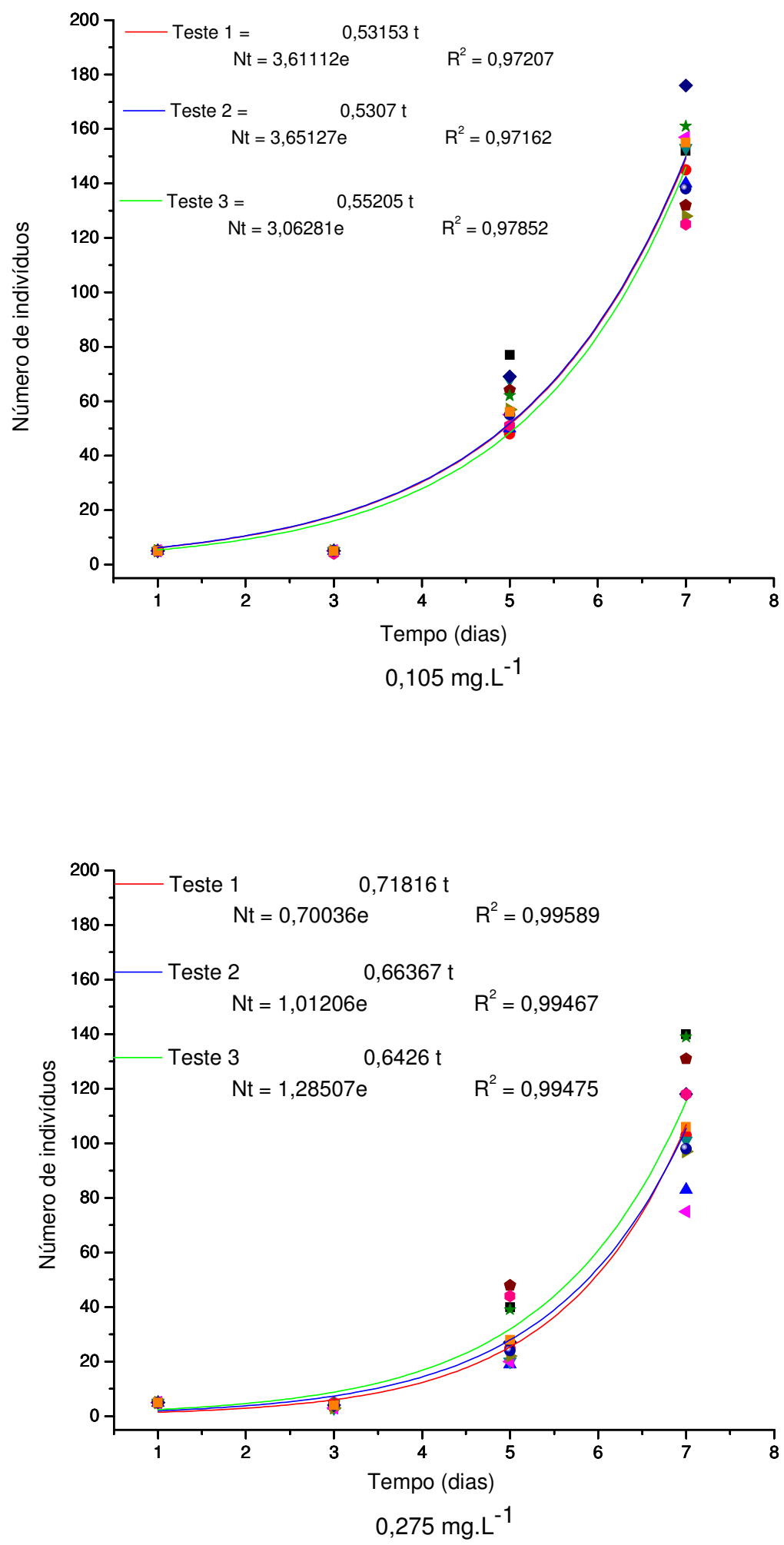

Figura 6 - Crescimento populacional $(\mathrm{n}=3)$ de $C$. silvestrii nas concentrações 0,$105 ; 0,275$; g. $\mathrm{L}^{-1}$ de $\mathrm{NaCl}$ a $25^{\circ} \mathrm{C}( \pm 2)$. Os diferentes pontos correspondem às réplicas de cada teste. (cont.) 


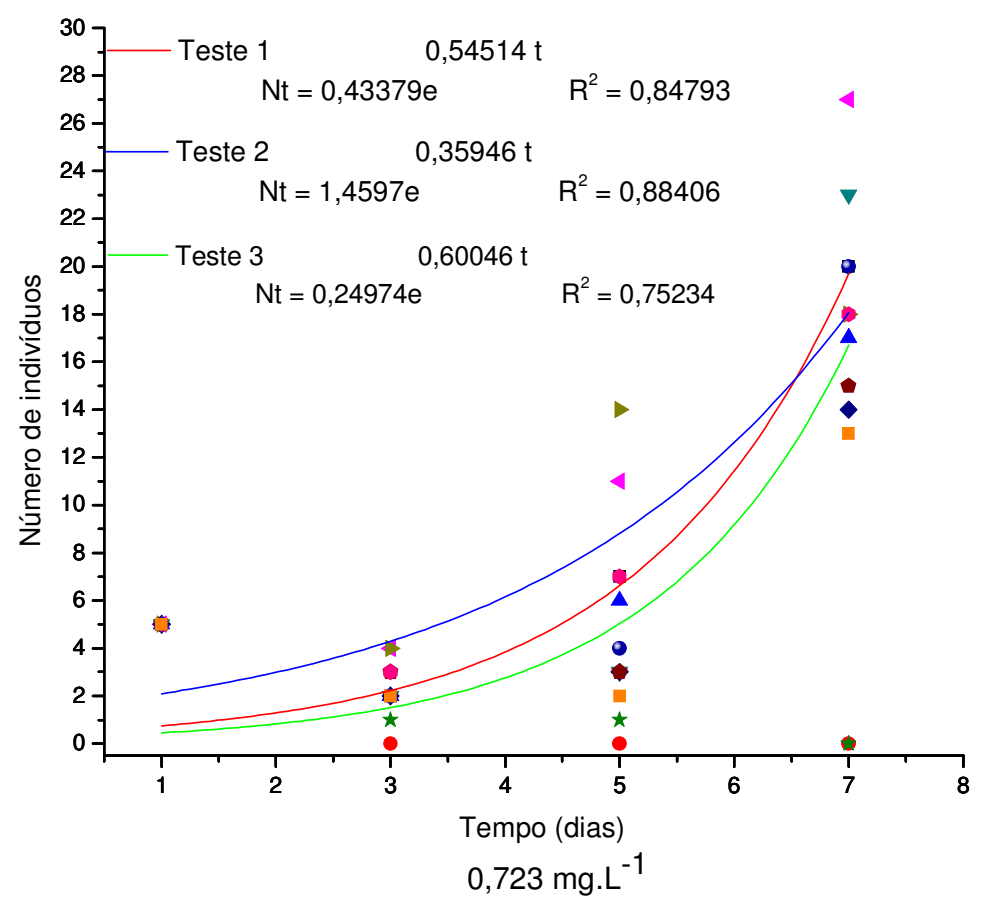

Figura 6 - Crescimento populacional $(\mathrm{n}=3)$ de $C$. silvestrii para a concentração 0,723 g.L $\mathrm{L}^{-1}$ de $\mathrm{NaCl}$ a $25^{\circ} \mathrm{C}( \pm 2)$. Os diferentes pontos correspondem às réplicas de cada teste.

A Figura 7 apresenta o crescimento populacional de $C$. silvestrii para os diferentes ensaios e as curvas de crescimento para cada concentração. 


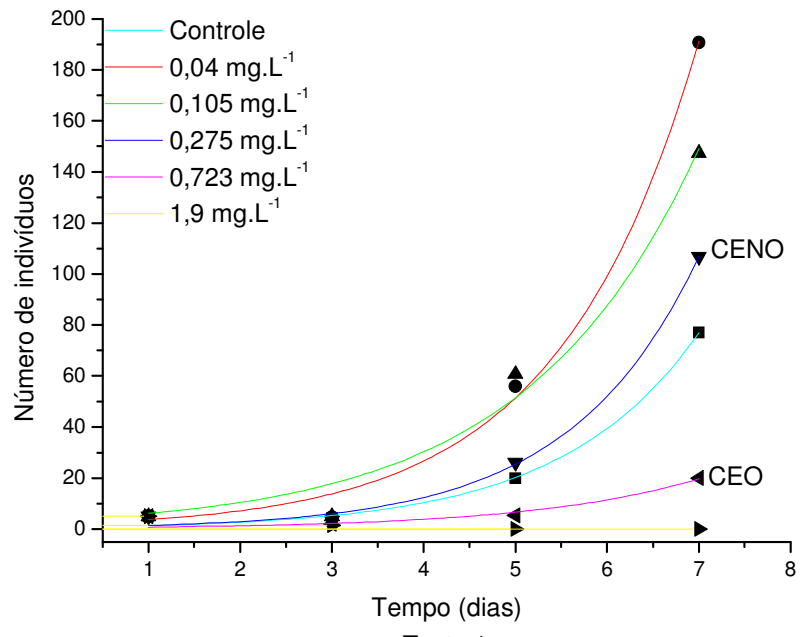

Teste 1

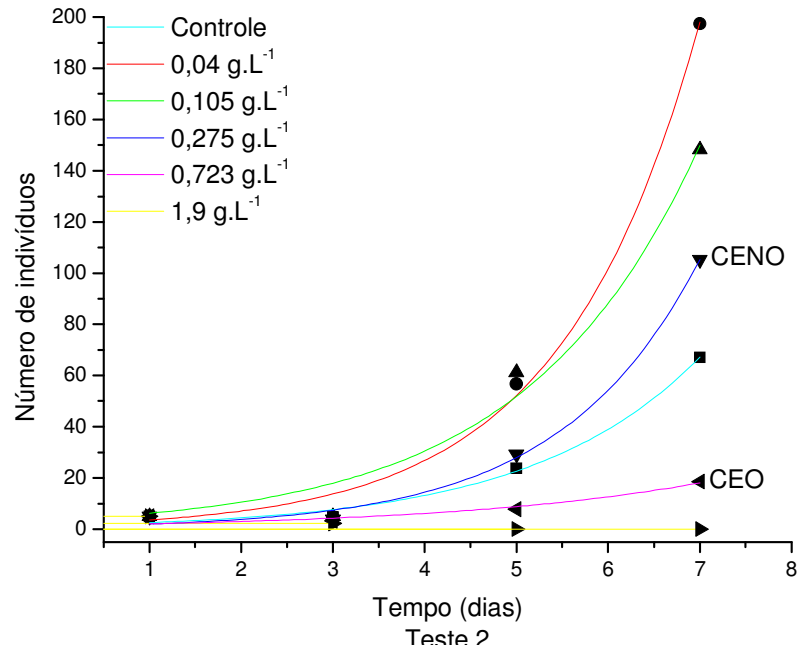

Teste 2

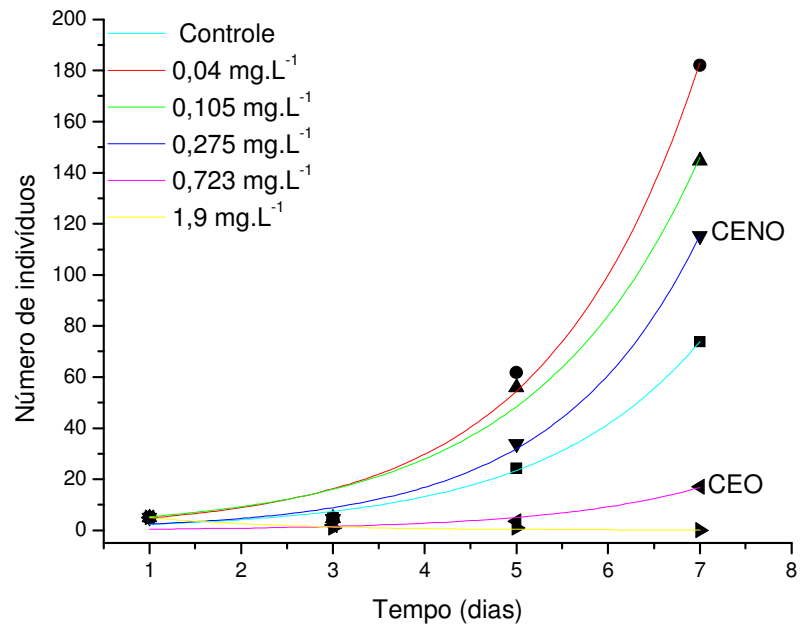

Teste 3

Figura 7 - Valores de CENO e $\mathrm{CEO}$ de $\mathrm{NaCl}\left(\mathrm{g} . \mathrm{L}^{-1}\right)$ para populações de $C$. silvestrii a $25^{\circ} \mathrm{C}( \pm 2)$. Os diferentes pontos correspondem às réplicas de cada teste. 
O IC25 e o IC50, isto é, a concentração do tóxico que causou a inibição de $25 \%$ e $50 \%$ no crescimento populacional em relação ao controle, respectivamente, apresenta-se na Tabela 19 para os diferentes testes.

Tabela 18 - Valores de IC25 e o IC50 de $\mathrm{NaCl}\left(\mathrm{mg} . \mathrm{L}^{-1}\right)$ nos ensaios com populações de C.silvestrii.

\begin{tabular}{ccc}
\hline Teste & $\begin{array}{c}\text { IC25 } \\
\left({\mathrm{mg} . ~ ~^{-1}}\right)\end{array}$ & $\begin{array}{c}\text { IC50 } \\
\left(\mathrm{mg.} \mathrm{L}^{-1}\right)\end{array}$ \\
\hline $\mathbf{1}$ & 0,29 & 0,45 \\
$\mathbf{2}$ & 0,28 & 0,46 \\
$\mathbf{3}$ & 0,34 & 0,48 \\
\hline Média & 0,30 & 0,46 \\
$\boldsymbol{\sigma}$ & 0,03 & 0,02 \\
$\mathbf{C V}$ & $11 \%$ & $3 \%$ \\
\hline
\end{tabular}

CV - Coeficiente de Variação.

\subsection{Toxicidade}

Os valores obtidos para CENO (p), CEO (p) e Ir\% para os testes crônicos populacionais com propanolol calculados a partir do número de neonatas em cada concentração são apresentados na Tabelas 20 e 21 e na Figura 8.

A Tabela 22 apresenta a taxa intrínseca de aumento natural média (r) para cada ensaios.

Os resultados obtidos estão dentro dos critérios de aceitabilidade para o controle para os ensaios de ecotoxicidade com populações de Ceriodaphnia silvestrii descritos no item 4.2.3.2.2, ou seja, número de organismos $(73 \pm 10)$ e valor da taxa $0,596( \pm 0,13)$.

Tabela 19 - Toxicidade crônica do propanolol (mg. $\left.\mathrm{L}^{-1}\right)$ para ensaios com populações $(\mathrm{n}=3)$ de $C$. silvestrii.

\begin{tabular}{cccc}
\hline TESTE & CENO $(\mathbf{p})$ & CEO $(\mathbf{p})$ & \% Ir \\
\hline $\mathbf{1}$ & 0,62 & 1,25 & $16 \%$ \\
$\mathbf{2}$ & 1,25 & 2,5 & $69 \%$ \\
$\mathbf{3}$ & 1,25 & 2,5 & $56 \%$ \\
\hline
\end{tabular}


Tabela 20 - Média de neonatas (3 réplicas) por concentração de propanolol (mg.L $\mathrm{L}^{-}$ ${ }^{1}$ ) em ensaios populacionais $(\mathrm{n}=3)$ de $C$. silvestrii.

\begin{tabular}{ccccccc}
\hline Concentração & Teste 1 & Teste 2 & Teste 3 & Média & $\boldsymbol{\sigma}$ & CV \\
\hline Controle & 87,3 & 78,3 & 85,3 & 83,7 & 4,7 & $6 \%$ \\
$\mathbf{0 , 1 6}$ & 77,0 & 78,3 & 79,3 & 78,2 & 1,2 & $1 \%$ \\
$\mathbf{0 , 3 1}$ & 75,0 & 83,7 & 81,3 & 80,0 & 4,5 & $6 \%$ \\
$\mathbf{0 , 6 2}$ & 63,0 & 88,0 & 68,3 & 73,1 & 13,2 & $18 \%$ \\
$\mathbf{1 , 2 5}$ & $56,0^{*}$ & 54,3 & 63,7 & 58,0 & 5,0 & $9 \%$ \\
$\mathbf{2 , 5}$ & 6,3 & $12,3 *$ & $11,7 *$ & 10,1 & 3,3 & $33 \%$ \\
\hline
\end{tabular}

*Concentração de efeito observado (CEO).

Tabela 21 - Taxa intrínseca de aumento natural média (r) para propranolol (mg. $\left.\mathrm{L}^{-1}\right)$ em um cultivo populacional de C.silvestrii a $25^{\circ} \mathrm{C}( \pm 2)$.

\begin{tabular}{ccccccc}
\hline Concentração & Teste 1 & Teste 2 & Teste 3 & Média & $\boldsymbol{\sigma}$ & CV \\
\hline Controle & 0,565 & 0,577 & 0,638 & 0,593 & 0,039 & $7 \%$ \\
$\mathbf{0 , 1 6}$ & 0,550 & 0,549 & 0,573 & 0,558 & 0,014 & $2 \%$ \\
$\mathbf{0 , 3 1}$ & 0,449 & 0,592 & 0,564 & 0,535 & 0,076 & $14 \%$ \\
$\mathbf{0 , 6 2}$ & 0,449 & 0,568 & 0,578 & 0,532 & 0,072 & $14 \%$ \\
$\mathbf{1 , 2 5}$ & $0,414 *$ & 0,464 & 0,601 & 0,493 & 0,097 & $20 \%$ \\
$\mathbf{2 , 5}$ & 0,044 & $0,328^{*}$ & $0,198 *$ & 0,190 & 0,142 & $75 \%$ \\
\hline
\end{tabular}

* Concentração de efeito observado (CEO) 

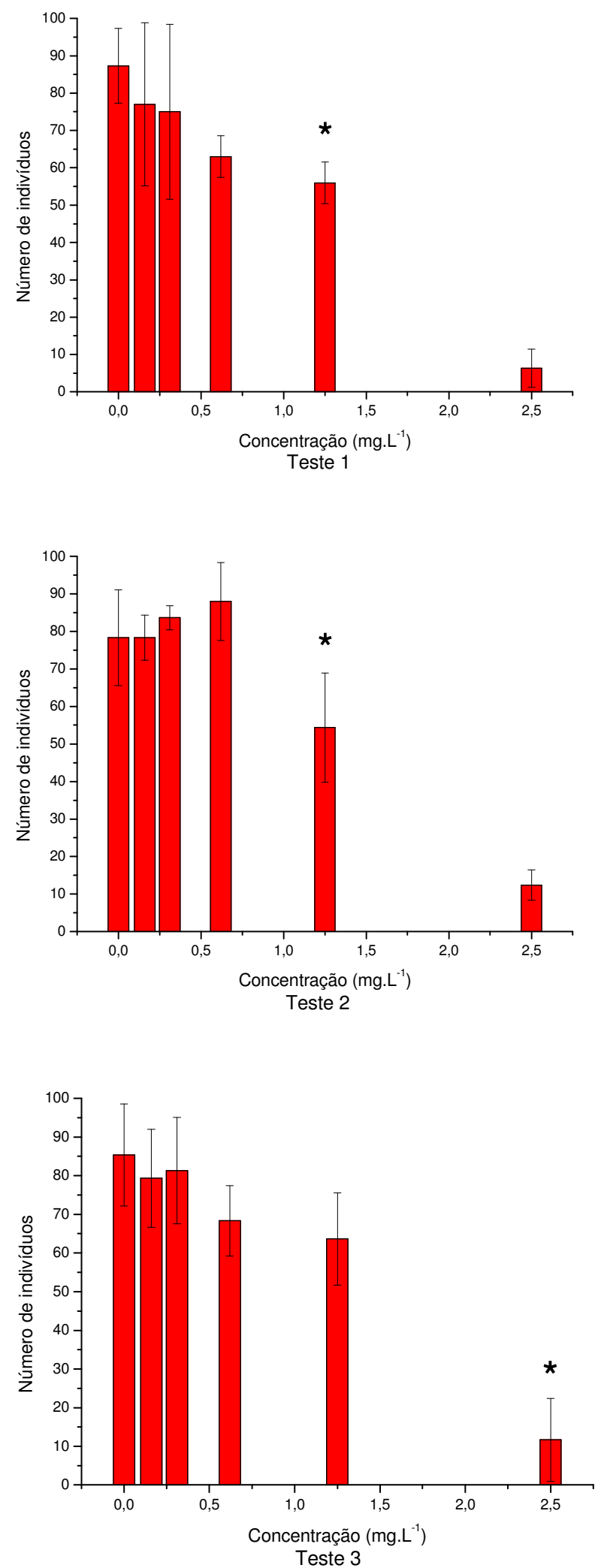

Figura 8 - Reprodução (número médio de neonatas) de $C$. silvestrii nos ensaios com populações com propranolol $\left(\mathrm{mg}\right.$. $\left.\mathrm{L}^{-1}\right)$. As barras indicam o desvio-padrão entre as réplicas de cada concentração e o asterisco a concentração de efeito observado (CEO). 
As Figuras 9 mostram o crescimento populacional de $C$. silvestrii para cada concentração nos diferentes ensaios. Os diferentes pontos correspondem às réplicas de cada teste.
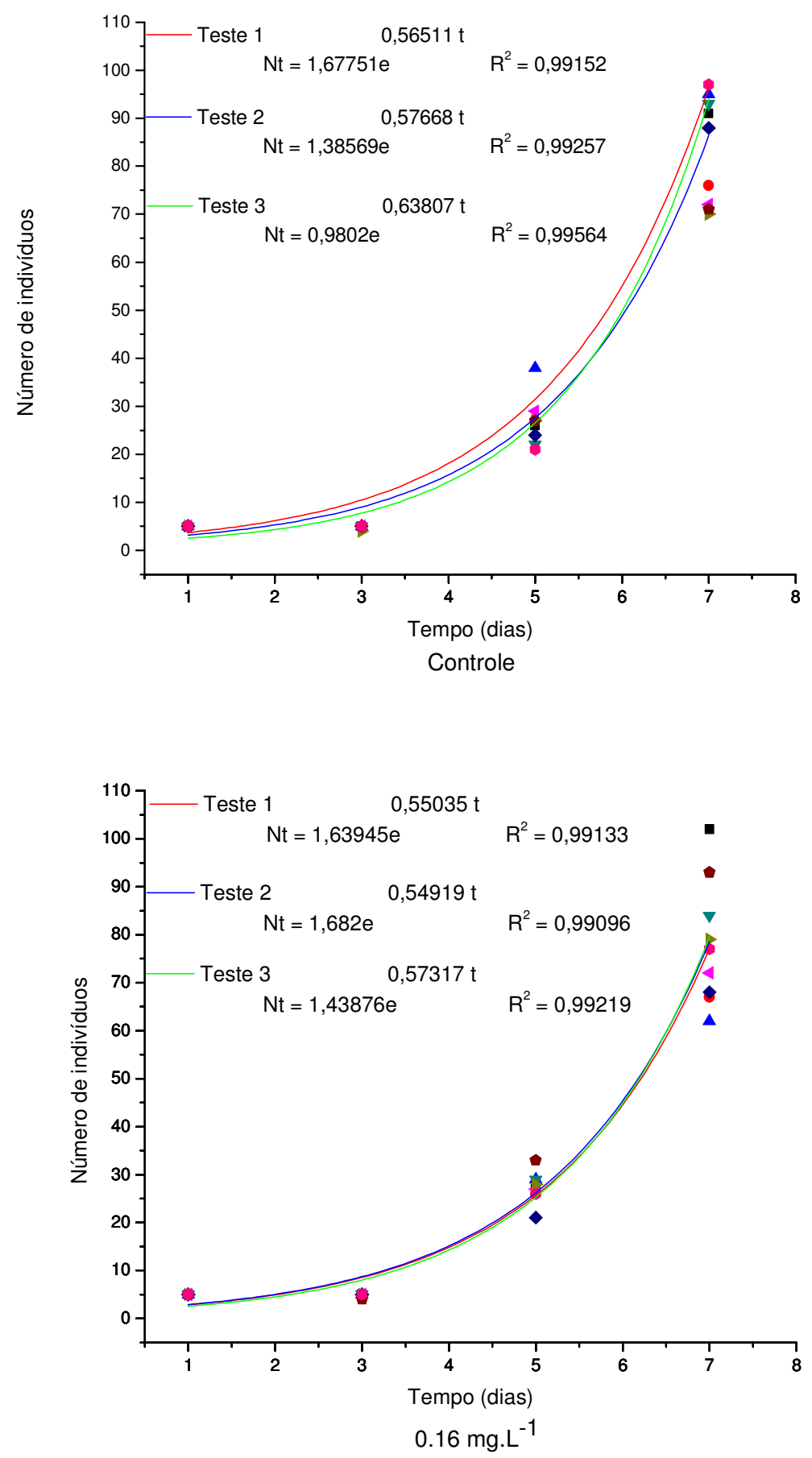

Figura 9 - Crescimento populacional $(\mathrm{n}=3)$ de $C$. silvestrii para o controle e a concentração $0,16 \mathrm{mg}$. $\mathrm{L}^{-1}$ de propranolol a $25^{\circ} \mathrm{C}( \pm 2)$ (cont.) 

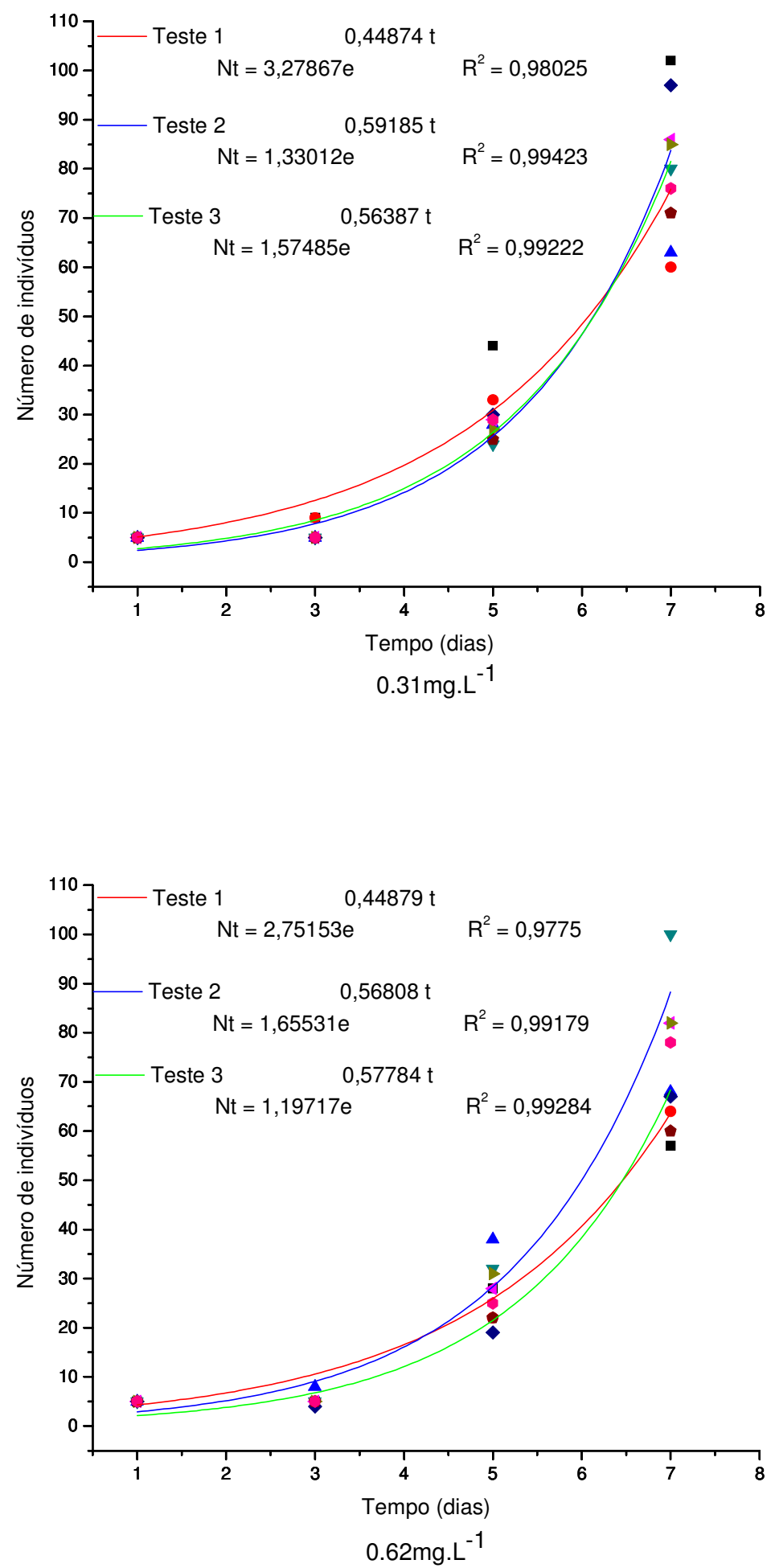

Figura 9 - Crescimento populacional $(\mathrm{n}=3)$ de $C$. silvestrii para as concentrações $0,31 \mathrm{e}$ $0,62 \mathrm{mg}$. $\mathrm{L}^{-1}$ de propranolol a $25^{\circ} \mathrm{C}( \pm 2)$ (cont.) 

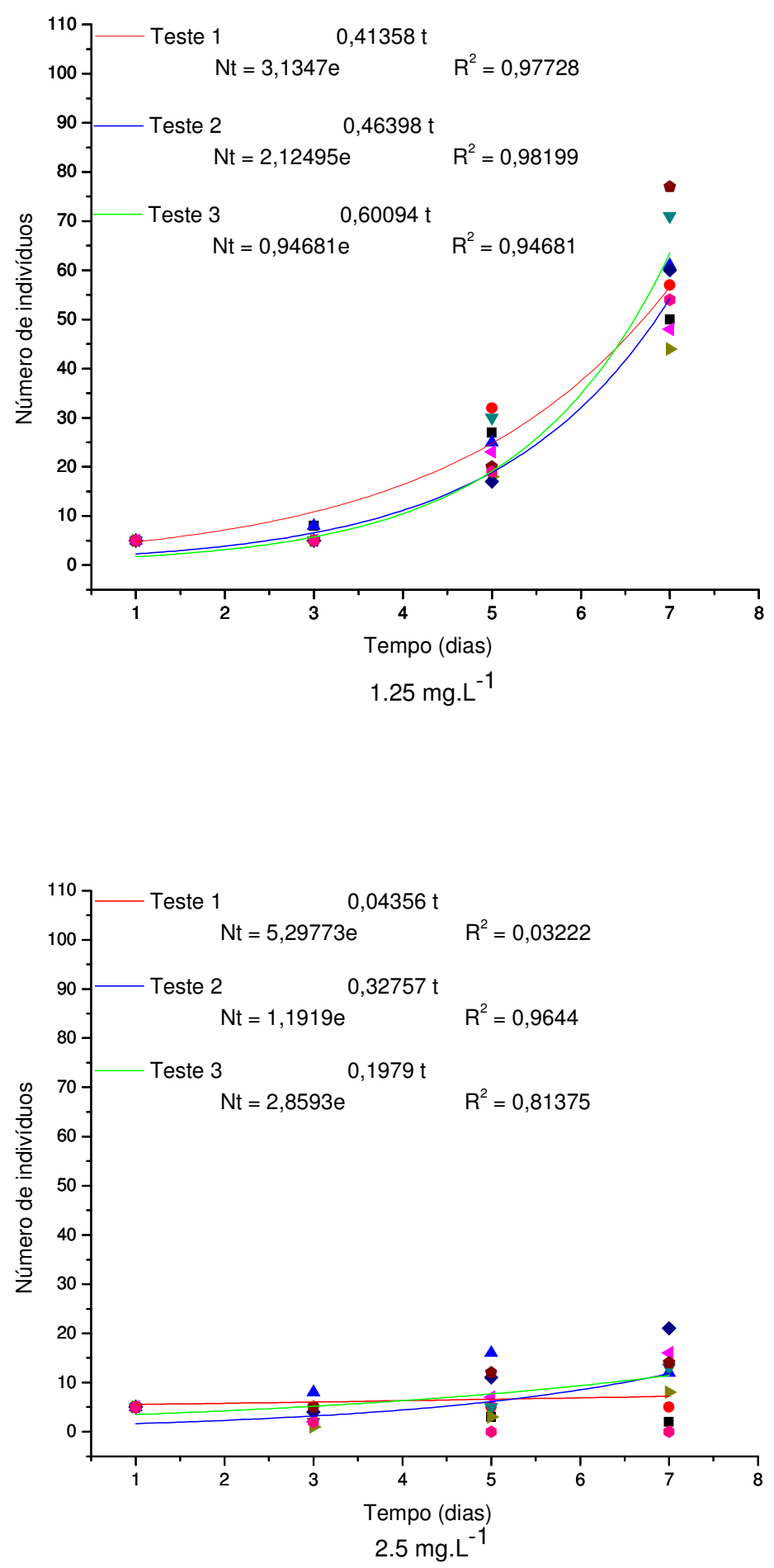

Figura 9 - Crescimento populacional $(\mathrm{n}=3)$ de $C$. silvestrii para as concentrações 1,25 e 2,5 mg. $\mathrm{L}^{-1}$ de propranolol a $25^{\circ} \mathrm{C}( \pm 2)$. 
A Figura 10 mostra o crescimento populacional de $C$. silvestrii para os diferentes ensaios e os valores de CENO e CEO.
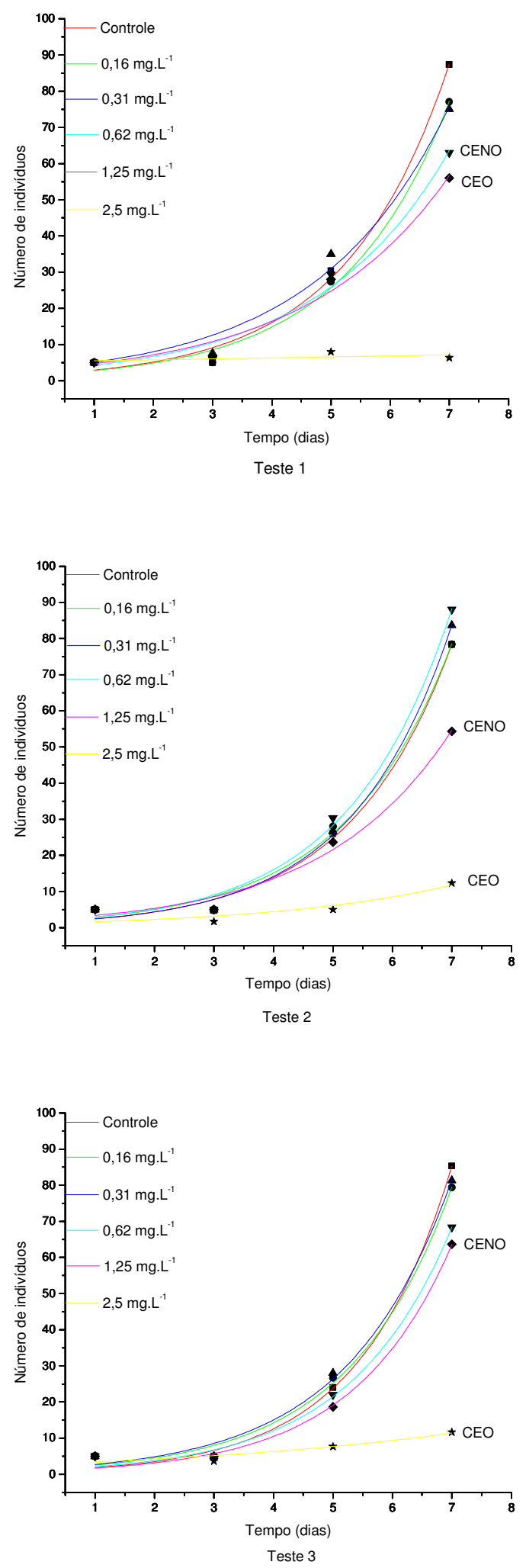

Figura 10 - Crescimento populacional de $C$. silvestrii $(\mathrm{n}=3)$ nas concentrações 0,$16 ; 0,31$; 0,$62 ; 1,25$ e $2,5 \mathrm{mg}$. $\mathrm{L}^{-1}$ de propranolol a $25^{\circ} \mathrm{C}( \pm 2)$. 
O IC25 e o IC50, isto é, a concentração do tóxico que causou a inibição de $25 \%$ e $50 \%$ no crescimento populacional em relação ao controle, respectivamente, apresenta-se na Tabela 23 para os diferentes testes.

Tabela 22 - Valores de IC25 e o IC50 de propanolol $\left(\mathrm{mg} . \mathrm{L}^{-1}\right)$ nos ensaios com populações de C.silvestrii.

\begin{tabular}{ccc}
\hline Teste & IC25 & IC50 \\
\hline $\mathbf{1}$ & 0,55 & 1,56 \\
$\mathbf{2}$ & 1,08 & 1,64 \\
$\mathbf{3}$ & 1.2 & 1,75 \\
\hline Média & 0,82 & 1,65 \\
$\boldsymbol{\sigma}$ & 0,37 & 0,10 \\
$\mathbf{C V}$ & $46 \%$ & $6 \%$ \\
\hline
\end{tabular}

$\mathrm{CV}$ - Coeficiente de Variação.

A Tabela 24 sumariza os valores encontrados para os diferentes "endpoints" avaliados neste trabalho.

Tabela 23 - Sumário dos resultados encontrados para os diferentes "endpoints" avaliados para a toxicidade do propranolol $\left(\mathrm{mg}^{-1} \mathrm{~L}^{-1}\right)$ e a razão IC50(p)/IC50 para C.silvestrii.

\begin{tabular}{cccccc}
\hline Teste & CE(I)50;48H & CEO & CEO (p) & IC50 & IC50 (p) \\
\hline $\mathbf{1}$ & 2,87 & 2,5 & 1,25 & 2,3 & 1,56 \\
$\mathbf{2}$ & 2,63 & 2,5 & 2,5 & 2,34 & 1,64 \\
$\mathbf{3}$ & & 1,25 & 2,5 & 2,42 & 1,75 \\
\hline Média & & & & $\mathbf{2 , 3 5}$ & $\mathbf{1 , 6 5}$ \\
Razão & & & & & $\mathbf{7 0 \%}$ \\
IC50 (p)/IC50 & & & & & \\
\hline
\end{tabular}




\subsection{Sensibilidade}

O organismo-teste, Ceriodaphnia silvestrii, teve uma avaliação das suas condições fisiológicas frente à substância de referência cloreto de sódio, verificando-se a mobilidade ou mortalidade. Mensalmente foram realizados testes de sensibilidade para se verificar se os organismos se encontravam em condições de serem utilizados em ensaios de toxicidade.

Os lotes utilizados sempre se encontraram dentro da faixa estabelecida para o Laboratório de Ecotoxicologia do IPEN. O valor médio obtido para $\mathrm{CE}(\mathrm{I}) 50 ; 48 \mathrm{H}$ foi de 1,648 g. $\mathrm{L}^{-1} \mathrm{NaCl}$ (Tabela 25). O valor do coeficiente de variação de $13 \%$ se encontra dentro da precisão analítica esperada para testes de sensibilidade.

Tabela 24 - Concentração efetiva $\mathrm{CE}(\mathrm{I}) 50 ; 48 \mathrm{H}$ de $\mathrm{NaCl}$ para Ceriodaphnia silvestrii à $25^{\circ} \mathrm{C}( \pm 2)$.

\begin{tabular}{ccc}
\hline Teste $^{\mathbf{0}}$ & $\begin{array}{c}\text { CE(I)50;48H } \\
\left(\mathrm{g} . \mathrm{L}^{-1}\right)\end{array}$ & Intervalo de confiança \\
\hline \hline $\mathbf{1}$ & 1,42 & \\
$\mathbf{2}$ & 1,36 & $1,305-1,475$ \\
$\mathbf{3}$ & 1,75 & $1,090-1,930$ \\
$\mathbf{4}$ & 1,49 & $1,161-1,849$ \\
$\mathbf{5}$ & 1,66 & $1,208-1,864$ \\
$\mathbf{6}$ & 1,48 & $1,237-1,859$ \\
$\mathbf{7}^{*}$ & 1,49 & $1,326-1,822$ \\
$\mathbf{8}^{*}$ & 1,89 & $1,247-1,957$ \\
$\mathbf{9}^{*}$ & 1,89 & $1,276-2,088$ \\
$\mathbf{1 0}^{*}$ & 2,01 & $1,255-2,249$ \\
$\mathbf{1 1}^{*}$ & 1,84 & $1,430-2,218$ \\
$\mathbf{1 2}^{*}$ & 1,54 & $1,482-2,186$ \\
$\mathbf{1 3}^{*}$ & 1,52 & $1,322-2,198$ \\
$\mathbf{1 4}^{*}$ & 1,76 & $1,320-2,148$ \\
$\mathbf{1 5}^{*}$ & 1,64 & $1,383-1,937$ \\
$\mathbf{1 6}^{*}$ & 1,68 & $1,429-1,827$ \\
$\mathbf{1 7}^{*}$ & 1,24 & $1,162-1,974$ \\
$\mathbf{1 8}^{*}$ & 1,95 & $1,133-2,175$ \\
$\mathbf{1 9}_{\mathbf{2 0}}^{\mathbf{2}}$ & 1,8 & $1,132-2,192$ \\
$\mathbf{\text { médio }}$ & 1,54 & $1,305-2,184$ \\
$\mathbf{\sigma}$ & 1,648 & $1,100-2,184$ \\
$\mathbf{C V}$ & 0,211 & \\
\hline
\end{tabular}

*Realização dos testes 
A Figura 11 mostra a carta-controle construída a partir de uma série histórica de vinte testes de sensibilidade com cloreto de sódio mais recentes.

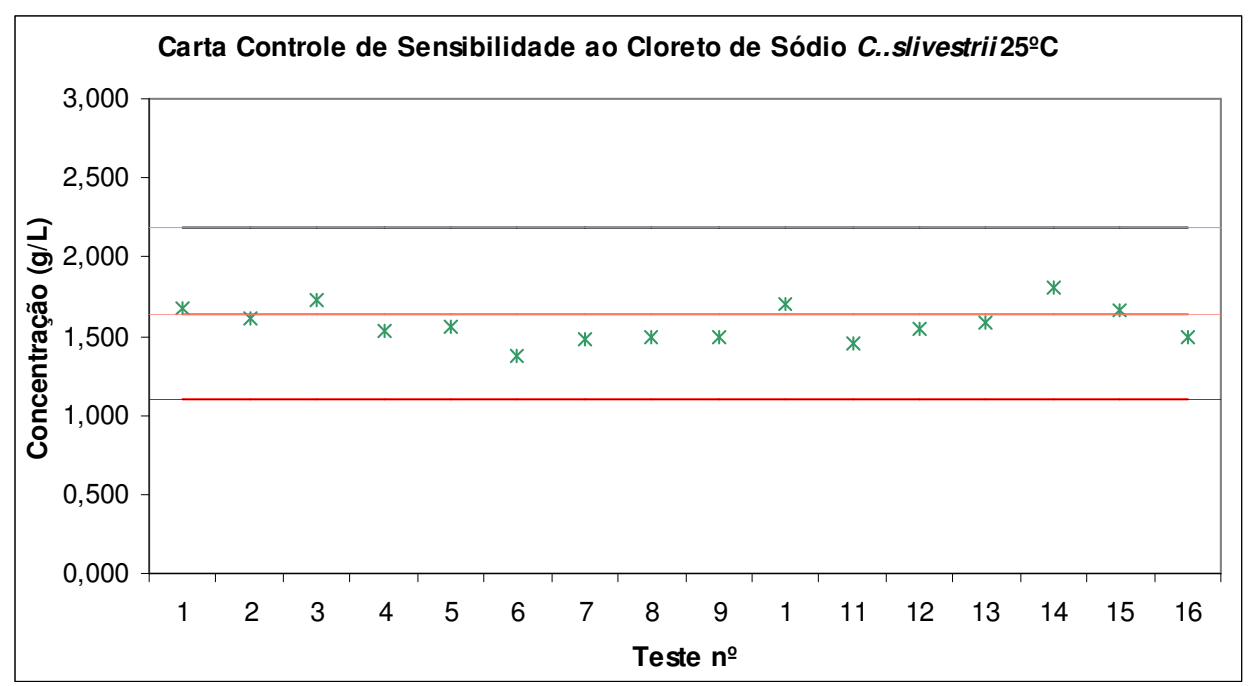

Figura 11 - Carta-controle de $\mathrm{NaCl}(\mathrm{CE}(\mathrm{I}) 50 ; 48 \mathrm{H})$ de Ceriodaphnia silvestrii. 


\section{Discussão}

\subsection{Avaliação da toxicidade}

\subsubsection{Toxicidade Aguda}

Fármacos no ambiente foram primeiramente descobertos por volta de 30 anos atrás (GARRISON et al., 1976; HIGNITE e AZARNOFF, 1977; WAGGOT, 1981). Até meados dos anos 90, melhorias nos métodos de detecção e ensaios de toxicidade conduziram a um aumento da investigação destes contaminantes no ambiente (CHRISTENSEN, 1998; TERNES et al, 1998; JONES et al., 2001).

Fármacos têm sido avaliados em sua toxicidade aguda para organismos aquáticos de acordo com diretrizes estabelecidas por OECD, EPA, entre outras, utilizando organismos estabelecidos em laboratório, tais como algas, zooplânctons e outros invertebrados e peixes.

Efeitos agudos e crônicos foram estudados para o cnidário Hydra vulgaris para os fármacos diazepam, digoxin e amlodipina por PASCOE et al., (2003). O pesquisador não encontrou efeito agudo destes contaminantes até uma concentração de $10 \mathrm{mg} . \mathrm{L}^{-1}$, porém, para esta mesma concentração, os efeitos crônicos foram observados pela inibição da regeneração do organismo teste.

Efeitos tóxicos em organismos aquáticos e bentônicos causados pela fluoxetina, um inibidor de reabsorção seletivo da serotonina, foi resumido em um artigo por BROOKS et al. (2003). Efeitos agudos foram observados em concentrações próximas de $14 \mu \mathrm{g} . \mathrm{L}^{-1}$ para o crescimento algal, $0,2 \mathrm{mg} . \mathrm{L}^{-1}$ para dafinídeos, $0,7 \mathrm{mg} \cdot \mathrm{L}^{-1}$ para peixes e $1 \mathrm{mg} \cdot \mathrm{kg}^{-1}$ para o crescimento de organismos bentônicos. Efeitos na reprodução dos crustáceos foram observados em $100 \mu \mathrm{g} . \mathrm{L}^{-1}$, enquanto a reprodução nos organismos bentônicos não foi reduzida. Os efeitos crônicos mais tóxicos da fluoxetina, porém, foram observado na alteração dos níveis de oestradiol no plasma dos peixes fêmea e em mal formações de embriões que ocorreram em concentrações próximas de $0,1 \mu \mathrm{g} \cdot \mathrm{L}^{-1}$.

Um estudo da toxicidade aguda para dez fármacos e o propranolol para D.magna, inibição do crescimento da alga Desmodesmus subspicatus e seus efeitos a longo prazo da inibição no crescimento da macrófita aquática Lemna minor, mostrou que a maioria das substâncias tiveram seu CL50 entre 10 mg.L $\mathrm{L}^{-1}$ e 100 mg.L ${ }^{-1}$ (CLEUVERS, 2003). 
Propranolol foi um dos fármacos mais tóxicos com o valor de CL50 em 7,5 mg.L ${ }^{-1}$ para D.magna.

Dados de toxicidade aguda para diversos fármacos foram compilados por HALLING - SORENSEN et al. (1998) e WEBB (2001), sendo que este último listou aproximadamente 100 fármacos para humanos de diferentes fontes, sendo que para os $\beta$ bloqueadores foi constatado que existem poucos dados relativos à sua toxicidade para organismos aquáticos.

Os primeiros dados relativos a toxicidade aguda do propranolol para os organismo aquáticos foi relatado por LILIUS et al. (1995), que encontrou para Daphnia magna e Daphnia pulex valores de CE(I)50;24H propranolol de 2,5 e 3,6 mg.L $\mathrm{L}^{-1}$, respectivamente.

HUGGETT et al. (2002) estudaram a toxicidade aguda dos $\beta$ - bloqueadores metroprolol, nadolol e propranolol para invertebrados aquáticos (Hyalella azteca, Daphnia magna e Ceriodaphnia dubia) e vertebrados aquáticos (Oryzias latipe). Este autor encontrou uma CE(I)50;48H de propranolol no valor de 0,8, 1,6, 24,3 e 29,8 mg.L - $^{-1}$ para Ceriodaphnia dubia, Daphnia magna, Oryzias latipe e Hyalella azteca, respectivamente. Para o autor, o propranolol se mostrou o $\beta$ - bloqueador mais tóxico entre os fármacos testados.

Em estudos para outros fármacos, foi avaliada a toxicidade aguda da carmamazepina, ácido clofibrinico e diclofenaco em vários organismos aquáticos e diferentes níveis tróficos (FERRARI et al., 2003). O diclofenaco foi o fármaco testado mais tóxico, tendo a CL50 de $11,5 \mathrm{mg}$. $\mathrm{L}^{-1}$ e a bactéria Vibrio fischeri a espécie mais sensível. Os autores encontraram para Daphnia magna e Ceriodaphnia dubia uma $\mathrm{CE}(\mathrm{I}) 50 ; 48 \mathrm{H}$ de propranolol no valor de $2,75 \mathrm{e} 1,51 \mathrm{mg}$. $\mathrm{L}^{-1}$, respectivamente. Os valores encontrados estão na mesma faixa dos encontrados por HUGGETT et al. (2002) e LILIUS et al. (1995) para D. magna.

Em um trabalho mais recente, FRAYSSE et al. (2005) encontrou para Ceriodaphnia dubia uma $\mathrm{CE}(\mathrm{I}) 50 ; 48 \mathrm{H}$ de $1,4 \mathrm{mg} . \mathrm{L}^{-1}$ de propranolol. Este valor está dentro da variação encontrado por HUGGETT et al. (2002) e FERRARI et al. (2003) e mostra que C. dubia parece ser mais sensível que D. magna, nestes trabalhos.

O presente trabalho encontrou para C.silvestrii uma CE(I)50;48H de propranolol um valor de 2,87 e 2,63 mg. $\mathrm{L}^{-1}$ de propranolol para água destilada reconstituída e natural reconstituída, respectivamente. Este valor é mais alto do que aquele encontrado por 
HUGGETT et al. (2002) para Ceriodaphnia dubia, mostrando que a espécie testada no presente trabalho parece ser mais resistente ao fármaco em questão.

Valores para a toxicidade aguda do propranolol para outros organismos são apresentados na Tabela 26.

Apesar do efeito do $\beta$-bloqueador propranolol ser constatado, o modo de ação da toxicidade ainda não é bem conhecida. Para D.magna, a taxa da freqüência cardíaca, fecundidade e biomassa foram reduzidas após uma exposição crônica de $0,11 \mathrm{mg} \cdot \mathrm{L}^{-1}$ de propranolol, no entanto, não é conhecida a presença de $\beta$-receptores em microcrustáceos (DZIALOWSKI et al., 2003).

POSTMES et al. (1989) mostrou que os efeitos cronotrópicos negativos do agonista epinefrina não pode ser bloqueada pelo antagonista propranolol em D.magna, sugerindo que as ações da droga, bem como a regulação normal da freqüência cardíaca nesta espécie não são mediadas através de adrenoreceptores.

Para os cladóceros, o coração é miogênico (POSTMES et al., 1989), isto é, a frequiência cardíaca é induzida por contrações do miocárdio, porém ela não é desencadeada por uma glândula cardíaca como nos crustáceos decápodos (YAMAGISHI, 1997). Alguns estudos em Branchiopoda mostraram que catecolaminas (adrenalina e noradrenalina) e seus antagonistas modificam a freqüência cardíaca, mas o fazem afetando as propriedades elétricas dos neurônios em vez de provocar uma interação com receptores neuroendócrinos (YAMAGISHI, 1997). 
Tabela 26 - CE (I)50 (mg. $\left.\mathrm{L}^{-1}\right)$ de propranolol para diferentes organismos encontrados na literatura.

\begin{tabular}{|c|c|c|c|c|c|}
\hline Organismo & Espécie & Tempo de exposição & "Endpoint" avaliado & CE (I)50 & Referência \\
\hline Bactéria & Vibrio fisheri & 5 minutos & Luminescência & 184,39 & CALLEJA et al. (1994) \\
\hline Bactéria & Vibrio fisheri & 30 minutos & Luminescência & 61,00 & FERRARI et al. (2003) \\
\hline Alga verde & $\begin{array}{c}\text { Pseudokirchneriella } \\
\text { subcapitata }\end{array}$ & 96 horas & Crescimento & 7,40 & $\begin{array}{c}\text { FERRARI ET et al. } \\
(2003)\end{array}$ \\
\hline Alga verde & Desmodesmus subspicatus & 72 horas & Crescimento & 5,8 & CLEUVERS (2002) \\
\hline Diatomácea & Cyclotella meneghiniana & 96 horas & Crescimento & 244,00 & FERRARI et al. (2003) \\
\hline Alga azul & Synechococcus leopolensis & 96 horas & Crescimento & 668,00 & FERRARI et al. (2003) \\
\hline Macrófita & Lemna minor & 7 dias & Crescimento & 114 & CLEUVERS (2002) \\
\hline Rotífera & Brachionus calyciflorus & 24 horas & Mortalidade & 2,59 & CALLEJA et al. (1994) \\
\hline Crustáceo & Streptocephalus proboscideus & - & Mortalidade & 1,87 & CALLEJA et al. (1994) \\
\hline Crustáceo & Daphnia pulex & 24 horas & Mortalidade & 3,83 & LILIUS et al (1995) \\
\hline Crustáceo & Daphnia magna & 24 horas & Mortalidade & 2,70 & LILIUS et al (1995) \\
\hline Crustáceo & Daphnia magna & 24 horas & Mortalidade & 15,87 & CALLEJA et al. (1994) \\
\hline Crustáceo & Daphnia magna & 48 horas & Mortalidade & 1,60 & HUGGET et al (2002) \\
\hline Crustáceo & Daphnia magna & 48 horas & Mortalidade & 2,75 & FERRARI et al. (2003) \\
\hline Crustáceo & Daphnia magna & 48 horas & Mortalidade & 7,5 & CLEUVERS (2002) \\
\hline Crustáceo & Daphnia magna & 49 horas & Mortalidade & 1,67 & STANLEY (2005) \\
\hline Crustáceo & Ceriodaphnia dubia & 48 horas & Mortalidade & 0,8 & HUGGET et al (2002) \\
\hline Crustáceo & Ceriodaphnia dubia & 48 horas & Mortalidade & 1,51 & FERRARI et al. (2003) \\
\hline Crustáceo & Ceriodaphnia dubia & 48 horas & Mortalidade & 1,40 & FRAYSSE et al (2005) \\
\hline Crustáceo & Ceriodaphnia silvestrii & 48 horas & Mortalidade & 2,87 & Presente estudo \\
\hline Crustáceo & Hyalella azteca & 48 horas & Mortalidade & 29,80 & HUGGET et al (2002) \\
\hline Peixe & Oryzias latipes & 48 horas & Mortalidade & 24,30 & HUGGET et al (2002) \\
\hline \multirow{3}{*}{ Peixe } & \multirow{3}{*}{ Pimephales promelas } & 14 dias & Crescimento & 0,50 & HUGGET et al (2002) \\
\hline & & 49 horas & Mortalidade & 1,21 & STANLEY (2005) \\
\hline & & 7 dias & Crescimento & 0,128 & STANLEY (2005) \\
\hline
\end{tabular}


Portanto, avaliar a toxicidade dos $\beta$-bloqueadores através de invertebrados utilizando apenas cladóceros não é suficiente. Estudos com diferentes classes de crustáceos se tornam necessários para se conhecer modos de ação específicos e melhorar a avaliação dos perigos ambientais desses compostos.

\subsubsection{Toxicidade Crônica}

A avaliação do potencial crônico de micropoluentes, como por exemplo os fármacos, torna-se importante devido ao fato de muitas espécies aquáticas serem expostas a eles continuamente por longos períodos de tempo, ou mesmo durante toda sua vida.

Pelo motivo da ocorrência dos fármacos em baixas concentrações e por serem persistentes no ambiente, é provável que os efeitos causados por estes contaminantes sejam crônicos e não agudos (JONES et al., 2002). Deste modo, ensaios agudos padronizados não são as bases mais adequadas par a avaliação de riscos ecológicos dos fármacos, e testes de toxicidade crônicos realizados com diferentes organismos devem ser implementados para estimar um melhor nível de proteção na avaliação dos riscos da contaminação ambiental para os fármacos.

A toxicidade crônica e aguda para antibióticos usados na medicina veterinária (metronidazole, olaquindox, ácido oxolinico, oxitetraciclina, streptomicina, sulfadiazina, tetraciclina, tiamulin and tylosin) foram testados em D.magna (WOLLENBERGER et al., 2000). O ácido oxilínico foi a substância mais tóxica com uma CL50 de 4,6 mg.L $\mathrm{L}^{-1}$, enquanto as outras substâncias testadas tiveram uma CL50 entre $40 \mathrm{mg} \cdot \mathrm{L}^{-1}$ e $680 \mathrm{mg}$. $\mathrm{L}^{-1}$. Os valores para a toxicidade crônica foi geralmente dez vezes menor e a única substância identificada como um potencial risco ao ambiente foi o ácido oxilínico devido seu uso na piscicultura.

Estudos com macrófitas aquáticas também foram realizados. BRAIN et al. (2004) examinou os efeitos fitotóxicos em Lemna gibba de 25 compostos farmacológicos de várias classes. A seleção destas substãncias foi baseada na sua ocorrência no ambiente e seu potencial em causar toxicidade no cloroplasto e plasmídeo. Um grande número de parâmetros foram estudados após 7 dias de exposição, sendo que o peso seco foi o escolhido como o mais adequado. Os resultados mostraram que fluoroquinolonas, sulfonamidas e tetraciclinas foram os mais tóxicos para as plantas. $\mathrm{O}$ valor encontrado para CL50 sobre o peso seco foi de $97 \mu \mathrm{g} . \mathrm{L}^{-1}$ para lomefloxacin, $81 \mu \mathrm{g} . \mathrm{L}^{-1}$ para sulfametoxazole e $219 \mu \mathrm{g} . \mathrm{L}^{-1}$ para clortetraciclina. Estas concentrações são de 10 a 100 vezes maiores que 
aquelas encontradas no ambiente. Porém os autores consideraram que o efeito no ambiente em baixas concentrações seria possível sendo que uma redução no crescimento acima de $20 \%$ é considerada ecologicamente relevante em macrófitas aquáticas e que os valores da CL25 e CL10 estariam próximos as concentrações ambientais.

No presente estudo os valores obtidos para CENO (Concentração de Efeito não Observado) e CEO (Concentração de Efeito Observado) para C. silvestrii estiveram na faixa de $0,62-1,25$ e 1,25-2,5 mg. $\mathrm{L}^{-1}$ de propranolol.

Efeitos crônicos do propranolol foram estudados por HUGGETT et al. (2002). Uma diminuição na reprodução foi verificada para Hyallella azteca em $0,1 \mathrm{mg}^{-\mathrm{L}^{-1}} \mathrm{e}$ Ceriodaphnia dubia em 0,25 mg. $\mathrm{L}^{-1}$. O autor também verificou que após quatro dias de exposição do peixe Oryzias latipe a $5 \mu \mathrm{g} . \mathrm{L}^{-1}$ de propranolol houve uma redução no número de ovos produzidos. Os níveis de oestradiol e testoterona no plasma dos peixes macho foram afetados após duas semanas de exposição à $1 \mu \mathrm{g} . \mathrm{L}^{-1}$ de propranolol. Nas fêmeas os níveis de oestradioal no plasma foram afetados em exposições de $100 \mu \mathrm{g} . \mathrm{L}^{-1}$ de propranolol. Com os valores obtidos neste estudo, o autor foi capaz de provar que existe um risco de efeito sobre a reprodução dos peixes, mas que é necessária uma maior investigação, a fim de caracterizar completamente o risco.

Os valores encontrados por este autor, tanto para a toxicidade aguda quanto para a crônica são menores do que os encontrados neste trabalho, demonstrando assim, que $C$. dubia parece ser mais sensível que $C$. silvestrii.

Valores para a toxicidade crônica do propranolol para outros organismos são apresentados na Tabela 27. 
Tabela 27 - Concentração de efeito não observado (CENO) (mg.L $\left.\mathrm{L}^{-1}\right)$ para diferentes organismos encontrados na literatura.

\begin{tabular}{cccccc}
\hline Organismo & Espécie & Tempo de exposição & "Endpoint" avaliado & CENO & Referência \\
\hline Alga verde & Pseudokirchneriella subcapitata & 96 horas & Crescimento & 0,0050 & FERRARI et al. (2003) \\
Diatomácea & Cyclotella meneghiniana & 96 horas & Crescimento & 0,0940 & FERRARI et al. (2003) \\
Alga azul & Synechococcus leopolensis & 96 horas & Crescimento & 0,3500 & FERRARI et al. (2003) \\
Rotífera & Brachionus calyciflorus & 48 horas & Reprodução & 0,1800 & FERRARI et al. (2003) \\
Crustáceo & Ceriodaphnia dubia & 7 dias & Reprodução & 0,0090 & FERRARI et al. (2003) \\
Crustáceo & Ceriodaphnia dubia & 7 dias & Reprodução & 0,1250 & HUGGETT et al (2002) \\
Crustáceo & Ceriodaphnia silvestrii & 7 dias & Reprodução & 1,2500 & Presente estudo \\
Crustáceo & Hyalella azteca & 27 dias & Reprodução & 0,0010 & HUGGETT et al (2002) \\
Embrião de peixe & Danio rerio & 10 dias & Mortalidade & 0,0020 & FERRARI et al. (2003) \\
Peixe & Oryzias latipes & Crescimento & 0,1000 & HUGGETT et al (2002) \\
Peixe & Oryzias latipes & 28 dias & Reprodução & 0,0005 & HUGGETT et al (2002) \\
\hline
\end{tabular}


É importante notar, que dentro da ação de um fármaco, diferentes alvos podem ser afetados alternadamente. Isso conseqüentemente pode gerar efeitos não esperados dentro de uma investigação da ação tóxica destes contaminantes. Exemplos são os efeitos sobre os hormônios sexuais no plasma sanguíneo de peixes e na diminuição da reprodução em $C$. dubia e H. azteca, já mencionados anteriormente, induzida pela ação do betabloqueador propranolol após longa exposição (HUGGETT et al., 2002), e os efeitos sobre os inibidores de reabsorção da serotonina na reprodução dos moluscos (FONG, 1998; FONG et al., 1998). Outro exemplo é quando a solubilidade dos lipídeos modifica algumas propriedades bioquímicas e farmacológicas dos $\beta$-bloqueadores. Este parâmetro influencia na duração do bloqueio dos $\beta$-receptores, na farmacocinética, na difusão através de barreiras biológicas e na concentração no tecido, mas não na $\beta_{1}$-afinidade e seletividade (NAKAMURA, 1999).

À luz das limitações dos ensaios de toxicidade agudos na utilização em avaliação dos riscos ambientais, mais análises de toxicidade devem ser realizadas, levando-se em consideração a vantagem do conhecimento do processo de desenvolvimento das drogas farmacêuticas (por exemplo, mecanismos de ação, comportamento farmacocinético e metabolismo, órgãos alvo e os efeitos secundários em mamíferos).

A classificação ambiental, bem como avaliações do risco de produtos farmacêuticos deveria, devido à sua atividade biológica e contínua liberação para o ambiente, serem baseadas no conhecimento sobre a toxicidade crônica após uma exposição prolongada em baixas concentrações, persistência e bioacumulação e, em menor medida sobre a toxicidade aguda. Além disso, compostos com baixa persistência ainda pode ter potencial de causar efeitos crônicos se continuamente liberados no ambiente (pseudopersistência) (DAUGHTON e TERNES, 1999).

Obviamente, os fármacos não ocorrem no ambiente como contaminantes isolados, mas sim como uma complexa mistura com outros medicamentos e contaminantes, como pesticidas ou produtos químicos industriais. CLEUVERS (2003) mostrou que ácido clofíbrico em combinação com carbamazepina, bem como a combinação do diclofenaco com ibuprofeno, exerceu um efeito tóxico muito maior nos organismos-teste, quando comparados à exposição a cada composto individualmente.

Serão requisitos os ensaios de toxicidade crônicos com algas, dafinídeos e peixes, em vez de apenas ensaios tradicionais de toxicidade aguda, o que caracterizará um importante passo (EMEA, 2005). Além do que, o potencial dos efeitos combinados dos fármacos deve ser abordado. No contexto ecológico, sutis alterações e distúrbios podem ter 
conseqüências negativas para o "fitness" do organismo. Como conseqüência muito mais deve ser conhecido sobre o potencial de efeitos crônicos de produtos farmacêuticos nos ecossistema aquáticos.

\subsubsection{Para populações de Ceriodaphnia silvestrii}

\subsection{Condição do ensaio e critérios de aceitabilidade}

Os "endpoints" toxicológicos populacionais são utilizados para encontrar o nível do contaminante que inibirá o crescimento populacional em comparação a uma população controle. É de suma importância determinar quando as populações controle têm sua taxa de crescimento máxima e testar o efeito destes contaminantes neste ponto (WALTHALL e STARK, 1997).

Umas das preocupações sobre a utilização da taxa intrínseca de aumento natural ( $r$ ) como parâmetro é o tempo máximo no qual um ensaio pode ser realizado. Em estudos toxicológicos usando microcosmos ou sistemas confinados, pode ser possível que espécies com alta taxa reprodutiva alcancem a capacidade suporte do ambiente antes do término do ensaio.

Uma diferença entre estudos ecotoxicológicos baseados na reprodução e populacionais é a quantidade de alimento disponível para o consumo. Estudos baseados em normas padronizadas são conduzidos em condições de alimentos constantes que muitas vezes são excessivamente elevadas (VAN LEEUWEN et al., 1987). Em ensaios com populações, no entanto, os dafinídeos inevitavelmente alcançam condições onde o alimento é um fator limitante, inerente ao crescimento populacional exacerbado em um ambiente limitado. Em um estudo realizado por WIRTZ (1999), verificou-se uma possível influência do estresse alimentar em ensaios populacionais, pelo fato do contaminante reduzir a capacidade suporte nas concentrações mais elevadas.

Experimentos que utilizam tabelas de vida são normalmente realizados em concentrações constantes de alimento que são muitas vezes excessivamente elevados (BUIKEMA et al., 1980).

Estresse alimentar significa que os dafinídeos têm que filtrar mais intensamente para obter alimento suficiente. No decorrer do ensaio, certamente o consumo 'per capita' de alimento irá declinar se o crescimento populacional não for impedido por algum outro fator. Este estresse e elevadas taxas de filtração, as quais são diretamente proporcionais ao 
consumo de energia (KERSTING, 1978), podem resultar assim em menos energia disponível para a reprodução. É esperado que o estresse alimentar seja máximo nas densidades populacionais mais elevadas e que o efeito do contaminante seja máximo nesse momento (KOOIJMAN e METZ, 1984).

ENSERINK et al. (1995) relatou um efeito sinérgico de baixas concentrações de alimento e exposição subletais de chumbo sobre a idade de maturidade de D. magna. Os autores também encontraram que os efeitos do chumbo na alocação de carbono para a reprodução eram ligeiramente superiores nas concentrações maiores de alimento, representando uma resposta a combinação dos níveis de alimento e o estresse causado pelo contaminante.

De acordo com a EPA (2002) um volume de $15 \mathrm{~mL}$ por organismo é adequado para realização de ensaios ecotoxicológicos. Baseado neste critério, o presente trabalho desenvolveu a comparação de ensaios com diferentes volumes com o objetivo de encontrar diferenças no crescimento populacional e assim, evidenciar um volume mais adequado para a realização destes ensaios. Como critério para seleção dos dados a serem utilizados na análise, foram computados os valores (ind. $\mathrm{mL}^{-1}$ ) obtidos até o $11^{0}$ dia, pois até então não houve decréscimo nas populações. Foi evidenciado que não há diferença estatística significativa entre os dois volumes, então, optou-se pela utilização de $75 \mathrm{~mL}$ para a realização dos experimentos.

Qualquer fator, seja limitante ou favorável para uma população, é independente ou dependente da densidade. A ação dependente da densidade é igualmente direta no sentido que se intensifica à medida que se aproxima a capacidade suporte do ambiente, sendo assim considerada como um dos principais agentes de controle de uma superpopulação e pela manutenção de um estado de equilíbrio (ODUM, 2001). Sendo assim, em ensaios ecotoxicológicos com abordagens populacionais, a rm declinará quando houver um aumento demasiado da população, afetando a avaliação do "endpoint" neste tipo de estudo toxicológico.

Este problema pode ser resolvido pela diminuição da duração do ensaio no qual a rm é maximizada nas populações controle. A duração e o número de organismos iniciais para os ensaios neste trabalho, ou seja, as condições do teste foram avaliadas através do acompanhamento do crescimento da população-controle em condições ótimas. Deste modo, adotou-se o sétimo dia que foi suficiente para fornecer um crescimento populacional satisfatório livre de interferências, além de permitir que os dados obtidos fossem comparados com os resultados de testes crônicos individuais. 
Um método para determinar o tempo mínimo de um ensaio foi sugerido por DANIELS e ALLAN (1981), que utilizaram análise de regressão para determinar o tempo necessário para gerar homogeneidade nas taxas diárias de crescimento e a taxa intrínseca de aumento natural final. Sua análise sugeriu que valores de $r m$ para populações de $D$. pulex expostas ao pesticida dieldrin para 21 dias apresentou a mesma taxa de crescimento de populações expostas ao longo de tabelas de vida de 55 dias.

A partir dos resultados obtidos para condição do teste foram adotados como critérios de aceitabilidade para o controle nos ensaios populacionais, com base na EPA (2002), os seguintes critérios de desempenho para os testes populacionais com C. silvestrii; números de neonatas produzidas de 73 organismos com desvio-padrão de \pm 10 e uma taxa intrínseca de aumento natural de 0,596 e desvio padrão de $\pm 0,13$, em sete dias de experimento.

No presente estudo, optou-se pela utilização da água natural reconstituída para a realização dos testes populacionais, a partir dos resultados obtidos em ensaios agudos comparativos para os diferentes meios. A ABNT (2005) não recomenda um meio para ensaios ecotoxicológicos para substâncias químicas, porém, segundo o "guideline" 211 da OECD (1998), é recomendado o uso de um meio definido e caso o meio inclua aditivos não conhecidos, estes aditivos devem ser especificados claramente e a informação deve ser fornecida no relatório do ensaio, particularmente no que diz respeito ao teor de carbono, já que este pode contribuir como alimento. Em testes preliminares, observou-se que a sobrevivência dos organismos-teste em água destilada reconstituída por longo período de tempo era prejudicada, justificando mais uma vez, a necessidade de se utilizar a água natural reconstituída como meio dos ensaios populacionais. Segundo a EPA (1996), água de superfície ou água reconstituída são aceitáveis como água de diluição se os dafinídeos sobreviverem na duração do cultivo, aclimatação e no período do teste sem mostrar sinais de estresse.

\subsection{Taxa intrínseca de aumento natural $(r)$}

A demografia em Ecotoxicologia tem sido cada vez mais usada em avaliações de toxicidade (VAN STRAALEN e KAMMENGA, 1998; FORBES e CALOW, 1999; KAMMENGA e LASKOWSKI, 2000). Pelo fato dos estudos demográficos levarem em conta efeitos letais e subletais que um tóxico possa ter em uma população, uma completa medida do efeito de um contaminante pode ser obtida. Parâmetros de toxicidade em nível 
de população combinam efeitos letais e subletais, sendo assim, permitem que o efeito tóxico total de um contaminante possa ser avaliado (STARK e BANKS, 2000).

FORBES \& CALOW (1999) chegaram à conclusão que a taxa intrínseca de aumento natural apresenta uma melhor resposta ao contaminante que medidas realizadas em nível individual porque integra vários fatores críticos de uma resposta populacional em uma única variável (VAN LEEUWEN et al., 1985) ao longo do ciclo de vida e fornece uma medida mais relevante de impacto ecológico. Na maioria dos casos analisados por estes autores, o crescimento populacional foi igualmente ou mais sensível à exposição ao contaminante.

Segundo SOUTHWOOD (1968), para o crescimento potencial de uma população, em determinadas condições, esta taxa seria a melhor descrição possível.

Existem vantagens inerentes importantes em usar parâmetros demográficos toxicológicos do que tradicionais estimativas de concentrações letais. Resultados de vários estudos têm indicado que efeitos subletais podem ser sutis e afetam populações em concentrações mais baixas do que curvas tradicionais de dose-resposta (STARK e BANKS, 2003).

WALTON et al. (1981) estudou o efeito da água ácida em populações de $D$. pulex. Os autores concluíram que ensaios de toxicidade aguda de 96-h não detectaram efeito da água acidificada, mas os efeitos negativos foram facilmente discernidos utilizando uma avaliação da taxa intrínseca de crescimento. BECHMANN (1994) descobriu que algumas substâncias tóxicas podem afetar os parâmetros demográficos bem abaixo da tradicional curva de concentração-resposta, resultando em um declínio populacional e extinção em níveis anteriormente assumidos sem efeito, baseados em parâmetros individuais.

No presente estudo os valores obtidos para CENO (Concentração de Efeito não Observado) e CEO (Concentração de Efeito Observado) populacional para $C$. silvestrii foi de 0,275 e $0,723 \mathrm{~g}$. $\mathrm{L}^{-1}$ de cloreto de sódio, respectivamente. Estes valores são ligeiramente maiores que os de CASTILHO (2005) que encontrou um CENO e CEO de 0,1 e 0,25 g. L ${ }^{-1}$ de cloreto de sódio, respectivamente.

Esta mesma diferença pode ser explicada pelo fato de ter sido observado um aumento na reprodução nas populações em baixas concentrações de cloreto de sódio. Ao contrario dos ensaios crônicos individuais realizados por CASTILHO (2005), pequenas concentrações desta substância parece estimular a reprodução em populações. 
Segundo (STARK e BANKS, 2003) um fenômeno que pode ocorrer em populações estressadas é o aumento na reprodução. Compensação populacional é o processo pelo qual o potencial reprodutivo dos indivíduos sobreviventes em uma população aumenta porque há menos concorrência por recursos (STARK et al., 1997). NICHOLSON (1954) já havia constatado uma redução de $25 \%$ da sobrevivência não produziram efeitos em longo prazo em populações de moscas de ovelhas, Lucilia cuprina.

Variações na reprodução são comuns na biologia reprodutiva dos animais vertebrados para compensar a perda de prole (AMAT et al., 1999; WILLIAMS, 1999; PARKER, 1985). No entanto STEPHENSON et al. (1991) não encontrou evidência que a reprodução compensatória contrabalanceou o atraso na reprodução em organismos dafinídeos expostos ao pentaclorofenol, ao contrário de RAIMONDO e MCKENNEY (2005), que observaram a ocorrência deste mecanismo na exposição de A. bahia ao efeito subletal de alguns contaminantes em laboratório.

Outro estudo demográfico toxicológico dos efeitos do inseticida imidacloprid sobre o pulgão da ervilha, Acyrthosiphon Pisum (Harris), indicou que pulgões poderiam manter elevados índices de crescimento populacional, mesmo quando expostos a uma CL60 aguda (WALTHALL \& STARK, 1997).

Deste modo, a complexidade evidente nos resultados do presente estudo em nível populacional é um indicador da importância de ampliar nossas perspectivas sobre os usos e as interpretações dos diferentes parâmetros toxicológicos.

Os ensaios crônicos individuais tiveram uma sensibilidade semelhante aos ensaios populacionais. Tanto nos ensaios crônicos populacionais quanto nos individuais, na maioria dos testes, o CENO e o CEO tiveram o valor de 1,25 e 2,5 mg. $\mathrm{L}^{-1}$, respectivamente. Assim, como em um estudo desenvolvido por FORBES e CALOW (1999), as análises indicaram que os ensaios populacionais, em geral, foram igualmente ou mais sensíveis aos efeitos tóxicos do contaminante do que a exposição individual. No entanto, pelo fato da taxa intrínseca aumento natural integrar respostas ao contaminante em nível populacional, ela é um melhor "endpoint" ecotoxicológico para as respostas populacionais que qualquer único "endpoint” em nível individual.

Para o propranolol, ao contrário do cloreto de sódio, não houve um mecanismo de compensação reprodutiva acentuada. Isto pode ocorrer pelo fato dos diferentes modos de ação dos contaminantes. O cloreto de sódio pode causar seu efeito tóxico no desequilíbrio da ormorregulação, principalmente quando os organismos sofrem mudas, o que torna as espécies mais vulneráveis, e que, conseqüentemente, prejudica a sobrevivência e 
reprodução (UTZ, 1994). Ao contrário, como descrito no item 9.1.2, o propranolol parece agir sobre a frequiência cardíaca, mas seu efeito tóxico não é bem conhecido para os dafinídeos.

A grande desvantagem para o uso de parâmetros demográficos na Ecotoxicologia é que o desenvolvimento de dados de tabelas de vida é caro e demorado. Além disso, existem limitações para as espécies que possuem um longo ciclo de vida, tempo de maturação sexual e gestação e baixo número de descendentes. Por esta razão, muitos estudos toxicológicos demográficos são feitos com invertebrados e restringem-se a avaliação de alguns ou um parâmetro populacional que contemple o máximo de atributos de uma população, como é o caso da taxa intrínseca de aumento natural (STARK e BANKS, 2003).

Taxas de crescimento populacionais obtidos em laboratório não refletem as condições de vida em estado selvagem: dependência da densidade, competição, imigração, emigração, predação, e/ou parasitismo normalmente não são medidos em experimentos de tabelas de vida. No entanto, vários autores como GRANT (1998) e SIBLY (2000) têm agora considerado a densidade-dependência no contexto desses experimentos.

Um problema com resultados obtidos em tabela vida é que os organismos testes são expostos continuamente às concentrações do contaminante quando na verdade muitos deles podem degradar no ambiente (WILLIS \& MCDOWELL, 1987).

BIRCH (1948) demonstrou a importância do tempo na primeira reprodução na estimativa de parâmetros populacionais. Para populações de dafinídeos com muitas sobreposições de gerações, $r$ será determinado principalmente pelo número de jovens produzidos por postura e a frequiência das primeiras posturas enquanto os descendentes produzidos tardiamente irão contribuir relativamente pouco para a $r$. Apenas os contaminantes que causam a diminuição no número e tamanho dos dafinídeos nas primeiras posturas irão causar uma diminuição significativa do $r$. No presente estudo esta diferença pode ser observada para o propranolol e $\mathrm{NaCl}$.

STARK et al. (2004) demonstrou a importância da estratégia da historia de vida na avaliação de risco com populações. Ele observou que atrasos na reprodução de organismos semélparos tiveram um efeito populacional maior que os observados no trabalho desenvolvido por RAIMONDO e MCKENNEY (2005).

A reprodução das espécies é dependente das condições ambientais (SASTRY, 1983), e qualquer atraso no início da reprodução pode potencialmente resultar numa 
redução reprodutiva total quando as condições ambientais se tornam desfavoráveis ou recursos se tornam limitados.

DAY e KAUSHIK (1987) estudaram o efeito do agrotóxico fenvalerate em populações de D. galeata e observaram que o valor de $r$ foi reduzido em concentrações que o agrotóxico diminuiu significativamente o número médio de jovens produzidos nas primeiras posturas. Resultado semelhante foi encontrado por DANIELS \& ALLAN (1987) que observaram que populações de Daphnia pulex expostas a concentrações crescentes de dieldrin tiveram uma pequena diminuição no $r$ nas concentrações em que o contaminante afetou a reprodução inicial dos ensaios.

Em concentrações subletais no qual a reprodução é significamente reduzida, demonstra-se que mesmo quando a sobrevivência não é afetada, efeitos reprodutivos isolados podem resultar em taxas de multiplicação populacionais significativamente menores. Esse fenômeno pode colocar a população em risco, seja pelo aumento de pressões biológicas ou tornando-a mais suscetível a aleatoriedade ambiental (RAIMONDO e MCKENNEY, 2005).

Análises de tabelas de vida podem fornecer importantes descobertas sobre os mecanismos e conseqüências em nível populacional da exposição a um contaminante e pode ser usado para gerar hipóteses para explicar porque algumas espécies são dominantes em certas áreas poluídas enquanto outras desaparecem nos estágios iniciais ou baixos graus de exposição ao tóxico (GRAY, 1979).

Para se compreender a importância ecológica da redução da taxa de crescimento populacional, a história de vida das espécies e a dinâmica natural delas devem ser incorporadas na avaliação de riscos. Espécies K-estrategista geralmente possuem baixas taxas de crescimento populacionais em relação a espécies r-estrategista, e uma diminuição em $10 \%$ na sua taxa de crescimento pode ter mais efeitos negativos para sua sustentabilidade populacional (STARK et al., 2004). Alternativamente, espécies estrategistas $r$ habitam ambientes mais susceptíveis a efeitos estocásticos (SMITH, 1996), o que pode aumentar o risco de declínio da população (HAKOYAMA, 2000). Modelos baseados em ensaios laboratoriais são úteis para isolar os efeitos do contaminante sobre a taxa de multiplicação populacional, mas a relação das espécies-teste em seu ambiente natural, a história de vida e a dinâmica populacional é essencial para a avaliação de riscos ecológicos RAIMONDO e MCKENNEY (2005).

NEWMAN et al. (2000) observou que muitas medidas feitas em nível de organismo têm deficiências significativas como medidas de efeitos sobre populações e 
métodos baseados em extrapolações destes efeitos acabam por compartilhar suas deficiências.

Em outra abordagem, quanto à análise dos resultados dos ensaios ecotoxicológicos populacionais, foi avaliada a diferença entre a sensibilidade da concentração de efeito não observado (CENO) e concentração de efeito observado (CEO) e a concentração de inibição percentual (ICp). MARKLE et al. (2000) avaliaram a toxicidade de efluentes para $R$. subcapitata através de duas metodologias estatísticas. Foi analisado os resultados dos testes utilizando CENO e CEO e a concentração de inibição percentual (ICp), também conhecida como concentração efetiva da amostra (CE) que pode inibir o crescimento dos organismos em diferentes porcentagens. Os autores concluíram que ICp (através do cálculo da IC25 em testes crônicos utilizando $R$. subcapitata) se apresenta como uma ferramenta muito melhor para avaliar a sensibilidade de espécies quando comparada aos resultados obtidos em testes utilizando como resposta valores de CENO e CEO. A mesma conclusão foi obtida por RODRIGUES et al. (2003) que observou o ICp como um excelente descritor de impacto que compostos tóxicos podem ter numa população algal.

O presente estudo também encontrou uma maior sensibilidade em medições do ICp em resposta ao efeito do contaminante propranolol em populações de C.silvestrii, parecendo assim, ser uma análise mais sensível do efeito deste contaminante sobre uma população de dafinídeos, quando comparados a aos valores de CENO e CEO. Além disto, o IC50 médio populacional foi mais sensível que o encontrado para os ensaios crônicos individuais. O IC50 médio populacional foi de 1,65 enquanto que o IC50 médio individual foi de 2,35 .

Em relação à toxicidade aguda, STARK et al. (2004) demonstrou que é difícil extrapolar resultados individuais de CL50 para outro tipo de estudo laboratorial, como o de crescimento populacional. ROEX et al. (2000) comparou a toxicidade aguda CL50 e a menor concentração de efeito observado para a taxa intrínseca de crescimento para algumas espécies. Este autor concluiu que estudos agudos com invertebrados podem fornecer uma boa indicação dos efeitos em nível populacional, porém grandes diferenças entre as taxas nos diferentes testes existem.

Um paradigma moderno da ecotoxicologia é que efeitos em nível de organismo medidos por normas de toxicidade são destinados em predizer efeitos em níveis populacionais, os quais são realizados com precisão e exatidão ambígua (NEWMAN, 2001.). Segundo o autor, os ecotoxicologistas devem manter a qualidade dos dados em 
nível de organismo a ser utilizado numa perspectiva hierarquizada e integrar os dois níveis da organização biológica para uma avaliação concreta dos efeitos ecológicos.

Diferentes procedimentos para a avaliação da toxicidade, tais como o demográfico seguido de modelagem populacional (BARNTHOUSE, 2004), podem nos fornecer melhores ferramentas para predizer o impacto que os contaminantes devem ter nos ecossistemas. Embora uma estimativa da concentração letal tenha seu lugar na Ecotoxicologia, na comparação da toxicidade de produtos químicos entre espécies ou susceptibilidade de uma espécie entre diferentes produtos químicos em curtos períodos de tempo, o crescimento populacional e estudos de taxas de crescimento são necessários para prever o efeito dos contaminantes em populações. 


\section{Conclusões}

- $\quad$ Na avaliação da toxicidade aguda de $C$. silvestrii a CE(I)50;48H de propranolol foi de 2,87 e 2,63 mg. $\mathrm{L}^{-1}$ para água destilada reconstituída e 2,63 mg. $\mathrm{L}^{-1}$ para natural reconstituída não havendo diferenças estatisticamente significativas.

- $\quad$ O valor de CENO (Concentração de Efeito Não Observado) e CEO (Concentração de Efeito Observado) para ensaios crônicos individuais de $C$. silvestrii foram de 1,25 e 2,5 mg. $\mathrm{L}^{-1}$ de propranolol, respectivamente.

- Como critérios de aceitabilidade do controle em testes crônicos populacionais com C. silvestrii ficam estabelecidos como aceitáveis o valor da reprodução de $73( \pm 7)$ neonatas e a taxa intrínseca de aumento natural $(r)$ de $0,596( \pm 0,065)$ em sete dias de experimento.

- Os coeficientes de variação da reprodução para as réplicas no controle (4\%), bem como dos controles $(8 \%)$ dos ensaios $(n=3)$, encontram-se dentro da precisão analítica esperada e asseguram a validação da metodologia adotada na avaliação da toxicidade crônica para populações de $C$. silvestrii.

- $\quad$ O coeficiente de variação $(11 \%)$ da taxa intrínseca de aumento natural $(r)$ dos controles dos ensaios $(n=3)$ encontra-se dentro da precisão analítica esperada e assegura a validação da metodologia adotada na avaliação da toxicidade crônica para populações de C. silvestrii.

- $\quad$ A sensibilidade (CEOp) das populações de $C$. silvestrii para cloreto de sódio foi de 0,723 g.L $\mathrm{L}^{-1}$ de $\mathrm{NaCl}$.

- A toxicidade crônica de propranolol para populações de C. silvestrii esteve compreendida na faixa de 0,62-1,25 (CENO) e 1,25-2,5 mg.L $\mathrm{L}^{-1}$ (CEO), respectivamente.

- A toxicidade de propranolol para populações (IC50 de 1,65 mg.L $\mathrm{L}^{-1}$ ) é maior quando comparada à toxicidade para indivíduos (IC50 de 2,35 mg. $\mathrm{L}^{-1}$ ) de C. silvestrii.

- $\quad$ O IC50 populacional $\left(1,65 \mathrm{mg} . \mathrm{L}^{-1}\right)$ foi $70 \%$ menor que IC50 individual $\left(2,35 \mathrm{mg} . \mathrm{L}^{-}\right.$ ${ }^{1}$ ) demonstrando ser uma medida mais sensível de efeito. 
- A taxa intrínseca de aumento natural $(r)$ constitui-se em uma melhor ferramenta na avaliação da toxicidade de contaminantes para $C$. silvestrii, pois integra vários parâmetros biológicos em uma única variável. 
Apêndice 1

Planilhas dos testes de toxicidade aguda do propranolol para C. silvestrii 


\section{ipen}

LABORATÓRIO DE ECOTOXICOLOGIA

Teste de avaliação da toxicidade aguda para Ceriodaphnia silvestrii

\begin{tabular}{|c|c|c|c|c|c|c|c|}
\hline \multicolumn{2}{|l|}{ Início do teste: $15 / 06$} & \multicolumn{3}{|c|}{ Final do teste: $17 / 06$} \\
\hline Lote & $\mathrm{pH}$ & $\mathrm{OD}\left(\mathrm{mg} \mathrm{L}^{-1}\right)$ & Cond. $\left(\mu \mathrm{sm}^{-1}\right)$ & Origem & Tipos & Lote & \multirow{2}{*}{ Responsável } \\
\hline HDR & 7.04 & 7.7 & 139.2 & Produto & Propranolol & & Gustavo \\
\hline
\end{tabular}

\begin{tabular}{|c|c|c|c|c|c|c|c|c|c|c|c|c|c|c|c|c|c|c|}
\hline \multirow{3}{*}{$\begin{array}{c}\text { Concentração } \\
(\mathrm{mgl})\end{array}$} & \multicolumn{12}{|c|}{ Número de indivíduos imóveis/tubo } & \multirow{2}{*}{\multicolumn{2}{|c|}{$\mathrm{pH}$}} & \multirow{2}{*}{\multicolumn{2}{|c|}{$\begin{array}{l}\text { Cond. } \\
(\mu \mathrm{S} / \mathrm{cm})\end{array}$}} & \multirow{2}{*}{\multicolumn{2}{|c|}{$\mathrm{OD}(\mathrm{mg} / \mathrm{L})$}} \\
\hline & \multicolumn{6}{|c|}{24 horas } & \multicolumn{6}{|c|}{48 horas } & & & & & & \\
\hline & 1 & 2 & 3 & 4 & total & $\%$ & 1 & 2 & 3 & 4 & total & $\%$ & ini & fin & ini & fin & ini & fin \\
\hline Controle & & & & & & & 1 & 0 & 0 & 0 & 1 & 5 & 7.04 & 7.16 & 139.2 & 141.6 & 7.7 & 7.9 \\
\hline $\begin{array}{ll}\text { A. } & 0,62 \\
\end{array}$ & & & & & & & 1 & 0 & 0 & 0 & 1 & 5 & 7.01 & 7.2 & 138.0 & 141.8 & 7.7 & 7.9 \\
\hline B. 1,25 & & & & & & & 1 & 2 & 1 & 1 & 5 & 25 & 7.01 & 7.34 & 138.5 & 139.2 & 7.4 & 7.5 \\
\hline C. 2,5 & & & & & & & 2 & 1 & 3 & 3 & 9 & 45 & 7.05 & 7.26 & 138.8 & 138.5 & 7.4 & 7.8 \\
\hline D. 5 & & & & & & & 4 & 2 & 3 & 2 & 11 & 55 & 7.02 & 7.29 & 139 & 138.9 & 7.5 & 7.8 \\
\hline E. 10 & & & & & & & 5 & 5 & 5 & 5 & 20 & 100 & 7.02 & 7.22 & 138.2 & 139.2 & 7.5 & 7.7 \\
\hline Resultados & \multicolumn{6}{|c|}{$\mathrm{EC}(\mathrm{I}) 50 ; 24 \mathrm{H}:$} & \multicolumn{6}{|c|}{ EC(I)50;48H: $2.98(2.23-3.97)$} & \multicolumn{6}{|c|}{ Método estatístico utilizado: Spearman } \\
\hline
\end{tabular}

OBSERVAÇÕES: 


\section{ipen}

Teste de avaliação da toxicidade aguda para Ceriodaphnia silvestrii

\begin{tabular}{|c|c|c|c|c|c|c|c|}
\hline \multicolumn{4}{|c|}{ Início do teste: $15 / 06$} & \multicolumn{4}{|c|}{ Final do teste: $17 / 06$} \\
\hline \multicolumn{4}{|c|}{ Água de cultivo e/ou de diluição } & \multicolumn{3}{|c|}{ Amostra } & \multirow{2}{*}{ Responsável } \\
\hline Lote & $\mathrm{pH}$ & $\mathrm{OD}\left(\mathrm{mg} \mathrm{L}^{-1}\right)$ & Cond. $\left(\mathrm{uS} \mathrm{cm}^{-1}\right)$ & Origem & Tipo & Lote & \\
\hline$\overline{\mathrm{HDR}}$ & 7.05 & 7.6 & 138.7 & Produto & Propranolol & & Gustavo \\
\hline
\end{tabular}

\begin{tabular}{|c|c|c|c|c|c|c|c|c|c|c|c|c|c|c|c|c|c|c|}
\hline \multirow{3}{*}{$\begin{array}{l}\text { Concentração } \\
(\mathrm{mglL})\end{array}$} & \multicolumn{12}{|c|}{ Número de indivíduos imóveis/tubo } & \multirow{2}{*}{\multicolumn{2}{|c|}{$\mathrm{pH}$}} & \multirow{2}{*}{\multicolumn{2}{|c|}{$\begin{array}{l}\text { Cond. } \\
(\mu \mathrm{S} / \mathrm{cm})\end{array}$}} & \multirow{2}{*}{\multicolumn{2}{|c|}{$\mathrm{OD}(\mathrm{mg} / \mathrm{L})$}} \\
\hline & \multicolumn{6}{|c|}{24 horas } & \multicolumn{6}{|c|}{48 horas } & & & & & & \\
\hline & 1 & 2 & 3 & 4 & total & $\%$ & 1 & 2 & 3 & 4 & total & $\%$ & ini & fin & ini & fin & ini & fin \\
\hline Controle & & & & & & & 1 & 0 & 0 & 0 & 1 & 5 & 7.05 & 7.44 & 138.7 & 140.2 & 7.6 & 8.7 \\
\hline $\begin{array}{ll}\text { A. } & 0,62 \\
\end{array}$ & & & & & & & 1 & 0 & 0 & 0 & 1 & 5 & 7.01 & 7.38 & 137.8 & 141 & 7.7 & 8.4 \\
\hline B. 1,25 & & & & & & & 1 & 2 & 1 & 1 & 5 & 25 & 7.04 & 7.56 & 137.4 & 142.5 & 7.8 & 8.4 \\
\hline 2,5 & & & & & & & 2 & 2 & 1 & 2 & 7 & 35 & 7.07 & 7.29 & 141.9 & 140.2 & 7.7 & 7.6 \\
\hline 5 & & & & & & & 5 & 2 & 3 & 4 & 14 & 70 & 6.98 & 7.39 & 139.6 & 142.8 & 7.6 & 7.8 \\
\hline 10 & & & & & & & 5 & 5 & 5 & 5 & 20 & 100 & 7.1 & 7.18 & 139.2 & 139.9 & 7.5 & 7.8 \\
\hline Resultados & \multicolumn{6}{|c|}{$\mathrm{EC}(\mathrm{I}) 50 ; 24 \mathrm{H}:$} & \multicolumn{6}{|c|}{$\mathrm{EC}(\mathrm{I}) 50 ; 48 \mathrm{H}: 2.87(2.18-3.77)$} & \multicolumn{6}{|c|}{ Método estatístico utilizado: Spearman } \\
\hline
\end{tabular}

OBSERVAÇÕES: 


\section{ipen}

LABORATÓRIO DE ECOTOXICOLOGIA

Teste de avaliação da toxicidade aguda para Ceriodaphnia silvestrii

\begin{tabular}{|c|c|c|c|c|c|c|c|}
\hline \multicolumn{4}{|c|}{ Início do teste: $28 / 06$} & \multicolumn{4}{|c|}{ Final do teste: $30 / 06$} \\
\hline \multicolumn{4}{|c|}{ Água de cultivo e/ou de diluição } & \multicolumn{3}{|c|}{ Amostra } & \multirow{2}{*}{ Responsáve } \\
\hline Lote & $\mathrm{pH}$ & $\mathrm{OD}\left(\mathrm{mg} \mathrm{L}^{-1}\right)$ & Cond. $\left(\mu \mathrm{S} \mathrm{cm}^{-1}\right)$ & Origem & Tipo & Lote & \\
\hline HDR & 7.02 & 7.5 & 139.0 & Produto & Propranolol & & Gustavo \\
\hline
\end{tabular}

\begin{tabular}{|c|c|c|c|c|c|c|c|c|c|c|c|c|c|c|c|c|c|c|}
\hline \multirow{3}{*}{$\begin{array}{l}\text { Concentração } \\
\quad(\mathrm{mglL})\end{array}$} & \multicolumn{12}{|c|}{ Número de indivíduos imóveis/tubo } & \multirow{2}{*}{\multicolumn{2}{|c|}{$\mathrm{pH}$}} & \multirow{2}{*}{\multicolumn{2}{|c|}{$\begin{array}{l}\text { Cond. } \\
(\mu \mathrm{s} / \mathrm{cm})\end{array}$}} & \multirow{2}{*}{\multicolumn{2}{|c|}{$\mathrm{OD}(\mathrm{mg} / \mathrm{L})$}} \\
\hline & \multicolumn{6}{|c|}{24 horas } & \multicolumn{6}{|c|}{48 horas } & & & & & & \\
\hline & 1 & 2 & 3 & 4 & total & $\%$ & 1 & 2 & 3 & 4 & total & $\%$ & ini & fin & ini & fin & ini & fin \\
\hline Controle & & & & & & & 0 & 1 & 0 & 0 & 1 & 5 & 7.02 & 7.36 & 7.5 & 7.9 & 139.0 & 142.0 \\
\hline A. 0,62 & & & & & & & 0 & 0 & 0 & 0 & 0 & 0 & 7.04 & 7.3 & 7.5 & 7.8 & 138.6 & 141.2 \\
\hline B. 1,25 & & & & & & & 1 & 1 & 1 & 0 & 3 & 15 & 7.02 & 7.28 & 7.6 & 7.8 & 138.9 & 141.0 \\
\hline C. 2,5 & & & & & & & 3 & 1 & 2 & 2 & 8 & 40 & 7.04 & 7.35 & 7.5 & 8.0 & 137.3 & 142.5 \\
\hline D. 5 & & & & & & & 3 & 4 & 5 & 4 & 16 & 80 & 7.04 & 7.16 & 7.6 & 7.7 & 139.9 & 140.8 \\
\hline E. 10 & & & & & & & 5 & 5 & 5 & 5 & 20 & 100 & 6.97 & 7.4 & 7.4 & 7.4 & 140.2 & 141.9 \\
\hline Resultados & \multicolumn{6}{|c|}{$\mathrm{EC}(\mathrm{I}) 50 ; 24 \mathrm{H}:$} & \multicolumn{6}{|c|}{ EC(I)50;48H: $2.77(2.21-3.47)$} & \multicolumn{6}{|c|}{ Método estatístico utilizado: Spearman } \\
\hline
\end{tabular}

OBSERVAÇÕES: 
LABORATÓRIO DE ECOTOXICOLOGIA

Teste de avaliação da toxicidade aguda para Ceriodaphnia silvestrii

\begin{tabular}{|c|c|c|c|c|c|c|c|}
\hline \multicolumn{4}{|c|}{ Início do teste: $12 / 06$} & \multicolumn{4}{|c|}{ Final do teste: $14 / 06$} \\
\hline \multicolumn{4}{|c|}{ Água de cultivo e/ou de diluição } & \multicolumn{3}{|c|}{ Amostra } & \multirow{2}{*}{ Responsáve } \\
\hline Lote & $\mathrm{pH}$ & $\mathrm{OD}\left(\mathrm{mg} \mathrm{L}^{-1}\right)$ & Cond. $\left(\mu \mathrm{S} \mathrm{cm}^{-1}\right)$ & Origem & Tipo & Lote & \\
\hline $\begin{array}{c}\text { Água natural } \\
\text { L-25 }\end{array}$ & 7.01 & 8.0 & 138.9 & Produto & Propranolol & & Gustavo \\
\hline
\end{tabular}

\begin{tabular}{|c|c|c|c|c|c|c|c|c|c|c|c|c|c|c|c|c|c|c|}
\hline \multirow{3}{*}{$\begin{array}{l}\text { Concentração } \\
\text { (mglL) }\end{array}$} & \multicolumn{12}{|c|}{ Número de indivíduos imóveis/tubo } & \multirow{2}{*}{\multicolumn{2}{|c|}{$\mathrm{pH}$}} & \multirow{2}{*}{\multicolumn{2}{|c|}{$\begin{array}{l}\text { Cond. } \\
(\mu \mathrm{S} / \mathrm{cm})\end{array}$}} & \multirow{2}{*}{\multicolumn{2}{|c|}{$\mathrm{OD}(\mathrm{mg} / \mathrm{L})$}} \\
\hline & \multicolumn{6}{|c|}{24 horas } & \multicolumn{6}{|c|}{48 horas } & & & & & & \\
\hline & 1 & 2 & 3 & 4 & total & $\%$ & 1 & 2 & 3 & 4 & total & $\%$ & ini & fin & ini & fin & ini & fin \\
\hline Controle & & & & & & & 0 & 0 & 0 & 1 & 1 & 5 & 7.01 & 7.32 & 138.9 & 141.0 & 8.0 & 8.2 \\
\hline A. 0,62 & & & & & & & 1 & 0 & 0 & 0 & 1 & 5 & 7.01 & 7.38 & 139.1 & 139.3 & 7.8 & 8.6 \\
\hline B. 1,25 & & & & & & & 1 & 0 & 0 & 1 & 2 & 10 & 7.04 & 7.24 & 138.4 & 138.7 & 7.8 & 8.6 \\
\hline 2,5 & & & & & & & 1 & 2 & 1 & 2 & 6 & 30 & 7.02 & 7.45 & 135.5 & 139.9 & 7.8 & 7.9 \\
\hline D. 5 & & & & & & & 4 & 5 & 4 & 4 & 17 & 85 & 7.07 & 7.3 & 138.4 & 140.2 & 7.9 & 7.7 \\
\hline \multirow[t]{2}{*}{ E. 10} & & & & & & & 5 & 5 & 5 & 5 & 20 & 100 & 7.03 & 7.21 & 139.9 & 140.5 & 8.0 & 7.9 \\
\hline & & & & & & & & & & & & & & & & & & \\
\hline Resultados & \multicolumn{6}{|c|}{$\mathrm{EC}(\mathrm{I}) 50 ; 24 \mathrm{H}:$} & \multicolumn{6}{|c|}{$\mathrm{EC}(\mathrm{I}) 50 ; 48 \mathrm{H}: 2.99(2.39-3.75)$} & \multicolumn{6}{|c|}{ Método estatístico utilizado: Spearman } \\
\hline
\end{tabular}

OBSERVAÇÕES: 


\section{ipen}

LABORATÓRIO DE ECOTOXICOLOGIA

Teste de avaliação da toxicidade aguda para Ceriodaphnia silvestrii

\begin{tabular}{|c|c|c|c|c|c|c|c|}
\hline \multicolumn{4}{|c|}{ Início do teste: 20/06 } & \multicolumn{4}{|c|}{ Final do teste: $22 / 06$} \\
\hline \multicolumn{4}{|c|}{ Água de cultivo e/ou de diluição } & \multicolumn{3}{|c|}{ Amostra } & \multirow{2}{*}{ Responsável } \\
\hline Lote & $\mathrm{pH}$ & $\mathrm{OD}\left(\mathrm{mg} \mathrm{L}^{-1}\right)$ & Cond. $\left(\mu \mathrm{S} \mathrm{cm}^{-1}\right)$ & Origem & Tipo & Lote & \\
\hline $\begin{array}{c}\text { Água natural } \\
\text { L-25 }\end{array}$ & 7,00 & 7,6 & 138.0 & Produto & Propranolol & & Gustavo \\
\hline
\end{tabular}

\begin{tabular}{|c|c|c|c|c|c|c|c|c|c|c|c|c|c|c|c|c|c|c|}
\hline \multirow{3}{*}{$\begin{array}{c}\text { Concentração } \\
(\mathrm{mglL})\end{array}$} & \multicolumn{12}{|c|}{ Número de indivíduos imóveis/tubo } & \multirow{2}{*}{\multicolumn{2}{|c|}{$\mathrm{pH}$}} & \multirow{2}{*}{\multicolumn{2}{|c|}{$\begin{array}{l}\text { Cond. } \\
(\mu \mathrm{S} / \mathrm{cm})\end{array}$}} & \multirow{2}{*}{\multicolumn{2}{|c|}{$\mathrm{OD}(\mathrm{mg} / \mathrm{L})$}} \\
\hline & \multicolumn{6}{|c|}{24 horas } & \multicolumn{6}{|c|}{48 horas } & & & & & & \\
\hline & 1 & 2 & 3 & 4 & total & $\%$ & 1 & 2 & 3 & 4 & total & $\%$ & ini & fin & Ini & fin & ini & fin \\
\hline Controle & & & & & & & 0 & 1 & 0 & & 1 & 5 & 7.00 & 7.15 & 138.0 & 139.0 & 7.6 & 7.7 \\
\hline A. $\quad 0,62$ & & & & & & & 0 & 0 & 1 & & 1 & 5 & 7.02 & 7.23 & 139.0 & 138.6 & 7.5 & 7.8 \\
\hline B. 1,25 & & & & & & & 1 & 1 & 0 & & 2 & 10 & 7.02 & 7.2 & 138.4 & 140.5 & 7.6 & 7.7 \\
\hline C. 2,5 & & & & & & & 2 & 3 & 1 & & 6 & 30 & 7.06 & 7.42 & 141.1 & 140.2 & 7.7 & 7.3 \\
\hline D. 5 & & & & & & & 4 & 5 & 4 & & 14 & 85 & 7.03 & 7.31 & 139.3 & 139.7 & 7.3 & 8.1 \\
\hline $\begin{array}{ll}\text { E. } & 10 \\
\end{array}$ & & & & & & & 5 & 5 & 5 & & 15 & 100 & 7.01 & 7.25 & 139 & 137.8 & 7.5 & 8.0 \\
\hline Resultados & \multicolumn{6}{|c|}{$\mathrm{EC}(\mathrm{I}) 50 ; 24 \mathrm{H}:$} & \multicolumn{6}{|c|}{$\mathrm{EC}(\mathrm{I}) 50 ; 48 \mathrm{H}: 2.57(1.98-3.32)$} & \multicolumn{6}{|c|}{ Método estatístico utilizado: Spearman } \\
\hline
\end{tabular}

OBSERVAÇÕES: 
LABORATÓRIO DE ECOTOXICOLOGIA

Teste de avaliação da toxicidade aguda para Ceriodaphnia silvestrii

\begin{tabular}{|c|c|c|c|c|c|c|c|}
\hline \multicolumn{9}{|l|}{ Início do teste: 28/06 } & \multicolumn{3}{|c|}{ Final do teste: 30/06 } & Amostra \\
\hline Lote & $\mathrm{pH}$ & $\mathrm{OD}\left(\mathrm{mg} \mathrm{L}^{-1}\right)$ & Cond. $\left(\mu \mathrm{Sm}^{-1}\right)$ & Origem & Tipo & Lote & \\
\hline $\begin{array}{c}\text { Água natural } \\
\text { L-25 }\end{array}$ & 7.02 & 7.7 & 138.0 & Produto & Propranolol & & Gustavo \\
\hline
\end{tabular}

\begin{tabular}{|c|c|c|c|c|c|c|c|c|c|c|c|c|c|c|c|c|c|c|}
\hline \multirow{3}{*}{$\begin{array}{l}\text { Concentração } \\
\text { (mglL) }\end{array}$} & \multicolumn{12}{|c|}{ Número de indivíduos imóveis/tubo } & \multirow{2}{*}{\multicolumn{2}{|c|}{$\mathrm{pH}$}} & \multirow{2}{*}{\multicolumn{2}{|c|}{$\begin{array}{l}\text { Cond. } \\
(\mu \mathrm{S} / \mathrm{cm})\end{array}$}} & \multirow{2}{*}{\multicolumn{2}{|c|}{$\mathrm{OD}(\mathrm{mg} / \mathrm{L})$}} \\
\hline & \multicolumn{6}{|c|}{24 horas } & \multicolumn{6}{|c|}{48 horas } & & & & & & \\
\hline & 1 & 2 & 3 & 4 & total & $\%$ & 1 & 2 & 3 & 4 & total & $\%$ & ini & fin & ini & fin & ini & fin \\
\hline Controle & & & & & & & 0 & 1 & 0 & & 1 & 5 & 7.02 & 7.24 & 138.0 & 141.1 & 7.7 & 8.3 \\
\hline A. 0,62 & & & & & & & 0 & 0 & 0 & & 0 & 0 & 7.01 & 7.30 & 138.5 & 139.2 & 7.7 & 8.2 \\
\hline B. 1,25 & & & & & & & 1 & 1 & 0 & & 2 & 10 & 7.00 & 7.15 & 137.4 & 137.9 & 7.8 & 8.0 \\
\hline C. 2,5 & & & & & & & 3 & 3 & 2 & & 8 & 40 & 7.01 & 7.2 & 138.9 & 139.9 & 7.9 & 8.0 \\
\hline D. 5 & & & & & & & 4 & 5 & 5 & & 14 & 70 & 7.03 & 7.33 & 139.9 & 140.3 & 8.0 & 8.1 \\
\hline E. 10 & & & & & & & 5 & 5 & 5 & & 15 & 100 & 7.02 & 7.17 & 137.6 & 140.9 & 7.6 & 7.8 \\
\hline & & & & & & & & & & & & & & & & & & \\
\hline Resultados & \multicolumn{6}{|c|}{$\mathrm{EC}(\mathrm{I}) 50 ; 24 \mathrm{H}:$} & \multicolumn{6}{|c|}{ EC(I)50;48H: $2.33(1.84-2.95)$} & \multicolumn{6}{|c|}{ Método estatístico utilizado: Spearman } \\
\hline
\end{tabular}

OBSERVAÇÕES: 


\section{ipen}

LABORATÓRIO DE ECOTOXICOLOGIA

Teste de avaliação da toxicidade aguda para Ceriodaphnia silvestrii

\begin{tabular}{|c|c|c|c|c|c|c|c|}
\hline \multicolumn{4}{|l|}{ Início do teste: } & \multicolumn{4}{|c|}{ Final do teste: } \\
\hline \multicolumn{4}{|c|}{ Água de cultivo e/ou de diluição } & \multicolumn{3}{|c|}{ Amostra } & \multirow{2}{*}{ Responsável } \\
\hline Lote & $\mathrm{pH}$ & $\mathrm{OD}\left(\mathrm{mg} \mathrm{L}^{-1}\right)$ & Cond. $\left(\mu \mathrm{S} \mathrm{cm}^{-1}\right)$ & Origem & Tipo & Lote & \\
\hline $\begin{array}{c}\text { Água natural } \\
\text { L-25 }\end{array}$ & 7,02 & 7,7 & 135,2 & Produto & Propranolol & & Gustavo \\
\hline
\end{tabular}

\begin{tabular}{|c|c|c|c|c|c|c|c|c|c|c|c|c|c|c|c|c|c|c|}
\hline \multirow{3}{*}{$\begin{array}{c}\text { Concentração } \\
(\mathrm{mglL})\end{array}$} & \multicolumn{12}{|c|}{ Número de indivíduos imóveis/tubo } & \multirow{2}{*}{\multicolumn{2}{|c|}{$\mathrm{pH}$}} & \multirow{2}{*}{\multicolumn{2}{|c|}{$\begin{array}{l}\text { Cond. } \\
(\mu \mathrm{S} / \mathrm{cm})\end{array}$}} & \multirow{2}{*}{\multicolumn{2}{|c|}{$\mathrm{OD}(\mathrm{mg} / \mathrm{L})$}} \\
\hline & \multicolumn{6}{|c|}{24 horas } & \multicolumn{6}{|c|}{48 horas } & & & & & & \\
\hline & 1 & 2 & 3 & 4 & total & $\%$ & 1 & 2 & 3 & 4 & total & $\%$ & ini & fin & ini & fin & ini & fin \\
\hline Controle & & & & & & & 0 & 0 & 0 & 1 & 1 & 5 & 7.01 & 7.32 & 138.9 & 141.0 & 8.0 & 8.2 \\
\hline A. 0,62 & & & & & & & 1 & 0 & 0 & 0 & 1 & 5 & 7.01 & 7.38 & 139.1 & 139.3 & 7.8 & 8.6 \\
\hline B. 1,25 & & & & & & & 1 & 1 & 0 & 1 & 2 & 10 & 7.04 & 7.24 & 138.4 & 138.7 & 7.8 & 8.6 \\
\hline C. 2,5 & & & & & & & 1 & 2 & 1 & 3 & 5 & 15 & 7.02 & 7.45 & 135.5 & 139.9 & 7.8 & 7.9 \\
\hline D. 5 & & & & & & & 5 & 5 & 4 & 4 & 16 & 90 & 7.07 & 7.3 & 138.4 & 140.2 & 7.9 & 7.7 \\
\hline E. 10 & & & & & & & 5 & 5 & 5 & 5 & 20 & 100 & 7.03 & 7.21 & 139.9 & 140.5 & 8.0 & 7.9 \\
\hline Resultados & \multicolumn{6}{|c|}{$\mathrm{EC}(\mathrm{I}) 50 ; 24 \mathrm{H}:$} & \multicolumn{6}{|c|}{$\mathrm{EC}(\mathrm{I}) 50 ; 48 \mathrm{H}: 2.67(2.13-3.36)$} & \multicolumn{6}{|c|}{ Método estatístico utilizado: Spearman } \\
\hline
\end{tabular}
OBSERVAÇÕES: 
Apêndice 2

Planilhas dos testes de toxicidade crônica do propranolol para C. silvestrii. 


\section{ipen}

Teste de avaliação da toxicidade crônica para Ceriodaphnia silvestrii 1

\begin{tabular}{|c|c|c|c|c|c|c|c|}
\hline Início do teste: & \multicolumn{3}{c|}{ Final do teste: } & \multicolumn{3}{c|}{ Amostra } \\
\hline \multirow{2}{|c|}{ Água de cultivo e/ou de diluição } & \multicolumn{3}{c|}{ Lote } & Gustavo \\
\hline Lote & $\mathrm{pH}$ & $\mathrm{OD}\left(\mathrm{mg} \mathrm{L}^{-1}\right)$ & Cond. $\left(\mu \mathrm{S} \mathrm{cm}^{-1}\right)$ & Origem & Tipo & \\
\hline
\end{tabular}

\begin{tabular}{|c|c|c|c|c|c|c|c|c|c|c|c|c|c|c|c|c|c|c|c|c|}
\hline \multicolumn{21}{|c|}{ Concentração: CONTROLE } \\
\hline \multirow[t]{2}{*}{ Data } & \multicolumn{2}{|c|}{$\mathrm{pH}$} & \multicolumn{2}{|c|}{ OD (mg/L) } & \multicolumn{2}{|c|}{$\begin{array}{l}\text { Cond. }(\mu S \\
\left.\mathrm{cm}^{-1}\right)\end{array}$} & \multicolumn{11}{|c|}{ Réplicas } & \multicolumn{3}{|c|}{$\begin{array}{c}\text { Número de } \\
\text { Embriões } \\
\text { Fêmea }\end{array}$} \\
\hline & & & & & & & 1 & 2 & 3 & 4 & 5 & 6 & 7 & 8 & 9 & 10 & Observações & 1 & 2 & 3 \\
\hline & Inic. & Fin. & Inic. & Fin. & Inic. & Fin. & & & & & & & & & & & & & & \\
\hline & 7.01 & 7.32 & 8.0 & 8.2 & 138.9 & 141.0 & . & . & . & . & . & . & . & . & . &. & & & & \\
\hline & 7.01 & 7.38 & 7.8 & 8.6 & 139.1 & 139.3 & 4 & 3 & 4 & 4 & 3 & 4 & 3 & 2 & 4 & 2 & & & & \\
\hline & 7.04 & 7.56 & 7.8 & 8.4 & 137.4 & 142.5 & 8 & 5 & 8 & 7 & 4 & 5 & 4 & 5 & 7 & 5 & & & & \\
\hline & & & & & & & 3 & 4 & 3 & 7 & 10 & 5 & 3 & 13 & 5 & 9 & & & & \\
\hline & & & & & & & & & & & & & & & & & & & & \\
\hline & & & & & & & & & & & & & & & & & & & & \\
\hline & & & & & & & & & & & & & & & & & & & & \\
\hline & & & Total & & & & 15 & 12 & 15 & 18 & 17 & 14 & 10 & 20 & 16 & 16 & & & tiva & \\
\hline
\end{tabular}




\begin{tabular}{|c|c|c|c|c|c|c|c|c|c|c|c|c|c|c|c|c|c|c|c|c|}
\hline \multicolumn{21}{|c|}{ Concentração: 0,16 mg.L-1 } \\
\hline \multirow[t]{2}{*}{ Data } & \multicolumn{2}{|c|}{$\mathrm{pH}$} & \multicolumn{2}{|c|}{ OD (mg/L) } & \multicolumn{2}{|c|}{$\begin{array}{l}\text { Cond. }(\mu S \\
\left.\mathrm{cm}^{-1}\right)\end{array}$} & \multicolumn{11}{|c|}{ Réplicas } & \multicolumn{3}{|c|}{$\begin{array}{l}\text { Número de } \\
\text { Embriões } \\
\text { Fêmea }\end{array}$} \\
\hline & & & & & & & 1 & 2 & 3 & 4 & 5 & 6 & 7 & 8 & 9 & 10 & Observações & 1 & 2 & 3 \\
\hline & Inic. & Fin. & Inic. & Fin. & Inic. & Fin. & & & & & & & & & & & & & & \\
\hline & 7.0 & 7.34 & 7.5 & 8 & 189.9 & 195.4 & . & . & . & . & . & . & . & . & . & . & & & & \\
\hline & 7.01 & 7.23 & 7.6 & 8.1 & 177.1 & 184.3 & 4 & 3 & 5 & 2 & 4 & 1 & 5 & 2 & 4 & 2 & & & & \\
\hline & 7.01 & 7.16 & 7.6 & 7.9 & 175 & 188.2 & 6 & 4 & 7 & 3 & 2 & 5 & 3 & 4 & 6 & 7 & & & & \\
\hline & & & & & & & 3 & 9 & 6 & 12 & 12 & 10 & 7 & 9 & 5 & 7 & & & & \\
\hline & & & & & & & & & & & & & & & & & & & & \\
\hline & & & & & & & & & & & & & & & & & & & & \\
\hline & & & & & & & & & & & & & & & & & & & & \\
\hline & & & Total & & & & 13 & 16 & 18 & 17 & 18 & 16 & 15 & 15 & 15 & 16 & & & & \\
\hline
\end{tabular}

\begin{tabular}{|c|c|c|c|c|c|c|c|c|c|c|c|c|c|c|c|c|c|c|c|c|}
\hline \multicolumn{21}{|c|}{ Concentração: $0,31 \mathrm{mg} \cdot \mathrm{L}^{-1}$} \\
\hline \multirow[t]{2}{*}{ Data } & \multicolumn{2}{|c|}{$\mathrm{pH}$} & \multicolumn{2}{|c|}{$\begin{array}{l}\text { OD } \\
\text { (mg/L) }\end{array}$} & \multicolumn{2}{|c|}{$\begin{array}{l}\text { Cond. ( } \mu \mathrm{S} \\
\left.\mathrm{cm}^{-1}\right)\end{array}$} & \multicolumn{11}{|c|}{ Réplicas } & \multicolumn{3}{|c|}{$\begin{array}{c}\text { Número de } \\
\text { Embriões } \\
\text { Fêmea }\end{array}$} \\
\hline & & & & & & & 1 & 2 & 3 & 4 & 5 & 6 & 7 & 8 & 9 & 10 & Observações & 1 & 2 & 3 \\
\hline & Inic. & Fin. & Inic. & Fin. & Inic. & Fin. & & & & & & & & & & & & & & \\
\hline & 7.01 & 7.25 & 7.7 & 8.1 & 165.4 & 195.2 & . & . & . & . & & . & . & & . & . & & & & \\
\hline & 7.04 & 7.14 & 7.7 & 8.2 & 185.2 & 186.4 & 3 & 4 & 4 & 3 & 2 & 2 & 5 & 3 & 1 & 2 & & & & \\
\hline & 7.03 & 7.3 & 7.9 & 8.1 & 176.3 & 186.9 & 7 & 4 & 8 & 6 & 7 & 6 & 5 & 8 & 8 & 4 & & & & \\
\hline & & & & & & & 7 & 12 & 2 & 5 & 11 & 13 & 11 & 12 & 15 & 10 & & & & \\
\hline & & & & & & & & & & & & & & & & & & & & \\
\hline & & & & & & & & & & & & & & & & & & & & \\
\hline
\end{tabular}




\begin{tabular}{|c|c|c|c|c|c|c|c|c|c|c|c|c|c|c|c|c|c|c|c|c|}
\hline \multicolumn{7}{|c|}{$\begin{array}{r}\text { Total } \\
\end{array}$} & 17 & 20 & 14 & 14 & 20 & 21 & 21 & 23 & 24 & 16 & & \multicolumn{3}{|c|}{ Objetiva 40X } \\
\hline \multicolumn{21}{|c|}{ Concentração: 0,62 mg.L-1 } \\
\hline \multirow[t]{2}{*}{ Data } & \multicolumn{2}{|c|}{ pH } & \multicolumn{2}{|c|}{$\begin{array}{c}\text { OD } \\
\text { (mg/L) }\end{array}$} & \multicolumn{2}{|c|}{$\begin{array}{l}\text { Cond. }(\mu S \\
\left.\mathrm{cm}^{-1}\right)\end{array}$} & \multicolumn{11}{|c|}{ Réplicas } & \multicolumn{3}{|c|}{$\begin{array}{c}\text { Número de } \\
\text { Embriões } \\
\text { Fêmea }\end{array}$} \\
\hline & & & & & & & 1 & 2 & 3 & 4 & 5 & 6 & 7 & 8 & 9 & 10 & Observações & 1 & 2 & 3 \\
\hline & Inic. & Fin. & Inic. & Fin. & Inic. & Fin. & & & & & & & & & & & & & & \\
\hline & 7.0 & 7.25 & 7.9 & 7.7 & 175.4 & 199.5 & . & . & . & . & . & . & . & . & . & . & & & & \\
\hline & 7.02 & 7.2 & 7.5 & 7.5 & 185.9 & 200.4 & 5 & 3 & 4 & 3 & 5 & 6 & 2 & 4 & 1 & 3 & & & & \\
\hline & 7.02 & 7.16 & 7.5 & 7.9 & 184.3 & 194.2 & 7 & 9 & 10 & 5 & 7 & 9 & 3 & 9 & 9 & 4 & & & & \\
\hline & & & & & & & 9 & 8 & 4 & 6 & 7 & 5 & 11 & 12 & 9 & 8 & & & & \\
\hline & & & & & & & & & & & & & & & & & & & & \\
\hline & & & & & & & & & & & & & & & & & & & & \\
\hline & & & & & & & & & & & & & & & & & & & & \\
\hline \multicolumn{7}{|c|}{ Total } & 21 & 20 & 18 & 14 & 19 & 20 & 16 & 25 & 19 & 15 & & \multicolumn{3}{|c|}{ Objetiva 40X } \\
\hline
\end{tabular}

\begin{tabular}{|c|c|c|c|c|c|c|c|c|c|c|c|c|c|c|c|c|c|c|c|c|}
\hline \multicolumn{21}{|c|}{ Concentração: 1,25 mg.L-1 } \\
\hline \multirow[t]{2}{*}{ Data } & \multicolumn{2}{|c|}{$\mathrm{pH}$} & \multicolumn{2}{|c|}{$\begin{array}{c}\text { OD } \\
(\mathrm{mg} / \mathrm{L})\end{array}$} & \multicolumn{2}{|c|}{$\begin{array}{l}\text { Cond. ( } \mu \mathrm{S} \\
\left.\mathrm{cm}^{-1}\right)\end{array}$} & \multicolumn{11}{|c|}{ Réplicas } & \multicolumn{3}{|c|}{$\begin{array}{l}\text { Número de } \\
\text { Embriões } \\
\text { Fêmea }\end{array}$} \\
\hline & & & & & & & 1 & 2 & 3 & 4 & 5 & 6 & 7 & 8 & 9 & 10 & Observações & 1 & 2 & 3 \\
\hline & Inic. & Fin. & Inic. & Fin. & Inic. & Fin. & & & & & & & & & & & & & & \\
\hline & 7.04 & 7.19 & 7.4 & 7.7 & 165.4 & 186.6 & . & . & . & & . & . & . & . & . & . & & & & \\
\hline & 7.01 & 7.57 & 7.4 & 7.9 & 159.8 & 184.2 & 3 & 1 & 1 & 4 & 3 & 5 & 4 & 5 & 3 & 6 & & & & \\
\hline & 7.03 & 7.26 & 7.9 & 7.9 & 169.7 & 199.1 & 6 & 8 & 6 & 7 & 4 & 5 & 3 & 6 & 8 & 5 & & & & \\
\hline & & & & & & & 7 & 4 & 7 & 1 & 10 & 1 & 9 & 11 & 5 & 5 & & & & \\
\hline
\end{tabular}




\begin{tabular}{|c|c|c|c|c|c|c|c|c|c|c|c|c|c|c|c|c|c|c|c|c|}
\hline & & & & & & & & & & & & & & & & & & & & \\
\hline & & & & & & & & & & & & & & & & & & & & \\
\hline & & & & & & & & & & & & & & & & & & & & \\
\hline \multicolumn{7}{|c|}{ Total } & 16 & 13 & 14 & 12 & 17 & 11 & 16 & 22 & 16 & 16 & & & etiva & \\
\hline \multicolumn{21}{|c|}{ Concentração: $2,5 \mathrm{mg} \cdot \mathrm{L}^{-1}$} \\
\hline \multirow[t]{2}{*}{ Data } & \multirow{2}{*}{\multicolumn{2}{|c|}{$\mathrm{pH}$}} & \multicolumn{2}{|c|}{$\begin{array}{c}\text { OD } \\
\text { (mg/L) }\end{array}$} & \multicolumn{2}{|c|}{$\begin{array}{l}\text { Cond. }(\mu \mathrm{S} \\
\left.\mathrm{cm}^{-1}\right)\end{array}$} & \multicolumn{11}{|c|}{ Réplicas } & \multicolumn{3}{|c|}{$\begin{array}{c}\text { Número de } \\
\text { Embriões } \\
\text { Fêmea }\end{array}$} \\
\hline & & & & & & & 1 & 2 & 3 & 4 & 5 & 6 & 7 & 8 & 9 & 10 & Observações & 1 & 2 & 3 \\
\hline & Inic. & Fin. & Inic. & Fin. & Inic. & Fin. & & & & & & & & & & & & & & \\
\hline & 7.01 & 7.31 & 7.6 & 8.0 & 179.9 & 185.4 & . & . & . & . & . & . & . & . & . & . & & & & \\
\hline & 7.03 & 7.25 & 7.5 & 8.1 & 170.5 & 175.9 & 2 & + & 3 & 2 & 4 & 3 & 1 & 4 & 2 & 2 & & & & \\
\hline & 7.07 & 7.43 & 7.7 & 8.0 & 141.9 & 179.1 & 2 & & 4 & 1 & 6 & 2 & 6 & . & 4 & 3 & & & & \\
\hline & & & & & & & 5 & & 6 & 3 & . & 1 & 2 & . & 3 & 3 & & & & \\
\hline & & & & & & & & & & & & & & & & & & & & \\
\hline & & & & & & & & & & & & & & & & & & & & \\
\hline & & & & & & & & & & & & & & & & & & & & \\
\hline & & & Total & & & & 9 & 0 & 13 & 6 & 10 & 6 & 9 & 4 & 9 & 8 & & & etiva & \\
\hline
\end{tabular}




\section{ipen}

Teste de avaliação da toxicidade crônica para Ceriodaphnia silvestrii

\begin{tabular}{|c|c|c|c|c|c|c|c|}
\hline \multicolumn{3}{|c|}{ Início do teste: } & \multicolumn{3}{c|}{ Amostra } & \multirow{2}{*}{ Responsável } \\
\hline Lote & $\mathrm{pH}$ & $\mathrm{OD}\left(\mathrm{mg} \mathrm{L}^{-1}\right)$ & Cond. $\left(\mu \mathrm{S} \mathrm{cm}^{-1}\right)$ & Origem & Tipo & Lote & $\begin{array}{c}\text { Gustavo } \\
\text { Teste 2 }\end{array}$ \\
\hline & 7,01 & 8.0 & 167.3 & propranolol & Substância & & \\
\hline
\end{tabular}

\begin{tabular}{|c|c|c|c|c|c|c|c|c|c|c|c|c|c|c|c|c|c|c|c|c|}
\hline \multicolumn{21}{|c|}{ Concentração: CONTROLE } \\
\hline \multirow[t]{2}{*}{ Data } & \multicolumn{2}{|c|}{$\mathrm{pH}$} & \multicolumn{2}{|c|}{ OD (mg/L) } & \multicolumn{2}{|c|}{$\begin{array}{l}\text { Cond. }(\mu S \\
\left.\mathrm{cm}^{-1}\right)\end{array}$} & \multicolumn{11}{|c|}{ Réplicas } & \multicolumn{3}{|c|}{$\begin{array}{c}\text { Número de } \\
\text { Embriões } \\
\text { Fêmea }\end{array}$} \\
\hline & & & & & & & 1 & 2 & 3 & 4 & 5 & 6 & 7 & 8 & 9 & 10 & Observações & 1 & 2 & 3 \\
\hline & Inic. & Fin. & Inic. & Fin. & Inic. & Fin. & & & & & & & & & & & & & & \\
\hline & 7.02 & 7.34 & 7.7 & 8 & 175.4 & & . & . & . & . & . & . & . & . & . & . & & & & \\
\hline & 7.01 & 7.21 & 7.8 & 8.1 & 179.3 & & 4 & 2 & 2 & 3 & 4 & 5 & 4 & 3 & 5 & 3 & & & & \\
\hline & 7.01 & 7.26 & 7.8 & 7.7 & 181.1 & & 7 & 6 & 9 & 10 & 8 & 6 & 4 & 7 & 8 & 7 & & & & \\
\hline & & & & & & & 7 & 4 & 6 & 2 & 10 & 2 & 5 & 4 & 3 & 6 & & & & \\
\hline & & & & & & & & & & & & & & & & & & & & \\
\hline & & & & & & & & & & & & & & & & & & & & \\
\hline & & & & & & & & & & & & & & & & & & & & \\
\hline & & & Total & & & & 18 & 12 & 16 & 15 & 22 & 13 & 13 & 14 & 16 & 16 & & & tiva & \\
\hline
\end{tabular}




\begin{tabular}{|c|c|c|c|c|c|c|c|c|c|c|c|c|c|c|c|c|c|c|}
\hline \multicolumn{10}{|c|}{ Concentração: 0,16 mg.L-1 } \\
\hline \multirow{2}{*}{ Data }
\end{tabular}

\begin{tabular}{|c|c|c|c|c|c|c|c|c|c|c|c|c|c|c|c|c|c|c|c|c|}
\hline \multicolumn{21}{|c|}{ Concentração: $0,31 \mathrm{mg} \cdot \mathrm{L}^{-1}$} \\
\hline \multirow[t]{2}{*}{ Data } & \multicolumn{2}{|c|}{$\mathrm{pH}$} & \multicolumn{2}{|c|}{$\begin{array}{c}\text { OD } \\
\text { (mg/L) }\end{array}$} & \multicolumn{2}{|c|}{$\begin{array}{l}\text { Cond. }(\mu \mathrm{S} \\
\left.\mathrm{cm}^{-1}\right)\end{array}$} & \multicolumn{11}{|c|}{ Réplicas } & \multicolumn{3}{|c|}{$\begin{array}{l}\text { Número de } \\
\text { Embriões } \\
\text { Fêmea }\end{array}$} \\
\hline & & & & & & & 1 & 2 & 3 & 4 & 5 & 6 & 7 & 8 & 9 & 10 & Observações & 1 & 2 & 3 \\
\hline & Inic. & Fin. & Inic. & Fin. & Inic. & Fin. & & & & & & & & & & & & & & \\
\hline & & & & & & & . & . & . & . & . & . & . & . & . & . & & & & \\
\hline & & & & & & & 5 & 4 & 4 & 6 & 2 & 5 & 4 & 3 & 3 & 4 & & & & \\
\hline & & & & & & & 6 & 7 & 5 & 3 & 6 & 4 & 6 & 8 & 9 & 7 & & & & \\
\hline & & & & & & & 0 & 6 & 3 & 6 & 9 & 3 & 9 & 12 & 4 & 10 & & & & \\
\hline & & & & & & & & & & & & & & & & & & & & \\
\hline & & & & & & & & & & & & & & & & & & & & \\
\hline
\end{tabular}




\begin{tabular}{|c|c|c|c|c|c|c|c|c|c|c|c|c|c|c|c|c|c|c|c|c|}
\hline \multicolumn{7}{|c|}{ Total } & 11 & 17 & 12 & 15 & 17 & 12 & 19 & 23 & 16 & 21 & & & tive & \\
\hline \multicolumn{21}{|c|}{ Concentração: $0,62 \mathrm{mg} \cdot \mathrm{L}^{-1}$} \\
\hline \multirow[t]{2}{*}{ Data } & \multicolumn{2}{|c|}{ pH } & \multicolumn{2}{|c|}{$\begin{array}{c}\text { OD } \\
\text { (mg/L) }\end{array}$} & \multicolumn{2}{|c|}{$\begin{array}{l}\text { Cond. }(\mu S \\
\left.\mathrm{cm}^{-1}\right)\end{array}$} & \multicolumn{11}{|c|}{ Réplicas } & \multicolumn{3}{|c|}{$\begin{array}{c}\text { Número de } \\
\text { Embriões } \\
\text { Fêmea }\end{array}$} \\
\hline & & & & & & & 1 & 2 & 3 & 4 & 5 & 6 & 7 & 8 & 9 & 10 & Observações & 1 & 2 & 3 \\
\hline & Inic. & Fin. & Inic. & Fin. & Inic. & Fin. & & & & & & & & & & & & & & \\
\hline & & & & & & & . & . & . & . & . & . & . & . & . & . & & & & \\
\hline & & & & & & & 3 & 4 & 2 & 5 & 3 & 5 & 4 & 3 & 2 & 6 & & & & \\
\hline & & & & & & & 5 & 5 & 7 & 5 & 7 & 4 & 5 & 5 & 6 & 6 & & & & \\
\hline & & & & & & & 2 & 7 & 8 & 10 & 7 & 3 & 6 & 2 & 6 & 0 & & & & \\
\hline & & & & & & & & & & & & & & & & & & & & \\
\hline & & & & & & & & & & & & & & & & & & & & \\
\hline & & & & & & & & & & & & & & & & & & & & \\
\hline \multicolumn{7}{|c|}{ Total } & 10 & 16 & 17 & 20 & 16 & 12 & 15 & 10 & 14 & 12 & & \multicolumn{3}{|c|}{ Objetiva 40X } \\
\hline
\end{tabular}

\begin{tabular}{|c|c|c|c|c|c|c|c|c|c|c|c|c|c|c|c|c|c|c|c|c|}
\hline \multicolumn{21}{|c|}{ Concentração: 1,25 mg.L-1 } \\
\hline \multirow[t]{2}{*}{ Data } & \multicolumn{2}{|c|}{$\mathrm{pH}$} & \multicolumn{2}{|c|}{$\begin{array}{c}\text { OD } \\
(\mathrm{mg} / \mathrm{L})\end{array}$} & \multicolumn{2}{|c|}{$\begin{array}{l}\text { Cond. ( } \mu \mathrm{S} \\
\left.\mathrm{cm}^{-1}\right)\end{array}$} & \multicolumn{11}{|c|}{ Réplicas } & \multicolumn{3}{|c|}{$\begin{array}{l}\text { Número de } \\
\text { Embriões } \\
\text { Fêmea }\end{array}$} \\
\hline & & & & & & & 1 & 2 & 3 & 4 & 5 & 6 & 7 & 8 & 9 & 10 & Observações & 1 & 2 & 3 \\
\hline & Inic. & Fin. & Inic. & Fin. & Inic. & Fin. & & & & & & & & & & & & & & \\
\hline & & & & & & & . & . & . & . & . & & . & . & . & . & & & & \\
\hline & & & & & & & 5 & 3 & 5 & 2 & 6 & 5 & 4 & 4 & 2 & 3 & & & & \\
\hline & & & & & & & 4 & 3 & 6 & 5 & 3 & 4 & 3 & 2 & 3 & 5 & & & & \\
\hline & & & & & & & 2 & 8 & 4 & 5 & 8 & 3 & 7 & 10 & 6 & 1 & & & & \\
\hline
\end{tabular}




\begin{tabular}{|c|c|c|c|c|c|c|c|c|c|c|c|c|c|c|c|c|c|c|c|c|}
\hline & & & & & & & & & & & & & & & & & & & & \\
\hline & & & & & & & & & & & & & & & & & & & & \\
\hline & & & & & & & & & & & & & & & & & & & & \\
\hline \multicolumn{7}{|c|}{ Total } & 11 & 14 & 15 & 12 & 17 & 12 & 14 & 16 & 11 & 9 & & & tiva & \\
\hline \multicolumn{21}{|c|}{ Concentração: $2,5 \mathrm{mg} \cdot \mathrm{L}^{-1}$} \\
\hline \multirow[t]{2}{*}{ Data } & \multicolumn{2}{|c|}{$\mathrm{pH}$} & \multicolumn{2}{|c|}{$\begin{array}{c}\text { OD } \\
\text { (mg/L) }\end{array}$} & \multicolumn{2}{|c|}{$\begin{array}{l}\text { Cond. }(\mu S \\
\left.\mathrm{cm}^{-1}\right)\end{array}$} & \multicolumn{11}{|c|}{ Réplicas } & \multicolumn{3}{|c|}{$\begin{array}{l}\text { Número de } \\
\text { Embriões } \\
\text { Fêmea }\end{array}$} \\
\hline & & & & & & & 1 & 2 & 3 & 4 & 5 & 6 & 7 & 8 & 9 & 10 & Observações & 1 & 2 & 3 \\
\hline & Inic. & Fin. & Inic. & Fin. & Inic. & Fin. & & & & & & & & & & & & & & \\
\hline & & & & & & & . & . & . & . & . & . & . & . & . & . & & & & \\
\hline & & & & & & & 2 & 2 & 1 & 4 & 3 & 0 & 3 & 4 & + & 2 & & & & \\
\hline & & & & & & & 0 & 2 & 3 & 7 & 7 & 3 & 3 & 3 & & 3 & & & & \\
\hline & & & & & & & 3 & 3 & 3 & 2 & 4 & 0 & 0 & 3 & & 3 & & & & \\
\hline & & & & & & & & & & & & & & & & & & & & \\
\hline & & & & & & & & & & & & & & & & & & & & \\
\hline & & & & & & & & & & & & & & & & & & & & \\
\hline & & & Total & & & & 5 & 7 & 7 & 13 & 14 & 3 & 6 & 10 & 0 & 8 & & & tiva & \\
\hline
\end{tabular}




\section{ipen}

Teste de avaliação da toxicidade crônica para Ceriodaphnia silvestrii

\begin{tabular}{|c|c|c|c|c|c|c|c|}
\hline \multicolumn{4}{|c|}{ Início do teste: } & \multicolumn{4}{|l|}{ Final do teste: } \\
\hline \multicolumn{4}{|c|}{ Água de cultivo e/ou de diluição } & \multicolumn{3}{|c|}{ Amostra } & \multirow{3}{*}{$\begin{array}{c}\text { Responsável } \\
\text { Gustavo } \\
\text { Teste } 3\end{array}$} \\
\hline \multirow[t]{2}{*}{ Lote } & $\mathrm{pH}$ & $\mathrm{OD}\left(\mathrm{mg} \mathrm{L}^{-1}\right)$ & Cond. $\left(\mu \mathrm{S} \mathrm{cm}^{-1}\right)$ & Origem & Tipo & Lote & \\
\hline & 7,0 & 7,9 & 187,2 & propranolol & Substância & & \\
\hline
\end{tabular}

\section{Concentração: CONTROLE}

\begin{tabular}{|c|c|c|c|c|c|c|c|c|c|c|c|c|c|c|c|c|c|c|c|c|}
\hline \multirow[t]{2}{*}{ Data } & \multicolumn{2}{|c|}{$\mathrm{pH}$} & \multicolumn{2}{|c|}{$O D(\mathrm{mg} / \mathrm{L})$} & \multicolumn{2}{|c|}{$\begin{array}{c}\text { Cond. }(\mu \mathrm{S} \mathrm{cm}- \\
1)\end{array}$} & \multicolumn{11}{|c|}{ Réplicas } & \multicolumn{3}{|c|}{$\begin{array}{l}\text { Número de } \\
\text { Embriões } \\
\text { Fêmea }\end{array}$} \\
\hline & & & & & & & 1 & 2 & 3 & 4 & 5 & 6 & 7 & 8 & 9 & 10 & Observações & 1 & 2 & 3 \\
\hline & Inic. & Fin. & Inic. & Fin. & Inic. & Fin. & & & & & & & & & & & & & & \\
\hline & & & & & & & . & . & . & . & . & . & . & . & . & . & & & & \\
\hline & & & & & & & 3 & 4 & 3 & 4 & 2 & 3 & 5 & 1 & 2 & 0 & & & & \\
\hline & & & & & & & 7 & 4 & 6 & 5 & 3 & 7 & 5 & 7 & 8 & 6 & & & & \\
\hline & & & & & & & 6 & 9 & 8 & 2 & 8 & 7 & 2 & 11 & 10 & 12 & & & & \\
\hline & & & & & & & & & & & & & & & & & & & & \\
\hline & & & & & & & & & & & & & & & & & & & & \\
\hline & & & & & & & 16 & 17 & 17 & 11 & 13 & 17 & 12 & 19 & 20 & 18 & & & & \\
\hline \multicolumn{7}{|c|}{ Total } & & & & & & & & & & & & \multicolumn{3}{|c|}{ Objetiva 40X } \\
\hline
\end{tabular}




\begin{tabular}{|c|c|c|c|c|c|c|c|c|c|c|c|c|c|c|c|c|c|c|c|c|}
\hline \multicolumn{21}{|c|}{ Concentração: 0,16 mg.L-1 } \\
\hline \multirow[t]{2}{*}{ Data } & \multicolumn{2}{|c|}{$\mathrm{pH}$} & \multicolumn{2}{|c|}{ OD (mg/L) } & \multicolumn{2}{|c|}{$\begin{array}{c}\text { Cond. ( } \mu \mathrm{S} \mathrm{cm}- \\
1)\end{array}$} & \multicolumn{11}{|c|}{ Réplicas } & \multicolumn{3}{|c|}{$\begin{array}{l}\text { Número de } \\
\text { Embriões } \\
\text { Fêmea }\end{array}$} \\
\hline & & & & & & & 1 & 2 & 3 & 4 & 5 & 6 & 7 & 8 & 9 & 10 & Observações & 1 & 2 & 3 \\
\hline & Inic. & Fin. & Inic. & Fin. & Inic. & Fin. & & & & & & & & & & & & & & \\
\hline & & & & & & & . & . & . & . & . & . & . & . & . & . & & & & \\
\hline & & & & & & & 4 & 3 & 5 & 3 & 4 & 3 & 5 & 3 & 2 & 4 & & & & \\
\hline & & & & & & & 6 & 8 & 7 & 5 & 9 & 8 & 7 & 8 & 7 & 5 & & & & \\
\hline & & & & & & & 2 & 6 & 1 & 8 & 7 & 11 & 9 & 4 & 6 & 3 & & & & \\
\hline & & & & & & & & & & & & & & & & & & & & \\
\hline & & & & & & & & & & & & & & & & & & & & \\
\hline & & & & & & & 12 & 17 & 13 & 16 & 20 & 22 & 21 & 15 & 15 & 12 & & & & \\
\hline \multicolumn{7}{|c|}{ Total } & & & & & & & & & & & & \multicolumn{3}{|c|}{ Objetiva 40X } \\
\hline
\end{tabular}

\begin{tabular}{|c|c|c|c|c|c|c|c|c|c|c|c|c|c|c|c|c|c|c|c|c|}
\hline \multicolumn{21}{|c|}{ Concentração: $0,31 \mathrm{mg} \cdot \mathrm{L}^{-1}$} \\
\hline \multirow[t]{2}{*}{ Data } & \multicolumn{2}{|c|}{$\mathrm{pH}$} & \multicolumn{2}{|c|}{$\begin{array}{c}\text { OD } \\
(\mathrm{mg} / \mathrm{L})\end{array}$} & \multicolumn{2}{|c|}{$\begin{array}{c}\text { Cond. }\left(\mu S \mathrm{~cm}^{-}\right. \\
\text {- }\end{array}$} & \multicolumn{11}{|c|}{ Réplicas } & \multicolumn{3}{|c|}{$\begin{array}{l}\text { Número de } \\
\text { Embriões } \\
\text { Fêmea }\end{array}$} \\
\hline & & & & & & & 1 & 2 & 3 & 4 & 5 & 6 & 7 & 8 & 9 & 10 & Observações & 1 & 2 & 3 \\
\hline & Inic. & Fin. & Inic. & Fin. & Inic. & Fin. & & & & & & & & & & & & & & \\
\hline & & & & & & & . & . & . & . & . & . & . & . & . & . & & & & \\
\hline & & & & & & & 2 & 3 & 2 & 4 & 3 & 2 & 3 & 2 & 2 & 3 & & & & \\
\hline & & & & & & & 4 & 5 & 3 & 6 & 5 & 7 & 4 & 9 & 6 & 6 & & & & \\
\hline & & & & & & & 10 & 10 & 10 & 4 & 6 & 7 & 10 & 14 & 6 & 6 & & & & \\
\hline & & & & & & & & & & & & & & & & & & & & \\
\hline & & & & & & & & & & & & & & & & & & & & \\
\hline
\end{tabular}




\begin{tabular}{|c|c|c|c|c|c|c|c|c|c|c|c|c|c|c|c|c|c|c|c|c|}
\hline \multicolumn{7}{|c|}{$\begin{array}{r}\text { Total } \\
\end{array}$} & 18 & 18 & 15 & 14 & 14 & 16 & 17 & 25 & 14 & 15 & & \multicolumn{3}{|c|}{ Objetiva 40X } \\
\hline \multicolumn{21}{|c|}{ Concentração: $0,62 \mathrm{mg} \cdot \mathrm{L}^{-1}$} \\
\hline \multirow[t]{2}{*}{ Data } & \multicolumn{2}{|c|}{$\mathrm{pH}$} & \multicolumn{2}{|c|}{$\begin{array}{l}\text { OD } \\
\text { (mg/L) }\end{array}$} & \multicolumn{2}{|c|}{$\begin{array}{c}\text { Cond. ( } \mu \mathrm{S} \mathrm{cm}^{-} \\
1 \text { ) }\end{array}$} & \multicolumn{11}{|c|}{ Réplicas } & \multicolumn{3}{|c|}{$\begin{array}{c}\text { Número de } \\
\text { Embriões } \\
\text { Fêmea }\end{array}$} \\
\hline & & & & & & & 1 & 2 & 3 & 4 & 5 & 6 & 7 & 8 & 9 & 10 & Observações & 1 & 2 & 3 \\
\hline & Inic. & Fin. & Inic. & Fin. & Inic. & Fin. & & & & & & & & & & & & & & \\
\hline & & & & & & & . & . & . &. & . & . & . & . & . & . & & & & \\
\hline & & & & & & & 3 & 4 & 3 & 5 & 4 & 3 & 2 & 3 & 4 & 0 & & & & \\
\hline & & & & & & & 4 & 6 & 5 & 6 & 4 & 7 & 6 & 8 & 3 & 8 & & & & \\
\hline & & & & & & & 8 & 7 & 5 & 4 & 11 & 6 & 12 & 2 & 11 & 8 & & & & \\
\hline & & & & & & & & & & & & & & & & & & & & \\
\hline & & & & & & & & & & & & & & & & & & & & \\
\hline & & & & & & & & & & & & & & & & & & & & \\
\hline \multicolumn{7}{|c|}{ Total } & 15 & 17 & 13 & 15 & 19 & 16 & 20 & 13 & 18 & 16 & & \multicolumn{3}{|c|}{ Objetiva 40X } \\
\hline
\end{tabular}

\begin{tabular}{|c|c|c|c|c|c|c|c|c|c|c|c|c|c|c|c|c|c|c|c|c|}
\hline \multicolumn{21}{|c|}{ Concentração: 1,25 mg.L-1 } \\
\hline \multirow[t]{2}{*}{ Data } & \multicolumn{2}{|c|}{$\mathrm{pH}$} & \multicolumn{2}{|c|}{$\begin{array}{c}\text { OD } \\
(\mathrm{mg} / \mathrm{L})\end{array}$} & \multicolumn{2}{|c|}{$\begin{array}{c}\text { Cond. }(\mu \mathrm{S} \mathrm{cm} \\
1)\end{array}$} & \multicolumn{11}{|c|}{ Réplicas } & \multicolumn{3}{|c|}{$\begin{array}{l}\text { Número de } \\
\text { Embriões } \\
\text { Fêmea }\end{array}$} \\
\hline & & & & & & & 1 & 2 & 3 & 4 & 5 & 6 & 7 & 8 & 9 & 10 & Observações & 1 & 2 & 3 \\
\hline & Inic. & Fin. & Inic. & Fin. & Inic. & Fin. & & & & & & & & & & & & & & \\
\hline & & & & & & & & & . & . & . & . & & & & & & & & \\
\hline & & & & & & & 3 & 0 & 4 & 1 & 3 & 0 & 1 & 3 & 5 & 2 & & & & \\
\hline & & & & & & & 4 & 6 & 5 & 7 & 3 & 4 & 8 & 2 & 3 & 4 & & & & \\
\hline & & & & & & & 6 & 3 & 3 & 3 & 9 & 13 & 5 & 8 & 0 & 5 & & & & \\
\hline
\end{tabular}




\begin{tabular}{|c|c|c|c|c|c|c|c|c|c|c|c|c|c|c|c|c|c|c|c|c|}
\hline & & & & & & & & & & & & & & & & & & & & \\
\hline & & & & & & & & & & & & & & & & & & & & \\
\hline & & & & & & & & & & & & & & & & & & & & \\
\hline \multicolumn{7}{|c|}{ Total } & 13 & 9 & 12 & 11 & 15 & 17 & 14 & 13 & 8 & 11 & & & tiva & \\
\hline \multicolumn{21}{|c|}{ Concentração: $2,5 \mathrm{mg} \cdot \mathrm{L}^{-1}$} \\
\hline \multirow[t]{2}{*}{ Data } & \multirow{2}{*}{\multicolumn{2}{|c|}{$\mathrm{pH}$}} & \multicolumn{2}{|c|}{$\begin{array}{l}\text { OD } \\
\text { (mg/L) }\end{array}$} & \multicolumn{2}{|c|}{$\underset{1)}{\text { Cond. }(\mu \mathrm{S} \mathrm{cm}-}$} & \multicolumn{11}{|c|}{ Réplicas } & \multicolumn{3}{|c|}{$\begin{array}{l}\text { Número de } \\
\text { Embriões } \\
\text { Fêmea }\end{array}$} \\
\hline & & & & & & & 1 & 2 & 3 & 4 & 5 & 6 & 7 & 8 & 9 & 10 & Observações & 1 & 2 & 3 \\
\hline & Inic. & Fin. & Inic. & Fin. & Inic. & Fin. & & & & & & & & & & & & & & \\
\hline & & & & & & & . & . & . & . & . & . & . & . & . & . & & & & \\
\hline & & & & & & & & 1 & 4 & 4 & 2 & 6 & 3 & 2 & 3 & 1 & & & & \\
\hline & & & & & & & & 2 & 5 & 3 & 3 & 3 & 5 & 6 & 2 & 3 & & & & \\
\hline & & & & & & & & & 3 & 3 & & 3 & 6 & & 1 & 5 & & & & \\
\hline & & & & & & & & & & & & & & & & & & & & \\
\hline & & & & & & & & & & & & & & & & & & & & \\
\hline & & & & & & & & & & & & & & & & & & & & \\
\hline & & & Total & & & & 0 & 3 & 12 & 10 & 5 & 12 & 14 & 8 & 6 & 9 & & & tiva & \\
\hline
\end{tabular}


Apêndice 3

Planilhas dos testes de toxicidade crônica do propranolol para populações de $C$. silvestrii. 


\section{ipen}

\section{Teste de avaliação da toxicidade crônica para Ceriodaphnia silvestrii}

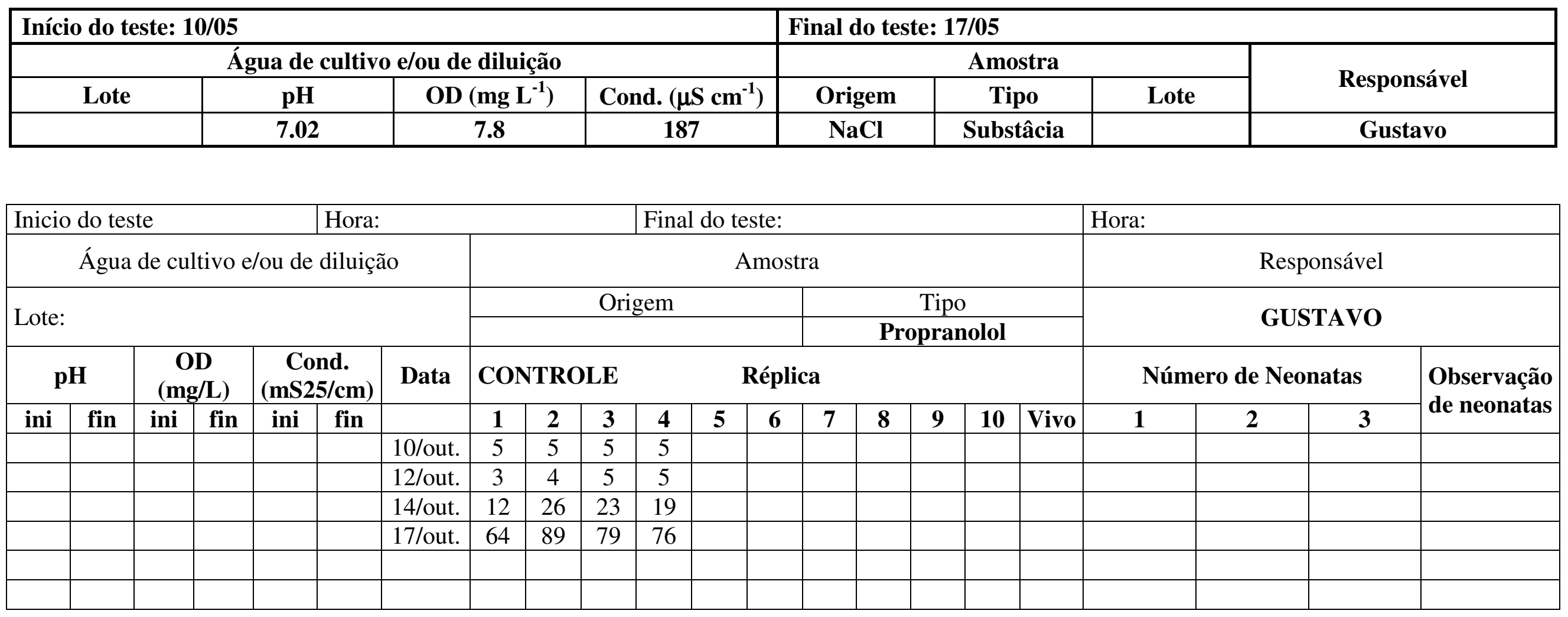




\begin{tabular}{|c|c|c|c|c|c|c|c|c|c|c|c|c|c|c|c|c|c|c|c|c|c|}
\hline \multirow{2}{*}{\multicolumn{7}{|c|}{\begin{tabular}{|l|l} 
Inicio do teste & Hora: \\
Água de cultivo e/ou de diluição
\end{tabular}}} & & & & \multicolumn{8}{|c|}{ Final do teste: } & \multicolumn{4}{|l|}{ Hora: } \\
\hline & & & & & & & \multicolumn{11}{|c|}{ Amostra } & \multicolumn{4}{|c|}{ Responsável } \\
\hline \multicolumn{7}{|c|}{ e } & \multicolumn{6}{|c|}{ Origem } & \multicolumn{5}{|c|}{ Tipo } & & & & \multirow{3}{*}{$\begin{array}{l}\text { Observação } \\
\text { de neonatas }\end{array}$} \\
\hline \multicolumn{2}{|c|}{$\mathbf{p H}$} & \multicolumn{2}{|c|}{$\begin{array}{c}\text { OD } \\
(\mathbf{m g} / \mathbf{L})\end{array}$} & \multicolumn{2}{|c|}{$\begin{array}{c}\text { Cond. } \\
(\mathrm{mS25} / \mathrm{cm})\end{array}$} & \multirow[t]{2}{*}{ Data } & \multicolumn{5}{|c|}{$0,04 \mathrm{~g} / \mathrm{L}$} & \multicolumn{6}{|c|}{ Réplica } & \multicolumn{3}{|c|}{ Número de Neonatas } & \\
\hline \multirow[t]{7}{*}{ ini } & fin & ini & fin & ini & fin & & 1 & 2 & 3 & 4 & 5 & 6 & 7 & 8 & 9 & 10 & Vivo & 1 & 2 & 3 & \\
\hline & & & & & & 10/out. & 5 & 5 & 5 & 5 & & & & & & & & & & & \\
\hline & & & & & & 12/out. & 5 & 5 & 4 & 5 & & & & & & & & & & & \\
\hline & & & & & & 14/out. & 48 & 52 & 74 & 50 & & & & & & & & & & & \\
\hline & & & & & & 17/out. & 173 & 159 & 206 & 225 & & & & & & & & & & & \\
\hline & & & & & & & & & & & & & & & & & & & & & \\
\hline & & & & & & & & & & & & & & & & & & & & & \\
\hline
\end{tabular}

\begin{tabular}{|c|c|c|c|c|c|c|c|c|c|c|c|c|c|c|c|c|c|c|c|c|c|}
\hline Inici & do te & & & & Hora: & & & & & Final & do t & & & & & & & Hora: & & & \\
\hline & Águ & $\mathrm{de} \mathrm{cl}$ & tivo & ou de & diluiçç & & & & & & & nos & & & & & & & & áve & \\
\hline Lote & & & & & & & & & Orig & em & & & & & $\mathrm{Ti}$ & & & & & & \\
\hline & & & $\begin{array}{l}\mathrm{D} \\
/ \mathrm{L})\end{array}$ & $\begin{array}{r}\mathbf{C} \\
(\mathbf{m S}\end{array}$ & $\begin{array}{l}1 \mathrm{id.} \\
/ \mathrm{cm})\end{array}$ & Data & 0,105 & $g / L$ & & & & épl & & & & & & & de & & $\begin{array}{l}\text { Observação } \\
\text { de neonatas }\end{array}$ \\
\hline ini & fin & ini & fin & ini & fin & & 1 & 2 & 3 & 4 & 5 & 6 & 7 & 8 & 9 & 10 & Vivo & 1 & 2 & 3 & \\
\hline & & & & & & 10/out. & 5 & 5 & 5 & 5 & & & & & & & & & & & \\
\hline & & & & & & 12/out. & 5 & 5 & 5 & 5 & & & & & & & & & & & \\
\hline & & & & & & 14/out. & 77 & 48 & 50 & 68 & & & & & & & & & & & \\
\hline & & & & & & 17/out. & 152 & 145 & 140 & 153 & & & & & & & & & & & \\
\hline & & & & & & & & & & & & & & & & & & & & & \\
\hline & & & & & & & & & & & & & & & & & & & & & \\
\hline
\end{tabular}




\begin{tabular}{|c|c|c|c|c|c|c|c|c|c|c|c|c|c|c|c|c|c|c|c|c|c|}
\hline \multirow{2}{*}{\multicolumn{7}{|c|}{\begin{tabular}{|l|l} 
Inicio do teste & Hora: \\
Água de cultivo e/ou de diluição
\end{tabular}}} & & & & \multicolumn{8}{|c|}{ Final do teste: } & \multicolumn{4}{|l|}{ Hora: } \\
\hline & & & & & & & \multicolumn{11}{|c|}{ Amostra } & \multicolumn{4}{|c|}{ Responsável } \\
\hline \multicolumn{7}{|c|}{ Lote: } & \multicolumn{6}{|c|}{ Origem } & \multicolumn{5}{|c|}{ Tipo } & & & & \\
\hline \multicolumn{2}{|c|}{ pH } & \multicolumn{2}{|c|}{$\underset{(\mathrm{mg} / \mathrm{L})}{\mathrm{OD}}$} & \multicolumn{2}{|c|}{$\begin{array}{c}\text { Cond. } \\
(\mathrm{mS} 25 / \mathrm{cm})\end{array}$} & \multirow[t]{2}{*}{ Data } & \multicolumn{5}{|c|}{$0,275 \mathrm{~g} / \mathrm{L}$} & \multicolumn{6}{|c|}{ Réplica } & \multicolumn{3}{|c|}{ Número de Neonatas } & \multirow[t]{2}{*}{$\begin{array}{l}\text { Observação } \\
\text { de neonatas }\end{array}$} \\
\hline ini & fin & ini & fin & ini & fin & & 1 & 2 & 3 & 4 & 5 & 6 & 7 & 8 & 9 & 10 & Vivo & 1 & 2 & 3 & \\
\hline & & & & & & 10/out. & 5 & 5 & 5 & 5 & & & & & & & & & & & \\
\hline & & & & & & 12/out. & 4 & 3 & 4 & 3 & & & & & & & & & & & \\
\hline & & & & & & 14/out. & 40 & 25 & 19 & 20 & & & & & & & & & & & \\
\hline & & & & & & 17/out. & 140 & 103 & 83 & 101 & & & & & & & & & & & \\
\hline & & & & & & & & & & & & & & & & & & & & & \\
\hline & & & & & & & & & & & & & & & & & & & & & \\
\hline
\end{tabular}

\begin{tabular}{|c|c|c|c|c|c|c|c|c|c|c|c|c|c|c|c|c|c|c|c|c|c|}
\hline \multicolumn{5}{|c|}{ Inicio do teste } & \multicolumn{5}{|c|}{ Hora: } & \multicolumn{8}{|c|}{ Final do teste: } & \multicolumn{4}{|l|}{ Hora: } \\
\hline \multicolumn{7}{|c|}{ Água de cultivo e/ou de diluição } & \multicolumn{11}{|c|}{ Amostra } & \multicolumn{4}{|c|}{ Responsável } \\
\hline \multicolumn{7}{|c|}{ Lote: } & \multicolumn{6}{|c|}{ Origem } & \multicolumn{5}{|c|}{ Tipo } & & & & \\
\hline \multicolumn{2}{|c|}{ pH } & \multicolumn{2}{|c|}{$\underset{(\mathrm{mg} / \mathrm{L})}{\text { OD }}$} & \multicolumn{2}{|c|}{$\begin{array}{c}\text { Cond. } \\
(\mathrm{mS25} / \mathrm{cm})\end{array}$} & \multirow[t]{2}{*}{ Data } & \multicolumn{5}{|c|}{$0,723 \mathrm{~g} / \mathrm{L}$} & \multicolumn{6}{|c|}{ Réplica } & \multicolumn{3}{|c|}{ Número de Neonatas } & \multirow{2}{*}{$\begin{array}{l}\text { Observação } \\
\text { de neonatas }\end{array}$} \\
\hline ini & fin & ini & fin & ini & fin & & 1 & 2 & 3 & 4 & 5 & 6 & 7 & 8 & 9 & 10 & Vivo & 1 & 2 & 3 & \\
\hline & & & & & & 10/out. & 5 & 5 & 5 & 5 & & & & & & & & & & & \\
\hline & & & & & & 12/out. & 2 & 0 & 2 & 2 & & & & & & & & & & & \\
\hline & & & & & & 14/out. & 7 & 0 & 6 & 3 & & & & & & & & & & & \\
\hline & & & & & & 17/out. & 20 & 0 & 1 & 23 & & & & & & & & & & & \\
\hline & & & & & & & & & & & & & & & & & & & & & \\
\hline & & & & & & & & & & & & & & & & & & & & & \\
\hline
\end{tabular}




\begin{tabular}{|c|c|c|c|c|c|c|c|c|c|c|c|c|c|c|c|c|c|c|c|c|c|}
\hline Inici & do te & & & & Hora: & & & & & Fina & lot & & & & & & & Hora: & & & \\
\hline & Águ & $\mathrm{de} \mathrm{cl}$ & ivo & ou d & diluiçã & & & & & & & mos & & & & & & & & sáve & \\
\hline & & & & & & & & & & & & & & & Tip & & & & & & \\
\hline Lote & & & & & & & & & & & & & & & & & & & & & \\
\hline & & & & $\begin{array}{r}\mathrm{C} \\
(\mathrm{mS}\end{array}$ & $\begin{array}{l}\text { nd. } \\
5 / \mathrm{cm})\end{array}$ & Data & 1,9 & & & & & Rép & & & & & & & de & & Observação \\
\hline ini & fin & ini & fin & ini & fin & & 1 & 2 & 3 & 4 & 5 & 6 & 7 & 8 & 9 & 10 & Vivo & 1 & 2 & 3 & de neonatas \\
\hline & & & & & & 18/ago. & 5 & 5 & 5 & 5 & & & & & & & & & & & \\
\hline & & & & & & 20/ago. & 1 & 2 & 0 & 0 & & & & & & & & & & & \\
\hline & & & & & & 22/ago. & 0 & 0 & 0 & 0 & & & & & & & & & & & \\
\hline & & & & & & 25/ago. & 0 & 0 & 0 & 0 & & & & & & & & & & & \\
\hline & & & & & & & & & & & & & & & & & & & & & \\
\hline
\end{tabular}




\section{ipen}

Teste de avaliação da toxicidade crônica para Ceriodaphnia silvestrii

\begin{tabular}{|c|c|c|c|c|c|c|c|}
\hline \multicolumn{4}{|c|}{ Início do teste: $19 / 07$} & \multicolumn{4}{|c|}{ Final do teste: $26 / 07$} \\
\hline \multicolumn{4}{|c|}{ Água de cultivo e/ou de diluição } & \multicolumn{3}{|c|}{ Amostra } & \multirow{2}{*}{ Responsável } \\
\hline Lote & pH & $\mathrm{OD}\left(\mathrm{mg} \mathrm{L}^{-1}\right)$ & Cond. $\left(\mu \mathrm{S} \mathrm{cm}^{-1}\right)$ & Origem & Tipo & Lote & \\
\hline & 7.02 & 7.5 & 201 & $\mathrm{NaCl}$ & Substância & & Gustavo \\
\hline
\end{tabular}

\begin{tabular}{|c|c|c|c|c|c|c|c|c|c|c|c|c|c|c|c|c|c|c|c|c|c|}
\hline \multicolumn{5}{|c|}{ Inicio do teste } & \multicolumn{5}{|l|}{ Hora: } & \multicolumn{8}{|c|}{ Final do teste: } & \multicolumn{4}{|l|}{ Hora: } \\
\hline \multicolumn{7}{|c|}{ Água de cultivo e/ou de diluição } & \multicolumn{11}{|c|}{ Amostra } & \multicolumn{4}{|c|}{ Responsável } \\
\hline \multicolumn{7}{|c|}{ Lote: } & \multicolumn{6}{|c|}{ Origem } & \multicolumn{5}{|c|}{$\begin{array}{c}\text { Tipo } \\
\text { Propranolol }\end{array}$} & \multicolumn{4}{|c|}{ GUSTAVO } \\
\hline \multicolumn{2}{|c|}{ pH } & \multicolumn{2}{|c|}{$\begin{array}{c}\text { OD } \\
(\mathrm{mg} / \mathrm{L})\end{array}$} & \multicolumn{2}{|c|}{$\begin{array}{c}\text { Cond. } \\
(\mathrm{mS25} / \mathrm{cm})\end{array}$} & \multirow[t]{2}{*}{ Data } & \multicolumn{5}{|c|}{ CONTROLE } & \multicolumn{6}{|c|}{ Réplica } & \multicolumn{3}{|c|}{ Número de Neonatas } & \multirow{2}{*}{$\begin{array}{l}\text { Observação } \\
\text { de neonatas }\end{array}$} \\
\hline ini & fin & ini & fin & ini & fin & & 1 & 2 & 3 & 4 & 5 & 6 & 7 & 8 & 9 & 1 & Vivo & 1 & 2 & 3 & \\
\hline & & & & & & 19/jul. & 5 & 5 & 5 & 5 & & & & & & & & & & & \\
\hline & & & & & & 21/jul. & 4 & 5 & 5 & 5 & & & & & & & & & & & \\
\hline & & & & & & 23/jul. & 21 & 26 & 28 & 20 & & & & & & & & & & & \\
\hline & & & & & & 26/jul. & 59 & 77 & 79 & 53 & & & & & & & & & & & \\
\hline & & & & & & & & & & & & & & & & & & & & & \\
\hline
\end{tabular}




\begin{tabular}{|c|c|c|c|c|c|c|c|c|c|c|c|c|c|c|c|c|c|c|c|c|c|}
\hline \multicolumn{5}{|c|}{ Inicio do teste } & \multicolumn{5}{|c|}{ Hora: } & \multicolumn{8}{|c|}{ Final do teste: } & \multicolumn{4}{|l|}{ Hora: } \\
\hline \multicolumn{7}{|c|}{ Água de cultivo e/ou de diluição } & \multicolumn{11}{|c|}{ Amostra } & \multicolumn{4}{|c|}{ Responsável } \\
\hline \multicolumn{7}{|c|}{ C } & \multicolumn{6}{|c|}{ Origem } & \multicolumn{5}{|c|}{ Tipo } & & & & \\
\hline \multicolumn{2}{|c|}{ pH } & \multicolumn{2}{|c|}{$\begin{array}{c}\text { OD } \\
(\mathrm{mg} / \mathrm{L})\end{array}$} & \multicolumn{2}{|c|}{$\begin{array}{c}\text { Cond. } \\
(\mathrm{mS25} / \mathrm{cm})\end{array}$} & \multirow[t]{2}{*}{ Data } & \multicolumn{5}{|c|}{$0,04 \mathrm{~g} / \mathrm{L}$} & \multicolumn{6}{|c|}{ Réplica } & \multicolumn{3}{|c|}{ Número de Neonatas } & \multirow{2}{*}{$\begin{array}{l}\text { Observação } \\
\text { de neonatas }\end{array}$} \\
\hline ini & fin & ini & fin & ini & fin & & 1 & 2 & 3 & 4 & 5 & 6 & 7 & 8 & 9 & 10 & Vivo & 1 & 2 & 3 & \\
\hline & & & & & & 19/jul. & 5 & 5 & 5 & 5 & & & & & & & & & & & \\
\hline & & & & & & 21/jul. & 5 & 4 & 5 & 4 & & & & & & & & & & & \\
\hline & & & & & & 23/jul. & 60 & 50 & 56 & 61 & & & & & & & & & & & \\
\hline & & & & & & 26/jul. & 214 & 203 & 197 & 176 & & & & & & & & & & & \\
\hline & & & & & & & & & & & & & & & & & & & & & \\
\hline & & & & & & & & & & & & & & & & & & & & & \\
\hline
\end{tabular}

\begin{tabular}{|c|c|c|c|c|c|c|c|c|c|c|c|c|c|c|c|c|c|c|c|c|c|}
\hline \multirow{2}{*}{\multicolumn{7}{|c|}{\begin{tabular}{|l|l|} 
Inicio do teste & Hora: \\
Água de cultivo e/ou de diluição \\
\end{tabular}}} & & & & \multicolumn{8}{|c|}{ Final do teste: } & \multicolumn{4}{|l|}{ Hora: } \\
\hline & & & & & & & \multicolumn{11}{|c|}{ Amostra } & \multicolumn{4}{|c|}{ Responsável } \\
\hline \multicolumn{7}{|c|}{ Lote: } & \multicolumn{6}{|c|}{ Origem } & \multicolumn{5}{|c|}{ Tipo } & & & & \\
\hline \multicolumn{2}{|c|}{ pH } & \multicolumn{2}{|c|}{$\begin{array}{c}\text { OD } \\
(\mathrm{mg} / \mathrm{L})\end{array}$} & \multicolumn{2}{|c|}{$\begin{array}{c}\text { Cond. } \\
(\mathrm{mS25} / \mathrm{cm})\end{array}$} & \multirow[t]{2}{*}{ Data } & \multicolumn{5}{|c|}{$0,105 \mathrm{~g} / \mathrm{L}$} & \multicolumn{6}{|c|}{ Réplica } & \multicolumn{3}{|c|}{ Número de Neonatas } & \multirow[t]{2}{*}{$\begin{array}{l}\text { Observação } \\
\text { de neonatas }\end{array}$} \\
\hline ini & fin & ini & fin & ini & fin & & $\mathbf{1}$ & 2 & 3 & 4 & 5 & 6 & 7 & 8 & 9 & 10 & Vivo & 1 & 2 & 3 & \\
\hline & & & & & & 19/jul. & 5 & 5 & 5 & 5 & & & & & & & & & & & \\
\hline & & & & & & 21/jul. & 5 & 5 & 5 & 5 & & & & & & & & & & & \\
\hline & & & & & & 23/jul. & 55 & 57 & 69 & 64 & & & & & & & & & & & \\
\hline & & & & & & 26/jul. & 157 & 128 & 176 & 132 & & & & & & & & & & & \\
\hline & & & & & & & & & & & & & & & & & & & & & \\
\hline
\end{tabular}




\begin{tabular}{|c|c|c|c|c|c|c|c|c|c|c|c|c|c|c|c|c|c|c|c|c|c|}
\hline \multicolumn{5}{|c|}{ Inicio do teste } & \multicolumn{5}{|l|}{ Hora: } & \multicolumn{8}{|c|}{ Final do teste: } & \multicolumn{4}{|l|}{ Hora: } \\
\hline \multicolumn{7}{|c|}{ Água de cultivo e/ou de diluição } & \multicolumn{11}{|c|}{ Amostra } & \multicolumn{4}{|c|}{ Responsável } \\
\hline \multicolumn{7}{|c|}{ 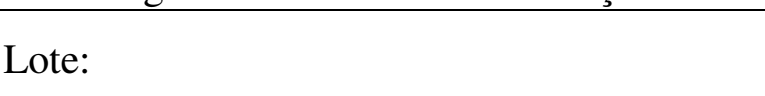 } & \multicolumn{6}{|c|}{ Origem } & \multicolumn{5}{|c|}{ Tipo } & & & & \\
\hline \multirow{2}{*}{\multicolumn{2}{|c|}{ pH }} & \multirow{2}{*}{\multicolumn{2}{|c|}{$\begin{array}{c}\text { OD } \\
(\mathbf{m g} / \mathbf{L})\end{array}$}} & \multirow{2}{*}{\multicolumn{2}{|c|}{$\begin{array}{c}\text { Cond. } \\
(\mathrm{mS25} / \mathrm{cm})\end{array}$}} & \multirow{3}{*}{ Data } & \multirow{2}{*}{\multicolumn{5}{|c|}{$0,275 \mathrm{~g} / \mathrm{L}$}} & \multirow{2}{*}{\multicolumn{6}{|c|}{ Réplica }} & \multirow{2}{*}{\multicolumn{3}{|c|}{ Número de Neonatas }} & \\
\hline & & & & & & & & & & & & & & & & & & & & & \multirow[t]{2}{*}{$\begin{array}{l}\text { Observação } \\
\text { de neonatas }\end{array}$} \\
\hline ini & fin & ini & fin & ini & fin & & 1 & 2 & 3 & 4 & 5 & 6 & 7 & 8 & 9 & 10 & Vivo & 1 & 2 & 3 & \\
\hline & & & & & & 19/jul. & 5 & 5 & 5 & 5 & & & & & & & & & & & \\
\hline & & & & & & 21/jul. & 3 & 3 & 4 & 5 & & & & & & & & & & & \\
\hline & & & & & & 23/jul. & 20 & 22 & 27 & 48 & & & & & & & & & & & \\
\hline & & & & & & 26/jul. & 75 & 97 & 118 & 131 & & & & & & & & & & & \\
\hline & & & & & & & & & & & & & & & & & & & & & \\
\hline & & & & & & & & & & & & & & & & & & & & & \\
\hline
\end{tabular}

\begin{tabular}{|c|c|c|c|c|c|c|c|c|c|c|c|c|c|c|c|c|c|c|c|c|c|}
\hline \multicolumn{5}{|c|}{ Inicio do teste } & \multicolumn{5}{|c|}{ Hora: } & \multicolumn{8}{|c|}{ Final do teste: } & \multicolumn{4}{|l|}{ Hora: } \\
\hline \multicolumn{7}{|c|}{ Água de cultivo e/ou de diluição } & \multicolumn{11}{|c|}{ Amostra } & \multicolumn{4}{|c|}{ Responsável } \\
\hline \multicolumn{7}{|c|}{ Lote: } & \multicolumn{6}{|c|}{ Origem } & \multicolumn{5}{|c|}{ Tipo } & & & & \\
\hline \multicolumn{2}{|c|}{$\mathbf{p H}$} & \multicolumn{2}{|c|}{$\begin{array}{c}\text { OD } \\
(\mathrm{mg} / \mathrm{L})\end{array}$} & \multicolumn{2}{|c|}{$\begin{array}{c}\text { Cond. } \\
(\mathrm{mS} 25 / \mathrm{cm})\end{array}$} & \multirow[t]{2}{*}{ Data } & \multicolumn{5}{|c|}{$0,723 \mathrm{~g} / \mathrm{L}$} & \multicolumn{6}{|c|}{ Réplica } & \multicolumn{3}{|c|}{ Número de Neonatas } & \multirow{2}{*}{$\begin{array}{l}\text { Observação } \\
\text { de neonatas }\end{array}$} \\
\hline \multirow[t]{6}{*}{ ini } & fin & ini & fin & ini & fin & & 1 & 2 & 3 & 4 & 5 & 6 & 7 & 8 & 9 & $\mathbf{1 0}$ & Vivo & 1 & 2 & 3 & \\
\hline & & & & & & 19/jul. & 5 & 5 & 5 & 5 & & & & & & & & & & & \\
\hline & & & & & & $21 /$ jul. & 4 & 4 & 2 & 3 & & & & & & & & & & & \\
\hline & & & & & & 23/jul. & 11 & 14 & 3 & 3 & & & & & & & & & & & \\
\hline & & & & & & 26/jul. & 27 & 18 & 14 & 15 & & & & & & & & & & & \\
\hline & & & & & & & & & & & & & & & & & & & & & \\
\hline
\end{tabular}




\begin{tabular}{|c|c|c|c|c|c|c|c|c|c|c|c|c|c|c|c|c|c|c|c|c|c|}
\hline \multicolumn{5}{|c|}{ Inicio do teste } & \multicolumn{5}{|l|}{ Hora: } & \multicolumn{8}{|c|}{ Final do teste: } & \multicolumn{4}{|l|}{ Hora: } \\
\hline \multicolumn{7}{|c|}{ Água de cultivo e/ou de diluição } & \multicolumn{11}{|c|}{ Amostra } & \multicolumn{4}{|c|}{ Responsável } \\
\hline \multicolumn{7}{|c|}{ Lote: } & \multicolumn{6}{|c|}{ Origem } & \multicolumn{5}{|c|}{ Tipo } & & & & \\
\hline \multicolumn{2}{|c|}{$\mathbf{p H}$} & \multicolumn{2}{|c|}{$\begin{array}{c}\text { OD } \\
(\mathrm{mg} / \mathrm{L})\end{array}$} & \multicolumn{2}{|c|}{$\begin{array}{c}\text { Cond. } \\
(\mathrm{mS25} / \mathrm{cm})\end{array}$} & \multirow[t]{2}{*}{ Data } & \multicolumn{5}{|c|}{$1,9 \mathrm{~g} / \mathrm{L}$} & \multicolumn{6}{|c|}{ Réplica } & \multicolumn{3}{|c|}{ Número de Neonatas } & \multirow{2}{*}{$\begin{array}{l}\text { Observação } \\
\text { de neonatas }\end{array}$} \\
\hline ini & fin & ini & fin & ini & fin & & 1 & 2 & 3 & 4 & 5 & 6 & 7 & 8 & 9 & 10 & Vivo & 1 & 2 & 3 & \\
\hline & & & & & & 19/jul. & 5 & 5 & 5 & 5 & & & & & & & & & & & \\
\hline & & & & & & 21/jul. & 0 & 3 & 1 & 5 & & & & & & & & & & & \\
\hline & & & & & & 23/jul. & 0 & 0 & 0 & 0 & & & & & & & & & & & \\
\hline & & & & & & 26/jul. & 0 & 0 & 0 & 0 & & & & & & & & & & & \\
\hline & & & & & & & & & & & & & & & & & & & & & \\
\hline
\end{tabular}




\section{ipen}

Teste de avaliação da toxicidade crônica para Ceriodaphnia silvestrii

\begin{tabular}{|c|c|c|c|c|c|c|c|}
\hline \multicolumn{4}{|c|}{ Início do teste: $6 / 10$} & \multicolumn{4}{|c|}{ Final do teste: $13 / 10$} \\
\hline \multicolumn{4}{|c|}{ Água de cultivo e/ou de diluição } & \multicolumn{3}{|c|}{ Amostra } & \multirow{2}{*}{ Responsável } \\
\hline Lote & pH & $\mathrm{OD}\left(\mathrm{mg} \mathrm{L}^{-1}\right)$ & Cond. $\left(\mu \mathrm{S} \mathrm{cm}^{-1}\right)$ & Origem & Tipo & Lote & \\
\hline & 7.0 & 8.1 & 197 & $\mathrm{NaCl}$ & Substância & & Gustavo \\
\hline
\end{tabular}

\begin{tabular}{|c|c|c|c|c|c|c|c|c|c|c|c|c|c|c|c|c|c|c|c|c|c|}
\hline \multicolumn{5}{|c|}{ Inicio do teste } & \multicolumn{5}{|c|}{ Hora: } & \multicolumn{8}{|c|}{ Final do teste: } & \multicolumn{4}{|l|}{ Hora: } \\
\hline \multicolumn{7}{|c|}{ Água de cultivo e/ou de diluição } & \multicolumn{11}{|c|}{ Amostra } & \multicolumn{4}{|c|}{ Responsável } \\
\hline \multicolumn{7}{|c|}{ Lote: } & \multicolumn{6}{|c|}{ Origem } & \multicolumn{5}{|c|}{$\begin{array}{c}\text { Tipo } \\
\text { Propranolol }\end{array}$} & \multicolumn{4}{|c|}{ GUSTAVO } \\
\hline \multicolumn{2}{|c|}{ pH } & \multicolumn{2}{|c|}{$\begin{array}{c}\text { OD } \\
(\mathrm{mg} / \mathrm{L})\end{array}$} & \multicolumn{2}{|c|}{$\begin{array}{c}\text { Cond. } \\
(\mathrm{mS25} / \mathrm{cm})\end{array}$} & \multirow[t]{2}{*}{ Data } & \multicolumn{5}{|c|}{ CONTROLE } & \multicolumn{6}{|c|}{ Réplica } & \multicolumn{3}{|c|}{ Número de Neonatas } & \multirow{2}{*}{$\begin{array}{l}\text { Observação } \\
\text { de neonatas }\end{array}$} \\
\hline ini. & fin & ini & fin & ini & fin & & $\mathbf{1}$ & 2 & 3 & 4 & 5 & 6 & 7 & 8 & ( & 1 & Vivo & 1 & 2 & 3 & \\
\hline & & & & & & 6/out. & 5 & 5 & 5 & 5 & & & & & & & & & & & \\
\hline & & & & & & $8 /$ out. & 5 & 5 & 5 & 4 & & & & & & & & & & & \\
\hline & & & & & & 10/out. & 26 & 27 & 24 & 20 & & & & & & & & & & & \\
\hline & & & & & & 13/out. & 87 & 82 & 62 & 64 & & & & & & & & & & & \\
\hline & & & & & & & & & & & & & & & & & & & & & \\
\hline
\end{tabular}




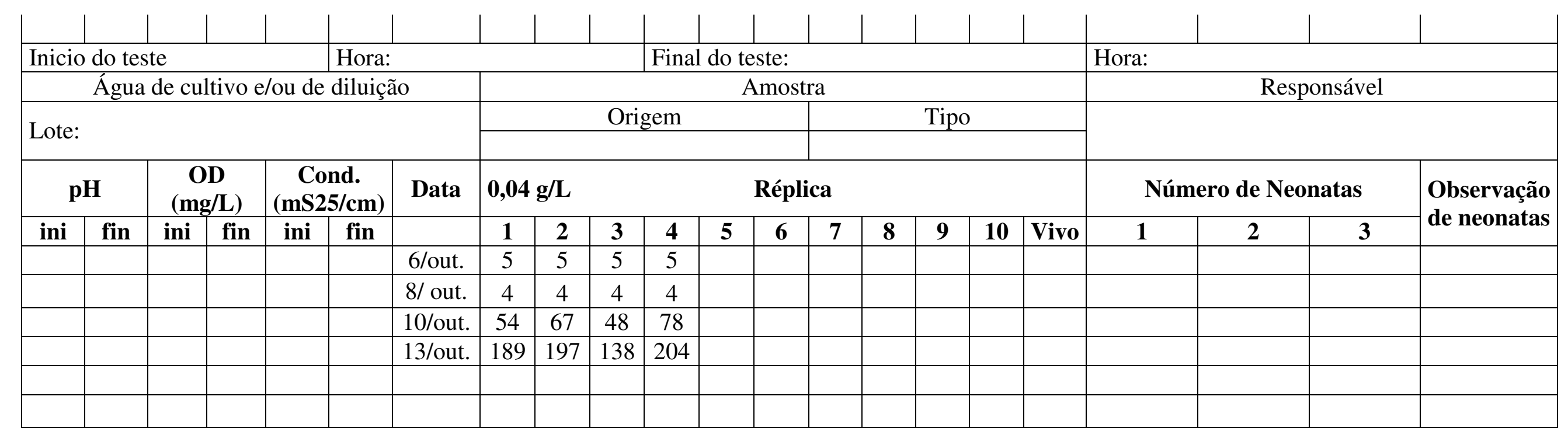

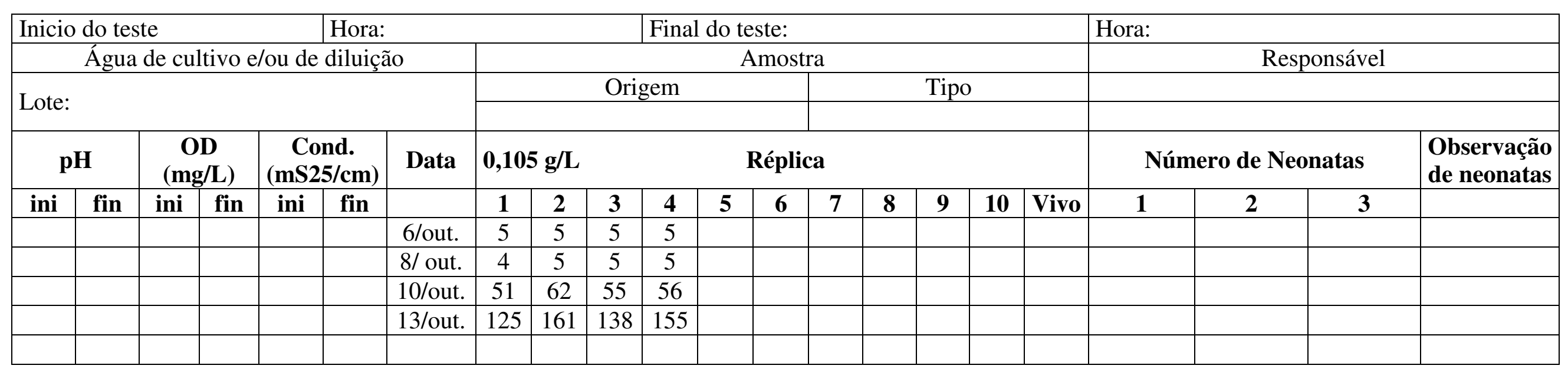




\begin{tabular}{|c|c|c|c|c|c|c|c|c|c|c|c|c|c|c|c|c|c|c|c|c|c|}
\hline \multicolumn{5}{|c|}{ Inicio do teste } & \multicolumn{5}{|c|}{ Hora: } & \multicolumn{8}{|c|}{ Final do teste: } & \multirow{2}{*}{\multicolumn{4}{|c|}{ Hora: }} \\
\hline \multicolumn{7}{|c|}{ Água de cultivo e/ou de diluição } & \multicolumn{11}{|c|}{ Amostra } & & & & Responsável \\
\hline \multicolumn{7}{|c|}{ Lote: } & \multicolumn{6}{|c|}{ Origem } & \multicolumn{5}{|c|}{ Tipo } & & & & \\
\hline & & & & & & & & & & & & & & & & & & \multirow{2}{*}{\multicolumn{3}{|c|}{ Número de Neonatas }} & \multirow{3}{*}{$\begin{array}{l}\text { Observação } \\
\text { de neonatas }\end{array}$} \\
\hline \multicolumn{2}{|c|}{ pH } & \multicolumn{2}{|c|}{$\begin{array}{c}\text { OD } \\
(\mathrm{mg} / \mathrm{L})\end{array}$} & \multicolumn{2}{|c|}{$\begin{array}{c}\text { Cond. } \\
(\mathrm{mS25} / \mathrm{cm})\end{array}$} & Data & \multicolumn{5}{|c|}{$0,275 \mathrm{~g} / \mathrm{L}$} & \multicolumn{6}{|c|}{ Réplica } & & & & \\
\hline ini & fin & ini & fin & ini & fin & & 1 & 2 & 3 & 4 & 5 & 6 & 7 & 8 & 9 & 10 & Vivo & 1 & 2 & 3 & \\
\hline & & & & & & 6/out. & 5 & 5 & 5 & 5 & & & & & & & & & & & \\
\hline & & & & & & 8/ out. & 5 & 5 & 4 & 4 & & & & & & & & & & & \\
\hline & & & & & & 10/out. & 44 & 39 & 24 & 28 & & & & & & & & & & & \\
\hline & & & & & & 13/out. & 118 & 139 & 98 & 106 & & & & & & & & & & & \\
\hline & & & & & & & & & & & & & & & & & & & & & \\
\hline & & & & & & & & & & & & & & & & & & & & & \\
\hline
\end{tabular}

\begin{tabular}{|c|c|c|c|c|c|c|c|c|c|c|c|c|c|c|c|c|c|c|c|c|c|}
\hline \multicolumn{5}{|c|}{ Inicio do teste } & \multicolumn{5}{|l|}{ Hora: } & \multicolumn{8}{|c|}{ Final do teste: } & \multicolumn{4}{|l|}{ Hora: } \\
\hline \multicolumn{7}{|c|}{ Água de cultivo e/ou de diluição } & \multicolumn{11}{|c|}{ Amostra } & \multicolumn{4}{|c|}{ Responsável } \\
\hline \multicolumn{7}{|c|}{ C } & \multicolumn{6}{|c|}{ Origem } & \multicolumn{5}{|c|}{ Tipo } & \multirow{2}{*}{\multicolumn{3}{|c|}{ Número de Neonatas }} & \multirow{3}{*}{$\begin{array}{l}\text { Observação } \\
\text { de neonatas }\end{array}$} \\
\hline \multicolumn{2}{|c|}{ pH } & \multicolumn{2}{|c|}{$\begin{array}{c}\text { OD } \\
(\mathrm{mg} / \mathrm{L})\end{array}$} & \multicolumn{2}{|c|}{$\begin{array}{c}\text { Cond. } \\
(\mathrm{mS} 25 / \mathrm{cm})\end{array}$} & \multirow[t]{2}{*}{ Data } & \multicolumn{11}{|c|}{$0,723 \mathrm{~g} / \mathrm{L}$} & & & & \\
\hline ini & fin & ini & fin & ini & fin & & 1 & 2 & 3 & 4 & 5 & 6 & 7 & 8 & 9 & 10 & Vivo & 1 & 2 & 3 & \\
\hline & & & & & & 6/out. & 5 & 5 & 5 & 5 & & & & & & & & & & & \\
\hline & & & & & & $8 /$ out. & 3 & 1 & 2 & 2 & & & & & & & & & & & \\
\hline & & & & & & 10/out. & 7 & 1 & 4 & 2 & & & & & & & & & & & \\
\hline & & & & & & 13/out. & 18 & 0 & 20 & 13 & & & & & & & & & & & \\
\hline & & & & & & & & & & & & & & & & & & & & & \\
\hline
\end{tabular}




\begin{tabular}{|c|c|c|c|c|c|c|c|c|c|c|c|c|c|c|c|c|c|c|c|c|c|}
\hline \multirow{2}{*}{\multicolumn{7}{|c|}{\begin{tabular}{c|l} 
Inicio do teste & Hora: \\
Água de cultivo e/ou de diluição
\end{tabular}}} & & & & \multicolumn{8}{|c|}{ Final do teste: } & \multirow{2}{*}{\multicolumn{4}{|c|}{ Hora: }} \\
\hline & & & & & & & \multicolumn{11}{|c|}{ Amostra } & \multicolumn{2}{|c|}{ Responsável } & & \\
\hline \multicolumn{7}{|c|}{ 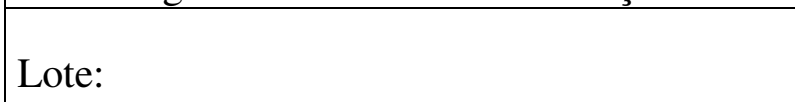 } & \multicolumn{6}{|c|}{ Origem } & \multicolumn{5}{|c|}{ Tipo } & & & & \\
\hline \multicolumn{2}{|c|}{$\mathbf{p H}$} & \multicolumn{2}{|c|}{$\begin{array}{c}\text { OD } \\
(\mathrm{mg} / \mathrm{L})\end{array}$} & \multicolumn{2}{|c|}{$\begin{array}{c}\text { Cond. } \\
(\mathrm{mS} 25 / \mathrm{cm})\end{array}$} & \multirow[t]{2}{*}{ Data } & \multicolumn{5}{|c|}{$1,9 \mathrm{~g} / \mathrm{L}$} & \multicolumn{6}{|c|}{ Réplica } & \multicolumn{3}{|c|}{ Número de Neonatas } & \multirow{2}{*}{$\begin{array}{l}\text { Observação } \\
\text { de neonatas }\end{array}$} \\
\hline \multirow[t]{6}{*}{ ini } & fin & ini & fir & ini & fin & & 1 & 2 & 3 & 4 & 5 & 6 & 7 & 8 & 9 & 10 & Vivo & 1 & 2 & 3 & \\
\hline & & & & & & 6/out. & 5 & 5 & 5 & 5 & & & & & & & & & & & \\
\hline & & & & & & $8 /$ out. & 0 & 1 & 1 & 1 & & & & & & & & & & & \\
\hline & & & & & & 10/out. & 0 & 0 & 1 & 0 & & & & & & & & & & & \\
\hline & & & & & & 13/out. & 0 & 0 & 0 & 0 & & & & & & & & & & & \\
\hline & & & & & & & & & & & & & & & & & & & & & \\
\hline
\end{tabular}




\section{ipen}

Teste de avaliação da toxicidade crônica para Ceriodaphnia silvestrii

\begin{tabular}{|c|c|c|c|c|c|c|c|}
\hline \multicolumn{2}{|l|}{ Início do teste: 13/07 } & \multicolumn{3}{|l|}{ Final do teste: 19/07 } \\
\hline \multicolumn{3}{|c|}{ Água de cultivo e/ou de diluição } & \multicolumn{3}{|c|}{ Responsável } \\
\hline Lote & pH & OD $\left(\mathrm{mg} \mathrm{L}^{-1}\right)$ & Cond. $\left(\mu \mathrm{S} \mathrm{cm}^{-1}\right)$ & Origem & Tipo & Lote & Gustavo \\
\hline
\end{tabular}

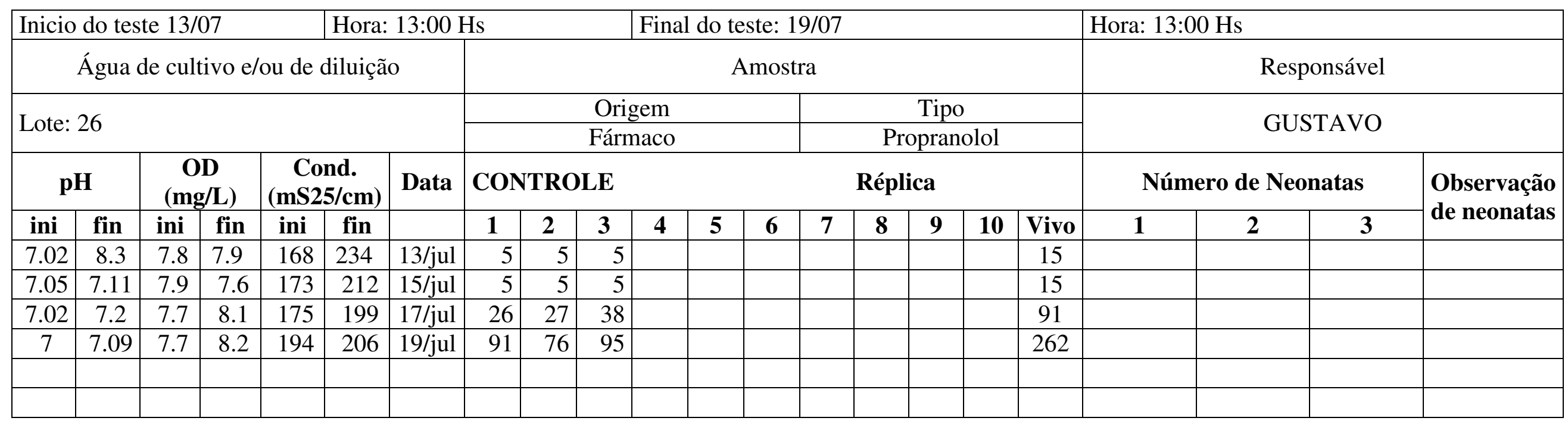




\begin{tabular}{|c|c|c|c|c|c|c|c|c|c|c|c|c|c|c|c|c|c|c|c|c|c|}
\hline \multicolumn{5}{|c|}{ Inicio do teste } & \multicolumn{5}{|c|}{ Hora: } & \multicolumn{8}{|c|}{ Final do teste: } & \multicolumn{4}{|l|}{ Hora: } \\
\hline \multicolumn{7}{|c|}{ Água de cultivo e/ou de diluição } & \multicolumn{11}{|c|}{ Amostra } & \multicolumn{4}{|c|}{ Responsável } \\
\hline \multicolumn{7}{|c|}{ 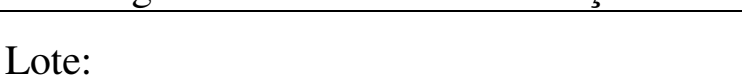 } & \multicolumn{6}{|c|}{ Origem } & \multicolumn{5}{|c|}{ Tipo } & & & & \\
\hline \multicolumn{2}{|c|}{ pH } & \multicolumn{2}{|c|}{$\begin{array}{c}\text { OD } \\
(\mathrm{mg} / \mathrm{L})\end{array}$} & \multicolumn{2}{|c|}{$\begin{array}{c}\text { Cond. } \\
(\mathrm{mS} 25 / \mathrm{cm})\end{array}$} & \multirow[t]{2}{*}{ Data } & \multicolumn{4}{|c|}{$0,16 \mathrm{mg} / \mathrm{L}$} & \multicolumn{7}{|c|}{ Réplica } & \multicolumn{3}{|c|}{ Número de Neonatas } & \multirow{2}{*}{$\begin{array}{r}\text { Observação } \\
\text { de neonatas }\end{array}$} \\
\hline ini & fin & ini & fin & ini & fin & & 1 & 2 & 3 & 4 & 5 & 6 & 7 & 8 & 9 & 10 & Vivo & 1 & 2 & 3 & \\
\hline 7.03 & 7.5 & 7.5 & 8.2 & 195 & 243 & 13/jul & 5 & 5 & 5 & & & & & & & & 15 & & & & \\
\hline 7.01 & 7.23 & 7.5 & 8.2 & 186 & 251 & 15/jul & 5 & 5 & 5 & & & & & & & & 15 & & & & \\
\hline 7.01 & 7.12 & 7.8 & 8.4 & 175 & 199 & $17 /$ jul & 27 & 26 & 29 & & & & & & & & 82 & & & & \\
\hline 7 & 7.42 & 7.8 & 7.9 & 198 & 231 & 19/jul & 102 & 67 & 62 & & & & & & & & 231 & & & & \\
\hline & & & & & & & & & & & & & & & & & & & & & \\
\hline & & & & & & & & & & & & & & & & & & & & & \\
\hline
\end{tabular}

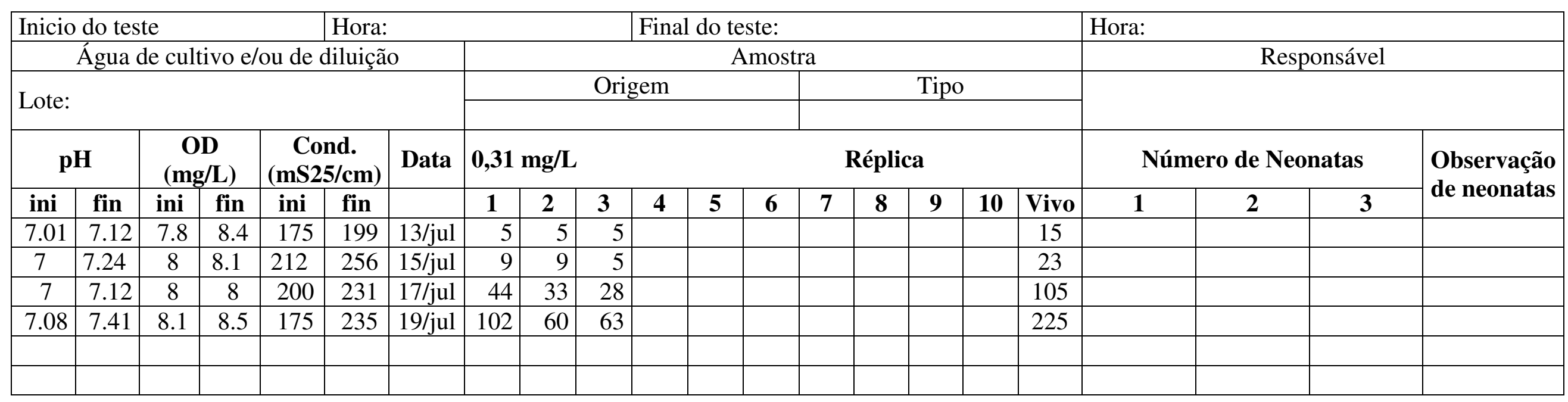




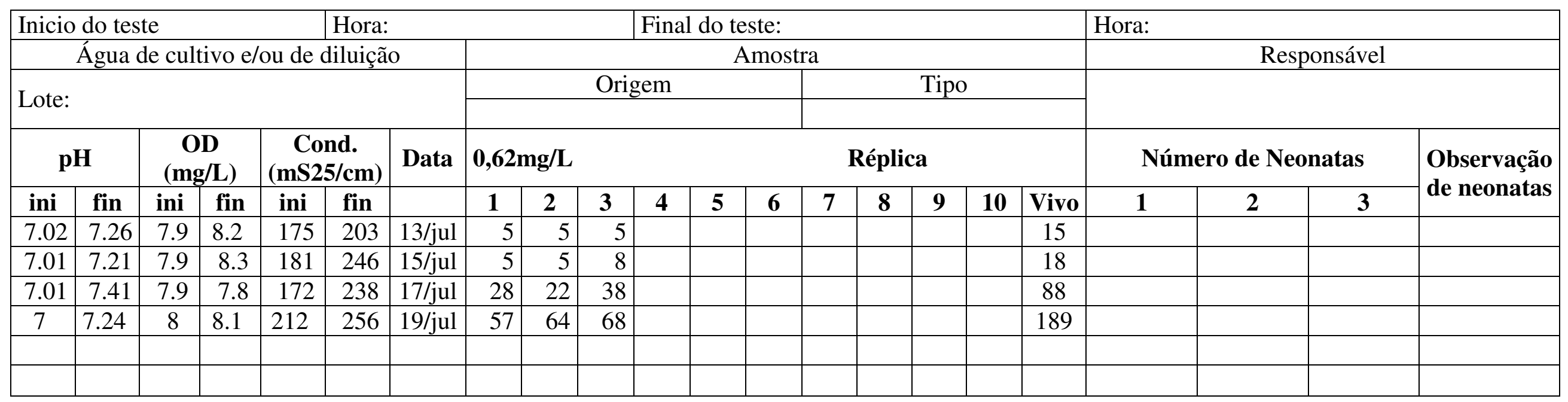

\begin{tabular}{|c|c|c|c|c|c|c|c|c|c|c|c|c|c|c|c|c|c|c|c|c|c|}
\hline \multicolumn{5}{|c|}{ Inicio do teste } & \multicolumn{5}{|c|}{ Hora: } & \multicolumn{8}{|c|}{ Final do teste: } & \multicolumn{4}{|l|}{ Hora: } \\
\hline \multicolumn{7}{|c|}{ Água de cultivo e/ou de diluição } & \multicolumn{11}{|c|}{ Amostra } & \multicolumn{4}{|c|}{ Responsável } \\
\hline \multicolumn{7}{|l|}{ Lote: } & \multicolumn{6}{|c|}{ Origem } & \multicolumn{5}{|c|}{ Tipo } & & & & \\
\hline \multicolumn{2}{|c|}{ pH } & \multicolumn{2}{|c|}{$\begin{array}{c}\text { OD } \\
(\mathrm{mg} / \mathrm{L})\end{array}$} & \multicolumn{2}{|c|}{$\begin{array}{c}\text { Cond. } \\
(\mathrm{mS25} / \mathrm{cm})\end{array}$} & \multirow[t]{2}{*}{ Data } & \multicolumn{4}{|c|}{$1,25 \mathrm{mg} / \mathrm{L}$} & \multicolumn{7}{|c|}{ Réplica } & \multicolumn{3}{|c|}{ Número de Neonatas } & \multirow{2}{*}{$\begin{array}{l}\text { Observação } \\
\text { de neonatas }\end{array}$} \\
\hline ini & fin & ini & fin & ini & fin & & 1 & 2 & 3 & 4 & 5 & 6 & 7 & 8 & 9 & 10 & Vivo & 1 & 2 & 3 & \\
\hline 7 & 7.12 & 8 & 8 & 201 & 231 & 13/jul & 5 & 5 & 5 & & & & & & & & 15 & & & & \\
\hline 7.01 & 7.41 & 7.9 & 8.2 & 188 & 246 & $15 /$ jul & 8 & 5 & 8 & & & & & & & & 21 & & & & \\
\hline 7.03 & 7.8 & 7.9 & 168 & 234 & 8.3 & 17/jul & 27 & 32 & 35 & & & & & & & & 94 & & & & \\
\hline 7.01 & 7.23 & 7.5 & 8.2 & 186 & 251 & 19/jul & 50 & 57 & 61 & & & & & & & & 168 & & & & \\
\hline & & & & & & & & & & & & & & & & & & & & & \\
\hline & & & & & & & & & & & & & & & & & & & & & \\
\hline
\end{tabular}




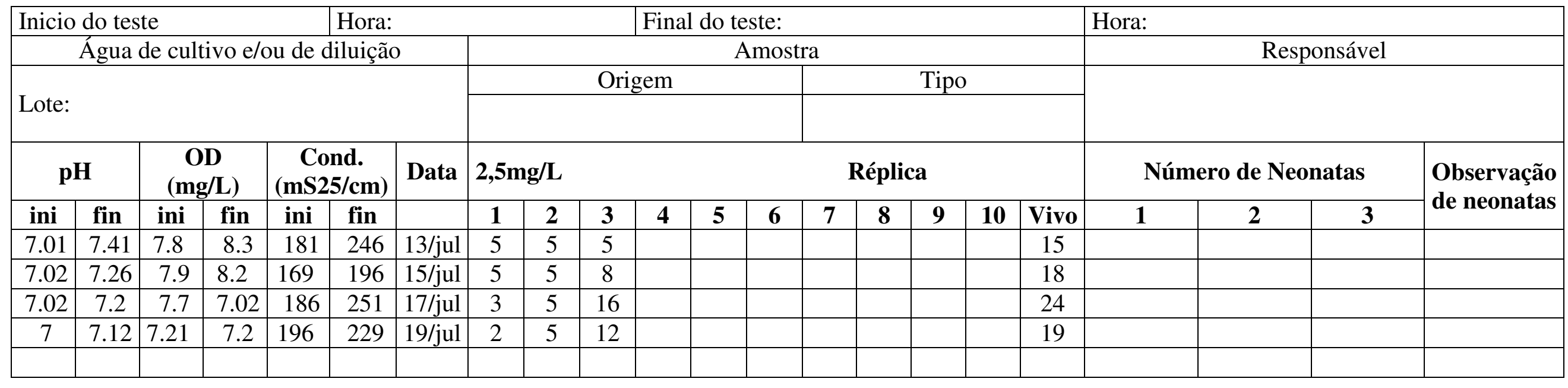


Teste de avaliação da toxicidade crônica para Ceriodaphnia silvestrii

\begin{tabular}{|c|c|c|c|c|c|c|c|}
\hline \multicolumn{2}{|l|}{ Início do teste: 14/08 } & \multicolumn{3}{c|}{ Final do teste: $21 / 08$} \\
\hline \multicolumn{3}{|c|}{ Água de cultivo e/ou de diluição } & \multicolumn{3}{c|}{ Amostra } & Responsável \\
\hline Lote & pH & OD $\left(\mathrm{mg} \mathrm{L}^{-1}\right)$ & Cond. $\left(\mu \mathrm{S} \mathrm{cm}^{-1}\right)$ & Origem & Tipo & Gote \\
\hline & 7.01 & 7.7 & 168 & Produto & Propranolol & Gustavo \\
\hline
\end{tabular}

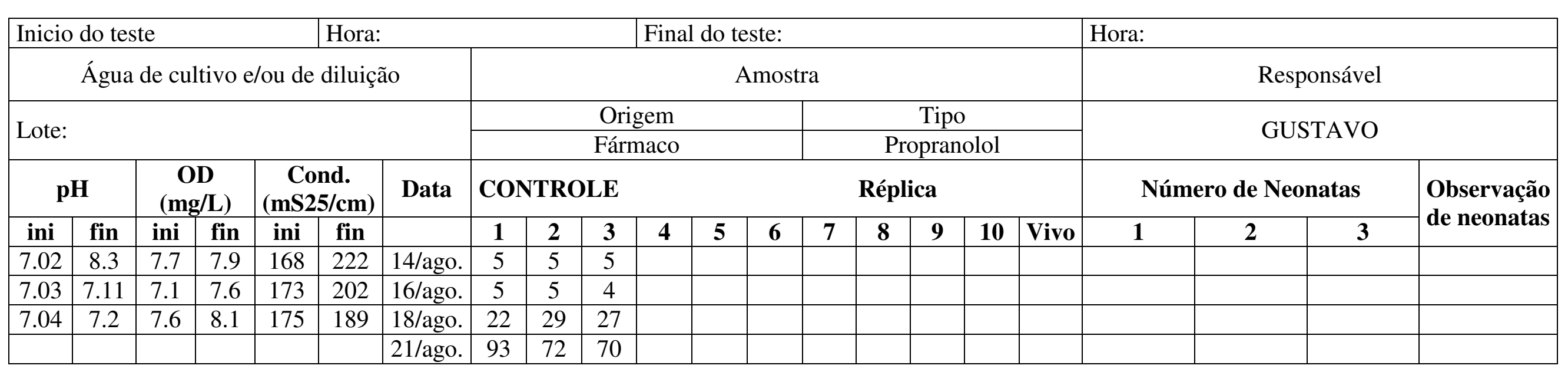




\begin{tabular}{|c|c|c|c|c|c|c|c|c|c|c|c|c|c|c|c|c|c|c|c|c|c|}
\hline \multicolumn{5}{|c|}{ Inicio do teste } & \multicolumn{5}{|l|}{ Hora: } & \multicolumn{8}{|c|}{ Final do teste: } & \multicolumn{4}{|l|}{ Hora: } \\
\hline \multicolumn{7}{|c|}{ Água de cultivo e/ou de diluição } & \multicolumn{11}{|c|}{ Amostra } & \multicolumn{4}{|c|}{ Responsável } \\
\hline \multicolumn{7}{|l|}{ Lote: } & \multicolumn{6}{|c|}{ Origem } & \multicolumn{5}{|c|}{ Tipo } & & & & \\
\hline \multicolumn{2}{|c|}{$\mathbf{p H}$} & \multicolumn{2}{|c|}{$\begin{array}{c}\text { OD } \\
(\mathrm{mg} / \mathrm{L})\end{array}$} & \multicolumn{2}{|c|}{$\begin{array}{c}\text { Cond. } \\
(\mathrm{mS25} / \mathrm{cm})\end{array}$} & Data & \multicolumn{4}{|c|}{$0,16 \mathrm{mg} / \mathrm{L}$} & & & \multicolumn{5}{|c|}{ Réplica } & \multicolumn{3}{|c|}{ Número de Neonatas } & \multirow{2}{*}{$\begin{array}{l}\text { Observação } \\
\text { de neonatas }\end{array}$} \\
\hline ini & fin & ini & fin & ini & fin & & 1 & 2 & 3 & 4 & 5 & 6 & 7 & 8 & 9 & 10 & Vivo & 1 & 2 & 3 & \\
\hline 7.02 & 7.3 & 7.4 & 8.2 & 195 & 243 & 14/ago. & 5 & 5 & 5 & & & & & & & & & & & & \\
\hline 7.05 & 7.2 & 7.6 & 8.2 & 186 & 251 & 16/ago. & 5 & 5 & 5 & & & & & & & & & & & & \\
\hline 7.02 & 7.16 & 7.7 & 8.4 & 175 & 199 & 18/ago. & 29 & 27 & 28 & & & & & & & & & & & & \\
\hline & & & & & & 21/ago. & 84 & 72 & 79 & & & & & & & & & & & & \\
\hline & & & & & & & & & & & & & & & & & & & & & \\
\hline & & & & & & & & & & & & & & & & & & & & & \\
\hline
\end{tabular}

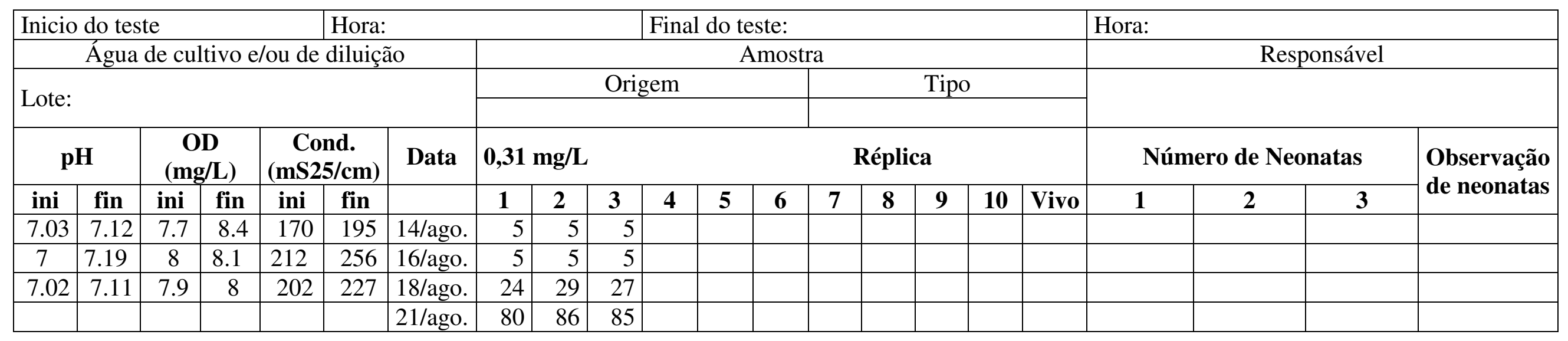




\begin{tabular}{|l|l|l|l|l|l|l|l|l|l|l|l|l|} 
\\
\hline
\end{tabular}

\begin{tabular}{|c|c|c|c|c|c|c|c|c|c|c|c|c|c|c|c|c|c|c|c|c|c|}
\hline \multicolumn{5}{|c|}{ Inicio do teste } & \multicolumn{5}{|l|}{ Hora: } & \multicolumn{8}{|c|}{ Final do teste: } & \multicolumn{4}{|l|}{ Hora: } \\
\hline \multicolumn{7}{|c|}{ Água de cultivo e/ou de diluição } & \multicolumn{11}{|c|}{ Amostra } & \multicolumn{4}{|c|}{ Responsável } \\
\hline \multicolumn{7}{|l|}{ Lote: } & \multicolumn{6}{|c|}{ Origem } & \multicolumn{5}{|c|}{ Tipo } & & & & \\
\hline \multicolumn{2}{|c|}{$\mathbf{p H}$} & \multicolumn{2}{|c|}{$\begin{array}{c}\text { OD } \\
(\mathrm{mg} / \mathrm{L})\end{array}$} & \multicolumn{2}{|c|}{$\begin{array}{c}\text { Cond. } \\
(\mathrm{mS} 25 / \mathrm{cm})\end{array}$} & \multirow[t]{2}{*}{ Data } & \multicolumn{4}{|c|}{$1,25 \mathrm{mg} / \mathrm{L}$} & \multicolumn{7}{|c|}{ Réplica } & \multicolumn{3}{|c|}{ Número de Neonatas } & \multirow{2}{*}{$\begin{array}{l}\text { Observação } \\
\text { de neonatas }\end{array}$} \\
\hline ini & fin & ini & fin & ini & fin & & 1 & 2 & 3 & 4 & 5 & 6 & 7 & 8 & 9 & $\mathbf{1 0}$ & Vivo & 1 & 2 & 3 & \\
\hline 7.03 & 7.12 & 7.7 & 8 & 204 & 230 & 14/ago. & 5 & 5 & 5 & & & & & & & & & & & & \\
\hline 7.01 & 7.38 & 7.9 & 8 & 197 & 248 & 16/ago. & 5 & 5 & 5 & & & & & & & & & & & & \\
\hline \multirow[t]{2}{*}{7} & 7.8 & 8 & 168 & 234 & 7.9 & 18/ago. & 30 & 23 & 18 & & & & & & & & & & & & \\
\hline & & & & & & 21/ago. & 71 & 48 & 44 & & & & & & & & & & & & \\
\hline
\end{tabular}




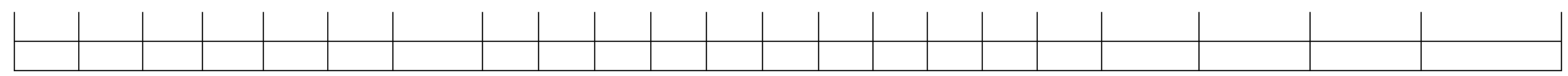

\begin{tabular}{|c|c|c|c|c|c|c|c|c|c|c|c|c|c|c|c|c|c|c|c|c|c|}
\hline \multicolumn{5}{|c|}{ Inicio do teste } & \multicolumn{5}{|c|}{ Hora: } & \multicolumn{8}{|c|}{ Final do teste: } & \multicolumn{4}{|l|}{ Hora: } \\
\hline \multicolumn{7}{|c|}{ Água de cultivo e/ou de diluição } & \multicolumn{11}{|c|}{ Amostra } & \multicolumn{4}{|c|}{ Responsável } \\
\hline \multirow{2}{*}{\multicolumn{7}{|c|}{ S }} & \multirow{2}{*}{\multicolumn{6}{|c|}{ Origem }} & \multirow{2}{*}{\multicolumn{5}{|c|}{ Tipo }} & & & & \\
\hline & & & & & & & & & & & & & & & & & & & & & \\
\hline \multicolumn{2}{|c|}{$\mathbf{p H}$} & \multicolumn{2}{|c|}{$\begin{array}{c}\text { OD } \\
(\mathrm{mg} / \mathrm{L})\end{array}$} & \multicolumn{2}{|c|}{$\begin{array}{c}\text { Cond. } \\
(\mathrm{mS} 25 / \mathrm{cm})\end{array}$} & \multirow[t]{2}{*}{ Data } & \multicolumn{4}{|c|}{$2,5 \mathrm{mg} / \mathrm{L}$} & & & \multicolumn{5}{|c|}{ Réplica } & \multicolumn{3}{|c|}{ Número de Neonatas } & \multirow{2}{*}{$\begin{array}{l}\text { Observação } \\
\text { de neonatas }\end{array}$} \\
\hline ini & fin & ini & fin & ini & fin & & 1 & 2 & 3 & 4 & 5 & & 7 & 8 & 9 & $\mathbf{1 0}$ & Vivo & 1 & 2 & 3 & \\
\hline 7.03 & 7.40 & 7.7 & 8.0 & 180 & 235 & 14/ago. & 5 & 5 & 5 & & & & & & & & & & & & \\
\hline 7.01 & 7.26 & 7.9 & 8.4 & 170 & 198 & 16/ago. & 2 & 2 & 1 & & & & & & & & & & & & \\
\hline \multirow[t]{3}{*}{7.02} & 7.22 & 7.5 & 7.1 & 189 & 258 & 18/ago. & 5 & 7 & 3 & & & & & & & & & & & & \\
\hline & & & & & & 21/ago. & 13 & 16 & 8 & & & & & & & & & & & & \\
\hline & & & & & & & & & & & & & & & & & & & & & \\
\hline
\end{tabular}




\section{ipen}

\section{Teste de avaliação da toxicidade crônica para Ceriodaphnia silvestrii}

\begin{tabular}{|c|c|c|c|c|c|c|c|}
\hline \multicolumn{4}{|c|}{ Início do teste: $18 / 09$} & \multicolumn{4}{|c|}{ Final do teste: $25 / 09$} \\
\hline \multicolumn{4}{|c|}{ Água de cultivo e/ou de diluição } & \multicolumn{3}{|c|}{ Amostra } & \multirow{2}{*}{ Responsável } \\
\hline Lote & pH & OD $\left(\mathrm{mg} \mathrm{L}^{-1}\right)$ & Cond. $\left(\mu \mathrm{S} \mathrm{cm}^{-1}\right)$ & Origem & Tipo & Lote & \\
\hline & 7.0 & 8.0 & 170 & Produto & Propranolol & & Gustavo \\
\hline
\end{tabular}

\begin{tabular}{|c|c|c|c|c|c|c|c|c|c|c|c|c|c|c|c|c|c|c|c|c|c|}
\hline \multicolumn{5}{|c|}{ Inicio do teste } & \multicolumn{5}{|c|}{ Hora: } & \multicolumn{8}{|c|}{ Final do teste: } & \multicolumn{4}{|l|}{ Hora: } \\
\hline \multicolumn{7}{|c|}{ Água de cultivo e/ou de diluição } & \multicolumn{11}{|c|}{ Amostra } & \multicolumn{4}{|c|}{ Responsável } \\
\hline \multirow{2}{*}{\multicolumn{7}{|c|}{ Lote: }} & \multirow{2}{*}{\multicolumn{6}{|c|}{$\begin{array}{c}\text { Origem } \\
\text { Fármaco } \\
\end{array}$}} & \multirow{2}{*}{\multicolumn{5}{|c|}{$\begin{array}{c}\text { Tipo } \\
\text { Propranolol } \\
\end{array}$}} & \multirow{2}{*}{\multicolumn{4}{|c|}{ GUSTAVO }} \\
\hline & & & & & & & & & & & & & & & & & & & & & \\
\hline \multicolumn{2}{|c|}{ pH } & \multicolumn{2}{|c|}{$\begin{array}{c}\text { OD } \\
(\mathrm{mg} / \mathrm{L})\end{array}$} & \multicolumn{2}{|c|}{$\begin{array}{c}\text { Cond. } \\
(\mathrm{mS25} / \mathrm{cm})\end{array}$} & \multirow[t]{2}{*}{ Data } & \multicolumn{4}{|c|}{ CONTROLE } & \multicolumn{7}{|c|}{ Réplica } & \multicolumn{3}{|c|}{ Número de Neonatas } & \multirow{2}{*}{$\begin{array}{l}\text { Observaçãc } \\
\text { de neonatas }\end{array}$} \\
\hline ini & fin & ini & fin & ini & fin & & 1 & 2 & 3 & 4 & 5 & 6 & 7 & 8 & 9 & 10 & Vivo & 1 & 2 & 3 & \\
\hline 7.0 & & 7.5 & & 175 & & 18/ago. & 5 & 5 & 5 & & & & & & & & & & & & \\
\hline 7.01 & 7.2 & 7.2 & 7.6 & 176 & 200 & 20/ago. & 5 & 5 & 5 & & & & & & & & & & & & \\
\hline \multirow[t]{4}{*}{7.05} & 7.15 & 7.3 & 8.1 & 181 & 212 & 22/ago. & 24 & 27 & 21 & & & & & & & & & & & & \\
\hline & & & & & & 25/ago. & 88 & 71 & 97 & & & & & & & & & & & & \\
\hline & & & & & & & & & & & & & & & & & & & & & \\
\hline & & & & & & & & & & & & & & & & & & & & & \\
\hline
\end{tabular}




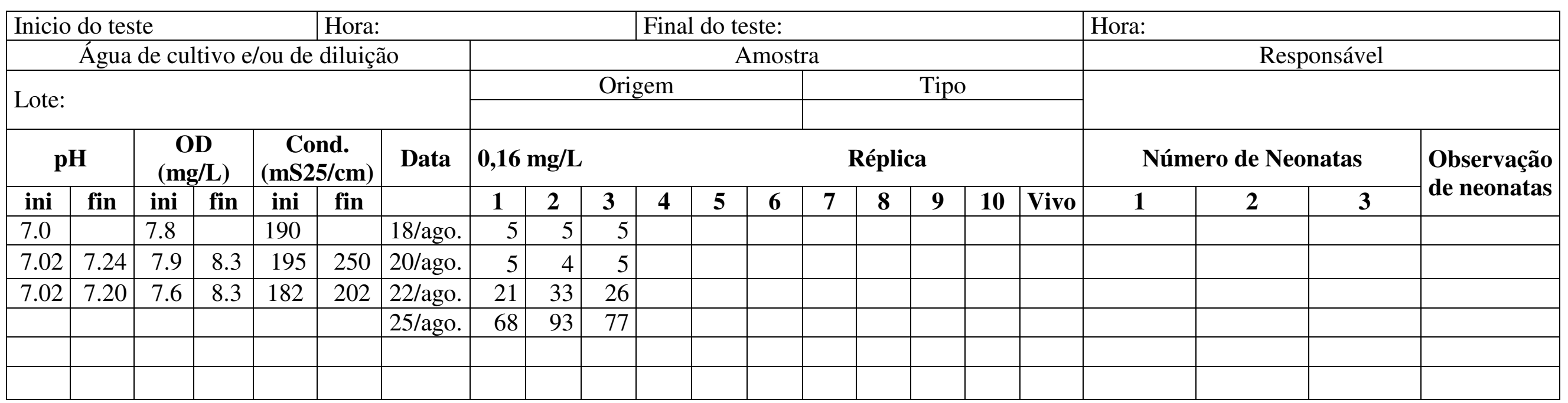

\begin{tabular}{|c|c|c|c|c|c|c|c|c|c|c|c|c|c|c|c|c|c|c|c|c|c|}
\hline Inicio & do tes & & & & Hora: & & & & & Fina & do & & & & & & & Hora: & & & \\
\hline & Água & de cu & tivo e & ou de & diluiçç & & & & & & & no & & & & & & & & áve & \\
\hline I te. & & & & & & & & & Orig & $\mathrm{em}$ & & & & & Tip & & & & & & \\
\hline $\mathbf{p}$ & H & $\begin{array}{r}\mathbf{C} \\
(\mathbf{m} \\
\end{array}$ & & $\begin{array}{r}\mathbf{C c} \\
(\mathrm{mS} 2 \\
\end{array}$ & id. & Data & 0,31 I & 1g/L & & & & & & ép & & & & & de & & $\begin{array}{l}\text { Observação } \\
\text { de neonatas }\end{array}$ \\
\hline ini & fin & ini & fin & ini & fin & & 1 & 2 & 3 & 4 & 5 & 6 & 7 & 8 & 9 & 10 & Vivo & 1 & 2 & 3 & \\
\hline 7.01 & & 7.7 & & 175 & & 18/ago. & 5 & 5 & 5 & & & & & & & & & & & & \\
\hline 7 & 7.15 & 8 & 8.2 & 212 & 256 & 20/ago. & 5 & 5 & 5 & & & & & & & & & & & & \\
\hline 7.01 & 7.24 & 7.9 & 8.1 & 202 & 242 & 22/ago. & 30 & 25 & 29 & & & & & & & & & & & & \\
\hline & & & & & & 25/ago. & 97 & 71 & 76 & & & & & & & & & & & & \\
\hline & & & & & & & & & & & & & & & & & & & & & \\
\hline & & & & & & & & & & & & & & & & & & & & & \\
\hline
\end{tabular}




\begin{tabular}{|c|c|c|c|c|c|c|c|c|c|c|c|c|c|c|c|c|c|c|c|c|c|}
\hline \multirow{2}{*}{\multicolumn{7}{|c|}{\begin{tabular}{|l|l} 
Inicio do teste & Hora: \\
Água de cultivo e/ou de diluição
\end{tabular}}} & & & & \multicolumn{8}{|c|}{ Final do teste: } & \multicolumn{4}{|l|}{ Hora: } \\
\hline & & & & & & & & & & & & no & & & & & & & & áve & \\
\hline Lote: & & & & & & & & & Orig & $\mathrm{em}$ & & & & & Tip & & & & & & \\
\hline & & & & $\begin{array}{r}\text { Co } \\
(\mathrm{mS2}\end{array}$ & \begin{tabular}{l|l} 
nd. \\
$5 / \mathrm{cm})$
\end{tabular} & Data & 0,62 I & $g / L$ & & & & & & ép & & & & & de & & $\begin{array}{l}\text { Observação } \\
\text { de neonatas }\end{array}$ \\
\hline ini & fin & ini & fin & ini & fin & & 1 & 2 & 3 & 4 & 5 & 6 & 7 & 8 & 9 & 10 & Vivo & 1 & 2 & 3 & \\
\hline 7.04 & & 7.7 & & 170 & 209 & 18/ago. & 5 & 5 & 5 & & & & & & & & & & & & \\
\hline 7.02 & 7.29 & 7.8 & 8.5 & 180 & 247 & 20/ago. & 4 & 5 & 5 & & & & & & & & & & & & \\
\hline 7.0 & 7.31 & 7.7 & 7.8 & 197 & 251 & 22/ago. & 19 & 22 & 25 & & & & & & & & & & & & \\
\hline & & & & & & 25/ago. & 67 & 60 & 78 & & & & & & & & & & & & \\
\hline & & & & & & & & & & & & & & & & & & & & & \\
\hline & & & & & & & & & & & & & & & & & & & & & \\
\hline
\end{tabular}

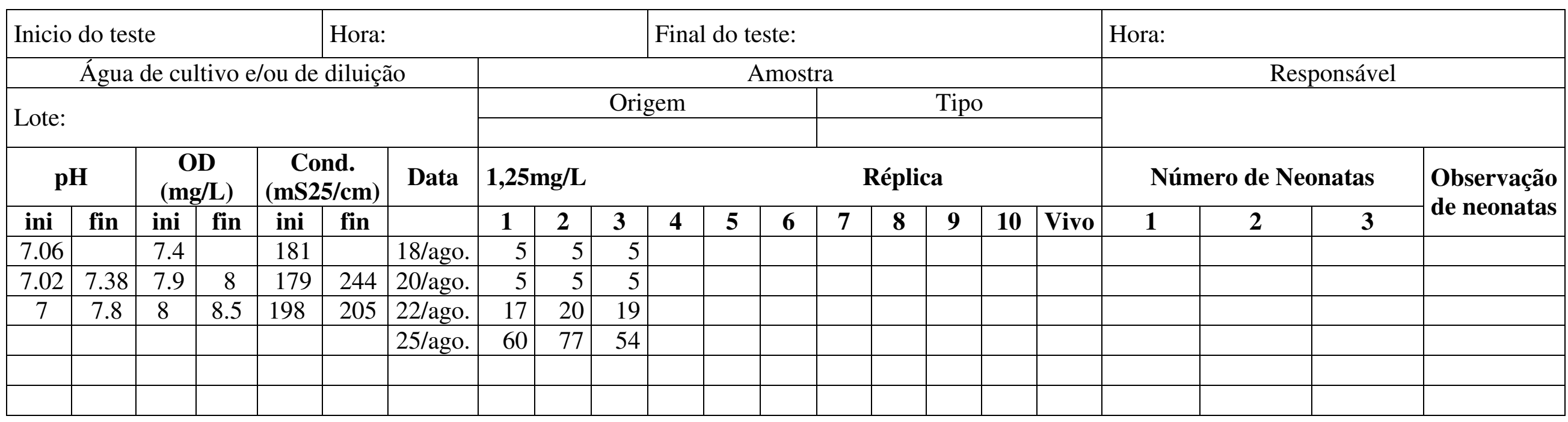




\begin{tabular}{|c|c|c|c|c|c|c|c|c|c|c|c|c|c|c|c|c|c|c|c|c|c|}
\hline Inicio & do tes & & & & Hora: & & & & & Fin: & do $t$ & & & & & & & Hora: & & & \\
\hline & Água & de cu & ivo & ou de & $\overline{\text { diluiçã }}$ & & & & & & & nos & & & & & & & & sáve & \\
\hline & & & & & & & & & Orig & $\mathrm{em}$ & & & & & Tip & & & & & & \\
\hline Lote. & & & & & & & & & & & & & & & & & & & & & \\
\hline & & $\begin{array}{r}\mathbf{C} \\
(\mathbf{m}\end{array}$ & & $\begin{array}{r}\mathrm{Co} \\
(\mathrm{mS} 2\end{array}$ & $\begin{array}{l}\text { nd. } \\
5 / \mathrm{cm})\end{array}$ & Data & $2,5 \mathrm{~m}$ & & & & & & & épli & & & & & de & & Observação \\
\hline ini & fin & ini & fin & ini & fin & & 1 & 2 & 3 & 4 & 5 & 6 & 7 & 8 & 9 & 10 & Vivo & 1 & 2 & 3 & de neonatas \\
\hline 7.01 & & 8.1 & & 200 & & 18/ago. & 5 & 5 & 5 & & & & & & & & & & & & \\
\hline 7.0 & 7.39 & 7.9 & 8.3 & 170 & 198 & 20/ago. & 4 & 5 & 2 & & & & & & & & & & & & \\
\hline 7.01 & 7.2 & 7.5 & 7.4 & 189 & 258 & 22/ago. & 11 & 12 & 0 & & & & & & & & & & & & \\
\hline & & & & & & 25/ago. & 21 & 14 & 0 & & & & & & & & & & & & \\
\hline & & & & & & & & & & & & & & & & & & & & & \\
\hline
\end{tabular}




\section{Apêndice 4}

Planilha do crescimento populacional de C. silvestrii para volumes de 75 e $150 \mathrm{~mL}$ e sumário estatístico da comparação de curvas destas populações. 
Crescimento populacional para Ceriodaphnia silvestrii em $75 \mathrm{~mL}$

\begin{tabular}{|c|c|c|c|c|c|c|c|c|c|c|c|c|c|c|}
\hline & & \multicolumn{7}{|c|}{ Final do teste: $15 / 03 / 2007$} \\
\hline \multicolumn{8}{|c|}{ Água de cultivo e/ou de diluição } & \multicolumn{4}{|c|}{\begin{tabular}{l|l} 
Amostra &
\end{tabular}} & \multirow{3}{*}{\multicolumn{3}{|c|}{$\begin{array}{c}\text { Responsável } \\
\text { Gustavo }\end{array}$}} \\
\hline \multirow{2}{*}{\multicolumn{2}{|c|}{ Lote }} & \multirow{2}{*}{\multicolumn{3}{|c|}{ pH }} & \multirow{2}{*}{\multicolumn{2}{|c|}{$\begin{array}{c}\begin{array}{c}\text { OD } \\
\left(\mathrm{mg.L}^{-1}\right)\end{array} \\
8.0\end{array}$}} & $\begin{array}{c}\text { Cond. }(\mu S \\
\left.\mathbf{c m}^{-1}\right)\end{array}$ & Origem & \multirow{2}{*}{\multicolumn{2}{|c|}{ Tipo }} & \multirow[t]{2}{*}{ Lote } & & & \\
\hline & & & & & & & 162.6 & & & & & & & \\
\hline \multicolumn{15}{|c|}{ Volume: } \\
\hline \multirow{2}{*}{ Dia } & \multicolumn{2}{|c|}{ pH } & \multicolumn{2}{|c|}{$\begin{array}{c}\text { OD } \\
(\mathrm{mg} / \mathrm{L})\end{array}$} & \multicolumn{2}{|c|}{$\begin{array}{l}\text { Cond. } \\
\left(\mu S \text { cm}^{-1}\right)\end{array}$} & \multicolumn{5}{|c|}{ Réplicas } & \multicolumn{3}{|c|}{$\begin{array}{c}\text { Sumário } \\
\text { estatístico }\end{array}$} \\
\hline & & & & & & & 1 & 2 & 3 & 4 & $\begin{array}{c}\text { Observaçõ } \\
\text { es }\end{array}$ & \begin{tabular}{|c|} 
Médi \\
a
\end{tabular} & $\begin{array}{l}\text { D. } \\
\text { P }\end{array}$ & $\begin{array}{l}\text { C. } \\
\text { V }\end{array}$ \\
\hline $\mathbf{0}$ & 7 & 7.23 & 7.4 & 7.8 & 168 & 236 & 5 & 5 & 5 & & & & & \\
\hline 1 & 7 & 7.34 & 7.4 & 7.8 & 184 & 212 & 5 & 5 & 5 & & & & & \\
\hline 2 & 7.03 & 7.15 & 7.7 & 7.7 & 176 & 234 & 5 & 5 & 5 & & & & & \\
\hline 3 & 7.02 & 7.49 & 7.9 & 7.9 & 159 & 227 & 4 & 8 & 4 & & & 5,33 & $\begin{array}{r}2,3 \\
1 \\
\end{array}$ & $\begin{array}{r}43 \\
\% \\
\end{array}$ \\
\hline 4 & 7.02 & 7.45 & 7.5 & 8.1 & 170 & 199 & 12 & 21 & 13 & & & 15,33 & $\begin{array}{r}4,9 \\
3\end{array}$ & $\begin{array}{r}32 \\
\%\end{array}$ \\
\hline 5 & 7.02 & 7.26 & 7.5 & 8.1 & 185 & 201 & 34 & 37 & 36 & & & 35,67 & $\begin{array}{r}1,5 \\
3\end{array}$ & $4 \%$ \\
\hline 6 & 7 & 7.35 & 7.1 & 8.4 & 169 & 235 & 52 & 57 & 51 & & & 53,33 & $\begin{array}{r}3,2 \\
1\end{array}$ & $6 \%$ \\
\hline 7 & 7 & 7.26 & 7.9 & 8.8 & 192 & 198 & 67 & 79 & 69 & & & 71,67 & $\begin{array}{r}6,4 \\
3\end{array}$ & $9 \%$ \\
\hline 8 & 7.1 & 7.18 & 7.9 & 8.5 & 173 & 209 & 96 & 107 & 88 & & & 97,00 & $\begin{array}{r}9,5 \\
4 \\
\end{array}$ & $\begin{array}{l}10 \\
\% \\
\end{array}$ \\
\hline 9 & 7.04 & 7.42 & 7.9 & 7.9 & 198 & 231 & 119 & 124 & 117 & & & $\begin{array}{r}120,0 \\
0 \\
\end{array}$ & $\begin{array}{r}3,6 \\
1 \\
\end{array}$ & $3 \%$ \\
\hline 10 & 7.02 & 7.21 & 8.3 & 7.8 & 171 & 225 & 140 & 144 & 124 & & & $\begin{array}{r}136,0 \\
0\end{array}$ & $\begin{array}{r}10, \\
58\end{array}$ & $8 \%$ \\
\hline
\end{tabular}




\begin{tabular}{|c|c|c|c|c|c|c|c|c|c|c|c|c|c|c|c|c|}
\hline \multirow[t]{2}{*}{ Dia } & \multicolumn{2}{|c|}{ pH } & \multicolumn{2}{|c|}{$\begin{array}{c}\text { OD } \\
(\mathrm{mg} / \mathrm{L})\end{array}$} & \multicolumn{2}{|c|}{$\begin{array}{l}\text { Cond. } \\
\left(\mu S \mathrm{~cm}^{-1}\right)\end{array}$} & $\begin{array}{c}\text { Béqu } \\
\text { er }\end{array}$ & \multicolumn{3}{|c|}{$\begin{array}{c}\text { Contagem em } \\
15 \mathrm{~mL}\end{array}$} & \multicolumn{3}{|c|}{$\begin{array}{c}\text { Para } 75 \mathrm{~mL}(15 \mathrm{~mL} \\
\times 5)\end{array}$} & \multicolumn{3}{|c|}{ Sumário estatístico } \\
\hline & & & & & & & & & & & & & & Média & D.P & C.V \\
\hline \multirow[t]{3}{*}{11} & 6.99 & 7.36 & 7.7 & 7.9 & 188 & 243 & 1 & 29 & 28 & 32 & 145 & 140 & 160 & 148,33 & 10,41 & $7 \%$ \\
\hline & 6.99 & 7.36 & 7.7 & 7.9 & 188 & 243 & 2 & 32 & 28 & 30 & 160 & 140 & 150 & 150,00 & 10,00 & $7 \%$ \\
\hline & 6.99 & 7.36 & 7.7 & 7.9 & 188 & 243 & 3 & 20 & 23 & 24 & 122 & 115 & 120 & 119,00 & 3,61 & $3 \%$ \\
\hline \multirow[t]{3}{*}{12} & 7.01 & 7.27 & 7.8 & 8.1 & 193 & 207 & 1 & 27 & 32 & 26 & 135 & 147 & 136 & 139,33 & 6,66 & $5 \%$ \\
\hline & 7.01 & 7.27 & 7.8 & 8.1 & 193 & 207 & 2 & 26 & 27 & 28 & 130 & 135 & 140 & 135,00 & 5,00 & $4 \%$ \\
\hline & 7.01 & 7.27 & 7.8 & 8.1 & 193 & 207 & 3 & 23 & 23 & 24 & 115 & 115 & 120 & 117,00 & 2,89 & $2 \%$ \\
\hline
\end{tabular}


Crescimento populacional para Ceriodaphnia silvestrii em $150 \mathrm{~mL}$

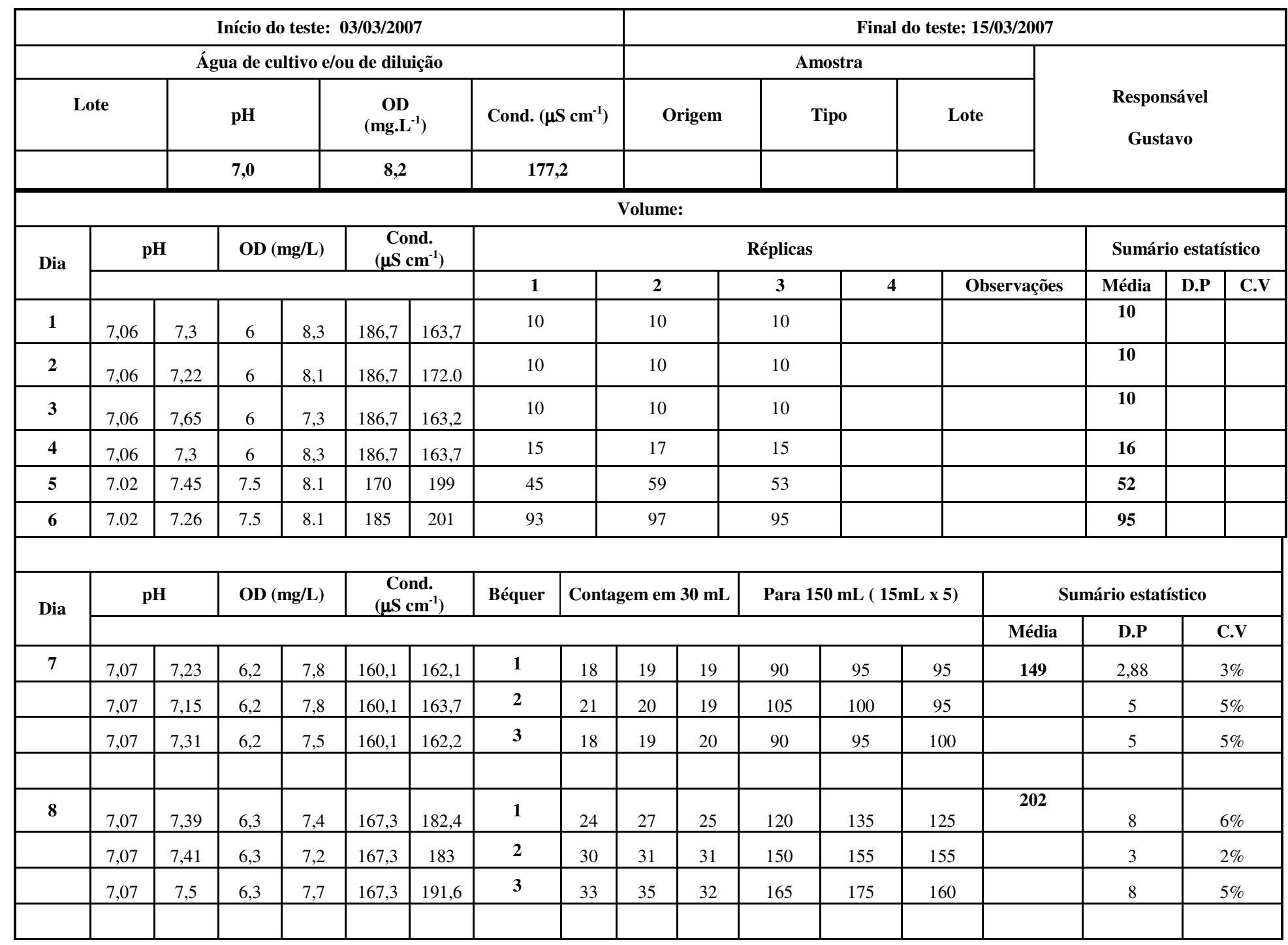




\begin{tabular}{|c|c|c|c|c|c|c|c|c|c|c|c|c|c|c|c|c|}
\hline 9 & 7,02 & 7,33 & 6 & 7,2 & 152,6 & 160,8 & $\mathbf{1}$ & 31 & 34 & 32 & 155 & 170 & 160 & $\mathbf{2 7 1}$ & 8 & $5 \%$ \\
\hline & 7,02 & 7,42 & 6 & 7,4 & 152,6 & 161 & $\mathbf{2}$ & 39 & 43 & 42 & 195 & 215 & 210 & & 10 & $5 \%$ \\
\hline & 7,02 & 7,28 & 6 & 7 & 152,6 & 159,7 & $\mathbf{3}$ & 48 & 50 & 45 & 240 & 250 & 225 & & 13 & $5 \%$ \\
\hline & & & & & & & & & & & & & & & & \\
\hline 10 & 7,07 & 7,3 & 6,2 & 7,4 & 161,1 & 170,4 & $\mathbf{1}$ & 40 & 39 & 39 & 201 & 194 & 196 & $\mathbf{2 9 2}$ & 4 & $2 \%$ \\
\hline & 7,07 & 7,22 & 6,2 & 7,2 & 161,1 & 179,6 & $\mathbf{2}$ & 63 & 65 & 66 & 315 & 325 & 330 & & 8 & $2 \%$ \\
\hline & 7,07 & 7,65 & 6,2 & 7,7 & 161,1 & 173,9 & $\mathbf{3}$ & 47 & 55 & 54 & 235 & 275 & 270 & & 22 & $8 \%$ \\
\hline & & & & & & & & & & & & & & & & \\
\hline 11 & 7 & 7,56 & 7,2 & 7,5 & 159,4 & 162,9 & $\mathbf{1}$ & 44 & 52 & 43 & 220 & 260 & 215 & $\mathbf{2 9 6}$ & 25 & $11 \%$ \\
\hline & 7 & 7,23 & 7,2 & 7,8 & 159,4 & 164,3 & $\mathbf{2}$ & 67 & 87 & 68 & 335 & 435 & 340 & & 56 & $15 \%$ \\
\hline & 7 & 7,41 & 7,2 & 7,7 & 159,4 & 161,3 & $\mathbf{3}$ & 53 & 61 & 50 & 265 & 305 & 250 & & 28 & $10 \%$ \\
\hline
\end{tabular}


$1 \quad$ NL Fit (Exp2PMod1) (09/11/2007 12:14:18)

Notes

\begin{tabular}{|r|l|}
\hline Description NL Fit \\
User Name & user \\
Operation Time & $09 / 11 / 2007$ 12:14:18 \\
Model Exp2PMod1 \\
Equation & $\mathrm{y}=\mathrm{a}^{*} \exp \left(\mathrm{b}^{*} \mathrm{x}\right)$ \\
\hline Report Status & New Analysis Report \\
\hline Multi-Data Fit Mode & $\begin{array}{l}\text { Independent Fit - Consolidated Re } \\
\text { port }\end{array}$ \\
\hline
\end{tabular}

Parameters

\begin{tabular}{|r|r|r|r|}
\hline \multirow{2}{*}{$\mathrm{B}$} & & \multicolumn{1}{|c|}{ Value } & Standard Error \\
$\mathrm{*}$ C & 0,08376 & 0,02382 \\
\cline { 2 - 4 } & b & 0,2881 & 0,0288 \\
\hline & a & 0,14658 & 0,05421 \\
\hline & b & 0,25147 & 0,03816 \\
\hline
\end{tabular}

All datasets were fitted successfully.

Statistics

\begin{tabular}{|r|r|r|}
\hline Number of Points & 11 & C \\
\hline Degrees of Freedom & 9 & 9 \\
\hline Reduced Chi-Sqr & 0,02037 & 0,06754 \\
Residual Sum of Squares & 0,18336 & 0,60784 \\
\hline R Value & 0,97874 & 0,95086 \\
\hline Adj. R-Square & 0,95326 & 0,89348 \\
\hline Fit Status & Succeeded(100) & Succeeded(100) \\
\hline
\end{tabular}

Fit Status Code:

100 : Fit converged

Summary

\begin{tabular}{|r|c|c|c|c|r|r|}
\hline & \multicolumn{3}{|c|}{ a } & \multicolumn{2}{c|}{ b } & \multicolumn{2}{c|}{ Statistics } \\
\hline & Value & Error & Value & Error & Reduced Chi-Sqr & Adj. R-Square \\
\hline C & 0,08376 & 0,02382 & 0,2881 & 0,0288 & 0,02037 & 0,95326 \\
\hline
\end{tabular}

\begin{tabular}{|c|c|c|c|c|c|c|}
\hline & & $\overline{D F}$ & Sum of Squares & Mean Square & F Value & Prob $>F$ \\
\hline \multirow{4}{*}{ B } & Regression & 2 & 9,04667 & 4,52333 & 222,02103 & $1,19531 \mathrm{E}-7$ \\
\hline & Residual & 9 & 0,18336 & 0,02037 & & \\
\hline & Uncorrected Total & 11 & 9,23003 & & & \\
\hline & Corrected Total & 10 & 4,35889 & & & \\
\hline \multirow{4}{*}{ c } & Regression & 2 & 13,686 & 6,843 & 101,3212 & $3,38793 \mathrm{E}-6$ \\
\hline & Residual & 9 & 0,60784 & 0,06754 & & \\
\hline & Uncorrected Total & 11 & 14,29384 & & & \\
\hline & Corrected Total & 10 & 6,34064 & & & \\
\hline
\end{tabular}

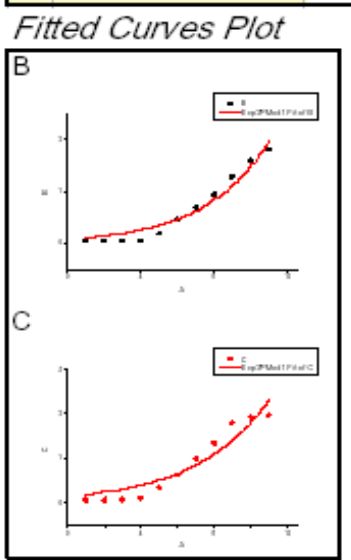




\section{Apêndice 5}

Ficha informativa relativa à segurança propranolol 


\section{Em conformidade com 93/112/CE e ISO 11014-1 \\ FICHA INFORMATIVA RELATIVA À SEGURANÇA $C A \mathrm{~A} O C \mathrm{HEM}^{\star}$ \\ Order \\ Customer \\ Number \\ Number}

1. Identificação da substãncia/preparação e da sociedade/empresa

\begin{tabular}{|c|c|c|c|}
\hline $\begin{array}{l}\text { Nome do } \\
\text { produto }\end{array}$ & : ( $( \pm)$-Propranolol, Hydrochloride & Catalog \# & : 537075 \\
\hline Fórmula química & $: \mathrm{C}_{16} \mathrm{H}_{21} \mathrm{NO}_{2} \cdot \mathrm{HCl}$ & Fornecedor & $\begin{array}{l}\text { : Manufactured by EMD Biosciences, Inc. } \\
10394 \text { Pacific Center Court } \\
\text { San Diego, CA } 92121 \\
(858) 450-5558 /(800) 854-3417 \\
\text { FAX: }(858) 453-3552\end{array}$ \\
\hline
\end{tabular}

Sinônimo $\quad$ : $( \pm)$-Propranolol, Hydrochloride

\section{Composição/informação sobre os ingredientes}

Substância/preparado : : Substância

\begin{tabular}{|c|c|c|c|c|}
\hline Nome químico* & $\mathrm{N}^{\circ} \mathrm{CAS}$ & Número da $\mathrm{Cl}$ & Símbolo & Frases R \\
\hline $\begin{array}{l}\text { 1) ( }( \pm)-1 \text {-(Isopropylamino)-3-(1-naphthyloxy)-2-propanol, } \\
\mathrm{HCl}\end{array}$ & $3506-09-0$ & $222-501-5$ & $x_{n}$ & R20/21/22 \\
\hline
\end{tabular}

3. Identificação dos perigos

$\begin{array}{ll}\text { Perigos de natureza fisica/química } & : \text { Não é aplicável. } \\ \text { Perigos para a saúde humana } & \text { : CUIDADO! } \\ & \text { PODE SER PREJUDICIAL SE INALADO, ABSORVIDO PELA PELE OU DEGLUTIDO. } \\ & \text { PODE CAUSAR DANOS AOS SEGUINTES ORGÄOS; SANGUE, CORAÇÄO, VIAS } \\ & \text { GASTROINTESTINAIS, PELE, GARGANTA. }\end{array}$

\section{Primeiros socorros}

\begin{tabular}{|c|c|}
\hline \multicolumn{2}{|l|}{ Primeiros socorros } \\
\hline Inalação & $\begin{array}{l}\text { : Se inalado, leve-o para o ar fresco. Se näo houver respiraçäo, fornecer respiraçăo artificial. Se houver } \\
\text { dificuldade de respiraçäo, fornecer oxigênio. Consulte um médico. }\end{array}$ \\
\hline Ingestão & $\begin{array}{l}\text { : Não provocar vômitos a náo ser sobre direçăo de pessoal médico. Nunca dar nada por via oral a uma pessoa } \\
\text { inconsciente. Se grande quantidade desta substância for ingerida, procure um médico imediatamente. Soltar } \\
\text { partes ajustadas da roupa, como colarinho, gravata, cinto ou cós. }\end{array}$ \\
\hline Contato com a pele & $\begin{array}{l}\text { : Em caso de contato, lavar a pele imediatamente com água em abundância. Remova roupas e calçados } \\
\text { contaminados. Pode-se utilizar água FRIA.Lavar as roupas antes de reutilizá-las. Limpe cuidadosamente os } \\
\text { sapatos antes de calçá-los. Consulte um médico. }\end{array}$ \\
\hline Contato com los olhos & $\begin{array}{l}\text { : Verificar se estäo sendo usadas lentes de contato e removê-las. Em caso de contato, lavar imediatamente os } \\
\text { olhos com água em abundância por } 15 \text { minutos no mínimo. Pode-se utilizar água FRIA. Consulte um médico. }\end{array}$ \\
\hline \multicolumn{2}{|l|}{ Efeitos e sintomas } \\
\hline Inalação & : Perigoso se de inalaçäo. \\
\hline Ingestão & : Perigoso se de ingestäo. \\
\hline Contato com a pele & : Perigoso se de contato com a pele (impregnante). \\
\hline Condições agravantes & : Não há casos conhecidos de agravamento da condição médica por exposição repetida ou prolongada. \\
\hline
\end{tabular}


5. Medidas de combate a incêndios

\begin{tabular}{|c|c|}
\hline Inflamubilidade do Produto & : Pode ser combustivel a altas temperaturas. \\
\hline \multicolumn{2}{|l|}{ Meix de extinchla } \\
\hline Adequado & $\begin{array}{l}\text { INCENDIO DE PEQUENAS PROPCRÇOES: Use po quimico seco } \\
\text { INCENDIO DE GRANDE ESCALA: Utilzar newoa, espuma de agua ou agua putverizada. NAOO utilzzar jato de } \\
\text { agua. }\end{array}$ \\
\hline $\begin{array}{l}\text { Produta perigosos de } \\
\text { (de)kompesiçión térmica }\end{array}$ & $\begin{array}{l}\text { : Esses produbos săo codos de cartono }(\mathrm{CO}, \mathrm{CO} 2) \text {, oxdos de nitroganio (NO, NO2 ...), compostos } \\
\text { hakogenados. }\end{array}$ \\
\hline $\begin{array}{l}\text { Proxedimentox expeciais de combate } \\
\text { a incên diex }\end{array}$ & : Os bombeiros deverm usa aparelho respiratorio aub-suliciente (SCBA) e engrenagem completa de desvio. \\
\hline $\begin{array}{l}\text { Protecyào das pessoas e avolvidas no } \\
\text { rombate a incêndios }\end{array}$ & : 0 uso de respirador aproradoicredenciado ou equmalente e corigakrio \\
\hline
\end{tabular}

\title{
6. Medidas a tomar em caso de fugas acidentais
}

\begin{tabular}{|c|c|}
\hline Preciuçòs pesxoais & 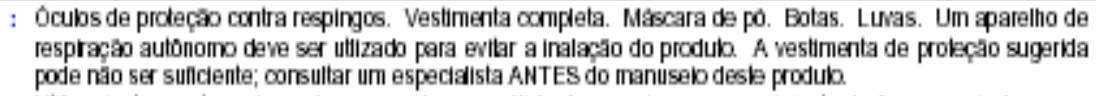 \\
\hline $\begin{array}{l}\text { Pequenos derramamentose } \\
\text { vazamentos }\end{array}$ & 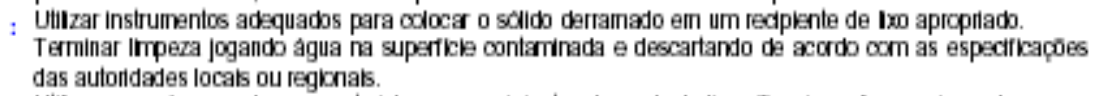 \\
\hline $\begin{array}{l}\text { Grande derramamento e } \\
\text { vazamentos }\end{array}$ & $\begin{array}{l}\text { : Uilizar uma pa pars cobcar o makrial em um recipiente adequado de Itxo. Termine a Impeza jogando } \\
\text { agua na superficie contaminada e daxe sair pelo siskama de esgoto. }\end{array}$ \\
\hline
\end{tabular}

\section{Manuseamento e armazenamento}

\begin{tabular}{|c|c|}
\hline Maniseame nto & 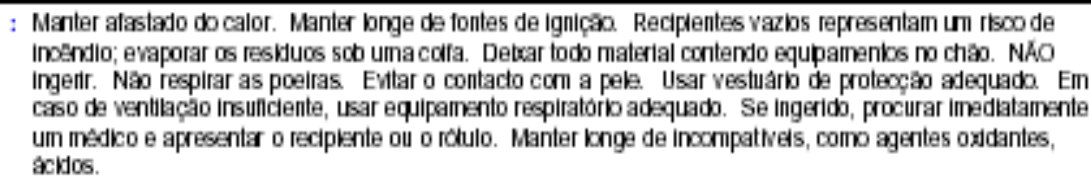 \\
\hline Armazenamento & $\begin{array}{l}\text { : Manter o recipiente bem fechado. Mantar o recipiente em local fresco e bem ventilado. Não armazene a } \\
\text { temperaturas acima de }-20^{\circ} \mathrm{C}\left(-4^{\circ} \mathrm{F}\right) \text {. }\end{array}$ \\
\hline \multicolumn{2}{|c|}{ Materiais desmbalaerm } \\
\hline Uso recom endado & : Use o redpiente crignal. \\
\hline
\end{tabular}

8. Controlo de exposição/protecção individual

\begin{tabular}{|c|c|}
\hline Medidas de eoncep̧̧ào & 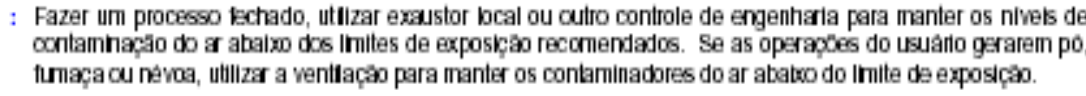 \\
\hline Medidas higiénicas & $\begin{array}{l}\text { : Lave multo bem as mãos, antebracos e rosto apos manusear os compostos, bem como antes de comer, } \\
\text { fumar, ir as banheiro e mo fina do dia. }\end{array}$ \\
\hline
\end{tabular}

\section{Somedoineredients} 1) (t)-Prcpranold, Hydrochiloride

Limites de exoxicionenofixsianil

\author{
Năo disponivel.
}

quipamentos de proteção pesxoal

Aparelhe respiraténio

Pele e corpe

Mầ

Olhes

Vestimenta de Protcx̧ào (Pictogramas)

\footnotetext{
: Máscara de po. O uso de resprador aprovado/credenciajo ou equivalente é corigakorio utiliza máscara adequada quands a ventilaça for nadequada.

: Aventalde labcratorio.

: Lumas.

: Cculos de proteçẫo.
}

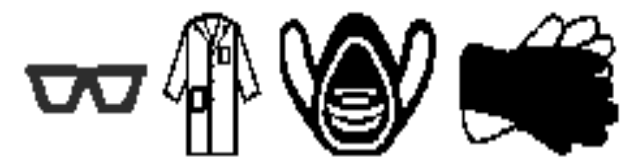


9. Propriedades fisico-químicas

\begin{tabular}{|c|c|}
\hline Estado físico & : Soldo (PO salvo.) \\
\hline Cor & : Branco. \\
\hline Peso molexular & : $295.8 \mathrm{~g} / \mathrm{mile}$ \\
\hline Ponte de fuxĩe & $: 163 \mathrm{a} 165^{\circ} \mathrm{C}\left(325.4 \mathrm{a} 329^{\circ} \mathrm{F}\right)$ \\
\hline Solubilidade & : Facilmente dissolvido em agua fria, Matanol. \\
\hline Ponte de ignição & : Nao dispontwe. \\
\hline Propriedades de explexào & 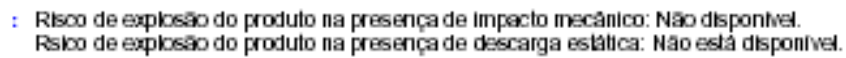 \\
\hline
\end{tabular}

10. Estabilidade e reactividade

\begin{tabular}{|c|c|}
\hline Estabilidade & : O produb e estaved. \\
\hline Condiçòes a evitar & : Incompattve oxm alguns acioos tortes. \\
\hline Materiais a evitar & : Reage com agentes oudantes, acilos. \\
\hline Produtox de decompoxição perigoss & $\begin{array}{l}\text { : Esses produtos sao oxidos de catbono }(\mathrm{OO}, \mathrm{COZ}) \text {, oxidos de nitrogerio (NO, NO2 ...), compostos } \\
\text { halogenados. }\end{array}$ \\
\hline
\end{tabular}

11. Informação toxicológica

\begin{tabular}{|c|c|c|}
\hline RTECS\# & $:$ & UB7526000 \\
\hline \multicolumn{3}{|l|}{ E.seites lacaix } \\
\hline Irritaçào da pele & : & Năo dspcnivel. \\
\hline Toxicidade agnuda & : & $\begin{array}{l}\text { LD50. Năo dspor } \\
\text { LC50. Năo dspor }\end{array}$ \\
\hline Toxicidade crónica & : & Năo ha casos cor \\
\hline \multirow[t]{3}{*}{$\begin{array}{l}\text { Outras Efítes Tóxicos em } \\
\text { Seres Humanos }\end{array}$} & : & $\begin{array}{l}\text { Näo disponivel. } \\
\text { Perigoso se de c }\end{array}$ \\
\hline & & Năo disponivel. \\
\hline & & A exposiçapod \\
\hline Veitos Carcinogênicos & : & Năo dsponivel. \\
\hline E. Feitos mutagênioxs & : & Năo dsponivel. \\
\hline Toxicida de para a reproduçào & : & Năo dsponivel. \\
\hline Veeitos teratogênioxs & : & Năo dsponivel. \\
\hline
\end{tabular}

12. Informação ecológica

Eeotoricidade : Nå disponivel.

Toxicidade dos Produtos de : : Cs produbs de degadaçăo såo menos toxicos que o proprio produb. Biodegradação

13. Questöes relativas à eliminação

Métodes de elimimaçào; Desperdicio : Os datrttos devem ser descatados de acordo com as regulamentaçes tedsraks, estatals e locals de controls de residuos; Embalage in ambiental. contaminada

14. Informações relativas ao transporte

Beaulamentos internacionais narao fransporte

$\underline{\text { Terra - Rodovia/Caminho de ferro }}$

Categoria ADR/RID : Năo controlado pela ADR (Eurcpa).

Mar

Categoria IMDG : Nă fol controlado pelo IMDG

Ar

Categoria LATA-DGR : Năo fol contrdado pelo IATA.

Provixões Espexiais para Nă e aplçavel.

Transporte

Catalog $\# \quad 537075$ 
15. Informação sobre regulamentação

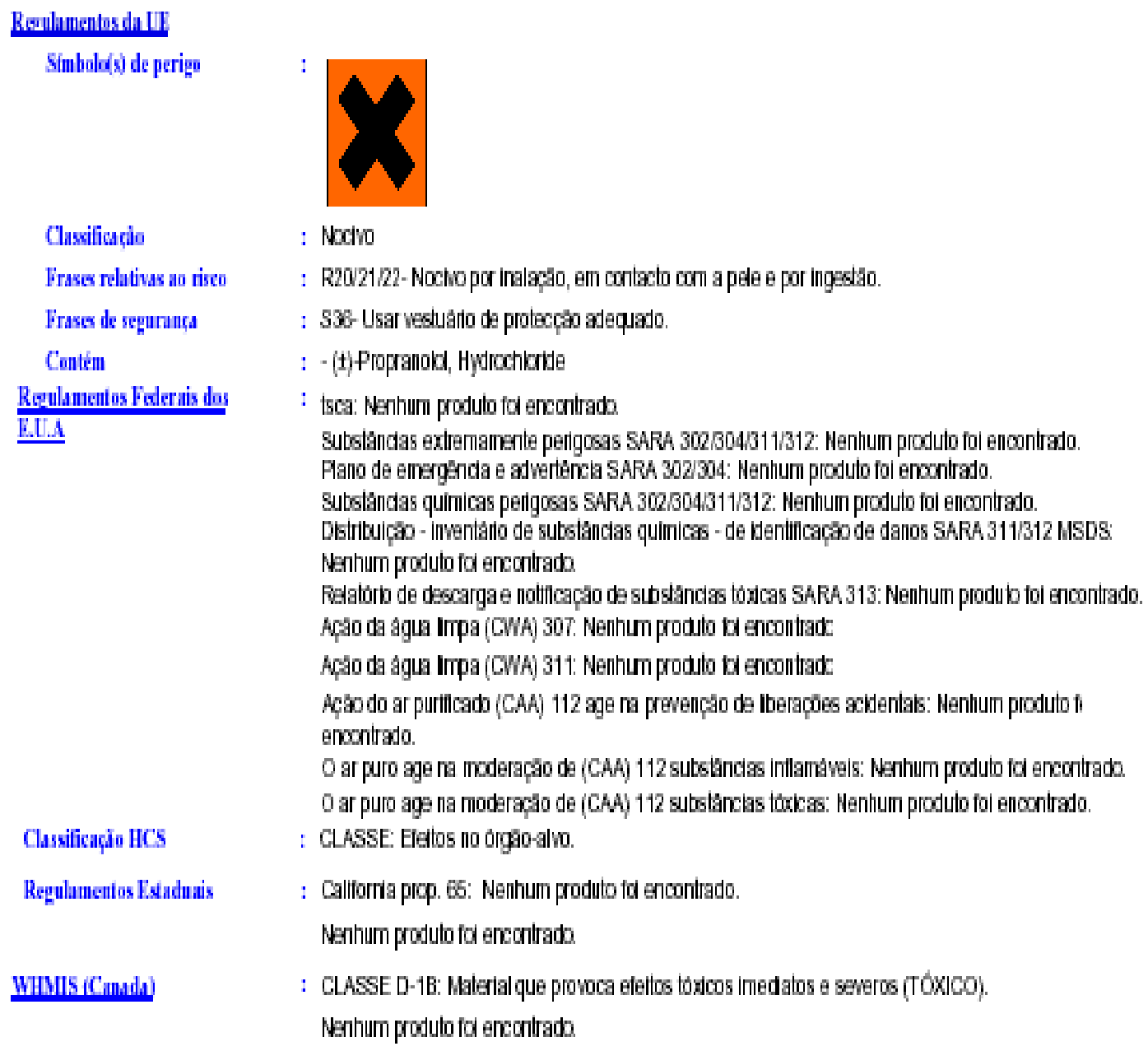

16. Outras informaçōes

Sistema de Informaçòes sobre Materiais

Perigosos

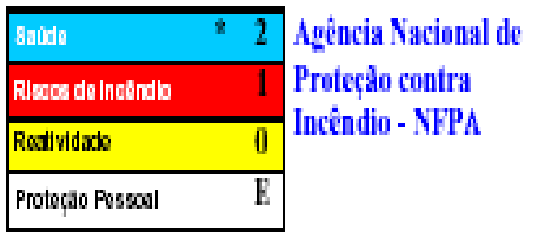

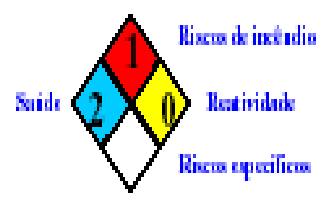

Observacio ano Leitor

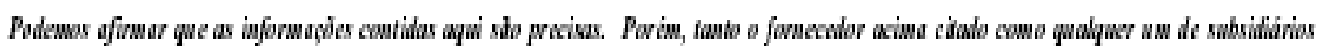

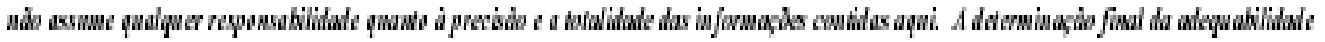

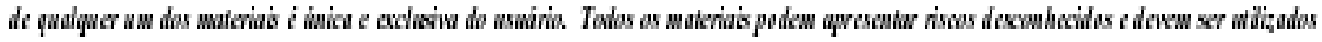

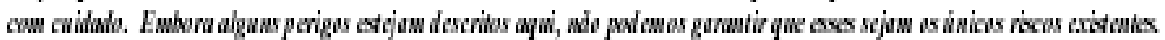

\begin{tabular}{|c|c|c|c|}
\hline \multirow[b]{2}{*}{ Catialog \# } & \multirow[b]{2}{*}{537075} & \multicolumn{2}{|l|}{$\begin{array}{l}\text { Data de } \\
\text { lançame nto }\end{array}$} \\
\hline & & 3262003. & Pagina: 414 \\
\hline
\end{tabular}




\section{- $\mathrm{CALBIOCHEM}^{\varpi}$}

(土)-Propranolol, Hydrochloride

Size

Cat. No. 537075

$100 \mathrm{mg}$

Synonym:

(土)-1-(Isopropylamino)-3-(1-naphthyloxy)-2-propanol, $\mathrm{HCl}$

Description: $\quad$ A highly lipophilic $\beta$-adrenergic blocker. Blocks both $\beta_{1}$ and $\beta_{2}$ receptors with equal potency. Has no effect on $\alpha$-adrenergic receptors. Also binds to $5 \mathrm{HT}-1 \mathrm{~B}$ receptors with high affinity $\left(\mathrm{K}_{\mathrm{i}}=17 \mathrm{nM}\right)$ in contrast to $5 \mathrm{HT}-1 \mathrm{D}$ receptors $\left(\mathrm{K}_{\mathrm{i}}=10.2 \mu \mathrm{M}\right)$. Readily enters the central nervous system. Blocks phospholipase D-derived diacylglycerol (DAG) formation by inhibiting phosphatidate phosphohydrolase. Useful tool for discriminating between phospholipase $\mathrm{D}$ or phospholipase $\mathrm{C}$ mediated DAG production. An antihypertensive agent that is also used in the treatment of cardiac arrhythmias.

Form:

White solid

CAS Number:

3506-09-0

RTECS:

UB7526000

Molecular Weight:

295.8

Molecular Formula:

$\mathrm{C}_{16} \mathrm{H}_{21} \mathrm{NO}_{2} \cdot \mathrm{HCl}$

Structure:

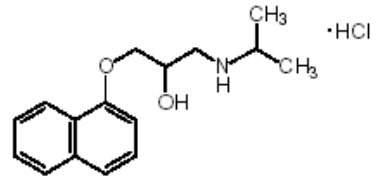

Purity:

$>98 \%$ by titration

Solubility:

Methanol and $\mathrm{H}_{2} \mathrm{O}$

Storage:

Freezer $\left(-20^{\circ} \mathrm{C}\right)$. This product is stable for 3 years as supplied.

Toxicity:

MSDS available upon request.

Merck Index:

12: 8025

References:

Fujita, K., et al. 1996. FEBS Lett. 395, 293.

Technical Service (800) 628-8470 
CN: 537075

Glennon, R.A., et al. 1996. Mol. Pharmacol. 49, 198.

Thompson, N.T., et al. 1991. Trends Pharmacol. Sci. 12, 404.

Hoffman, B.B., and Lefkowitz, R.J. 1990. In The Pharmacological Basis of Therapeutics (Gilman, A.G., et al. Eds.) New York, Pergamon Press, p 221.

FOR RESEARCH USE ONLY. NOT FOR HUMAN OR DRUG USE. 
Referências bibliográficas

ABEL, P.D. Water Pollutions. New York. John Wiley \& Sons, 230 p.,1989.

ABNT. Água - Avaliação de toxicidade crônica, utilizando Ceriodaphnia dubia Richard, 1894 (Cladocera, Crustacea). NBR 13373. Rio de Janeiro, Associação Brasileira de Normas Técnicas, 2005.

ADAMS, W. J. Aquatic Toxicoiogy Testing Methods. In: HOFFMAN, D.J.; RATTNER, B.A.; BURTON, G.A.J. (Org.). Handbook of Ecotoxicology. Boca Raton: Lewis, 1995.

ARONOW, W. Post infarction use of beta-blockers in elderly patients. Druas Aqinq, Cleveland, v. 11 n. 6 p. 424- 432. 1997.

AZEVEDO, FA \& CHASIN, AAM. As bases toxicológicas da ecotoxicologia. Rima Editora. São Paulo. 340p. 2003.

BASSOI, L.J, R.NIETO e D. TREMAROLI, Implementação de testes de toxicidade no controle de efluentes líquidos. Serie Manuais 8, São Paulo, Brasil, 1990.

BECHMANN, R.K. Use of life tables and LC50 tests to evaluate chronic and acute toxicity effects of copper on the marine copepod Tisbe furcata (Baird). Environ. Toxicol. Chem. 13: 1509-1517. 1994.

BEHRENS, A. Avaliação da toxicidade aguda (FD) em efluentes industriais galvanoplastia. Curitiba. Monografia (Bacharelado em Biologia) - Centro de Ciências Biológicas e da Saúde, Pontifícia Universidade Católica do Paraná. 1995 
BERTOLETTI, E. Tratabilidade e toxicidade de efluentes industriais. Engenharia Sanitária, 28 (1) :p.38-41. 1989.

BERTOLETTI, E.; GOLDSTEIN, E.G.; ZAGATTO, P.A. Variabilidade de testes de toxicidade com peixes. Ambiente, v. 3, n. 1, p. 52-58, 1989.

BEAUSSE, J. Pharmaceuticals - horizontal - 26 Junho. 2004.

BOHRER, M.B.C. Biomonitoramento das lagoas de tratamento terciário do Sistema de Tratamento de Efluentes Líquidos Industriais (SITEL) do Pólo Petroquímico do Sul, Triunfo, RS, através da comunidade zooplanctônica. São Carlos: UFSCar, 1995. 469p. Tese (Doutorado em Ciências, Área de Concentração em Ecologia e Recursos Naturais)-Universidade Federal de São Carlos, 1995.

BERGMAN, L. and PUGH, D.M. (eds.). The EC Directive on Drinking Water: Institutional Aspects, Environmental Toxicology, Economics and Institutions. Kluwer Academic Publishers, 1994.

BITTON,G \& DUTTKA, B.J. Toxicity testing using microorganisms. vol. 1, CRC Press Inc., Bcca Raton, Flórida, 1986.

BRASIL. CONSELHO NACIONAL DO MEIO AMBIENTE - CONAMA (2005).Resolução no 357 - 17 de março de 2005. Dispõe sobre a classificação dos corposde água e diretrizes ambientais para o seu enquadramento, bem como estabelece ascondições e padrões de lançamento de efluentes, e dá outras providências. Brasília, 2005.

BRENTANO, D. M; LOBO, E. Biomonitoramento de caráter ecotoxicológico no Vale do Rio Pardo, RS, Brasil. Revista Tecno-Lógica, Santa Cruz do Sul, n. 2, v. 7, p. 85-95. 2003. 
CAIRNS JR, J.; NIEDERLEHNER, B. R.; BIDWELL, J. R.. Ecological toxicity testing. In: MEYERS, R. A., cd. Encyclopedia of Environmental Analysis and Remediation. John Wiley \& Sons, mc. 1998.

CASTILHO, P.M.J. Validação de ensaios ecotoxicológicos com organismos autóctones Daphnia laevis e Ceriodaphnia silvestrii. Dissertação de Mestrado em Tecnologia Nuclear-Materiais.Ipen.2005.

CASWELL H. Matrix Population Models. Sunderland, MA: Sinauer.1989

CETESB. Companhia de Tecnologia e Saneamento Ambiental de São Paulo. Água do Mar - Teste de toxicidade aguda com Artemia. Norma Técnica L5. 021. São Paulo, CETESB. 16p. 1987.

CETESB. Companhia de Tecnologia de Saneamento Ambiental. Considerações preliminares sobre toxicidade aos organismos aquáticos. n. 3. 11p. Informativo Técnico. 1990.

CETESB. Companhia de Tecnologia de Saneamento Ambiental Ensaios biológicos com organismos aquáticos e sua aplicação. São Paulo: CETESB,. p. 50. 1990a

CETESB. Companhia de Tecnologia de Saneamento Ambiental. Água - Teste de toxicidade aguda com Daphnia similis Claus, 1876 (Cladocera, Crustacea). Norma técnica L5 018, 1991.

CETESB. Companhia de Tecnologia de Saneamento Ambiental. Métodos de Avaliação da Toxicidade de Poluentes a Organismos Aquáticos. São Paulo, 1992.

CONOVER, W.J. Practical Nonparametric Statistics. Second edition. John Wiley and Sons, New York, NY. pp. 466-467. 1980. 
CHAPMAN, P. M. Current approaches to developing sediment quality criteria. Environmental Toxicology and Chemistry. V. 8. p. 589-599. 1989.

CHAPMAN, RM. Extrapolating laboratory toxicity results to the field. Environ. Toxicol. Chem. Pp. 927-930.v.14. 1995.

CLEUVERS, M.,. Initial risk assessment for three [beta]-blockers found in the aquatic environment. Chemosphere 59 (2), 199-205, 2005 Daniele Maia Bila e Márcia Dezotti* fármacos no meio ambiente Quim. Nova, Vol. 26, No. 4, 523-530, 2003.

CORSON, W.H. Manual Global de Ecologia. $4^{\circ}$ edição. São Paulo: Ed. Augustus. 412p. 2002.

CULLEN, P. The turbuient boundary between water science and water management. Freshwater Biology, 24, 20 1-209. 1990.

DAMATO, M., "Estudo da influência do nível de tratamento de efluentes de refinarias de petróleo na sua toxicidade, empregando diferentes espécies indicadoras - Tese de Doutorado, EPUSP”. 1997.

DAUGHTON, C.G.,. Cradle-to-cradle stewardship of drugs for minimizing their environmental disposition while promoting human health. 1 . Rationale for and avenues toward a green pharmacy. Environ. Health Perspect. 111, 757-774, 2003.

$D A Y, K, K A U S H I K$, N.K. Short-term exposure of zooplankton to the synthetic pyrethroid, fenvalerate, and its effects on rates of filtration and assimilation of the alga,Chlamydomonas reinhardii. Arch. Environ. Contam. Toxicol, 1987.

DUNNETT, C.W. New table for multiple comparisons with a control. Biometrics 20:482. 1964. 
DZIALOWSKI EM, TURNER PK, BROOKS BW. In press. Physiological and reproductive effects of beta adrenergic receptor antagonists on Daphnia magna. Arch. Environ. Contam. toxicol.2003.

ELDER, J. F. Applicability of ambient toxicity to national or regional waterquality assessment. U. S. Geological Survey Circular, n. 1049, 1990.

ESPINDOLA, E. L. G.; BRIGANTE, J. (Org.). Limnologia fluvial. São Carlos: Rima,.p.129_148. 2003.

EPA. U. S. ENVIRONMENTAL PROTECTION AGENCY. Methods for measuring the acute toxicity of effuents and receiving waters to freshwater ang marine organisms. $4^{\mathrm{a}}$ ed. Washington,DC: U.S. Environmental Protection Agency, 1991.

EPA. U. S. ENVIRONMENTAL PROTECTION AGENCY. Methods for measuring the toxicity and bioaccumulation of sediment associed contaminants with freshwater invertebrates. Duluth, Minnesota. EPA - 6001R-941024. 1994.

EPA. U. S. ENVIRONMENTAL PROTECTION AGENCY. Short-term Methods for Estimating the Chronic Toxicity of Effluents and Receiving Waters to Freshwater Organisms. 4th ed. Washington, USA, 2002.

FENT,K; WESTON,A.A; CAMINADA, D Ecotoxicology of human pharmaceuticals. Aquatic Toxicology 76 122-159, 2003.

FERRARI B, MONS R, VOLLAT B, FRAYSSE B, PAXEUS N, Lo GIUDICE R, POLLIO A, GARRIC J. Environmental risk Assessment of six human pharmaceuticals: Are the current Environmental Risk Assessment procedures 
sufficient for the protection of the aquatic environment? Environ Toxicol Chem 23:1344-1354. 2004.

FONSECA, A.L. A biologia das espécies Daphnia laevis, Ceriodaphnia dubia silvestris ( Crustacea, Cladocera) e Poecilia reticulata (Piscis, Poeciledae) e o comportamento destes em testes de toxicidade aquática com efluentes industriais. Dissertação de Mestrado em Hidráulica e Saneamento. Escola de engenharia de São Carlos.Universidade de São Paulo. 1991.

FORBES VE, CALOW P. Is the per capita rate of increase a good measure of population-level effects in ecotoxicology? Environ Toxicol Chem 18(7): 15441556. 1999.

FORNO, D.A. Sustainable development starts with agriculture. In: FAIRCLOUGH A.J. (ed). Sustainable agriculture solutions the actions report of the sustainable agriculture initiative. London:The Novelho Press, Cap.1.p.8-11. 1999.

FOWLER, H. G.; AGUIAR, A. M. A integração da teoria ecológica na análise ambiental. In: TAUK, S. M.; GOBBI, N.; FOWLER, H. G. (Org.) Análise Ambiental: uma visão multidisciplinar. São Paulo, Editora UNESP, p. 133-141. 1991.

FRAYSSE B, GARRIC J. Prediction and experimental validation of acute toxicity of b-blockers in Ceriodaphnia dubia. Environ Toxicol Chem 24:24702476. 2005.

GENTILE, J.H., S.M. GENTILE, N.G. HAIRSTON, Jr. and B.K. SULLIVAN.

The use of life-tables for evaluating the chronic toxicity of pollutants to Mysidopsis bahia. Hydrobiologia 93: 179-187. 1982. 
GIGER, W., Produits chimiques : Facteurs de risque pour l'environnement et la santé, EAWAG news 53, 3-5, 2002.

GOLDSTEIN, E. G. Testes de toxicidade de efluentes industriais. In: Revista Ambiente, v. 2, n. 2, p. 33-38, 1988.

GOLDSTEIN, E.; BERTOLETTI, E.; ZAGATTO, P.A.; ARAÚJO, P.R.A.; RAMOS, M.L.L.C. Procedimentos para a utilização de testes de toxicidade no controle de efluentes líquidos. São Paulo: CETESB, 17p. 1990.

GOTTLIEB, S. S.; MCCARTER, R. J. Comparative effects of three beta blockers (atenolol, metoprolol, and propranolol) on survival after acute myocardial infarction. American Journal Cardioloçy, NewYork, v. 87, n.7, p.8236,2001 .

GUlley, D.D.; BOElTER, A.M.; BERGMAN, H.L. TOXTAT 3.3 Computer Program., 1991.

HALLAM, T. G., CANZIANI, G. A., and LASSITER, R. R. Sublethal narco- and population persistence: A modelling study on growth effects. J.Plankton Res. 15, Environ. Toxicol. Chem. 12, 947-954. 1993.

HAMILTON, M.A; RUSSO, R.C.; THURTON, R.V. Trimed Spearman-Karber method for estimating median lethal concentrations in toxicity bioassays. Environ. Sci. Technol., New York, v. 11, n. 7, p. 714-719. 1977.

HOLM, J.V., RUGGE, K., BJERG, P.L., CHRISTENSEN, T.H. Occurrence and distribution of pharmaceutical organic-compounds in the groundwater downgradient of a landfill (Grindsted, Denmark). Environ. Sci. Technol. 29 (5), 1415-1420, 1995. 
HOLT, M. S. Sources of Chemical Contaminants and Routes into the Freshwater Environment, Food and Chemical Toxicology, v.38, pp. 21-27. 2000.

HUGGETT DB, BROOKS BW, PETERSON B, FORAN CM, SCHLENK D.. Toxicity of select $\mathbf{b}$-adrenergic receptor-blocking pharmaceuticals (b-blockers) on aquatic organisms. Arch Environ Contam Toxicol 43:229-235. 2002.

HOUK,V.S. The genotoxicity of industrial wastes and effluents - a review. Mutation Research, Amsterdan, v.277, p. 91-138,1992.

JONES OAH, VOULVOULIS N, LESTER JN. Aquatic environmental assessment of the top 25 English prescription pharmaceuticals. Water Res 36:5013-5022. 2002.

JØRGENSEN, S.E., HALLING-SØRENSEN, B.,. Editorial: Drugs in the environment. Chemosphere 40, 691-699, 2000.

KUMMERER, K., STEGER-HARTMANN, T., MEYER, M.,. Biodegradability of the anti-tumour agent ifosfamide and its occurrence in hospital effluents and communal sewage. Water Res. 31 (11), 2705-2710, 1997.

KAMMENGA JE, BUSSCHERS M, van STRAALENNM, JEPSON PC, BAKKER J. Stress-induced fitness reduction is not determined by the most sensitive lifecycle trait. Funct. Ecol. 10:106-11.1996.

KAREIVA, P. and R. SAHAKIAN. Tritrophic effects of a simple architectural mutation in pea plants. Nature 345:433-434. 1990.

KAREIVA P, STARK J,WENNERGREN U. Using demographic theory, community ecology and spatial models to illuminate ecotoxicology. 
Ecotoxicology: Ecological Dimensions, ed. DJ Baird, L Maltby, PW Greig-Smith, PET Douben, pp. 13- 23. London: Chapman \& Hall1996.

KWAN, K.K. AND DUTKA, B.J. Evaluation of Toxi - Chromotest Direct Sediment Toxicity Testing Procedure and Microtox Solid - Phase Testing Procedure. Bull Environm. Contam. Toxicol .49 : 656 -662, 1992.

L1NDEGAARD, C. Classification of water-bodies and pollution, In: ARMITAGE, P.D., CRANSTON, P.S., P1NDER, L.C.V., cd. The biology and ecology of nonbiting midges. Chapman \& Hall. p.385-4O4. 1995.

MALTBY L, CALOW P. Scope for growth in Gammarus pulex, a freshwater detritivore. Hydrobiologia. 188/189:517-523. 27.1989.

MARSHALL, J.S. Population dynamics of Daphnia galeata mendotae as modified by chronic cadmium stress. J. Fish. Res. Board Can. 35:461-469. 1978.

MATTHEWS, R.A., BUIKEMA Jr., A.L., CAIRNS Jr., J. \& RODGERS Jr., J.H. Receiving system functional methods, relationships and índices. 1982.

MEYBECK, M. River water quality global ranges, time and space variabilities, proposal for some redefinitions. Verh. Internat. Verei Limnol. Stuttgart. 26. 8196p. 1996.

METCALF \& EDDY, Wastewater Engineering, 3 ed. Mc Graw-Hill Series in Water Resources and Environmental Engineering New York, 1991.

MILLER, R.G.. Simultaneous statistical inference. Springer-Verlag, New York, NY. 299 pp. 1981. 
MOUNT, D. I.; NORBERG, T. J. A seven-day lifecycle cladoceran toxicity test. Environmental toxicology and chemistry 3: 425-434. 1984.

NAVAS-PEREIRA, D.; GHERARDI-GOLDSTEIN, E.; ZAGATTO, P.A.; SASSI, R. Bioensaios: um programa a serviço do controle da poluição. Resultados iniciais. Ambiente, 1 (1) p. 32 - 36, 1987.

NATIONAL RESEARCH COUNCIL. Testing for effects of chemicals on ecosystems. National Academy Press, Washington, DC. 1981.

NEWMAN, M.C. and M.A. UNGER. Fundamentals of Ecotoxicology, second edition.CRC Press LLC, Boca Raton, Florida. 458 pp. 2003.

LAMPERT, W., FLECKNER, W., POTT, E., SCHOBER, U., and STORKEL, K. Herbicide effects on planktonic systems of different complexity. Hydrobi ologia 188/189, 415-424. 1989.

LEE, K. Long term effects of Marek's disease vaccination with cell-free Herpesvirus of turkey and age at debeaking on performance and mortality of WhiteLeghorns. Poultry Science, v.59, p.2002-2007, 1980.

LILIUS H, HASTBACKA T, ISOMAA B. A comparison of the toxicity of $\mathbf{3 0}$ reference chemicals to Daphnia magna and Daphnia pulex. Environ Tox Chem 14:2085-2088.1995.

LOBO, E. A.; CALLEGARO, V. L. Avaliação da qualidade de águas doces continentais com base em algas diatomáceas epilíticas: Enfoque metodológico. p. 277- 300. In: TUCCI, C. E. M. \& MARQUES, D. M. (Org.),Avaliação e Controle da Drenagem Urbana. Porto Alegre: Ed. Universidade/UFRGS. 558p. 2000. 
OECD - Organization For Economic Co-Operation And Development. Guidelines 202: Daphnia sp., acute immobilization test and reproduction test -. Paris, 2006.

ODUM, Ecologia. Rio de Janeiro-RJ: Guanabara, 1988.

OLIVEIRA-NETO, A.L.; BOTTA-PASCHOAL, C. M. R. Sensibilidade do cladocero lacustre planctônico Ceriodaphnia silvestrii (Família Daphniidae) aos metais cádmio, cromo e chumbo. Em: Ecotoxicologia: Perspectivas para o século XXI. Evaldo L.G. Espíndola et al. (eds.) Ed. Rima Artes e textos. pp 537- 543. 2000.

POSTMES TJ, PRICK R, BORENS I. The deceleration of the heart frequency in the waterflea Daphnia magna by adrenoceptor agonists and antagonists. Hydrobiologia 171:141-148. 1989.

PRINTES, L.B,. Biomonitoramento da Microrregião Carbonífera do Baixo Jacuí, RS, Através de Testes de Toxicidade com Cladocera e Implantação de Cultivos de Hyallella azteca (Crustacea; Amphipoda) ao Cloreto de Sódio (NaCl). Dissertação (Mestrado em Ecologia) - Universidade Federal do Rio Grande do Sul. 1996.

RAND, G. M.; PETROCELli, S. R. Fundamentals of Aquatic Toxicology: Methods and Applications. New York: Hemisphere Publishing Corporation, 1985.

RAND, G. M. Fundamentals of aquatic toxicology: effects, envioronmental fate, and risk assessment. 2nd edition. North Palm Beach, Florida: Taylor e Francis. 1125p. 1995.

RAVERA, O. Utility and limits of biological and chemical monitoring of the aquatic environment. Annali di Chimica, 88(11-12) 909-913. 1998. 
RAYA-RODRIGUEZ, M. T. O Uso de bioindicadores para Avaliação da Qualidade do Ar em Porto Alegre. In: ZURITA, M. L. L.; TOLFO, A.M. (Org.) A Qualidade do Ar em Porto Alegre. Porto Alegre, Secretaria Municipal do Meio Ambiente. p.68-76. 2000.

RODGHER, 5. Determinação da faixa de sensibilidade de organismos aquáticos a uma substância de referência, o cloreto de sódio ( $\mathrm{NaC1}$ ) e avaliação da qualidade da água da Represa do Monjolinho (São Carlos, SP) através de testes de toxicidade aguda. 69p. (monografia) - Centro de Ciências Biológicas e Saúde - Departamento de Biologia Evolutiva - Universidade Federal de SãoCarlos.1998.

SAXENA,J. In vitro test systems for mutagenicity screening of environmental chemicals. Revista de Microbiologia, São Paulo, v.15,p.1-16, 1984.

SEILER, J.P.,. Pharmacodynamic activity of drugs and ecotoxicology - can the two be connected? Toxicol. Lett. 131, 105-115, 2002.

SIBLY RM. Efficient experimental designs for studying stress and population density in animal populations. Ecol Appl 9:496- 503. 1999.

SIBLY, R. M. \& HONE, J. Population growth rate and its determinants: an overview. Phil. Trans. R. Soc. Lond. B , 357, 1149-1170.2002.

SNEDECOR, G.W. and W.G. COCHRAN. Statistical Methods. Seventh Edition. Iowa State University Press, Ames, Iowa. 593 pp. 1980.

SOARES, A. M. V. M. Ecotoxicologia e Determinação de Riscos Ecológicos. Prática e Perspectivas. In: CONFERENCIA NACIONAL SOBRE A QUALIDADE DO AMBIENTE. 1990, Lisboa. Lisboa: Universidade de Lisboa. V.1.. p. 43-52. 1991. 
STEEL, R.G.D..A multiple comparison rank sum test: treatments versus control. Biometrics 15:560-572. 1959.

STEPHENS, M.A.. EDF Statistics for goodness of fit and some comparisons. J. Amer. Stat. Assoc. (JASA) 69:730-373. 1974.

SWEETMAN SC, ed. Martindale: The Complete Drug Reference, 33rd ed. Pharmaceutical Press, London, UK. 2002.

TERRA, N.R \& FEIDEN , I.R. Reproduction and survival of Daphnia magna Straus, 1820 (Crustacea:Cladocera) under different hardness conditions. Acta Limnol. Bras., 15(2):51-55, 2003.

TERNES, T., HIRSCH, R., MUELLER, J., HABERER, K.,. Methods for the determination of neutral drugs as well as betablockers and alpha2sympathomimetics in aqueous matrices using GC/MS and LC/MS/MS. Fresen. J. Anal. Chem. 362 (3), 329- 340, 1998.

TERNES, T., BONERZ, M., SCHMIDT, T.,. Determination of neutral pharmaceuticals in wastewater and rivers by liquid chromatographyelectrospray tandem mass spectrometry. J. Chromatogr. A 938 (1/2), 175-185, 2001.

TERNES, T., MEISENHEIMER, M., MCDOWELL, D., SACHER, F., BRAUCH, H.-J., Haist-GLUDE, B., PREUSS, G., WILME, U., ZULEI-SEIBERT, N.,. Removal of pharmaceuticals during drinking water treatment. Environ. Sci. Technol. 36, 3855-3863. 2002

TUNDISI, J.G. Água no Século XXI - Enfrentando a Escassez. São Carlos: Rima Editora/Instituto Internacional de Ecologia, 2003. 
USEPA (United States Environmental Protection Agency). Washington. Technical support document for water quality based toxics control Washington. D.C. USEPA.. 74p. 1985.

VAN DER VELDE, G. \& LEUVEN, R. S. E. W. Polluted river systems: monitoring and assessment of ecotoxicological risks. Acta Hydrochimica et Hydrobiologica, 27(5):251-256. 1999.

VAN LEEUWEN, C.J., W.J. LUTTMER and P.S. GRIFFIOEN. The use of cohorts and populations in chronic toxicity studies with Daphnia magna: A cadmium example. Ecotoxicol. Environ. Saf. 9:26-39. 1985.

VAN LEEUWEN, C.J., G. NIEBEEK and M. RIJKEBOER. Effects of chemical stress on the population dynamics of Daphnia magna: A comparison of two test procedures. Ecotoxicol. Environ. Saf. 14:1-11. 1987.

WALTHALL WK, STARK JD. Comparison of two population level ecotoxicological endpoints: The intrinsic $(\mathrm{rm})$ and instantaneous (ri) rates of increase. Environ Toxicol Chem 16:1068-1073. 1997.

WALTON, W.E ., S.M. COMPTON, J.D. ALLAN and R.E. DANIELS. The effect of acid stress on survivorship and reproduction of Daphnia pulex (Crustacea: Cladocera). Can. J. Zool. 60:573- 579. 1981.

WHO. Mayor Poisoning Episodes from Envrironmental Chemicals. Environmental \& Occupational Epidemiology Séries (Document Pep), 1992.

ZAGATTO, P.A. Ecotoxicologia Aquática. In: VII CONGRESSO BRASILEIRO DE LIMNOLOGIA. Universidade Federal de Santa Catarina, Florianópolis, SC. Apostila.18p. 1999. 
ZAGATTO P. A., Ecotoxicologia e desenvolvimento sustentável: Perspectivas para o século XXI", in Encontro de Ecotoxicologia, Mini Curso: Ecotoxicologia Aquática, São Carlos-SP, Brasil, 2000.

ZAGATto, P. A.; Bertoletti, E.; GOLDStein, E. G. Toxicidade de efluentes industriais da bacia do rio Piracicaba. In: Revista Ambiente, v. 2, n. 1, p. 39-42, 1988.

ZAR, J.H. Biostatistical Analysis. 4ª ed. Prendice-Hall, p. 663, 1999. 